JONAS RUBINI JUNIOR

DESENVOLVIMENTO DE CÉLULA POCKELS NA TOPOLOGIA REFLEXIVA APLICADA A TP ÓPTICO DE ALTA TENSÃO 
JONAS RUBINI JUNIOR

\section{DESENVOLVIMENTO DE CÉLULA POCKELS NA TOPOLOGIA REFLEXIVA APLICADA A TP ÓPTICO DE ALTA TENSÃO}

Tese apresentada à Escola Politécnica da Universidade de São Paulo para obtenção do título de Doutor em Ciências. 
JONAS RUBINI JUNIOR

\section{DESENVOLVIMENTO DE CÉLULA POCKELS NA TOPOLOGIA REFLEXIVA APLICADA A TP ÓPTICO DE ALTA TENSÃO}

Tese apresentada à Escola Politécnica da Universidade de São Paulo para obtenção do título de Doutor em Ciências.

Área de Concentração: Sistema de Potência

Orientador: Prof. Dr. Josemir Coelho Santos 
Este exemplar foi revisado e alterado em relação à versão original, sob responsabilidade única do autor e com a anuência de seu orientador.

São Paulo, ........ de Março de 2016

Assinatura do autor

Assinatura do orientador

Catalogação-na-publicação

RUBINI, Jonas Jr.

Desenvolvimento de Célula Pockels na Topologia Reflexiva Aplicada a TP Óptico de Alta Tensão, v. corr./ J. J. RUBINI -- São Paulo, 2016. $183 \mathrm{p}$.

Tese (Doutorado) - Escola Politécnica da Universidade de São Paulo. Departamento de Engenharia de Energia e Automação Elétricas.

1.Alta Tensão 2.Sensores Ópticos 3.Célula Pockels 4.Transformador de Potencial Óptico 5.Simulação FEM Universidade de São Paulo. Escola Politécnica. Departamento de Engenharia de Energia e Automação Elétricas II.t. 
À Ilzinha, Amábilinha e Sofiazinha razões de minha vida. 


\section{AGRADECIMENTOS}

Primeiramente agradeço à DEUS, por estar sempre iluminando o meu caminho.

Ao orientador, Prof. Dr. Josemir Coelho Santos, o meu reconhecimento e apoio na realização deste trabalho de pesquisa na área de Sensores Eletro-ópticos. Obrigado pela confiança depositada em mim, pelo apoio e orientações nas minhas atividades científicas ao longo dessa última década.

Ao meu grande amigo Erik dos Reis Ribeiro, pela sua valorosa amizade, pelas longas "voltas científicas" que cujas conversas orientaram e confrontaram os meus conhecimentos dando um grande auxílio na execução deste trabalho.

Ao meu eterno amigo Luiz Pinheiro C., pelo apoio no desenvolvimento dos protótipos que foram fundamentais para a realização deste trabalho, além das divertidas conversas que tornaram todos esses anos inesquecíveis.

A minha grande amiga Sandra Sayuri Sato, pelo exemplo de luta e determinação e sua preciosa amizade.

Aos colegas, Raul, Shigueru e Gleison pela ajuda e apoio de sempre no laboratório do Laboratório de Sistemas Ópticos (LSO).

Aos amigos e companheiros da divisão de Sensores Ópticos (EFO-S) do IEAV Major Rogério Moreira Cazo, Capitão Hugo Lira, Tenente Mateus Minelli, Sergio de Antônio Carlos de Jesus, Rodolfo Cesario e Keila Viana Couto pela disponibilidade e apoio técnico.

Aos colegas Ana Maria, Sargento Ferraz, Lavras e Marcos V., pela disponibilidade e apoio técnico nos laboratórios da Fotônica do IEAV, no polimento e deposição de filmes finos.

Ao pessoal do laboratório do PEA nas pessoas Adelino, Edson e Marcos, sempre prestativos.

Ao Professor Walter Kaiser como exemplo de pessoa, professor e orientador.

Ao Departamento de Engenharia e Automação - PEA-USP, por dar condições para realização deste trabalho.

Às secretárias do PEA: Diná, Valquíria, Solange, Rosangela, Beta e Patrícia.

A todas as pessoas que direta ou indiretamente colaboraram na realização deste trabalho. 
"O Senhor é meu pastor e nada me faltará" Salmo 23 


\section{RESUMO}

O trabalho aborda o estudo e o desenvolvimento de um interferômetro sensor de alta tensão, baseado em célula Pockels (modulador eletro-óptico) na topologia reflexiva ("double pass") e que é parte integrante de um Transformador de Potencial Óptico (TPO), que utiliza sistema interferométrico de luz branca (WLI-White Light Interferometry), que está sendo desenvolvido pelo grupo do Laboratório de Sensores Ópticos (LSO) do PEA-EPUSP, e é capaz de medir diretamente tensões presentes em sistema elétrico de potência (SEP) classe $69 \mathrm{kV} \mathrm{VMS}_{\text {. }}$

Para desenvolver o tema proposto foi feita uma revisão da literatura baseada em livros, artigos e teses para identificar topologias em moduladores eletro-ópticos transmissiva ("single pass") e reflexiva ("double pass") para definir o tipo de modulador mais adequado para a aplicação em questão. A partir dos estudos e implementações realizadas, verificou-se um enorme potencial para 0 desenvolvimento e aplicação da topologia "double pass" no sensor interferométrico da célula de alta tensão do TPO. A topologia mostrou-se vantajosa em relação aos protótipos dos TPOs desenvolvidos anteriormente, a partir de características tais como: a facilidade de recurso de alinhamento do feixe de luz, construção e reprodução relacionados ao cristal eletro-óptico, diminuição do número de componentes ópticos volumétricos e aumento da rigidez dielétrica da célula sensora.

Simulações computacionais foram realizadas mediante a aplicação do método dos elementos finitos (MEF) que contribuíram para o auxílio do projeto da célula sensora, particularmente, para estimativa do valor da voltagem de meia onda, $\mathrm{V}_{\pi}$, parâmetro importante para o projeto do TPO. Um protótipo do TPO com célula sensora de alta tensão reflexiva foi implementado e testado no laboratório de alta tensão do IEEUSP a partir de ensaios com tensões nominais de $69 \mathrm{kV}_{\text {rms }}$ a $60 \mathrm{~Hz}$ e máxima de $140 \mathrm{kV}_{\text {rms }}$ a $60 \mathrm{~Hz}$. Como resultado deste trabalho, amplia-se o conhecimento e domínio das técnicas de construção de interferômetros sensores de alta tensão na topologia reflexiva aplicadas a TPOs.

Palavras-chave: Alta Tensão, Sensores Ópticos, Célula Pockels, Transformador de Potencial Óptico, simulação FEM. 


\begin{abstract}
This work describes the study and development of a high-voltage interferometer sensor based on Pockels cell (electro-optical modulator) in the reflective topology (double pass), which is part of an optical potential transformer (OPT) using a white light interferometry system (WLI) being developed by the Optical Sensors Laboratory (LSO) group from PEA-EPUSP, which is able to directly measure power electrical system (PES) voltages for the $69 \mathrm{kV}_{\mathrm{rms}}$ class.
\end{abstract}

To develop the work, a bibliographic review was made on books, papers and theses in order to identify electro-optical modulators related to transmissive (single pass) and reflective (double pass) topologies aiming at defining the most appropriate modulator type for the present application. From the studies and implementations performed, it was realized that there is a huge potential for the development and application of 'double pass' topology in the OPT high-voltage interferometric sensor. This topology showed to be advantageous compared to previously developed OPT prototypes for characteristics such as: ease of beam alignment feature, construction and reproduction related to the electro optical crystals, decrease of volumetric optical components number and increase of the sensor cell dielectric strength.

Computer simulations were performed by applying the Finite Element Method (FEM) that contributed to the sensor cell design, particularly in estimating the half-wave voltage value, $\mathrm{V}_{\pi}$. The OPT with the reflective high-voltage sensing cell was implemented and tested at the high voltage laboratory of IEE-USP for the $69 \mathrm{kV}_{\mathrm{rms}}$ at $60 \mathrm{~Hz}$ nominal voltage and the $140 \mathrm{kV}_{\mathrm{rms}}$ at $60 \mathrm{~Hz}$ maximum voltage. As a result of this work, nationwide expertise over the techniques of construction of high-voltage interferometer sensors in reflective topology applied to OPTs was achieved and knowledge was broadened.

Keywords: High Voltage. Optical Sensor. Pockels Cell. Optical Potential Transformer. FEM simulation. 


\section{LISTA DE ILUSTRAÇÔES}

Figura 1 - Esquema de ligação de Tls indutivos monofásicos. .32

Figura 2 - Transformadores para instrumentos indutivos. (a) Transformador de

tensão. (b) Transformador de corrente

Figura 3 - Transformador de potencial capacitivo. (a) foto ilustrativa de um TP capacitivo comercial, (b) Esquemático representativo.

Figura 4 - COSI - Compact Optical Sensor Intelligence Combined Metering Unit

COSI-CM. TP óptico (que inclui também um TC óptico) podendo ser de $69 \mathrm{kV}$ até $765 \mathrm{kV}$.

Figura 5 - Padrão teórico de intensidade de saída de um interferômetro de luz

branca. 46

Figura 6 - Sistema de coordenadas de uma célula unitária de estrutura cúbica.

Figura 7 - Relação entre os sistemas de coordenadas, perturbado e não perturbado em um material eletro-óptico cúbico com campo elétrico aplicado paralelamente ao eixo $z$.

Figura 8 - Tipos Célula Pockels com cristal eletro-óptico em configuração

longitudinal.

Figura 9 - Célula Pockels com cristal eletro-óptico em configuração transversal. ......60

Figura 10 - Célula Pockels como modulador de amplitude.

Figura 11 - Curva de transmissão da célula Pockels em função da tensão aplicada

(normalizada pelo valor de $\mathrm{V} \pi$ ).

Figura12- Célula Pockels, como modulador de amplitude, com a inserção de uma

Lâmina de retardo de $\lambda / 4$ onda. 66

Figura 13 - Curva de transmissão da célula Pockels em função da tensão aplicada (relacionada ao valor de $\mathrm{V} \pi$ ) e com a influência de uma lâmina de retardo de $N / 4$

Figura 14 - Representação da modulação da intensidade de saída devida à variação da tensão aplicada à célula Pockels.

Figura 15 - Célula Pockels integrando modulador de amplitude na configuração "double pass".

Figura 16- Curva de transmissão em função da tensão aplicada (relacionada ao valor de $\vee \pi$ ) da configuração "double pass". 
Figura 17 - Representação da modulação da intensidade devida ã variação da tensão aplicada na célula Pockels na configuração "double pass"

Figura 18 - Diagrama em blocos de um protótipo de TPO baseado na técnica WLI.78

Figura 19 - ilustração das topologias de células Pockels de alta tensão. (a) cristal

único e (b) multissegmentada ou multicristais.

Figura 20 - Topologia multi-segmentada de um modulador óptico eletro longitudinal:

campo elétrico na direção da propagação da luz

Figura 21 - a) Esquema representativo a composição dos discos com o cilindro de acrílico contendo o cristal eletro-óptico e b) Vista lateral em corte do aspecto final do elemento sensor do modulador eletro-óptico longitudinal para medição de altas tensões.

Figura 22 - Pocionadores de colimação e alinhamento do feixe óptico incorporados à célula sensora de alta tensão

Figura 23- a) Vista em corte da célula eletro-óptica de alta tensão e b) Célula eletroóptica montada.

Figura 24- a) Célula eletro-óptica de alta tensão e b) Célula de alta tensão e transformador de potencial.

Figura 25 - a) Desenho da célula de alta tensão desenvolvida por Santos e b) característica da Lâmina de cristal eletro-óptico utilizada na construção do sensor.

Figura 26 - a) Primeira célula de alta tensão desenvolvida no doutorado e b) detalhe das lâminas de cristais $\mathrm{BGO}$ e c) foto ilustrativa dos elementos da célula desenvolvida

Figura 27 - Fotos do suporte do de acrílico de acondicionamento dos Cristais: a) aberto, b) fechado e c) com os cristais posicionados .90

Figura 28 - Desenho do isolador cerâmico utilizado para encapsular a célula de alta tensão do protótipo de TPO desenvolvido .92

Figura 29 - Diagrama em blocos da nova configuração de protótipo de TPO baseado na técnica WLI com célula sensora na topologia reflexiva "double pass" com detalhe da óptica utilizada e do cristal eletro-óptico com faces espelhada e antireflexiva.

Figura 30 - Vista explodida da nova topologia (a) e foto das peças da célula sensora na topologia reflexiva "double pass" (b).

Figura 31 - Arranjo representativo do modulador eletro-óptico na topologia reflexiva "double pass" da nova célula de alta tensão. 
Figura 32 - Evaporadora LEYBOLD L-560 utilizada no processo (PVD)..

Figura 33 - Amostra de cristal eletro-óptico de $\mathrm{Bi}_{4} \mathrm{Ge}_{3} \mathrm{O}_{12}$ onde a) antes das

aplicações dos filmes, b) face de entrada do feixe de luz com filme anti-reflexão

(AR coating) e c) face posterior "espelhada" com filme para reflexão total.

Figura 34 - Lote de BGOs adquiridos onde a) vários tamanhos, b), c) e d)detalhe da

face "espelhada" realizada no IEAv.

Figura 35 - Esquema do sistema Sensor Eletro-óptico em WLI com interferômetro recuperador volumétrico.

Figura 36 - Interferômetro recuperador volumétrico construído.

Figura 37 - Representação esquemática do modulador eletro-óptico em Y, em óptica integrada com pigtails de três acessos.

Figura 38 - Representação esquemática do modulador eletro-óptico ilustrando as

fibras de saída com seus comprimentos ajustados para uma diferença de caminho óptico $\Delta \mathrm{L}$

Figura 39 - a) Chip óptico integrado multifuncional (IOC - LiNbO3 multi-function integrated optical chip), modelo PMD1333-I b) Aspecto final do modulador $Y$ em óptica integrada. Em primeiro plano estão as fibras ópticas de acesso de saída do modulador após a metalização com Prata 108

Figura 40 - Esquema do TPO proposto por Silva (2011), que utiliza interferômetro recuperador em óptica integrada reflexivo e interferômetro sensor transmissivo (single pass).

Figura 41 - Esquema do TPO proposto neste trabalho, que utiliza interferômetro recuperador em óptica integrada reflexivo e interferômetro sensor reflexivo (double pass).

Figura 42 - Esquema de arranjo de TPO com circulador ligado ao SLD. 114

Figura 43 - Esquema do novo sistema proposto para desenvolvimento do protótipo de TPO neste trabalho. 116

Figura 44 - Controlador de polarização multiestágio

Figura 45 - Controlador de polarização OESPACE: a) configuração de guia de onda tipo canal com eletrodos, de um estágio e b) configuração da disposição dos 3 estágios internos...

Figura 46 - Foto do arranjo óptico da nova célula sensora de alta tensão com a indicação dos elementos que o compõem 119

Figura 47 - a) Desenho ilustrativo de um Faraday Mirror, b) Foto do componente da OZoptics 121 
Figura 48 - a) Desenho do rotator Faraday 45 da OZoptics com o elemento refletor retirado e com distância de trabalho modificada e b) Foto do colimador Faraday adquirido da OZoptics.

Figura 49 - a) Nova célula sensora de alta tensão montada com componentes ópticos discretos (rotator Faraday e pigtail colimador) e b) nova célula sensora de alta tensão montada já com o novo componente óptico desenvolvido (colimador Faraday)....

Figura 50 - Forma de onda simulando 32 ciclos da foto-corrente detectada no fotodiodo conectado à fibra óptica de saída do interferômetro recuperador (sem modulação de fase óptica aplicada ao interferômetro sensor). 127

Figura $51-I_{d}(t)$, para as modulações $\phi_{1}(t)=0,5 \operatorname{sen}\left(\omega_{1} t\right)$ e $\phi_{2}(t)=\pi / 2 \operatorname{sen}\left(\omega_{2} t\right)$, sendo $\omega_{2}=16 \omega_{1}$ 128

Figura 52 - Ampliação no domínio do tempo de um ciclo de $l_{d}(t)$, para as modulações $\phi_{1}(t)=0,5 \operatorname{sen}\left(\omega_{1} t\right)$ e $\phi_{2}(t)=2 \pi \operatorname{sen}\left(\omega_{2} t\right)$, sendo $\omega_{2}=256 \omega_{1}$

Figura 53 - Configuração básica e um amplificador de transimpedância. 130

Figura 54 - Diagrama de blocos do processador do sinal de saída do interferômetro recuperador do protótipo de TPO (Almeida, J.C.J., Santo). 134

Figura 55 - Geometria final obtida para o sensor eletro-óptico usando o método CSM (SANTOS, 1996) 136

Figura 56 - Geometria utilizada para verificação da influência de objeto aterrado nas proximidades do sensor eletro-óptico usando o método CSM 138

Figura 57 - A geometria do sensor eletro-óptico multisegmentado 142

Figura 58: Geometria do Sensor eletro-óptico para os casos 0, 1 e 2 - a) Caso 0 Sem a interferência de um objeto aterrado, b) e c) Com a interferência de um objeto (anel) aterrad.

Figura 59- Gráfico do campo elétrico em relação às lâminas de cristal (número) para os casos 0,1 e 2 ..

Figura 60 - Gráfico do campo elétrico em relação às lâminas de cristal (número)

(com espaçadores de ar e dielétrico). 146

Figura 61 - Gráfico da tensão $\bigvee_{\pi}$ em função da variação do diâmetro dos eletrodos do sensor eletro-óptico para o caso 0 . 147

Figura 62 - Gráfico da Tensão $\bigvee_{\pi}$ para os sensores com e sem anel aterrado e com espaçadores dielétricos de Teflon e Acrílico 
Figura 63 - Média do campo elétrico dentro de cada lâmina (configuração 1) para vários raios do cristal eletro-óptic.

Figura 64 - Tensão $V_{\pi}$ em função do raio do cristal eletro-óptico para a configuração 1. 148

Figura 65 - Campo elétrico médio nas laminas de cristal BGO para a configuração 2. 149

Figura 66 - Configuração $2-V_{\pi} / \lambda$ em função do diâmetro do eletrodo 150

Figura 67 - Campo Elétrico Médio e $V \pi / \lambda$ em função da espessura do cristal para o sensor de Cristal Único 151

Figura 68- Comparação da variação do campo elétrico dentro dos cristais de mesma espessura e raio diferente. As curvas mostram o campo elétrico em 10 pontos dentro do cristal e ao longo da linha central axial

Figura 69 - Comparação do campo elétrico obtido para os casos 0, 1 e 2 aplicando os métodos CSM e FEM 153

Figura 70 - Discrepância entre os métodos de simulação para os casos 0,1 e 2... 153 Figura 71 - Obtenção do valor de $V \pi(@ 1550 \mathrm{~nm})$ para um cristal de 30mm de espessura. 155

Figura 72 - Foto do arranjo utilizado para os ensaios do protótipo de TPO nas instalações do laboratório de alta tensão da CTEEP 158

Figura 73 - Foto da bancada com o sistema da célula recuperador em conjunto sistema de aquisição de dados visando o ensaio do TPO, sendo: a) Fonte óptica (alimentação+SLD+circulador óptico), b) Célula Recuperadora (transmissiva"single pass"-modulador OESPACE), c) Unidade de Processamento Eletrônico de sinais, e) Osciloscópio e f) Computador (para leitura dos dados provenientes da unidade de processamento eletrônico). 159

Figura 74 - Forma de onda proveniente da célula recuperadora (cor verde) e o sinal eletro-óptico na malha interna do detector de vale (cor magenta) sem sinal de alta tensão aplicada (vales em equilíbrio). ( $O$ sinal, de cor azul, mostra os pulsos de sincronismo interno da Unidade de Processamento Eletrônico de sinais e o sinal em amarelo, representa o valor armazenado do vale).............160

Figura 75 - Forma de onda proveniente da célula recuperadora (cor verde) e o sinal eletro-óptico na malha interna do detector de vale (cor roxa) sem sinal de alta tensão de aplicada (vales em desequilíbrio). (O sinal, de cor azul, mostra os pulsos de sincronismo interno da Unidade de Processamento Eletrônico de sinais e o sinal, em amarelo, representa o valor armazenado do vale) 160 
Figura 76 - Formas de onda da tensão da ordem de $25 \mathrm{kVrms}$, aplicada à célula sensora de alta tensão do TPO (cor amarela) e aos TPs de referência do IEE (cor roxa) e do CTEEP (cor verde). 161

Figura 77 - Formas de onda da tensão da ordem de 69kVrms, aplicada à célula sensora de alta tensão do TPO (cor amarela) e aos TPs de referência do IEE (cor roxa) e do CTEEP (cor verde).

Figura 78 - Resposta do TPO às tensões aplicadas (na faixa de $25 \mathrm{kV}$ a $69 \mathrm{kV}$ ) referenciada ao TP padrão pertencente ao IEE. 164

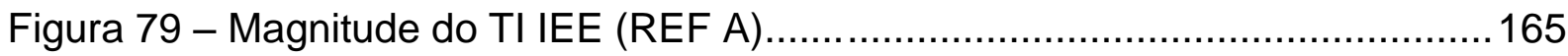

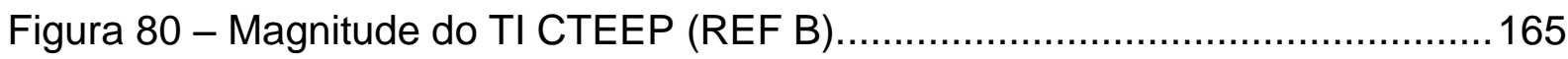

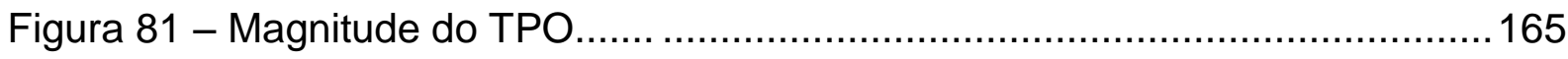




\section{LISTA DE TABELAS}

Tabela 1 - Dados da relação de transformação $\left(\mathrm{K}_{\mathrm{T}}\right)$ do TPO.............................. 105

Tabela 2 - Média do Campo elétrico em cada lâmina ...................................... 137

Tabela 3 - Descrição das medidas utilizadas para os casos 1 e 2 .................... 139

Tabela 4 - Dados da Simulação pelo método CSM para os casos 0, 1 e 2 relativo a objetos aterrados próximos ao sensor eletro-óptico. ................................ 139

Tabela 5 - Características da célula Sensora .................................................. 142

Tabela 6 - Variação da tensão $\vee \pi$ para os casos 0, 1 e 2 (espaçamento ar)...... 146

Tabela 7 - Valores de $V \pi / \lambda$ obtidos experimentalmente.................................. 151

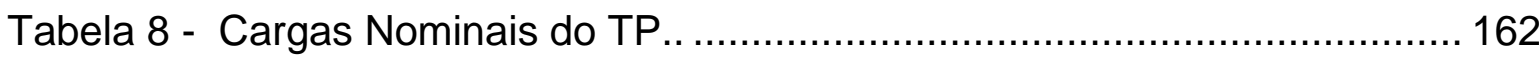

Tabela 9 - Componentes fundamentais dos sinais dos dispositivos ensaiados obtidos por Transformada de Fourier ................................................................. 164 
LISTA DE ABREVIATURAS E SIGLAS

BGO Germanato de Bismuto (Bi4Ge3012)

CA Corrente Alternada

CCE Centro de Computação Eletrônica

CTEEP Companhia de Transmissão de Energia Elétrica Paulista

COELBA Companhia de Eletricidade do Estado da Bahia

CPS Symmetric Coplanar Strips

DCTA Departamento de Ciência e Tecnologia Aeroespacial

EFA Divisão de Física Aplicada

EFA-E Subdivisão de Eletromagnetismo Aplicado

EFO Divisão de Fotônica

EFO-O Laboratório de Subdivisão de Óptica Aplicada

EMI Eletromagnetic Interference

EMP Eletromagnetic Pulse

E/O Conversão Elétrica/Óptica

EPUSP Escola Politécnica da Universidade de São Paulo

FOI Fiber Optic Interferometer

FOLCI Fiber Optic Low Coherence Interferometry

GRIN Gradual Index

IEC International Eletrotecnical Comission

IEAv Instituto de Estudos Avançados

IEE Instituto de Engenharia e Eletrotécnica

LASER Light Amplification by Stimulated Emission of Radiation

LED Light Emitting Diode

LiNbO3 Niobato de Lítio

LiTaO3 Tantalato de Lítio

LSO Laboratório de Sensores Ópticos

MEF Método dos Elementos Finitos

O/E Conversão Óptica/Elétrica

Ol Óptica Integrada

OPD Optical Path Diference

SEP Sistema Elétrico de Potência

SF6 Hexafluoreto de enxofre

WLI White Light Interferometry 


\section{LISTA DE SÍMBOLOS}

I Intensidade luminosa.

U Intensidade luminosa de uma componente da onda polarizada.

$\Delta \phi \quad$ Diferença de fase entre duas componentes da onda polarizada.

$\Delta n \quad$ Birrefringência Induzida.

$\Delta n_{o} \quad$ Birrefringência natural.

$\gamma(\tau) \quad$ Função de auto-correlação.

$\left|\gamma_{11}(\tau)\right| \quad$ Grau de coerência.

c Velocidade da luz no vácuo.

$\lambda \quad$ Comprimento de onda da luz no vácuo.

K Visibilidade.

$K_{O} \quad$ Visibilidade da franja central.

$K_{r} \quad$ Visibilidade do interferômetro recuperador.

$K_{s}=K_{o s} \quad$ Visibilidade do interferômetro sensor.

$I(\sigma)$ Distribuição do espectro de intensidade de uma fonte óptica de banda larga.

$\delta \sigma \quad$ Largura da banda espectral.

$\sigma \quad$ Número de onda de uma componente espectral.

$\sigma_{o} \quad$ Número de onda central da fonte luminosa.

$I_{o} \quad$ Intensidade em $\left(\sigma_{o}\right)$.

$L_{c} \quad$ Comprimento de coerência.

$\Delta L_{r} \quad$ Diferença de caminho óptico introduzido pelo interferômetro recuperador.

$\Delta L_{S} \quad$ Diferença de caminho óptico introduzido pelo interferômetro sensor.

$T_{1} \quad$ Fator de transmissão do enlace óptico de ida.

$T_{2} \quad$ Fator de transmissão do enlace óptico de volta.

$T_{S} \quad$ Fator de transmissão do interferômetro sensor.

$T_{r} \quad$ Fator de transmissão do interferômetro recuperador. 
$\Delta L_{s} \quad$ Diferença de caminho óptico introduzido pelo interferômetro sensor.

$\Delta L_{r} \quad$ Diferença de caminho óptico introduzido pelo interferômetro recuperador.

[ $\eta] \quad$ Tensor de impermeabilidade.

$\eta_{i j} \quad$ Elemento do tensor de impermeabilidade.

$n_{x}, n_{y}, n_{z} \quad$ Índice de refração nas direções $x, y, z$, respectivamente.

$n_{o} \quad$ Índice de refração ordinário.

$n_{e} \quad$ Índice de refração extraordinário.

$r_{i j k} \quad$ Coeficiente eletro-óptico de Pockels.

$s_{i j k l} \quad$ Coeficiente eletro-óptico de Kerr.

$\vec{E} \quad$ Campo elétrico.

E Intensidade do campo elétrico

$V \quad$ Tensão elétrica aplicada.

$V_{\pi} \quad$ Tensão de meia-onda.

$\phi_{r} \quad$ Atraso de fase fixo devido à lâmina retardadora.

$\Gamma \quad$ Atraso de fase induzido.

$L \quad$ Comprimento do cristal eletro-óptico.

$r_{41} \quad$ Coeficiente eletro-óptico de Pockels.

$V(t) \quad$ Tensão aplicada ao modulador eletro-óptico.

$V_{s} \quad$ Tensão aplicada no interferômetro sensor.

$V_{\text {out }}(t) \quad$ Tensão de saída do circuito de processamento eletrônico de sinais.

$V_{\text {out } p p} \quad$ Valor pico a pico de tensão do circuito de processamento eletrônico de sinais.

$V_{\text {out rms }} \quad$ Valor rms de tensão do circuito de processamento eletrônico de sinais.

$I_{x} \quad$ Intensidade da onda polarizada no eixo.

$I_{y} \quad$ Intensidade da onda polarizada no eixo $y$.

$\Delta n_{c} \quad$ Birrefringência natural da lâmina retardadora.

$\Delta \phi_{c} \quad$ Atraso de fase óptico introduzido pela lâmina retardadora. 
$\alpha_{s} \quad$ Atenuação introduzida na luz transmitida pelo interferômetro sensor.

$\alpha_{r} \quad$ Atenuação introduzida na luz transmitida pelo interferômetro.

$\Delta L_{r} \quad$ Atraso de fase fixo do interferômetro recuperador.

$\Delta L_{s} \quad$ Atraso de fase fixo do interferômetro sensor.

W Watt.

$\varepsilon \quad$ Permissividade dielétrica do meio.

$\mu \quad$ Permeabilidade magnética do meio.

$V / m \quad$ Volts por metro.

$V_{D 1} \quad$ Tensão na saída do transimpedância 1.

$V_{D 2} \quad$ Tensão na saída do transimpedância 2. 


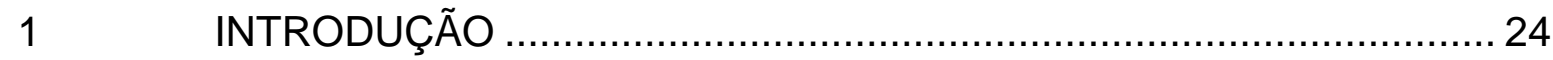

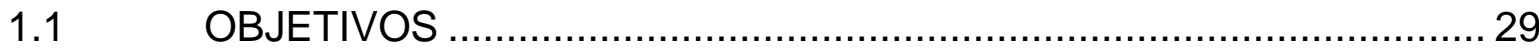

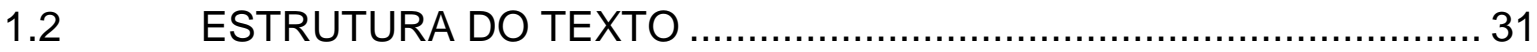

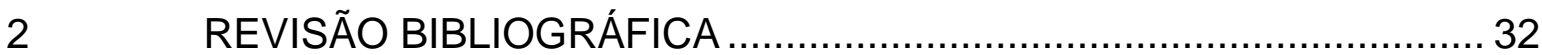

$2.1 \quad$ TRANSFORMADOR DE POTENCIAL - TP .................................... 32

2.1.1 Transformadores para instrumentos indutivos …............................ 32

2.1.2 Transformadores para Instrumentos capacitivos............................... 34

2.1.3 Transformadores para Instrumentos ópticos(TIOs) ............................. 35

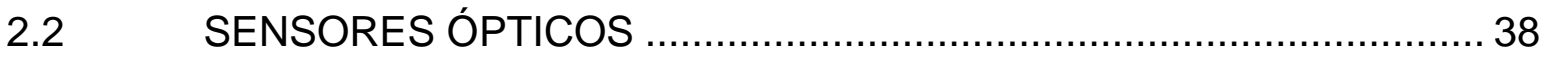

2.3 SENSORES BASEADOS NA TÉCNICA DE INTERFERÔMETRIA DE LUZ

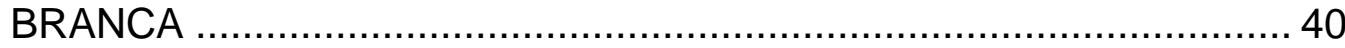

2.3.1 Princípio de funcionamento ........................................................ 41

$2.4 \quad$ INTERAÇÃO ELETRO-ÓPTICA ................................................. 47

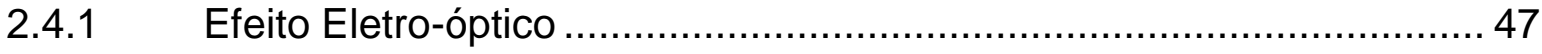

2.4.2 Efeito Eletro-óptico Linear ........................................................... 49

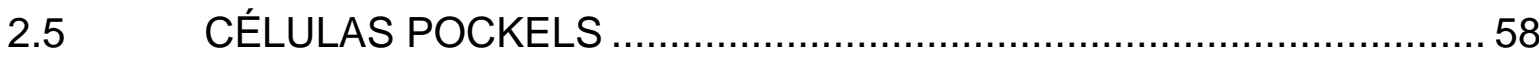

2.5.1 Topologias das Células Pockels ................................................... 58

2.6 MODULADORES ELETRO-ÓPTICOS ............................................. 61

2.6.1 Análise das Configurações de Células Pockesl por Matriz de Jones ... 71

3 MATERIAIS E MÉTODOS 77 
3.1 ESTUDO DOS TRANSFORMADORES ÓPTICOS PARA ALTA TENSÃO

3.1.1 Interferõmetro sensor (Célula de Alta Tensão) 79

3.1.2 Evolução dos protótipos de TPO do LSO em relação à célula pockels de alta tensão. 85

3.1.2.1 Espelhamento e Aplicação de filmes anti-reflexo (AR Coating) dos Cristais de BGO para Utilização no Modulador Eletro-Óptico Sensor 95

3.1.3 Enlace Óptico 99

3.1.4 Interferômetro Recuperador (Célula de Baixa Tensão) 103

3.1.4.1 Interferômetro Recuperador em Òptica Volumétrica 103

3.1.4.2 Interferômetro Recuperador em Òptica Integrada 106

3.2 NOVA TOPOLOGIA DE TPO COM INTERFERÔMETRO SENSOR REFLEXIVO (DOUBLE PASS) E INTERFERÔMETRO RECUPERADOR EM ÓPTICA INTEGRADA TRANSMISSIVO (SINGLE PASS) 112

3.3 UNIDADE DE PROCESSAMENTO DE SINAL DE SAÍDA DO TRANSFORMADOR DE POTENCIAL ÓPTICO 123

4 MÉTODOS COMPUTACIONAIS PARA O AUXÍLIO AO PROJETO DE CÉLULAS POCKELS DE ALTA TENSÃO. 135

4.1 MÉTODO DE SIMULAÇÃO DE CARGAS - CSM 135

4.2 MÉTODO DOS ELEMENTOS FINITOS - MEF 140

4.2.1 Casos Estudados 140

4.2.1.1 Tipo Multi-segmentado (várias lâminas de cristal). 141

4.2.1.2 Sensor de cristal Único 150

4.3. COMPARAÇÃO ENTRE OS MÉTODOS CSM E MEF (LEVSOFT) ... 153 
4.4. ESPECIFICAÇÃO DA DIMENSÃO DO CRISTAL DE BGO PARA A CÉLULA DE ALTA TENSÃO NA CONFIGURAÇÃO DOUBLE PASS 154

5 RESULTADOS EXPERIMENTAIS 156

5.1 ENSAIOS FUNCIONAIS DO CONJUNTO TPO E UNIDADE DE PROCESSAMENTO ELETRÔNICO 157

6 DISCUSSÃO DOS RESULTADOS 163

7 COMENTÁRIOS E CONCLUSÕES 166

TRABALHOS FUTUROS 167

REFERÊNCIAS 169

ADENDO A 176

ADENDO B. 178

ANEXO 1 179

ANEXO 2 180

ANEXO 3 181

ANEXO 4 183 


\section{INTRODUÇÃO}

Os Transformadores de Potencial Ópticos (TPO) aplicados na medida de altas tensões tiveram uma evolução considerável nos últimos anos e cada vez mais tem sido observada a substituição dos Transformadores de Potencial (TPs) convencionais (capacitivos e indutivos) por ópticos [R-AINGROUP, 2015; MARSENERGO, 2015 ]. Além disso, estão sendo encontradas propostas para utilizá-los como Transformadores de Referência (TR) para verificação e/ou calibração dos TP convencionais em uso nos Sistemas Elétricos de Potência (SEP), tais como no Projeto USP/COELBA, o qual é descrito no item 3.1.2, a seguir.

Em trabalho recente (LIMA, 2013) estudou-se a viabilidade de se utilizar Transformadores para Instrumentos Ópticos (TIO) no setor elétrico brasileiro e concluiu-se que há grande viabilidade na implantação dos mesmos devido a vantagens que eles apresentam frente aos convencionais, tais como: redução do peso, melhor precisão, ausência de óleo isolante, eliminação da saturação do material ferromagnético do núcleo e ampla faixa de resposta em frequência. Entretanto, constatou-se que há como ponto fraco a dificuldade da integração desses novos dispositivos com os atuais sistemas existentes nas subestações, tanto na medição como na proteção e no controle. Contudo, espera-se que com o advento da norma IEC 61850-9-2 (IGARASHI, 2014; PEREIRA, 2009), que promete viabilizar a implantação de um padrão de rede de comunicação digital universal para os ambientes de subestações, com acesso inclusive às grandezas instantâneas do processo, essa dificuldade seja superada.

Em relação à evolução no desenvolvimento de sensores, verifica-se que as áreas da instrumentação e da medição estão entre as que mais rapidamente cresceram com a aplicação de tecnologias ópticas. O desenvolvimento dos TPOs segue avançando atualmente nos estudos das topologias, dos materiais ópticos e das técnicas de processamento de sinais empregadas (RIBEIRO 2011, FENG et al., 2011, 2012, LIMA, 2013; PEREIRA, 2013).

As demonstrações de superioridade dos sensores que utilizam tecnologias ópticas, que descrevam melhores desempenhos e relações entre custo e benefício sobre os 
outros tipos de sensores são necessárias a fim de atrair os usuários já acostumados com tecnologias tradicionais. Assim os sensores ópticos devem estar disponíveis comercialmente a preços economicamente competitivos com os dos sensores tradicionais e de forma completa, incluindo o enlace de comunicação a fibras ópticas, a transdução optoeletrônica e o processamento eletrônico do sinal.

Atualmente tornou-se evidente a necessidade de integração de sensores de elevada qualidade nos mais sofisticados sistemas de medição e controle e em paralelo com o desenvolvimento acelerado de sensores baseados em tecnologia microeletrônica, outros sensores baseados em tecnologias ópticas têm também progredido significativamente durante os últimos 10 anos (EOSPACE, 2015; OZOPTICS, 2015; MRA.PT, 2015), em particular, desde o aparecimento das fibras ópticas e dispositivos ópticos especiais.

O avanço desta área de sensores ópticos deve muito aos desenvolvimentos das fibras ópticas, de materiais e de dispositivos opto-eletrônicos, sendo que grande parte dos sensores ópticos aproveita o baixo custo relativo dos componentes desenvolvidos para uso em sistemas de telecomunicações por fibras ópticas, particularmente fontes ópticas, detectores e moduladores eletro-ópticos. Com a expansão mundial das redes de comunicação, existe agora uma grande disponibilidade de componentes ópticos e eletrônicos de alta qualidade a preços competitivos e a expansão do mercado opto-eletrônico para produtos de consumo doméstico têm também conduzido a um aumento de novas tecnologias disponíveis e passíveis de serem utilizadas no desenvolvimento futuro de novos sensores ópticos.

Assim, um aumento do número de aplicações destes sensores e uma maior presença deles no mercado são previstas, visto que os preços dos componentes estão decrescendo, reduzindo os preços dos sensores e viabilizando uma maior inserção dos mesmos nas áreas em que seja necessário um grande número de sensores ópticos operando simultaneamente.

Em ambientes que apresentem altos níveis de campos elétricos e magnéticos, típicos de instalações de alta tensão que compõem os SEPs, e devido à contínua necessidade de sensoriamento das diversas grandezas envolvidas nos processos 
de geração, transmissão e distribuição de energia elétrica, os sensores ópticos são indicados devido principalmente às suas características particulares, como sua potencial natureza dielétrica, imunidade a Interferências eletromagnéticas conduzidas pelo enlace a fibras ópticas, baixo peso, dimensões reduzidas, entre outras. A natureza dos sensores eletroeletrônicos impede ou dificulta as medições nesses ambientes com incerteza mais baixa.

A instrumentação baseada em sensores ópticos vem conquistando espaço no setor elétrico devido à fase atual da sua tecnologia, que permite que sejam fabricados sistemas de medição (compostos por sensores, enlaces de comunicação, processadores de sinais e de medidas) praticamente imunes às interferências inerentes às medições neste setor.

Contudo, pesquisas e desenvolvimentos de sensores ópticos estão sendo voltadas para a miniaturização, aumento de versatilidade e, principalmente, melhoria da compatibilidade eletromagnética, características que asseguram aos sensores a fibras ópticas uma ampla gama de aplicações no setor elétrico. Assim, verifica-se que existe uma enorme gama de grandezas de medição de interesse no setor que podem ser realizadas por meio de sensores ópticos, desde grandezas químicas, como a presença de determinados contaminantes em óleos de isolamento de transformadores, até as clássicas grandezas físicas, como temperatura, força, vibração, tensão, corrente e campos eletromagnéticos em geral.

O efeito eletro-óptico é normalmente utilizado para construir moduladores eletroópticos e, a partir de células Pockels (YARIV, 2003), são utilizados para conversão de grandezas elétricas, tais como o campo elétrico e a tensão, em grandezas ópticas, como a intensidade luminosa ou o padrão de polarização da luz. Tais dispositivos podem dar origem a sensores ópticos que possuem características elétricas que permitem seu uso em sistemas de medição e proteção de SEP em alta tensão, proporcionando um melhor uso das vantagens dos enlaces a fibras ópticas.

De forma convencional, a medição da tensão elétrica em potenciais elevados é feita por meio de transformadores eletromagnéticos de acoplamento indutivo (TPI), por vezes associados a divisores capacitivos de tensão (TPC). Recentemente, esforços 
têm sido realizados no sentido de se desenvolverem sensores eletro-ópticos adequados para medir diretamente elevados níveis de tensão com as vantagens já descritas (PENÃ-LEGONA et al., 2007; MARCHESE et al., 2012; FENG et al., 2011, 2012).

Nas últimas décadas o Laboratório de Sensores Ópticos (LSO) do Departamento de Engenharia de Energia e Automação Elétricas (PEA) da Escola Politécnica da USP (EPUSP), vem sediando pesquisas na área de sistemas de sensoriamento a fibras ópticas aplicados aos SEPs, tais como os TPOs baseados em modernas tecnologias e, ao mesmo tempo, vem realizando estudos acerca dos aspectos relativos à substituição dos transformadores convencionais pelos seus similares com tecnologia óptica. Assim o desenvolvimento realizado neste período não só culminou na capacitação do grupo que forma o LSO, mas também no desenvolvimento de protótipos de laboratório de TPOs (classes $13,8 \mathrm{kV}$ até $69 \mathrm{kV}$ ) e que já foram, e estão sendo, construídos e testados.

As pesquisas e desenvolvimentos realizados resultaram em publicações em revistas e eventos da área em âmbito nacional e internacional (LIMA, 2009, SANTOS, ALMEIDA, SILVA, 2007, 2011; SATO et al., 2012; RUBINI et al., 2005), e em trabalhos de mestrado e doutorado concluídos e em andamento (SILVA, 2006, 2011; LIMA, 2009; SATO, 2014; IGARASHI, 2015) evidenciando a evolução da capacitação adquirida pelo grupo nessa área muito promissora.

Em vários dos TPOs estudados e desenvolvidos, utilizou-se como base a técnica de Interferometria de Luz Branca (White Light Interferometry - WLI), constituída basicamente por dois interferômetros serialmente conectados e excitados por uma fonte de luz de banda larga, normalmente Diodos Superluminescentes (Superluminescent Diodes - SLD). Esses dois interferômetros recebem as denominações de Interferômetro Sensor e interferômetro Recuperador. O interferômetro sensor, que é constituído por um sistema óptico que tem como elemento principal um cristal eletro-óptico, é mecânica e eletricamente acondicionado de modo adequado para que possa ser submetido a elevados níveis de tensão, constituindo assim a célula sensora de alta tensão. 
Utilizando-se enlaces a fibras ópticas, conecta-se o interferômetro sensor à fonte de luz e ao interferômetro recuperador, que também pode ser constituído por um modulador eletro-óptico, só que, nesse caso, construído de tal maneira que possa ser modulado por tensões muito inferiores àquelas a que o interferômetro sensor será submetido. O sinal óptico de saída do interferômetro recuperador é enviado a um diodo fotodetector acoplado a um amplificador de transimpedância, o qual fornece, em sua saída, um sinal elétrico de corrente que deve ser amplificado e processado para dar origem ao sinal de saída do TPO. Tal sinal, contudo, encontrase ainda numa forma "bruta", devendo ser mais uma vez processado para finalmente fornecer as medidas do TPO no formato analógico ou digital desejado (SANTOS, ALMEIDA, SILVA, 2007, 2011; ALMEIDA, 1998).

Em trabalhos anteriores realizados por pesquisadores do LSO (SILVA, 2011; SANTOS, 1996) foram apresentados desenvolvimentos de protótipos de TPOs em que o interferômetro que integra o elemento sensor primário (submetido a altas tensões) tem como característica a passagem do feixe de luz pelo cristal eletroóptico numa única direção (denominada topologia transmissiva ou "single pass") e que apresenta algumas características inadequadas, tais como: extrema dificuldade nos alinhamentos (lateral e angular) do feixe com os dispositivos ópticos e com o cristal, posicionamento de parte do enlace a fibra óptica entre o eletrodo de alta tensão e o terra, necessidade de maior número de conectores, alta sensibilidade mecânica, entre outras.

Neste contexto, o estudo, desenvolvimento e implementação de novas topologias de interferômetros sensores, como por exemplo, o baseado em dupla passagem (reflexiva ou "double pass") do feixe óptico pelo sensor, a partir do espelhamento de uma das faces do cristal eletro-óptico, é de interesse, pois tem potencial para minimizar ou até eliminar algumas das inadequações citadas. 


\section{$1.1 \quad$ OBJETIVOS}

Tendo em vista o cenário anteriormente apresentado, pretende-se através deste trabalho, contribuir com as atividades de pesquisa em andamento no LSO do PEAEPUSP, ligadas ao desenvolvimento de um sistema de sensoriamento a fibras ópticas capaz de medir diretamente tensões presentes em instalações de sistemas elétricos de potência que operem com tensão nominal de linha de até 69 kV RMs.

Neste trabalho o objetivo geral engloba o estudo, o desenvolvimento e a construção de um protótipo de sensor eletro-óptico de alta tensão constituído por uma célula Pockels na topologia "double pass", ou seja, na qual o sinal óptico passa duas vezes pelo cristal eletro-óptico a partir de uma reflexão total conseguida por espelhamento de uma das faces do cristal.

O sensor de que trata este trabalho deve inserir-se num sistema de sensoriamento a fibras ópticas baseado na técnica de WLI, desempenhando o papel de Interferômetro sensor de um tipo inovador de TPO, no qual o interferômetro recuperador utilizado baseia-se num modulador eletro-óptico construído em óptica integrada. O uso de componentes em óptica integrada para desempenhar tal função já foi objeto do trabalho de doutorado de Silva (2011), porém, no presente trabalho tanto a topologia proposta quanto as características do componente utilizado são diferentes e originais, como apresentado no decorrer do texto.

Assim sendo, os objetivos específicos do presente trabalho são:

- Estudar a topologia "double pass" a ser utilizada no interferômetro sensor da célula de alta tensão, buscando alternativas que apresentem as seguintes características:

- Facilidade no alinhamento axial e angular de precisão;

- Facilidade de conectorização,

- Montagem compacta e robusta,

- Baixa susceptibilidade a interferências eletromagnéticas,

- Baixa sensibilidade a vibrações mecânicas, 
- Verificar dentre as alternativas identificadas aquela que seja mais indicada e adequada para a implementação de um interferômetro sensor visando substituir a versão, "single pass", utilizada nos protótipos de TPOs anteriores.

- Implementar e testar um protótipo de célula Pockels de alta tensão baseada no interferômetro sensor na configuração "double pass" selecionado, visando a demonstração de sua funcionalidade.

- Realizar simulações numéricas utilizando um programa computacional baseado no Método dos Elementos Finitos (MEF) a fim de verificar a distribuição de campos elétricos no interior da célula Pockels e auxiliar seu projeto, permitindo, entre outras coisas, estabelecer uma correlação entre o tamanho e tipo do cristal com a tensão de meia onda $\left(V_{\pi}\right)$ da célula,

- Desenvolver e aperfeiçoar o sistema de processamento de sinais ópticos do sistema de sensoriamento, visando adequar o desempenho do mesmo para operar em conjunto com o novo interferômetro sensor "double pass".

Por fim, com esse trabalho vislumbra-se aumentar a capacitação no conhecimento, $e$ possivelmente o domínio, sobre as técnicas de projeto e construção de interferômetros sensores baseados na topologia "double pass" aplicáveis à TPOs que utilizam sistemas interferométricos de luz branca para medição de altas tensões. 


\subsection{ESTRUTURA DO TEXTO}

O trabalho é organizado de forma a apresentar no capitulo 2, um levantamento da revisão bibliográfica de tópicos relacionados com os conceitos que envolvem os transformadores de potencial e sensores ópticos. É apresentada uma visão geral dos trabalhos publicados na área de sensores a fibras ópticas. Em seguida é feito um levantamento das principais topologias de interferômetros utilizados em sistemas de sensoriamento a fibras ópticas.

No capítulo 3 são apresentadas as atividades realizadas no desenvolvimento deste trabalho: o estudo das alternativas de implementação de interferômetros sensores (células Pockels de alta tensão) baseados na topologia reflexiva ("double pass"), a escolha do modulador eletro-óptico, a técnica de aplicação de filmes anti-reflexo (AR) e de reflexão total (espelhamento) dos cristais eletro-ópticos e a montagem do interferômetro sensor, já com a topologia reflexiva.

No capítulo 4 são apresentados os métodos computacionais para auxílio ao projeto de células Pockels de alta tensão e que utiliza o método de elementos finitos.

No capítulo 5 são apresentados a topologia de ensaios e os resultados experimentais do TPO desenvolvido.

No capítulo 6 são discutidos e analisados os resultados experimentais obtidos com o TPO desenvolvido, com relação às variações de tensão CC e CA.

O Capítulo 7 encerra o texto com as conclusões obtidas durante a realização do trabalho e apresenta discussões concernentes ao tema. Por último são apresentadas as perspectivas futuras para a continuidade e melhorias no trabalho desenvolvido. 


\section{REVISÃO BIBLIOGRÁFICA}

\section{$2.1 \quad$ TRANSFORMADORES DE POTENCIAL - TP}

O Transformador de potencial (TP) é definido, pela NBR 6546 (1991. p. 4), resumidamente, como um transformador para instrumentos ( $\mathrm{TI})$ que reproduz no seu circuito secundário (rede secundária) uma tensão proporcional à do seu primário (rede primária) e que está ligado em derivação nesse circuito elétrico, mantendo, relativamente, a sua posição fasorial.

Os dois tipos de TPs utilizados em sistemas elétricos de potência (SEP) são os indutivos e os capacitivos.

\subsubsection{TRANSFORMADORES PARA INSTRUMENTOS INDUTIVOS}

O esquema de ligação dos TI s indutivos é ilustrado na figura 1 (monofásico).

Figura1 - Esquema de ligação de TIs indutivos monofásicos.

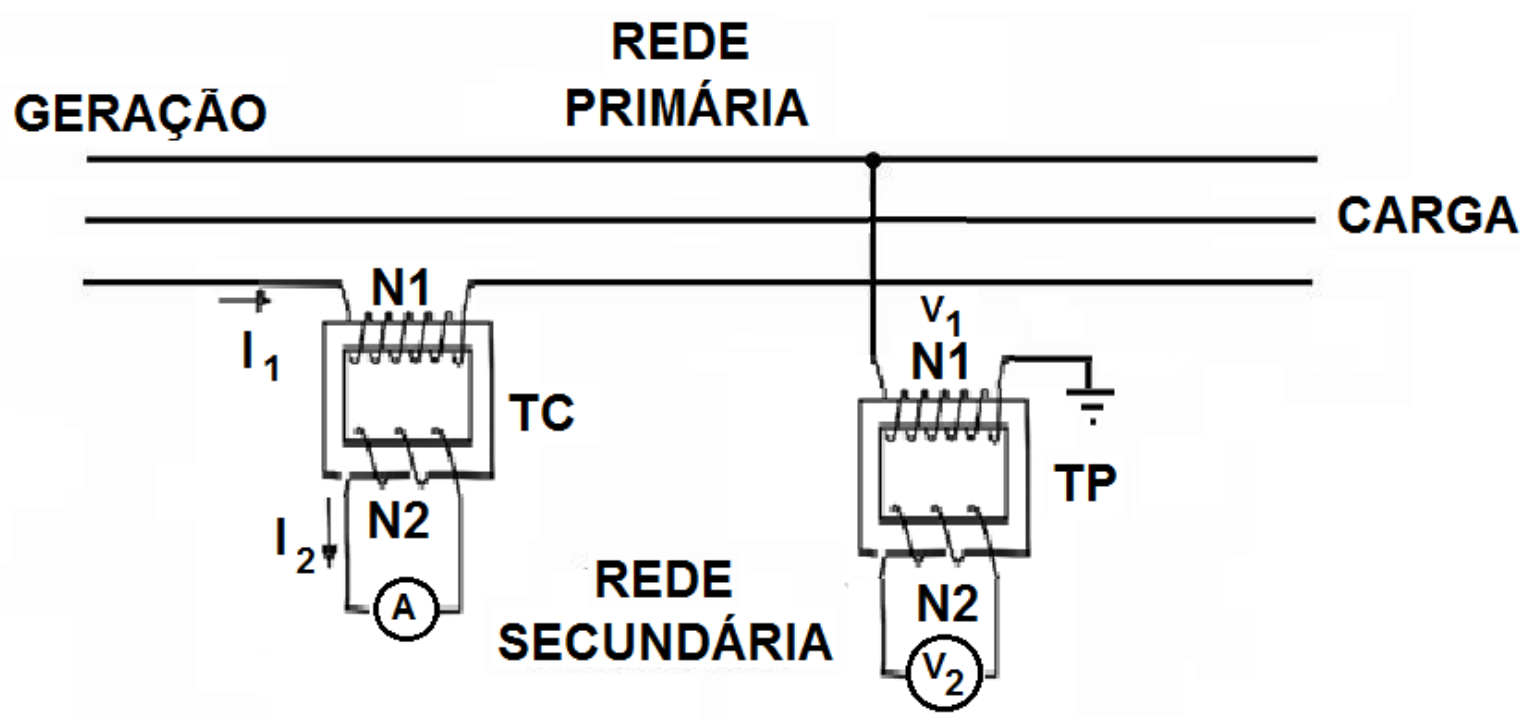

Fonte: Autor 
$\mathrm{Na}$ figura 1 verifica-se que o TP possui enrolamento primário conectado em paralelo com rede primária de potência, visando medir ou monitorar as altas tensões. O enrolamento secundário no TP tem um número menor de espiras que o primário. A relação de transformação nominal dos TPs é tão mais rigorosa quanto maior for sua classe de exatidão. Por trabalhar praticamente sem carga, o TP opera com correntes muito baixas. Da mesma forma que o transformador de alta potência, o tamanho de um TI está relacionado com a tensão nominal do sistema. Por outro lado, o fluido isolante em seu interior, óleo ou gás $\left(\mathrm{SF}_{6}\right)$, é usado somente para isolação e não para resfriamento.

Na figura 2.1, também, verifica-se que o TC possui enrolamento primário conectado em série com rede primária de potência, visando medir ou monitorar as altas correntes. Normalmente o enrolamento primário no TC consiste de uma ou poucas espiras e, uma vez que os amperímetros ou instrumentos de medição de corrente, possuem impedâncias muito baixas, considera-se que o enrolamento secundário é ligado sempre praticamente em curto.

Em aplicações em altas tensões, os TC necessitam de isoladores poliméricos ou de porcelana que devem ser utilizados para proporcionar isolação entre os terminais primários e secundários. Existe uma padronização nas tensões ou correntes nominais oferecidas nas saídas da rede secundária dos Tls e que são determinadas pelas normas NBR 6856 (1992. p. 3) (5 Arms, 2 Arms ou 1 Arms de corrente de saída nominal para os TCs) e NBR 6855 (2009. p. 15) (115 Vrms, $115 / \sqrt{3} \mathrm{Vrms}$ ou 115/3 Vrms de tensão de saída nominal para os TPs), permitindo uma produção em larga escala pelos fabricantes de Tls.

Entretanto, é importante salientar que essa padronização não é compatível com as novas tecnologias que vem surgindo, tal como a dos Tls ópticos, que usam circuitos eletrônicos em seus estágios analógicos de saída, os quais são mais aptos a oferecerem valores menores de tensão e corrente (como por exemplo $\pm 10 \mathrm{~V}$ ou 4 a $20 \mathrm{~mA}$ ), ou estão preparados para oferecerem sinais de saída digitais. Recentemente foi lançada uma proposta de norma (draft) pelo IEEE (2010, p. 7) que define os valores de tensão nominal de saída para a interface analógica de TIOs como sendo: 
- 4 Vrms de corrente nominal para um sistema de sensor óptico de corrente utilizado para a medição,

- $200 \mathrm{mVrms}$ de corrente nominal para um sistema de sensor óptico de corrente utilizado para a proteção, e

- 4 Vrms Na tensão nominal para um sistema de sensor ópticade tensão.

A figura 2, a seguir, ilustra TPs e TCs convencionais.

Figura 2 - Transformadores para instrumentos indutivos. (a) Transformador de tensão. (b) Transformador de corrente.

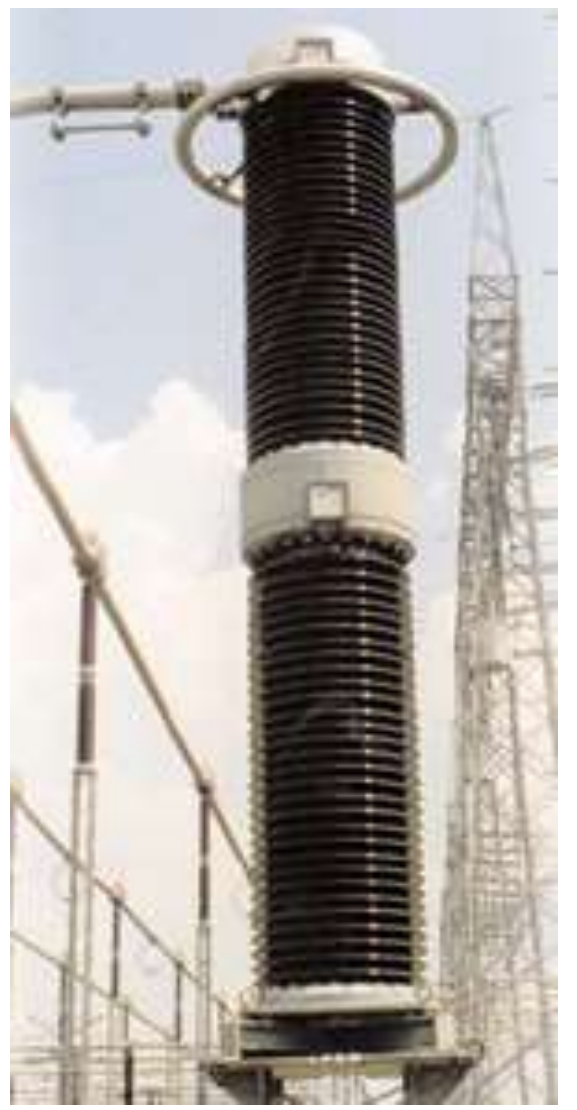

(a)

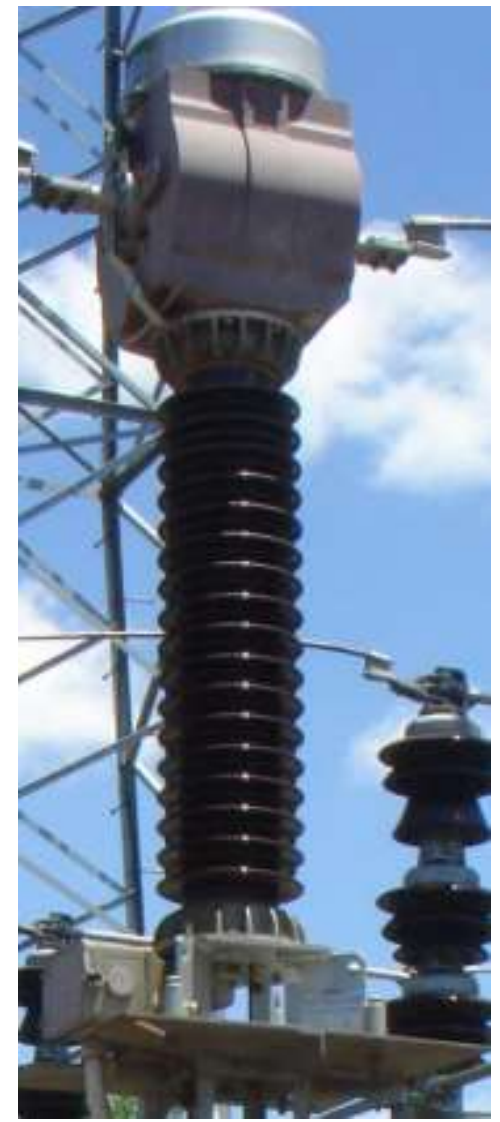

(b)

Fonte: Arteche (www.arteche.com/)

\subsubsection{TRANSFORMADORES PARA INSTRUMENTOS CAPACITIVOS}

Em sistemas elétricos de elevadas tensões, a construção de TPs indutivos vai progressivamente se inviabilizando devido às dimensões e aos custos crescentes. Nesses casos, os TPs capacitivos são aplicados, sendo que os mesmos consistem, basicamente, em uma cadeia de capacitores ligados em série e atuando como 
divisores de tensão. Visando a compensação de erros de fase devido à impedância da carga, uma indutância é utilizada em conjunto com os capacitores. A figura 3 , a seguir, ilustra um TP capacitivo comercial.

Figura 3 - Transformador de potencial capacitivo. (a) foto ilustrativa de um TP capacitivo comercial, (b) Esquemático representativo.

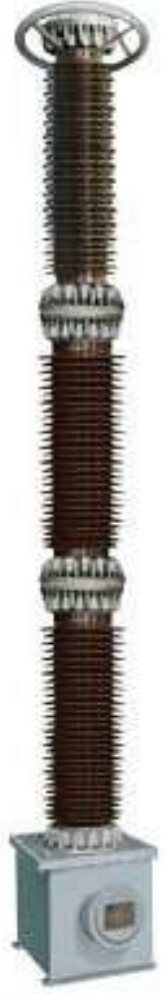

(a)

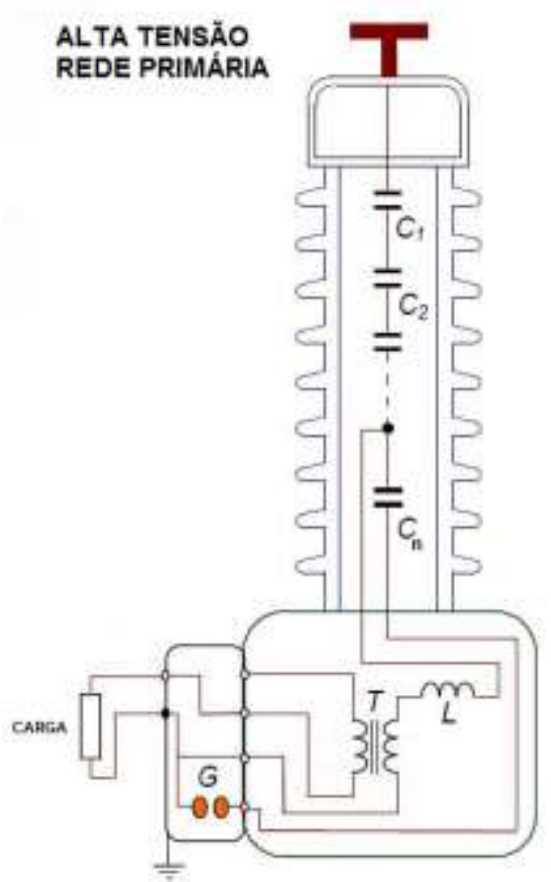

(b)

Fonte: Arteche (www.arteche.com/)

Apesar do custo inicial do sistema de medição que utiliza o TP capacitivo ser reduzido em relação aos TPs indutivos, o documento ABNT NBR IEC 61000-4-30 (2011) indica que existe uma forte limitação quanto à resposta em frequência das medições realizadas com TPCs, alertando textualmente que a mesma é "não apropriada para medições em nenhuma frequência além da fundamental", não permitindo, portanto, a medição, com exatidão, de harmônicas.

\subsubsection{TRANSFORMADORES PARA INSTRUMENTOS ÓPTICOS (TIOS)}

Os TPs convencionais, indutivos e capacitivos, são amplamente utilizados devido à sua confiabilidade, alcançada após a consolidação das suas tecnologias 
construtivas, e são aplicados, como descrito anteriormente, na medição, proteção e monitoração de redes primárias em SEPs, reduzindo níveis elevados de tensão a valores adequados e seguros, valores esses que devem ser transmitidos, através de condutores metálicos, até os pontos de leitura da instrumentação nas subestações.

Contudo, atualmente, necessidades recentes de sistemas com tensões e correntes extra elevadas têm exigido a construção de TPs com enormes dimensões e exigido aumentos na capacidade de isolação, na faixa dinâmica e, consequentemente, nos custos. Esses sistemas exigem uma alta confiabilidade de operação de modo a reduzir falhas. Além disso, os Tls têm que suprir necessidades tais como aumento de precisão e velocidade de resposta.

Os TIOs vêm de encontro a essas necessidades e já são disponíveis comercialmente, sendo ofertados por empresas como: GEC Alstom (França), ABB (Suíça), dentre outras. Como exemplo, a figura 4 ilustra um TP óptico (TPO), que inclui também um TC óptico (TCO), comercial fabricado pela empresa NxtPhase (RAHMATIAN et al.,2002; RAHMATIAN; CHAVEZ, 2003), originalmente canadense, posteriormente comprada pela Alstom e mais recentemente pela GE.

Os transdutores ópticos de tensão apresentam vantagens potencias em relação aos transformadores de potencial indutivos e capacitivos convencionais. Esses tipos de sensores apresentam características muito interessantes, tais como: resposta rápida a transitórios (maior largura de banda), maior faixa dinâmica, baixa susceptibilidade à interferência eletromagnética, elevada relação Sinal/Ruído, tamanho e peso reduzidos, alta isolação galvânica e, atualmente, custo em declínio (SILVA, 2011).

Desde a década de 1970, a tecnologia dos sensores ópticos de tensão vem sendo investigada (ROGERS, 1977, JACKSON, JONES, 1986), mas, somente a partir da década de 1990 (KEISER, 1991; UDD, 1991,1995) surgiu a viabilidade comercial da mesma. Apesar de apresentarem resolução e precisão maiores que as dos convencionais, havia ainda o inconveniente da incompatibilidade entre os sinais provenientes dos sensores ópticos com a instrumentação analógica, contida nas cabines de monitoração, medição, proteção e controle. Contudo, com o advento da instalação de relés e medidores digitais, à base de microcontroladores ou 
microprocessadores, nos SEPs, e que operaram com baixo nível de potência de sinal, a tecnologia dos TPOs tornou-se mais atrativa, viável e competitiva.

Figura 4 - COSI - Compact Optical Sensor Intelligence Combined Metering Unit COSI-CM. TP óptico (que inclui também um TC óptico) podendo ser de $69 \mathrm{kV}$ até $765 \mathrm{kV}$.
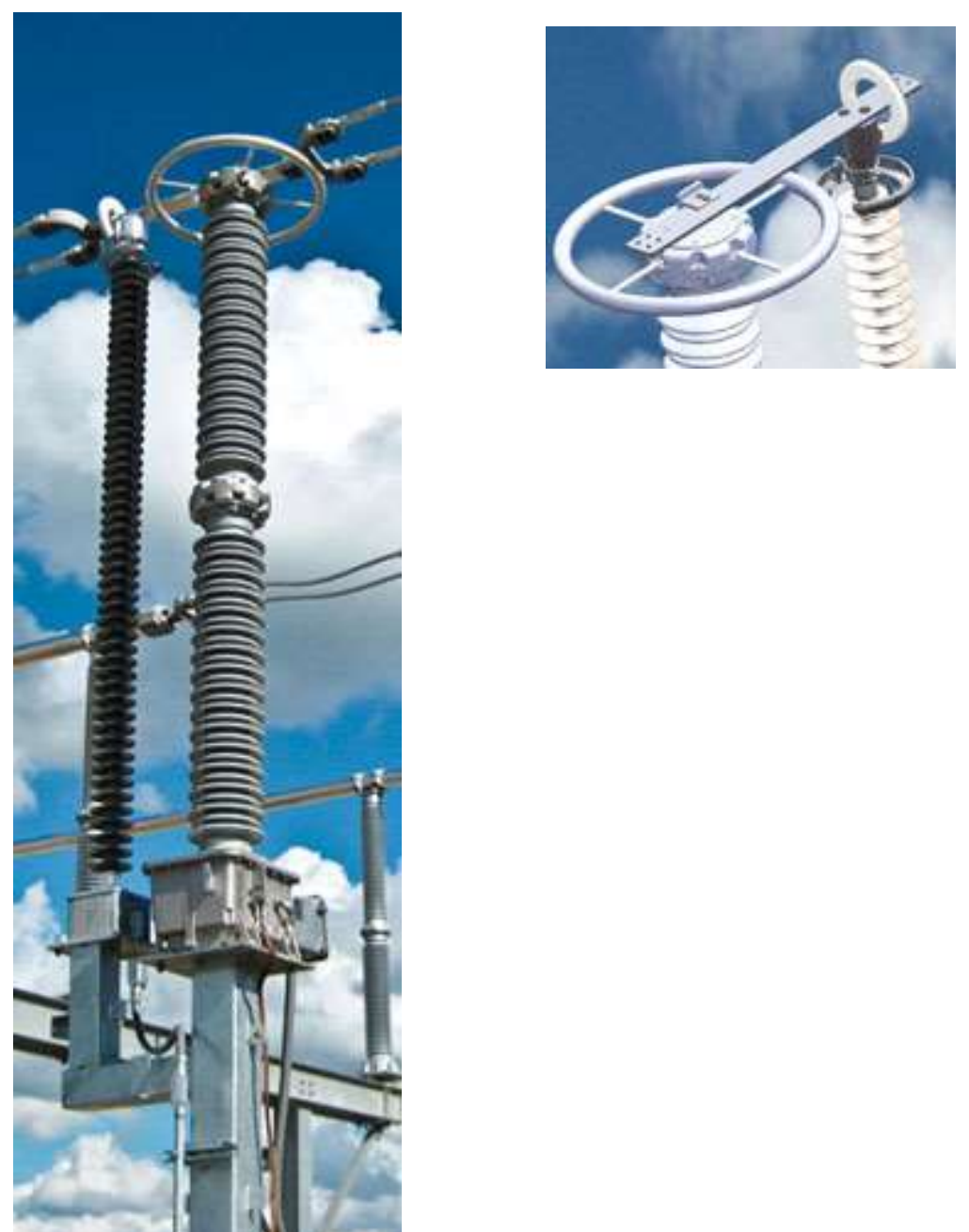

Fonte: ALSTON (www.arteche.com)

Os TCs ópticos não serão abordados ao longo deste trabalho, embora sejam estreitamente ligados tanto na aplicação como na operação aos TPOs.

Basicamente o TPO opera medindo não diretamente a tensão elétrica, mas as variações provocadas nas características da luz que se propaga em materiais eletroópticos e que são afetados pelos campos elétricos associados a essa tensão. 


\subsection{SENSORES ÓPTICOS}

Por volta de 1960 com o surgimento do laser e em meados da década de $1970 \mathrm{com}$ o crescente desenvolvimento das fibras ópticas, a união desses adventos, inicialmente, promoveu o surgimento da área das comunicações ópticas. A partir da evolução da tecnologia de fabricação das fibras, as mesmas começaram a ser aplicadas também no sensoriamento de processos e na medição de grandezas físicas, principalmente devido às vantagens apresentadas tais como: elevada sensibilidade, imunidade a interferências eletromagnéticas, versatilidade geométrica quanto ao tamanho e à forma, elevada faixa dinâmica, entre outras. Por serem totalmente construídos com materiais dielétricos podem ser utilizados em ambientes sujeitos a alta tensão, alta temperatura, alta atividade eletromagnética, ambientes corrosivos, com elevado nível de vibração, com presença de radiação ionizante e em outros ambientes normalmente hostis aos sensores elétricos ou eletromecânicos convencionais.

As características de baixo peso e de tamanho reduzido das fibras tornam atrativa a utilização dos sensores a fibra em aplicações aeroespaciais. Entretanto, no início, mesmo havendo uma perspectiva de aproveitamento desta tecnologia em sensores industriais para um grande espectro de aplicações, os custos elevados mudaram essa perspectiva e os sensores a fibras ópticas foram direcionados para aplicações especiais de mais alto custo, tais como instrumentação médica, sistemas de segurança críticos, aeronáutica, monitoração ambiental e, muito recentemente, na construção civil (BURAS, 2013), sendo que a evolução da área de sensores deve-se muito ao fato das fibras ópticas e dos dispositivos opto-eletrônicos (particularmente fontes e detectores ópticos) estarem mais acessíveis devido ao seus custos estarem em declínio, o que advém da larga escala de fabricação empreendida para atender à grande demanda da indústria das telecomunicações.

A gama de grandezas que pode ser medida com sensores à fibra óptica tem crescido rapidamente, bem como o número de mecanismos de transdução que estão sendo desenvolvidos. 
Para a classificação dos sensores a fibras ópticas, as características a serem levadas em consideração são: os principais tipos de sensores, as grandezas medidas, os mecanismos de interação da luz com a grandeza medida e as técnicas empregadas na construção e/ou interrogação dos sensores. A partir disso, facilita-se o processo de identificação dos sensores a fibras ópticas, em especial os de interesse deste trabalho, bem como as suas áreas de aplicação.

No contexto deste trabalho, os sensores que utilizam fibras ópticas podem ser agrupados em quatro classes distintas:

- De acordo com o tipo de grandeza medida;

- Quanto ao tipo de distribuição espacial da grandeza medida;

- De acordo com a forma como eles se integram com o enlace óptico (ou quanto à transdução); e

- Quanto ao tipo de modulação óptica utilizada.

Esse assunto será tratado em detalhes na sequência do texto, o qual abordará os seguintes tópicos:

- Fibra óptica como sensor;

- Sensores extrínsecos e intrínsecos;

- Sensores de intensidade;

- Sensores interferométricos;

- Tipos de interferômetros;

- Interferometria de luz branca;

- Coerência óptica;

- Interferência entre dois feixes de luz branca;

- Sensores à fibra óptica com modulação por espectro;

Como o assunto dos sensores baseados na técnica de interferometria de luz branca é essencial para a compreensão do tema tratado neste texto, o mesmo é abordado a seguir de forma resumida para permitir a visualização do cenário em que se inserem as atividades realizadas pelo autor em seu trabalho. 


\subsection{SENSORES BASEADOS NA TÉCNICA DE INTERFERÔMETRIA DE LUZ BRANCA}

Interferometria é a técnica derivada da interferência, que é a observação experimental do fenômeno de coerência. A teoria de coerência é uma descrição estatística da radiação expressa em termos de funções de correlação. A coerência temporal de uma fonte de luz real, não completamente coerente, pode ser representada por sua função de auto-correlação (SANTOS, 1996).

A técnica de Interferometria de Luz Branca (White Light Interferometry - WLI) pode ser utilizada para construir moduladores de espectro óptico e tem como base um interferômetro que separa a luz, proveniente, de uma fonte óptica de espectro largo (luz "branca") em duas componentes da luz. Em seguida é inserido um atraso de fase entre elas, também definido como diferença de caminho óptico (Optical Path Diference - OPD). Considerando que o atraso inserido seja maior que o comprimento de coerência $\left(L_{c}\right)$ da luz empregada, ao interferirem-se estas duas componentes surge, na saída do modulador, um feixe óptico com modulação em conteúdo espectral.

A recuperação da informação introduzida nesse modulador pode ser obtida de duas formas: utilizando-se um analisador de espectro óptico ou a partir da inserção de um segundo interferômetro, operando de forma a introduzir o mesmo atraso de fase (ou OPD) introduzido pelo primeiro interferômetro.

Sistemas interferométricos baseados em WLI que implementam moduladores ópticos têm como vantagens principais, em relação aos moduladores baseados em intensidade ou polarimétricos (ROGERS, 1977; SANTOS, 1996), a baixa sensibilidade às variações de potência, que possam ocorrer ao longo do enlace, e a possibilidade de fornecer linearidade e faixa dinâmica superiores às dos moduladores citados, o que permite vislumbrar esta técnica como sendo muito promissora em várias aplicações como sensores.

A interferometria de baixa coerência é um fenômeno muito bem descrito pela óptica clássica (HECHT LEFEVRE; ZAJAC, 1987; RAO; JACKSON, 1996; AL-CHALABI, 
1983) e o uso da técnica foi primeiramente relatado em 1973 (TOLANSKY, 1973), embora seu princípio de operação tenha sido proposto originalmente pelo mesmo autor em 1945 (TOLANSKY, 1945) e demonstrado em 1976 (HICKMAN, 1988) como um possível método de transmissão para uso em comunicações ópticas. O primeiro sistema sensor desenvolvido baseado na técnica de WLI foi reportado em 1984, por Bosselmann (1984), em um sensor para medida de deslocamento que utilizava como fonte de luz uma lâmpada convencional. Os vários trabalhos publicados neste período serviram para mostrar que a técnica WLI também poderia ser aplicada adequadamente na medida de outras grandezas físicas com elevada precisão (GHATAK, THYAGARAJAN, 1989). As aplicações da técnica WLI no desenvolvimento de sensores ópticos são na sua grande maioria, compostas por sensores de temperatura (AL-CHALABI, 1983; GHATAK, THYAGARAJAN, 1989; YUAN et al., 2000; ALLIL, 2010) de deformação (TIEME, 2000) e de pressão (CHOI, 1997).

\subsubsection{PRINCÍPIO DE FUNCIONAMENTO}

Nos sensores interferométricos que usam a técnica WLI, são usados, geralmente, dois interferômetros de divisão de amplitude, sendo que, neste tipo, dois divisores de feixe são utilizados: um para dividir o feixe de luz inicial em outros dois feixes que, após propagarem por diferentes braços do interferômetro, serão recombinados pelo segundo divisor, localizado no final destes braços. Se os braços possuírem comprimentos diferentes $\left(L_{1}\right.$ e $\left.L_{2}\right)$, a diferença de fase introduzida entre os dois feixes luminosos será proporcional à diferença de caminho óptico, $\Delta L=L_{1}-L_{2}$. Se $I_{1}$ e $I_{2}$ forem as intensidades luminosas destes dois feixes, respectivamente, após a recombinação deles (se as propriedades de polarização da luz forem mantidas) a intensidade resultante dependerá do grau de coerência temporal da fonte, $\gamma_{12 c}(\tau)$, desenvolvida por Santos (1996), descrita no adendo A, será dada por:

$$
I=I_{1}+I_{2}+2 \sqrt{I_{1} I_{2}}\left|\gamma_{12 c}(\tau)\right| \cos \Delta \phi(t)
$$

onde: $\tau=\frac{\left|L_{1}-L_{2}\right|}{c}=\frac{\Delta L}{c}$ é a diferença de tempo, $c$ é a velocidade de propagação da luz no vácuo e $\Delta \phi$ é a diferença de fase óptica, que pode ser escrita como: 


$$
\Delta \phi(t)=k \cdot \Delta L \quad \text { e } \quad k=\frac{2 \pi}{\lambda}
$$

onde $\lambda$ é o comprimento de onda da luz no meio.

Em um padrão de franjas de interferência, a intensidade varia entre dois limites: a intensidade máxima e a intensidade mínima, $I_{\max }$ e $I_{\min }$, respectivamente, sendo $I_{\max }$ observada na saída do interferômetro quando ambas as ondas estão em fase ( $\Delta \varphi=2 \mathrm{~m} \pi$, com $\mathrm{m}$ sendo um número inteiro) e $I_{\min }$ observada quando ambas as ondas estão em oposição de fase $(\Delta \varphi=(2 m+1) \pi)$.

A qualidade das franjas de interferência produzidas por um interferômetro pode ser descrita quantitativamente usando o conceito de visibilidade, $\vartheta=\left(\frac{I_{\max }-I_{\min }}{I_{\max }+I_{\min }}\right)$.

A visibilidade pode ser descrita em termos da função de coerência $112(\tau)$ da fonte de radiação óptica (LEFÉVRE, 1993), por:

$$
\vartheta=\vartheta_{0}\left|\gamma_{12 c}(\tau)\right|
$$

onde: $\vartheta_{0}$ é a visibilidade da franja central, que corresponde a uma diferença de caminhos ópticos igual a zero (OPD $=0)$, equivalentemente a $\tau=0$.

Um padrão de interferência aparece se o valor absoluto de $\gamma_{12 c}(\tau)$ diverge de zero.

Fazendo $\vartheta_{0}=2 \frac{\sqrt{\left(I_{1} \cdot I_{2}\right)}}{l_{1}+I_{2}}$, usando também a eq.(3) e substituindo este resultado na eq.(1), obtém-se:

$$
I=\left(I_{1}+I_{2}\right)[1 \pm \vartheta \cos \Delta \phi(t)]
$$

O padrão de intensidade de saída de um interferômetro de luz branca dado pela eq.(4) possui um perfil de visibilidade dado pela eq.(3), determinado pela 
propriedade de baixa coerência da fonte de banda larga utilizada. A distribuição do espectro de intensidade de uma fonte óptica de banda larga típica pode ser representada, aproximadamente, por uma função gaussiana, tal como (SANTOS, 1996):

$$
I_{\sigma}(\sigma)=\frac{I_{O}}{\sqrt{\pi}(\delta \sigma)} e^{-\left[\frac{\sigma-\sigma_{O}}{(\delta \sigma)}\right]^{2}}
$$

onde: $\sigma=1 / \lambda$ é o número de onda de uma componente espectral, $\sigma_{O}$ é o número de onda central da fonte luminosa, $\delta \sigma$ é a largura da banda espectral e $l_{o}$ é a intensidade em $\sigma_{O}$.

Neste caso, o comprimento de coerência da fonte, $L_{c}$, é dado, de forma aproximada, por (SANTOS, 1996):

$$
L_{c} \cong \frac{1}{(\delta \sigma)} \cong \frac{\lambda_{0}^{2}}{(\delta \lambda)}
$$

Visto que a saída de um interferômetro é, em teoria, a transformada de Fourier do espectro da fonte e, a transformada de Fourier de uma função gaussiana é também uma função gaussiana, como descrito anteriormente, deduz-se que o padrão de intensidade de saída normalizado de um interferômetro de luz branca é uma função cosseno modificado por um perfil de visibilidade gaussiano.

Uma das maneiras de se construir um sistema de sensoriamento utilizando a técnica WLI é baseada na ligação em série de dois interferômetros. De uma forma genérica, o princípio de funcionamento de um sistema de sensoriamento WLI deste tipo pode ser explicado da seguinte maneira: a luz emitida de uma fonte espectral de luz de banda larga (um diodo superluminescente - SLD, por exemplo) é acoplada a uma 
fibra óptica que é conectada ao divisor de feixe localizado na entrada de um sensor interferométrico.

A diferença de caminho óptico introduzido pelo interferômetro sensor, $\Delta L_{s}$, é linearmente sensível à grandeza externa a ser medida, que no caso deste trabalho é o campo elétrico relacionado à alta tensão aplicada a esse interferômetro. No caso da fonte de luz ser de banda larga, com um comprimento de coerência pequeno, se o OPD introduzido pelo interferômetro sensor for maior que o comprimento de coerência $L_{c}$ da fonte, não será observado nenhuma interferência na saída do interferômetro sensor. Se a luz que sai do interferômetro sensor for acoplada a outra fibra óptica e inserida em um segundo interferômetro, chamado interferômetro recuperador, poder-se-á observar interferência em sua saída se, e somente se, a diferença de caminho óptico introduzida pelo interferômetro recuperador, $\Delta L_{r}$, se aproximar da que foi introduzida no interferômetro sensor, $\Delta L_{s}$.

Uma demonstração analítica deste princípio pode ser feita utilizando a eq.(4) e omitindo a dependência espectral do OPD. O comportamento do interferômetro sensor pode ser descrito pela seguinte relação (SANTOS, 1996):

$$
I_{s}(\sigma)=T_{1} T_{s} I_{\sigma}(\sigma)\left[1+\vartheta_{s} \cos \left(2 \pi \sigma \Delta L_{s}\right)\right]
$$

onde: $T_{1}$ e $T_{s}$ são os fatores de transmissão dos enlaces ópticos de ida e do interferômetro sensor, respectivamente, $\vartheta_{s}$ é a visibilidade dada pela eq.(3) e $\Delta L_{s}$ é o OPD inserido pelo interferômetro sensor, $\sigma$ é o número de onda de uma componente espectral e $I_{\sigma}(\sigma)$ é a distribuição de intensidade espectral da fonte óptica, descrita anteriormente.

Analogamente, o comportamento do interferômetro recuperador pode ser descrito como:

$$
I_{r}(\sigma)=T_{2} T_{r} I_{\sigma}(\sigma)\left[1+\vartheta_{r} \cos \left(2 \pi \sigma \Delta L_{r}\right)\right]
$$


onde: $T_{2}$ e $T_{r}$ são os fatores de transmissão dos enlaces ópticos de volta e do interferômetro recuperador, respectivamente, $\vartheta_{r}$ é a visibilidade dada pela eq.(3) e $\Delta L_{r}$ é o OPD inserido pelo interferômetro recuperador, $\sigma$ é o número de onda de uma componente espectral e $I_{\sigma}(\sigma)$ é a distribuição de intensidade espectral da fonte óptica, descrita anteriormente.

A intensidade total disponível na saída do sistema interferométrico é obtida pela integração sobre todos os números de onda:

$$
I=\int_{\sigma} I_{r}(\sigma) d \sigma
$$

Se a fonte possuir uma distribuição espectral gaussiana, esta integral torna-se:

$$
I=T_{1} T_{2} T_{s} T_{r} I_{o}\left[1+\frac{1}{2} K_{o s} K_{o r} e^{-\left[\frac{\pi\left(\Delta L_{s}-\Delta L_{r}\right)}{L_{c}}\right]^{2}} \cos 2 \pi\left(\frac{\Delta L_{s}-\Delta L_{r}}{\lambda_{o}}\right)\right]
$$

onde Kos é a visibilidade da franja central do interferômetro sensor e Kor é a visibilidade da franja central do interferômetro recuperador.

A intensidade / resultante aparece como uma função cosseno do OPD modificado por uma visibilidade dependente da fase, exatamente como mostrado na figura 5 , a seguir. Verifica-se que o sistema apresenta a vantagem de um espectrômetro de transformada de Fourier, onde o sinal é proporcional à potência total de saída, e que a máxima visibilidade ocorre no ponto de casamento $\Delta L_{s}=\Delta L_{r}$. 
Figura 5 - Padrão teórico de intensidade de saída de um interferômetro de luz branca.

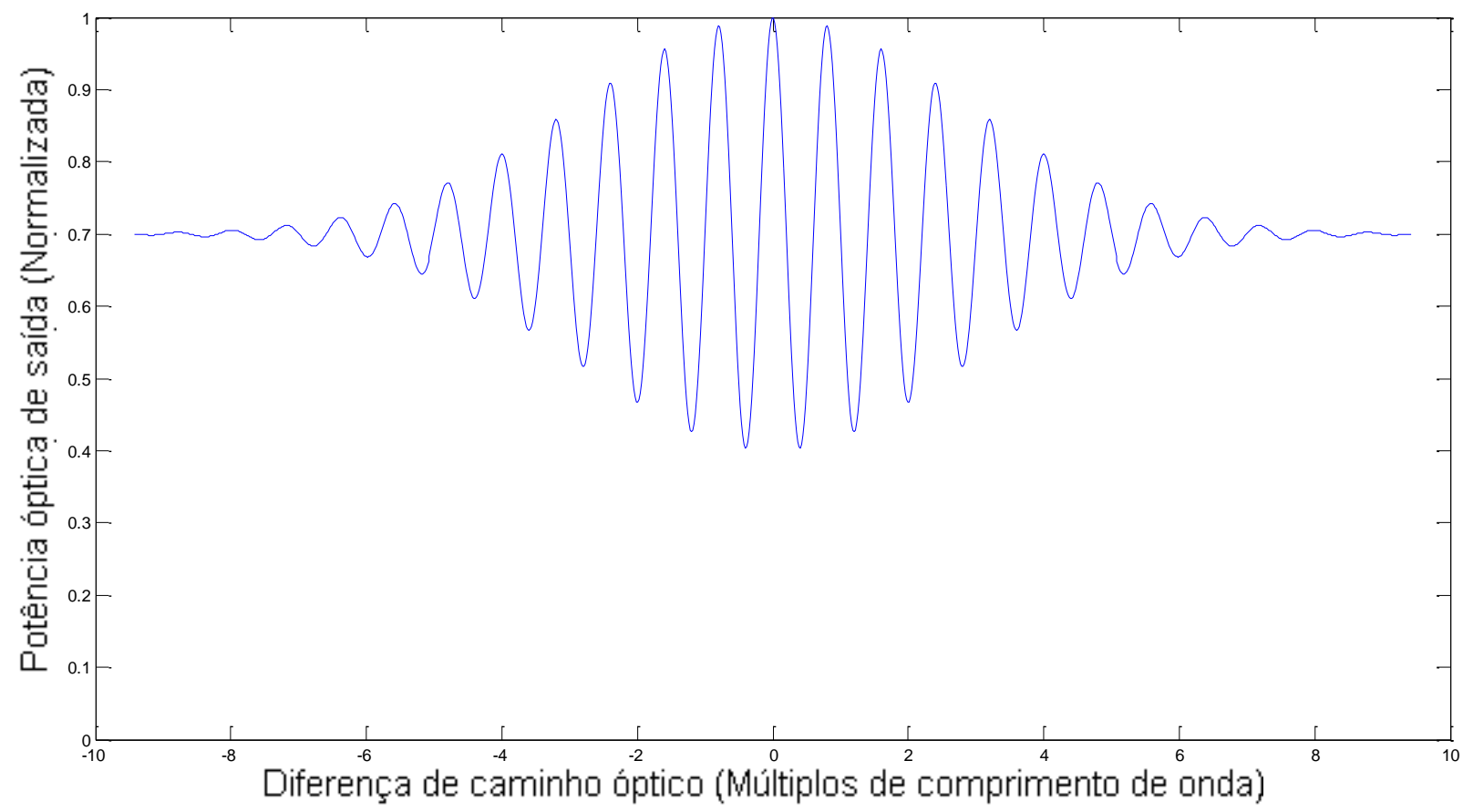

Fonte: Autor

O OPD introduzido pelo interferômetro recuperador $\left(\Delta L_{r}\right)$ pode ser ajustado para se igualar ao OPD do interferômetro sensor $\left(\Delta L_{S}\right)$ quando a grandeza medida é igual a zero. Nesse caso, verifica-se através da eq.(10) que, no ponto de casamento, a saída do interferômetro recuperador está no pico central da figura de interferência.

Se $\Delta L_{r}$ for fixo, verifica-se que a intensidade óptica na saída do sistema depende do $\Delta L_{S}$, proporcional à grandeza a ser medida, e das transmissões dos componentes ópticos do sistema. Caso essas transmissões variem no tempo o resultado dessa variação será confundido com o sinal a ser medido, o que é indesejável. Para garantir a estabilidade da medida em relação à variação da potência óptica total transmitida pelo enlace faz-se necessário o uso de um método para eliminar esta dependência. O método utilizado para este fim no presente trabalho é modulação e demodulação síncrona por meio da variação do $\Delta L_{r}$ imposto pelo interferômetro recuperador, é descrito no item 3.3. 


\subsection{INTERAÇÃO ELETRO-ÓPTICA}

\subsubsection{EFEITO ELETRO-ÓPTICO}

Inicialmente é importante expor o princípio de operação do sensor eletro-óptico e os fundamentos do efeito eletro-óptico, em que se baseia o sensor.

O elemento chave de qualquer sensor eletro-óptico é o material eletro-óptico utilizado, cujas características determinam o desempenho global sensor. Dentre os diversos tipos de materiais eletro-ópticos disponíveis na natureza os cristais são de especial interesse neste trabalho por suas características vantajosas em termos de estabilidade de longo termo, elevada sensibilidade a campos elétricos e baixa deriva térmica, entre outras.

Os cristais eletro-ópticos são caraterizados por serem sólidos cujos átomos estão dispostos de forma ordenada e repetitiva (estrutura cristalina) e por apresentarem algum tipo de propriedade eletro-óptica.

As propriedades eletro-ópticas são aquelas que implicam na mudança no índice de refração linear do cristal com a presença de um campo elétrico.

O foco de interesse deste trabalho será o efeito Pockels, que é descrito na próxima sessão.

Pelos motivos apontados anteriormente na sessão 1, os cristais pesquisados neste trabalho são de estrutura atômica com simetria cúbica, sendo que esta estrutura fornece uma maneira conveniente de descrever a orientação do cristal pela aplicação de um sistema de coordenadas retangulares baseado nos eixos cristalinos. Relativamente a este sistema de coordenadas, pode-se matematicamente definir o sentido de propagação e polarização da luz no cristal. Quando se monta um sistema óptico, composto por um conjunto de componentes ópticos, destinado a processar um sinal luminoso, como um sensor óptico por exemplo, o sistema de coordenadas do cristal também é usado como forma de referenciar e orientar os componentes ópticos adicionais. 
A figura 6, a seguir, mostra a orientação do sistema de coordenadas para célula unitária que define a estrutura de um cristal cúbico. Deve ser salientado que só as direções coordenadas são importantes e que a localização da origem é irrelevante.

Figura 6 - Sistema de coordenadas de uma célula unitária de estrutura cúbica.

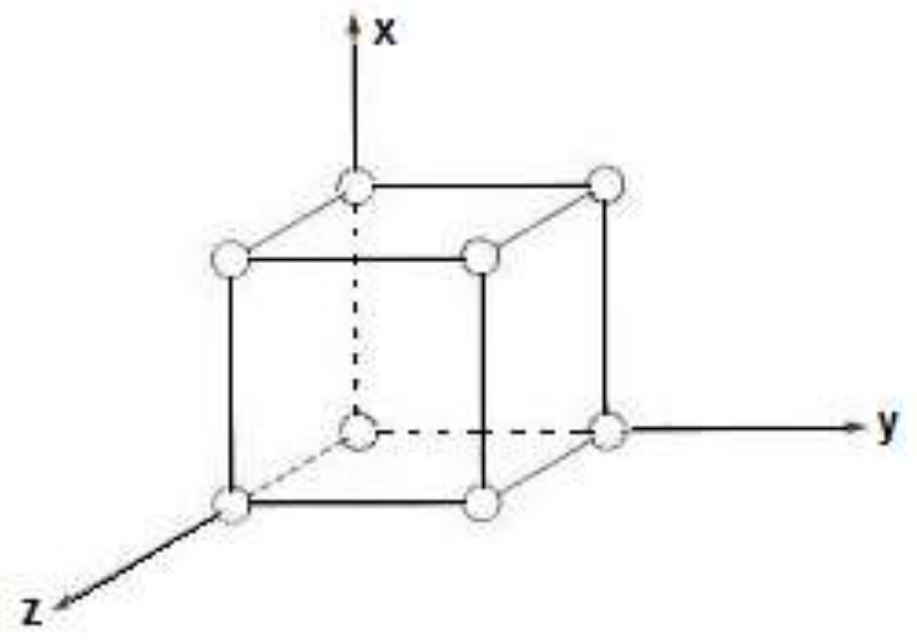

Fonte: Santos (1996) adaptado

Como exemplo de cristais cúbicos pode-se citar o Germanato de Bismuto, (BGO$\mathrm{Bi}_{4} \mathrm{Ge}_{3} \mathrm{O}_{12}$ ), Seleneto de Zinco (ZnSe) e Óxido de Silício Bismuto (BSO), sendo que tanto o BGO como o ZnSe são pertencentes ao grupo de simetria 43m (Td) e o BSO pertencente ao grupo 23 (T) (YARIV, 1989).

O BGO e o ZnSe são funcionalmente idênticos, porém o BSO apresenta uma propriedade intrínseca denominada atividade óptica que faz com que luz linearmente polarizada aplicada ao cristal tenha sua direção de polarização incidente girada à medida que trafega através do cristal.

De acordo com a teoria quântica dos sólidos, o tensor de impermeabilidade dielétrica, $\eta_{i j}$, depende da distribuição de cargas no cristal (YARIV, 1989). Quando uma pequena deformação na rede iônica ocorre, devido à redistribuição das cargas ligadas a partir da aplicação de um campo elétrico externo $\overrightarrow{\vec{E}}$, o resultado é uma variação no tensor impermeabilidade, dada por: 


$$
\Delta \eta_{i j}=\eta_{i j}(\overrightarrow{\vec{E}})-\eta_{i j}(0)
$$

onde $\eta_{i j}$ é o tensor impermeabilidade perturbado pelo campo $(\overrightarrow{\vec{E}})$ e $\eta_{i j}(0)$ é o tensor impermeabilidade não perturbado sendo $i, j=1,2,3$.

A relação entre o campo elétrico e a variação no índice de refração pode ser expressa escrevendo-se a expansão da equação anterior em série de potências, obtendo-se:

$$
\Delta \eta_{i j}=r_{i j k} E_{k}+s_{i j k l} E_{k} E_{l}+\ldots \ldots
$$

onde $r_{i j k}$ é um tensor de terceira ordem, denominado tensor eletro-óptico linear, e $s_{i j k l}$ é um tensor de quarta ordem, denominado tensor eletro-óptico quadrático. No caso linear, a variação de impermeabilidade e, consequentemente, de índice de refração, é proporcional à intensidade de campo elétrico. Por outro lado, no efeito quadrático, a variação de impermeabilidade é proporcional ao quadrado do campo elétrico.

O efeito Pockels é descrito a seguir a partir da descrição do efeito eletro-óptico linear feita por Yariv (2003).

\subsubsection{EFEITO ELETRO-ÓPTICO LINEAR}

Se o cristal de interesse é opticamente transparente para o comprimento de onda de interesse, então a propriedade óptica primária importante a ser estudada é o índice de refração. Na sua descrição mais simples, o efeito eletro-óptico é descrito com uma mudança no índice de refração do cristal quando o mesmo é submetido a um campo elétrico externo. As propriedades ópticas de um cristal eletro-óptico podem ser descritas pelo elipsoide de índices de refração do mesmo, sendo que a equação que o define é dada por:

$$
\left(\frac{1}{n_{x}^{2}}\right) x^{2}+\left(\frac{1}{n_{y}^{2}}\right) y^{2}+\left(\frac{1}{n_{z}^{2}}\right) z^{2}=1
$$


em que $x, y$ e $z$ são os eixos principais, ou cristalográficos, do cristal e $n_{x}, n_{y}$ e $n_{z}$ são os índices de refração nos eixos principais $x, y$ e $z$, respectivamente. Esta equação é válida sem campo elétrico aplicado. A equação geral para o elipsoide de índice de um cristal, com campo elétrico externo $\vec{E}(E x, E y, E z)$ é:

$$
\left(\frac{1}{n^{2}}\right)_{1} x^{2}+\left(\frac{1}{n^{2}}\right)_{2} y^{2}+\left(\frac{1}{n^{2}}\right)_{3} z^{2}+2\left(\frac{1}{n^{2}}\right)_{4} y z+2\left(\frac{1}{n^{2}}\right)_{5} x z+2\left(\frac{1}{n^{2}}\right)_{6} x y=1
$$

Caso $x$, y e $z$ estejam alinhados com os eixos principais do cristal e $\vec{E}=0$, então a eq.(14) deve reduzir a eq.(13) e

$$
\begin{aligned}
& \left.\left(\frac{1}{n^{2}}\right)_{1}\right|_{E=0}=\left(\frac{1}{n_{x}^{2}}\right) \\
& \left.\left(\frac{1}{n^{2}}\right)_{2}\right|_{E=0}=\left(\frac{1}{n_{y}^{2}}\right) \\
& \left.\left(\frac{1}{n^{2}}\right)_{3}\right|_{E=0}=\left(\frac{1}{n_{z}^{2}}\right) \\
& \left.\left(\frac{1}{n^{2}}\right)_{4}\right|_{E=0}=0 \\
& \left.\left(\frac{1}{n^{2}}\right)_{5}\right|_{E=0}=0 \\
& \left.\left(\frac{1}{n^{2}}\right)_{6}\right|_{E=0}=0
\end{aligned}
$$

A alteração dos coeficientes das equações em função do campo elétrico aplicado é definida por:

$$
\Delta\left(\frac{1}{n^{2}}\right)_{i}=\sum_{j=1}^{3} r_{i j} E_{j}
$$

sendo que os valores de $\mathrm{j}=1,2,3$ representam $x, y$ e $z$, respectivamente. Desta forma esta definição permite-se expressar a eq.(16) na forma de uma matriz 


$$
\left[\begin{array}{l}
\Delta\left(\frac{1}{n^{2}}\right)_{1} \\
\Delta\left(\frac{1}{n^{2}}\right)_{2} \\
\Delta\left(\frac{1}{n^{2}}\right)_{3} \mid \\
\Delta\left(\frac{1}{n^{2}}\right)_{4} \mid \\
\Delta\left(\frac{1}{n^{2}}\right)_{5} \\
\Delta\left(\frac{1}{n^{2}}\right)_{6}
\end{array}\right]=\left[\begin{array}{lll}
r_{11} & r_{12} & r_{13} \\
r_{21} & r_{22} & r_{23} \\
r_{31} & r_{32} & r_{33} \\
r_{41} & r_{42} & r_{43} \\
r_{51} & r_{52} & r_{53} \\
r_{61} & r_{62} & r_{63}
\end{array}\right] \cdot\left[\begin{array}{c}
E_{x} \\
E_{y} \\
E_{z}
\end{array}\right]
$$

onde a matriz de $6 \times 3$ de $r_{\mathrm{ij}}$ é descrita como tensor eletro-óptico do cristal. Assim, substituindo-se a eq.(15) e a eq.(17) na eq.(16) têm-se:

$$
\left[\begin{array}{l}
\left(\frac{1}{n^{2}}\right)_{1}=r_{11} E_{x}+r_{12} E_{y}+r_{13} E_{z}+\frac{1}{n_{x}^{2}} \\
\left(\frac{1}{n^{2}}\right)_{2}=r_{21} E_{x}+r_{22} E_{y}+r_{23} E_{z}+\frac{1}{n_{y}^{2}} \\
\left(\frac{1}{n^{2}}\right)_{3}=r_{31} E_{x}+r_{32} E_{y}+r_{33} E_{z}+\frac{1}{n_{z}^{2}} \\
\left(\frac{1}{n^{2}}\right)_{4}=r_{41} E_{x}+r_{42} E_{y}+r_{43} E_{z} \\
\left(\frac{1}{n^{2}}\right)_{5}=r_{51} E_{x}+r_{52} E_{y}+r_{53} E_{z} \\
\left(\frac{1}{n^{2}}\right)_{6}=r_{61} E_{x}+r_{62} E_{y}+r_{63} E_{z}
\end{array}\right]
$$

que pode ser substituído na eq.(14) para expansão da equação de elipsoide índice, resultando em:

$$
\begin{aligned}
& \left(r_{11} E_{x}+r_{12} E_{y}+r_{13} E_{z}+\frac{1}{n_{x}^{2}}\right) x^{2}+\left(r_{21} E_{x}+r_{22} E_{y}+r_{23} E_{z}+\frac{1}{n_{y}^{2}}\right) y^{2}+\left(r_{31} E_{x}+r_{32} E_{y}+r_{33} E_{z}+\frac{1}{n_{z}^{2}}\right) z^{2}+ \\
& 2\left(r_{41} E_{x}+r_{42} E_{y}+r_{43} E_{z}\right) y z+2\left(r_{51} E_{x}+r_{52} E_{y}+r_{53} E_{z}\right) x z+2\left(r_{61} E_{x}+r_{62} E_{y}+r_{63} E_{z}\right) x y=1
\end{aligned}
$$


A matriz do tensor eletro-óptico de cristais eletro-ópticos tais como BGO, ZnSe e BSO, devido à simetria cúbica (grupos 43m e 23), pode ser reduzida como descrito a seguir.

$$
\left[\begin{array}{lll}
r_{11} & r_{12} & r_{13} \\
r_{21} & r_{22} & r_{23} \\
r_{31} & r_{32} & r_{33} \\
r_{41} & r_{42} & r_{43} \\
r_{51} & r_{52} & r_{53} \\
r_{61} & r_{62} & r_{63}
\end{array}\right]=\left[\begin{array}{ccc}
0 & 0 & 0 \\
0 & 0 & 0 \\
0 & 0 & 0 \\
r_{41} & 0 & 0 \\
0 & r_{41} & 0 \\
0 & 0 & r_{41}
\end{array}\right]
$$

Adotando-se $x, y$ e $z$ paralelos aos eixos cristalográficos de um cristal cúbico, a eq.(19) pode ser reduzida à forma:

$$
\left(\frac{1}{n_{o}^{2}}\right) x^{2}+\left(\frac{1}{n_{o}^{2}}\right) y^{2}+\left(\frac{1}{n_{o}^{2}}\right) z^{2}+2 r_{41} E_{x} y z+2 r_{41} E_{y} x z+2 r_{41} E_{z} x y=1
$$

O campo elétrico pode ser aplicado em qualquer direção, mas um caso particular de interesse neste trabalho é aquele em que a direção do campo elétrico coincide com a de um dos eixos cristalinos do cristal. Neste caso, a eq.(21) pode ser simplificada. Definindo-se a orientação do campo elétrico aplicado paralelo, por exemplo, à direção z, ou seja, fazendo $E_{x}=E_{y}=0$ e $E_{z}=E$, obtém-se:

$$
\left(\frac{1}{n_{o}^{2}}\right) x^{2}+\left(\frac{1}{n_{o}^{2}}\right) y^{2}+\left(\frac{1}{n_{o}^{2}}\right) z^{2}+2 r_{41} E_{z} x y=1
$$

A partir da eq.(22), pode ser facilmente visto que sem o campo aplicado a mesma torna-se igual à eq.(13) que é o elipsoide de índices de refração não perturbado. $O$ termo misto adicional na eq.(22) significa que os eixos maiores do elipsoide perturbado $\left(x^{\prime}, y^{\prime}\right.$ e $\left.z^{\prime}\right)$ já não são paralelos aos eixos cristalográficos do cristal $(x, y$ e $z)$. Para explicitar este fato deve-se escolher um novo sistema de coordenadas de modo que a eq.(22) assuma a forma: 


$$
\left(\frac{1}{n_{x}^{2}}\right) x^{2}+\left(\frac{1}{n_{y}^{2}}\right) y^{\prime 2}+\left(\frac{1}{n_{z}^{2}}\right) z^{2}=1
$$

Por inspeção, pode-se ver que o novo sistema de coordenadas deve ter $z \dot{z}$ paralelo a $z$ e também que $x^{\prime}$ e $y^{\prime}$ são relacionados com $x$ e y por uma rotação de um ângulo $\theta$ sobre o eixo z. A figura 7, a seguir, mostra este novo sistema de coordenadas.

Figura 7 - Relação entre os sistemas de coordenadas, perturbado e não perturbado em um material eletro-óptico cúbico com campo elétrico aplicado paralelamente ao eixo z.

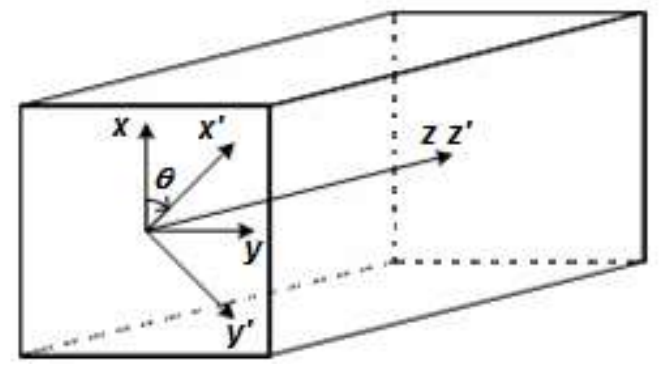

Fonte: Silva (2006) modificado

Assim o novo sistema de coordenadas pode ser descrito por:

$$
\begin{aligned}
& x=x^{\prime} \cos \theta-y^{\prime} \sin \theta \\
& y=x^{\prime} \sin \theta+y^{\prime} \cos \theta \\
& z=z^{\prime}
\end{aligned}
$$

Substituindo-se a eq.(24) na eq.(22) tem-se:

$$
\begin{aligned}
& \frac{\left(x \cdot \cos \theta-y^{\prime} \sin \theta\right)^{2}}{n_{o}^{2}}+\frac{\left(x \cdot \sin \theta+y^{\prime} \cos \theta\right)^{2}}{n_{o}^{2}}+\left(\frac{1}{n_{o}^{2}}\right) z^{2}+ \\
& 2 r_{41} E_{z}\left(x^{\prime} \cos \theta-y^{\prime} \sin \theta\right)\left(x^{\prime} \sin \theta+y^{\prime} \cos \theta\right)=1
\end{aligned}
$$

E consequentemente,

$$
\begin{aligned}
& \left(\frac{\cos ^{2} \theta+\sin ^{2} \theta}{n_{o}^{2}}\right) x^{2}+\left(\frac{\sin ^{2} \theta+\cos ^{2} \theta}{n_{o}^{2}}\right) y^{\prime 2}+\left(\frac{1}{n_{o}^{2}}\right) z^{2}+ \\
& 2 r_{41} E_{z}\left(x^{2} \cos \theta \sin \theta+x^{\prime} y^{\prime} \cos ^{2} \theta-x^{\prime} y^{\prime} \sin ^{2} \theta-y^{\prime 2} \sin \theta \cos \theta\right)=1
\end{aligned}
$$


Tornando-se:

$$
\begin{gathered}
\left(\frac{1}{n_{o}^{2}}\right) x^{2}+\left(\frac{1}{n_{o}^{2}}\right) y^{2}+\left(\frac{1}{n_{o}^{2}}\right) z^{2}+2 r_{41} E_{z} \\
\left(x^{2} \cos \theta \sin \theta+x^{\prime} y^{\prime} \cos ^{2} \theta-x y^{\prime} \sin ^{2} \theta-y^{\prime 2} \sin \theta \cos \theta\right)=1
\end{gathered}
$$

A fim de obter uma elipsoide cujos eixos principais estejam alinhados com o novo sistema $\left(x^{\prime}, y^{\prime}\right.$ e $\left.z^{\prime}\right)$ é necessário zerar a parcela em $x^{\prime} y^{\prime}$ (termos cruzados). Como os elementos $r_{41}, E_{z \neq 0} \Rightarrow \cos ^{2} \theta-\operatorname{sen}^{2} \theta=0 \Rightarrow \theta=45^{\circ}$, assim a eq.(27), pode ser simplificada para:

$$
\left(\frac{1}{n_{o}^{2}}\right) x^{2}+\left(\frac{1}{n_{o}^{2}}\right) y^{2}+\left(\frac{1}{n_{o}^{2}}\right) z^{2}+2 r_{41} E_{z}\left(\frac{x^{2}}{2}-\frac{y^{2}}{2}\right)=1
$$

ou

$$
\left(\frac{1}{n_{o}^{2}}+r_{41} E_{z}\right) x^{2}+\left(\frac{1}{n_{o}^{2}}-r_{41} E_{z}\right) y^{2}+\left(\frac{1}{n_{o}^{2}}\right) z^{2}=1
$$

Para que a eq.(28b) assuma a forma da eq.(23), faz-se:

$$
\begin{aligned}
& \left(\frac{1}{n_{x}^{2}}\right)=\frac{1}{n_{o}^{2}}+r_{41} E_{z} \\
& \left(\frac{1}{n_{y}^{2}}\right)=\frac{1}{n_{o}^{2}}-r_{41} E_{z} \\
& \left(\frac{1}{n_{z}^{2}}\right)=\frac{1}{n_{o}^{2}}
\end{aligned}
$$

Se assumirmos que o diferencial de mudança no índice de refração do cristal é pequeno na presença de um campo elétrico,

$$
r_{41} E_{z} \ll \frac{1}{n_{o}^{2}}
$$

Assim a eq.(29) pode ser reescrita como 


$$
\begin{aligned}
\frac{1}{n_{x}^{2}} & \approx \frac{1}{n_{o}^{2}} \\
\frac{1}{n_{y}^{2}} & \approx \frac{1}{n_{o}^{2}} \\
\frac{1}{n_{z}^{2}} & \approx \frac{1}{n_{o}^{2}}
\end{aligned}
$$

$\log 0$

$$
\begin{aligned}
& n_{x^{\prime}}^{2} \approx n_{o}^{2} \\
& n_{y^{\prime}}^{2} \approx n_{o}^{2} \\
& n_{z}^{2} \approx n_{o}^{2}
\end{aligned}
$$

As equações (31) e (32), baseando-se na hipótese de uma pequena mudança diferencial no índice de refração, podem ser reescritas como:

$$
\begin{aligned}
& \frac{1}{n_{x}^{2}}=\frac{1}{n_{o}^{2}}+\frac{d}{d n}\left(\frac{1}{n_{o}^{2}}\right) \\
& \frac{1}{n_{y}^{2}}=\frac{1}{n_{o}^{2}}-\frac{d}{d n}\left(\frac{1}{n_{o}^{2}}\right) \\
& \frac{1}{n_{z}^{2}}=\frac{1}{n_{o}^{2}}
\end{aligned}
$$

e

$$
\begin{aligned}
& n_{x}=n_{o}+\frac{d}{d n}\left(n_{o}\right) \\
& n_{y}=n_{o}+\frac{d}{d n}\left(n_{o}\right) \\
& n_{z}=n_{o}
\end{aligned}
$$

Pode-se resolver $n_{x^{\prime}}$ e $n_{y^{\prime}}$ na eq.(34) usando a identidade diferencial:

$$
\frac{d}{d n}\left(n_{o}\right)=-\frac{1}{2} n_{o}^{3} \frac{d}{d n}\left(\frac{1}{n_{o}^{2}}\right)
$$

Substituindo-se as equações (35) e (33), na eq.(34) obtêm-se: 


$$
\begin{aligned}
& n_{x^{\prime}}-n_{o}=-\frac{1}{2} n_{o}^{3}\left(\frac{1}{n_{x}^{2}}-\frac{1}{n_{o}^{2}}\right) \\
& n_{y^{\prime}}-n_{o}=-\frac{1}{2} n_{o}^{3}\left(\frac{1}{n_{y}^{2}}-\frac{1}{n_{o}^{2}}\right) \\
& n_{z}=n_{o}
\end{aligned}
$$

e aplicando-se a série de Taylor na eq.(29), pode-se reescrever:

$$
\begin{aligned}
& n_{x}=n_{0}-\frac{1}{2} n_{0}^{3} r_{41} E_{z} \\
& n_{y}=n_{o}+\frac{1}{2} n_{0}^{3} r_{41} E_{z} \\
& n_{z}=n_{0}
\end{aligned}
$$

A eq.(37), anterior, descreve os novos índices de refração relacionados ao elipsoide de índices do cristal com o campo elétrico aplicado longitudinalmente ao eixo z, $E_{z}$. A diferença entre os índices de refração observados por feixes de luz polarizados paralelamente aos eixos $x^{\prime}$ e $y^{\prime}$, propagando-se na direção do eixo $z$, é a birrefringência induzida causada pelo campo elétrico e é dada por:

$$
\left(n_{y}-n_{x}\right)=n_{o}^{3} r_{41} E_{z}
$$

A mudança no índice de refração provoca uma diferença de fase na luz que trafega através do cristal. Considere-se, então, a aplicação de um feixe de luz polarizado linearmente propagando-se na direção z cujo campo elétrico pode ser descrito por:

$$
\varepsilon=A e^{i(\omega t-k z)}
$$

onde $A$ é a amplitude do campo, $\omega$ é sua frequência angular e $k$ é a constante de propagação ao longo de $z$. Esse feixe pode ainda ser considerado como tendo componentes nos eixos $x^{\prime}$ e $y^{\prime}$, dadas por: 


$$
\begin{aligned}
& \varepsilon_{x^{\prime}}=A e^{i\left(\omega t-k_{x^{\prime}} z\right)} \\
& \varepsilon_{y^{\prime}}=A e^{i\left(\omega t-k_{y^{\prime}} z\right)}
\end{aligned}
$$

onde $k_{x^{\prime}}=\left(\frac{2 \pi}{\lambda_{0}}\right) n_{x^{\prime}}$ e $k_{y^{\prime}}=\left(\frac{2 \pi}{\lambda_{0}}\right) n_{y^{\prime}}$ são descritas como constantes de propagação para ondas polarizadas paralelamente aos eixos $x^{\prime}$ e $y^{\prime}$, respectivamente. Assim reescrevendo a eq.(40) a partir da eq.(39) têm-se

$$
\begin{aligned}
& \varepsilon_{x^{\prime}}=A e^{i\left\{\omega t-\frac{2 \pi}{\lambda_{0}}\left(n_{o}-\frac{1}{2} n_{o}^{3} r_{41} E_{z}\right) z\right\}}=A e^{i \phi_{x^{\prime}}} \\
& \varepsilon_{y^{\prime}}=A e^{i\left\{\omega t-\frac{2 \pi}{\lambda_{0}}\left(n_{o}+\frac{1}{2} n_{o}^{3} r_{r_{4}} E_{z}\right) z\right\}}=A e^{i \phi_{y^{\prime}}}
\end{aligned}
$$

Define-se então a diferença de fase entre $\varepsilon_{x^{\prime}}$ e $\varepsilon_{y^{\prime}}$, denominado atraso de fase, $\Gamma$, que é dado por:

$$
\Gamma=\phi_{x^{\prime}}-\phi_{y^{\prime}}
$$

A partir da expansão da eq.(42) obtêm-se:

$$
\Gamma=\omega t-\frac{2 \pi}{\lambda_{0}}\left(n_{o}-\frac{1}{2} n_{o}^{3} r_{41} E_{z}\right) z-\omega t-\frac{2 \pi}{\lambda_{0}}\left(n_{o}+\frac{1}{2} n_{o}^{3} r_{41} E_{z}\right) z
$$

e que, se assumirmos que o campo elétrico $E_{z}$ é uniforme e constante ao longo do comprimento $L$ do cristal, reduz-se a:

$$
\Gamma=\frac{2 \pi n_{o}^{3} r_{41} V}{\lambda_{0}}
$$

onde $V=E_{z} L$. 
Essa diferença de fase é essencialmente o atraso de fase entre as polarizações ortogonais, e é decorrente do efeito de birrefringência eletricamente induzida (diferença entre os índices de refração nas direções ortogonais principais, que ocorre nos cristais eletro-ópticos devido a um campo elétrico aplicado). Entretanto, existem materiais que exibem, inerentemente, birrefringência natural, tais como a calcita, o quartzo e a mica. O termo dupla refração também é comumente usado ao invés de birrefringência. A seguir será descrito o efeito eletro-óptico aplicado em sensores eletro-ópticos a partir das chamadas Células Pockels (YARIV, 2003).

O efeito Pockels, ou efeito eletro-óptico linear é, como este último nome sugere, o termo linear em $\vec{E}$ da perturbação do tensor de impermeabilidade dielétrica (YARIV, 2003), envolvendo apenas os coeficientes $r_{i j k}$, com desprezo do termo quadrático por este ser grande, na maioria das aplicações muito reduzida, dada a pequenez relativa do campo elétrico aplicado face ao campo elétrico interatômico (da ordem típica de $100 \mathrm{MV} / \mathrm{cm}$ ). Ressalva-se, no entanto, a existência de uma classe especial de materiais (centrossimétricos) para os quais os coeficientes $r_{i j k}$ são nulos, onde, por consequência, o efeito quadrático é o que se faz sentir dominantemente.

\subsection{CÉLULAS POCKELS}

O termo célula Pockels descreve um dispositivo óptico sensível ao campo elétrico que emprega como elemento sensor um material que apresenta o efeito eletro-óptico linear, chamado efeito Pockels. Uma célula de Pockels, tecnicamente, é constituída por um cristal eletro-óptico entre dois eletrodos metálicos, utilizados para proporcionar um campo elétrico, a partir de uma diferença de potencial aplicada aos mesmos.

\subsubsection{TOPOLOGIAS DAS CÉLULAS POCKELS}

A primeira característica que define as topologias das células Pockels é a posição em que são colocados os eletrodos na célula e pode estar em duas configurações, ou transversais ou longitudinais e são denominados de tal forma a descrever a orientação do campo elétrico em relação ao feixe óptico que propaga pelo cristal. $\mathrm{Na}$ 
configuração longitudinal o campo elétrico é aplicado paralelamente à direção de propagação da luz. Para permitir a passagem do feixe luminoso os eletrodos devem ser feitos de material transparente ou vazados. Normalmente são utilizados como eletrodos óxidos metálicos depositados, filmes metálicos, grades ou anéis aplicados às faces opostas do elemento sensor, como ilustra a figura 8, a seguir.

Figura 8 - Tipos Célula Pockels com cristal eletro-óptico em configuração longitudinal.

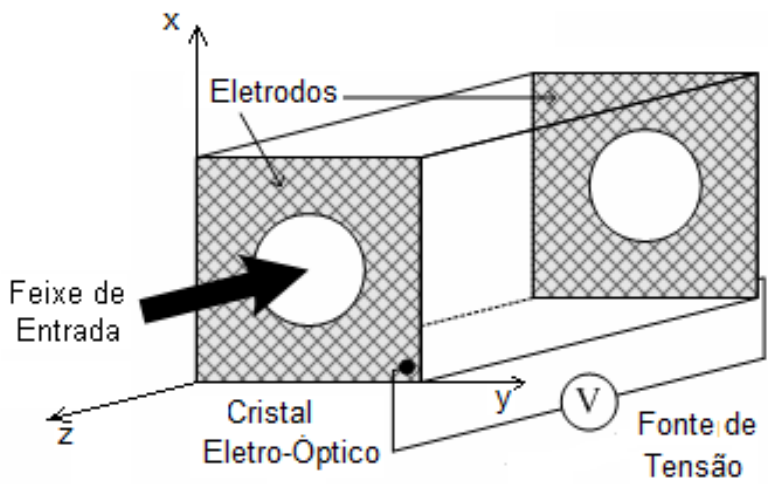

(a)

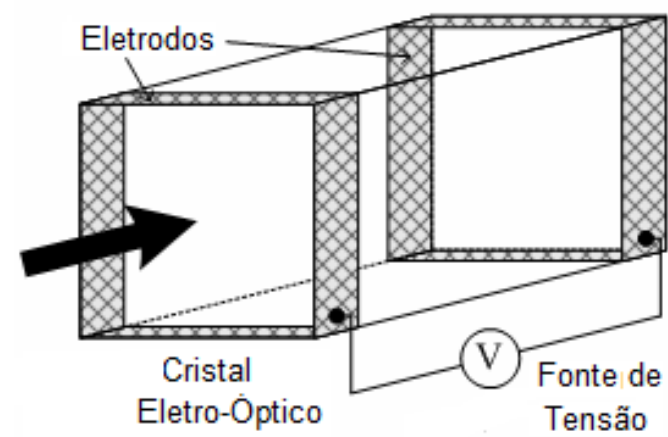

(b)

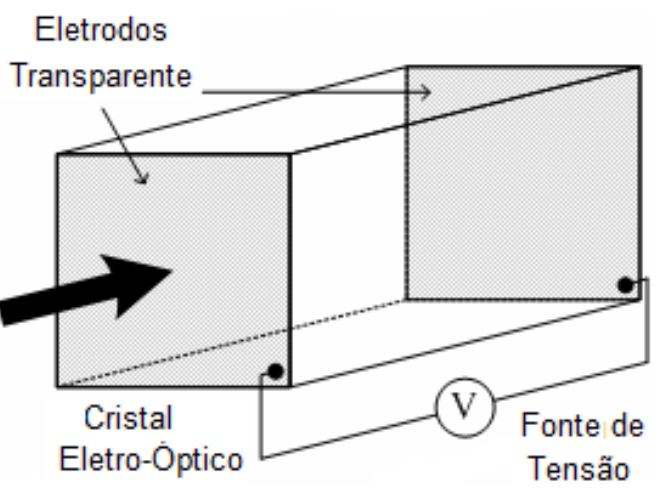

(c)

Fonte: Silva (2006) modificado

A figura 8 mostra três tipos de eletrodos da célula Pockels na configuração longitudinal, sendo que o item (a) mostra os eletrodos montados nas extremidades do cristal e que possuem furos suficientemente grandes (contudo, suficientemente pequenos para não afetar significativamente a distribuição do campo elétrico) para o feixe óptico ser inserido no cristal. $O$ item (b) mostra a possibilidade de montagem dos eletrodos nos lados próximos das extremidades do cristal, permitindo que o feixe tenha acesso completo à face do cristal. Esta configuração é normalmente usada quando o tamanho do cristal é próximo do tamanho do feixe, deixando pouco espaço para os eletrodos nas extremidades do cristal. 
A distribuição do campo elétrico será essencialmente paralela ao feixe óptico, ao longo do eixo central do cristal. O item (c) utiliza uma película condutora opticamente transparente revestindo as extremidades do cristal e proporcionando assim eletrodos transparentes. Essa configuração proporciona um campo de visão amplo e uma distribuição uniforme do campo eléctrico longitudinal, mas pode acarretar problemas de perda de inserção, devido à película transparente.

$\mathrm{Na}$ configuração transversal o campo elétrico é colocado numa direção perpendicular à de propagação da luz. Nesta configuração a aplicação do campo elétrico é simplificada, podendo ser feita também através de placas metálicas ou tintas condutoras aplicadas nas superfícies laterais do elemento sensor, como na forma esquematizada na figura 9, a seguir:

Figura 9 - Célula Pockels com cristal eletro-óptico em configuração transversal.

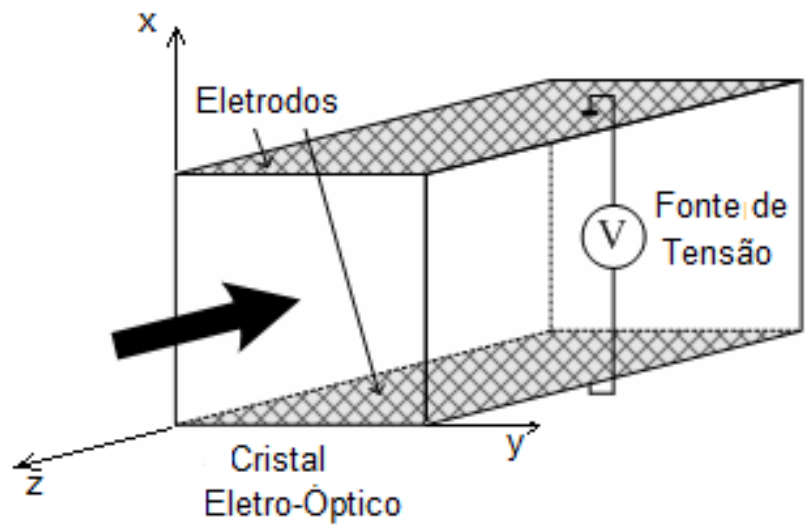

Fonte: Fonte: Silva (2006) modificado

O desempenho da célula de Pockels transversal é diferente daquela da célula longitudinal. De acordo com a teoria de eletro-óptica, a birrefringência induzida por uma célula de Pockels longitudinal independente da geometria do cristal. $\mathrm{Na}$ configuração transversal, a birrefringência depende da intensidade do campo aplicado e da relação entre o comprimento e a espessura da célula Pockels. Isso pode ou não ser útil, dependendo da aplicação. Para se modular a birrefringência, no caso longitudinal, basta variar a intensidade do campo elétrico aplicado. Contudo é importante ressaltar que campos elétricos intensos podem culminar em tensões superiores à de ruptura dielétrica do conjunto, danificando as células: No caso da célula transversal, é possível, além de variar a intensidade do campo, especificar 
uma relação favorável das dimensões da célula Pockels para atingir a birrefringência máxima desejada. Caso deseje-se uma birrefringência elevada, a tendência natural na configuração transversal é aumentar o comprimento do cristal mantendo-se sua espessura. Deve-se, contudo, considerar que em sensores com cristais de comprimento grande a atenuação da luz transmitida aumenta devido às perdas ópticas no cristal.

Neste trabalho foi utilizada a configuração longitudinal devido ao fato de que na aplicação em TPOs deseja-se medir uma tensão elevada aplicada entre os eletrodos, o que exige uma grande rigidez dielétrica da célula Pockels. Como o efeito eletro-óptico é sensível ao campo elétrico, na configuração longitudinal a modulação obtida é proporcional à integral de linha do campo elétrico entre os eletrodos, o que equivale, por definição, à tensão aplicada.

\subsection{MODULADORES ELETRO-ÓPTICOS}

Moduladores eletro-ópticos são dispositivos que modificam alguma característica de um feixe óptico que o atravesse em função de um campo elétrico ou de uma tensão elétrica que Ihe seja aplicada. As características da luz que podem ser modificadas por um modulador são: a frequência (ou conteúdo espectral), a fase, a amplitude (ou intensidade) e o padrão de polarização.

Um modulador eletro-óptico de fase pode ser construído a partir de uma célula Pockels inserindo uma luz linearmente polarizada com o plano de polarização paralelo à direção de um eixo óptico do cristal, de modo a proporcionar, pelo efeito eletro-óptico, um retardo de fase variável para a luz polarizada. No entanto, não existe método direto para medição da fase óptica. Tão pouco é possível medir diretamente a frequência ou o estado de polarização de uma onda óptica. A única característica da luz que pode ser medida diretamente é a sua intensidade, que é proporcional ao quadrado de sua amplitude. Tal medida é feita através de dispositivos chamados fotodetectores, que convertem o fluxo de fótons em um fluxo de elétrons. Assim, para que seja possível medir a variação de qualquer das características da luz é necessário antes convertê-la em variação de intensidade. Por exemplo, é possível realizar a medida de diferença de fase relativa entre dois feixes ópticos convertendo esta diferença em informação de amplitude, sendo para 
isso necessário a utilização de dispositivos denominados interferômetros. Tais dispositivos separam um feixe óptico incidente em duas partes, fazem com que as partes se propaguem por caminhos independentes (ao longo dos quais podem acumular diferentes atrasos de fase, de acordo com as influências a que forem submetidos) e as recombina no final do percurso, permitindo que se superponham e criem um feixe de saída modulado em amplitude (ou intensidade), a qual depende da diferença de fase entre as partes do feixe óptico no ponto de sua recombinação.

Há diversas maneiras para se obter, modular em fase, e posteriormente recombinar feixes ópticos, o que possibilita diversas maneiras para montagem de interferômetros. Uma maneira que se torna atraente quando se utilizam células Pockels é implementar um interferômetro birrefringente. Neste tipo de interferômetro o feixe óptico incidente é polarizado e aplicado a um cristal eletro-óptico com a direção de propagação paralela a um dos eixos cristalinos do material e com a direção do plano de polarização orientada a $45^{\circ}$ de inclinação em relação às direções dos dois eixos ópticos transversais à propagação, já perturbados pela presença de um campo elétrico externo.

Este arranjo faz com que o feixe incidente se divida em duas componentes de polarização, cada uma se propagando ao longo do cristal paralelamente a um dos eixos ópticos perturbados. Cada uma dessas componentes acumulará um atraso de fase que será influenciado pelo índice de refração que o cristal apresentar na direção paralela à sua polarização. Ao deixarem o cristal, essas duas componentes estarão com atrasos de fase diferentes. A conversão desta diferença de fase em intensidade óptica é conseguida utilizando-se um segundo polarizador, também chamado de analisador, orientado a $90^{\circ}$ em relação ao primeiro. Essa configuração é mostrada na figura 10, a seguir. 
Figura 10 - Célula Pockels como modulador de amplitude.

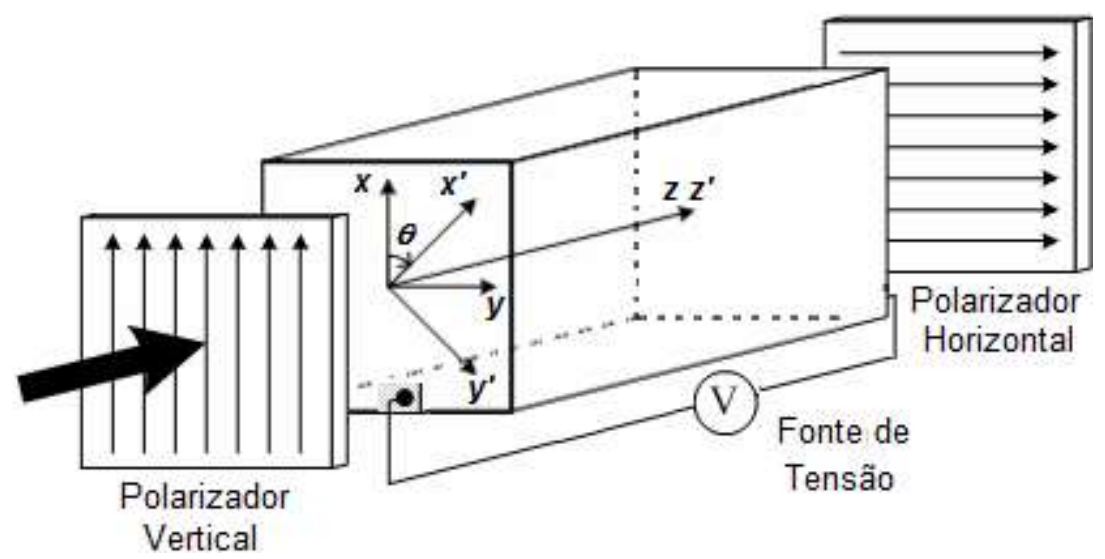

Fonte: Autor

No modulador polarimétrico, em configuração longitudinal, mostrado na figura 10, com a direção do eixo do polarizador cruzada em relação à direção do eixo do analisador, $\mathrm{o}$ atraso de fase induzido, $\Gamma$, entre as duas componentes ortogonais da luz será dado pela eq.(45), a seguir:

$$
\Gamma=\frac{2 \pi}{\lambda_{0}} \Delta n \cdot L
$$

onde: $\lambda$ é o comprimento de onda da luz utilizada, $\Delta n$ é a birrefringência induzida $\mathrm{e}$ $L$ é o comprimento do cristal.

Exemplificando: usando-se um cristal cúbico (do grupo de simetria $\overline{4} 3 m$ ) em uma configuração longitudinal, e considerando-se o campo elétrico uniformemente distribuído, implicando que $V=E \cdot L$, a birrefringência induzida é dada pela eq.(46):

$$
\Delta n=n_{o}^{3} r_{41} \frac{V}{L}
$$

onde $n_{0}$ é o índice de refração ordinário do cristal e $r_{41}$ é o coeficiente eletro-óptico relevante do cristal.

A tensão de meia onda, $V \pi$, que é definida como sendo o valor da tensão $V$ que produz um atraso de fase $\Gamma$ igual a $\pi$, é dado pela eq.(47). 


$$
V_{\pi}=\frac{\lambda_{0}}{2 n_{o}^{3} r_{41}}
$$

O fator de transmissão, ou intensidade da luz transmitida, $T$, relacionado ao modulador, que é a relação entre a intensidade da luz de saída $\left(I_{0}\right)$ e a de entrada $\left(l_{i}\right)$, como uma função da tensão aplicada $V(t)$ é representado por (YARIV, 2003, p. 341):

$$
T=\frac{l_{0}}{l_{i}}=\operatorname{sen}^{2}\left(\frac{\Gamma}{2}\right)
$$

A eq.(48) pode ser expandida através da substituição por $\Gamma$ usando a eq.(49), obtendo-se:

$$
T=\operatorname{sen}^{2}\left(\frac{\pi n_{o}^{3} r_{41} V}{\lambda_{0}}\right)
$$

À medida que a tensão aplicada " $V$ " varia, o valor do fator de transmissão do sistema " $T$ ", muda. A figura 11, a seguir, mostra o fator de transmissão normalizado (relacionado ao valor de $V \pi$ ) em função da tensão aplicada.

Figura 11 - Curva de transmissão da célula Pockels em função da tensão aplicada (normalizada pelo

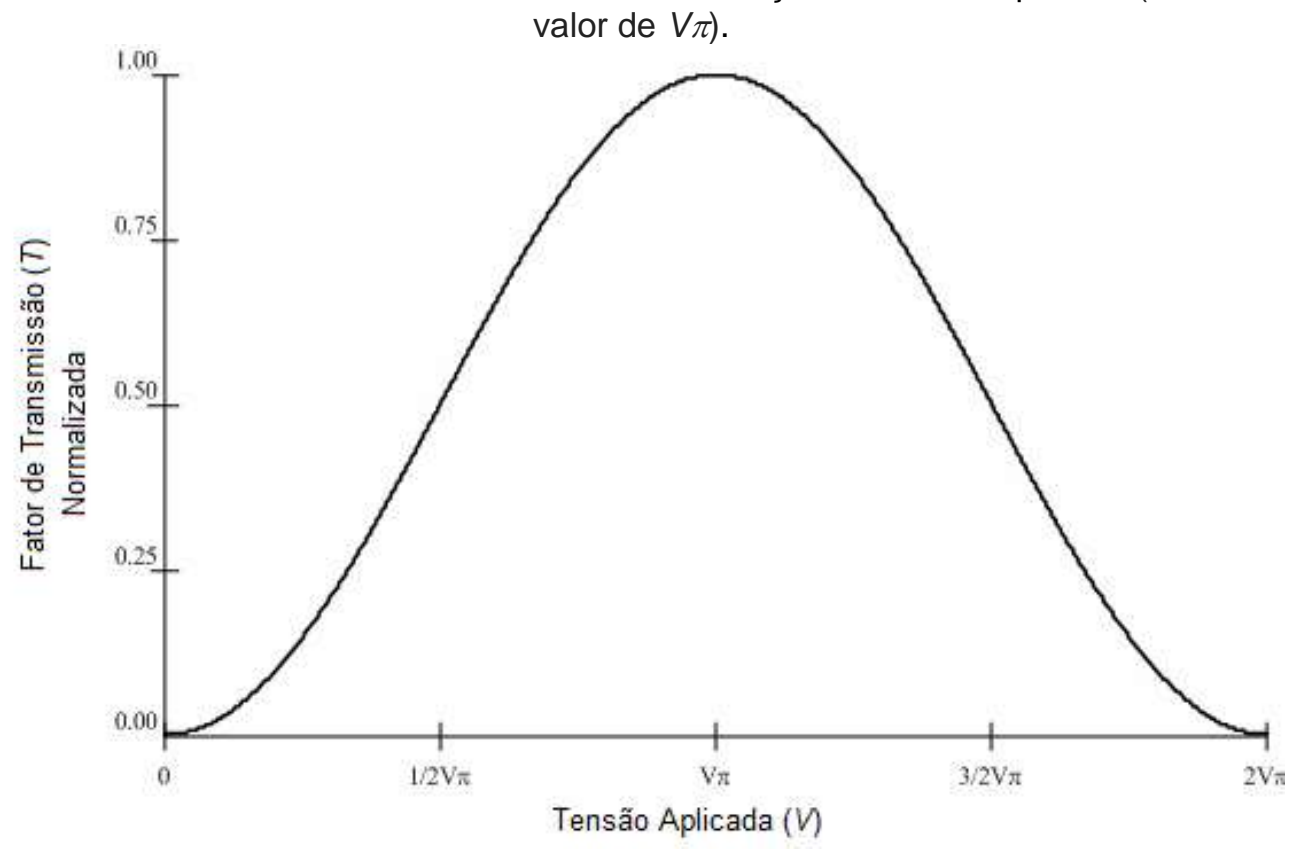

Fonte: Autor Autor 
Como já descrito, a tensão aplicada ao cristal que leva a um retardo de fase de $\pi$ radianos $\left(180^{\circ}\right)$ é chamado de tensão de meia onda, $V \pi$, e quando esta tensão é aplicada à célula Pockels, a polarização linear vertical inicialmente inserida na célula de Pockels é convertida em polarização linear horizontal. Isto permite então, que $100 \%$ da luz passe pelo analisador. Caso o aumento de tensão seja ainda maior, o atraso de fase é aumentado até que a polarização da luz se torne novamente linear vertical e a intensidade da luz transmitida diminua para zero. Aumentando-se a tensão o processo descrito se repete de forma contínua indefinidamente, obedecendo ao caminhamento de uma função $\operatorname{sen}^{2}$.

Existem três fatores que contribuem para a sensibilidade de um sensor eletro-óptico baseado em um cristal eletro-óptico, que são: o comprimento de onda de operação $\left(\lambda_{0}\right)$, o índice de refração ordinário do cristal $\left(n_{0}\right)$ e o coeficiente eletro-óptico $\left(r_{41}\right)$.

Com a definição de $V \pi$ pode-se reescrever a equação do fator de transmissão (eq.(50)), para um modulador de amplitude, como (YARIV, 2003, p. 241):

$$
T=\operatorname{sen}^{2}\left(\frac{\pi}{2} \frac{v}{V_{\pi}}\right)
$$

Incluindo uma lâmina de retardo de onda (waveplate), o que seria o mesmo que a aplicação de uma tensão de polarização contínua à célula Pockels, adiciona-se um retardo de fase fixo natural na luz que trafega pela célula. Isto é feito com o intuito de adicionar uma birrefringência fixa extra, e consequentemente, induzir que a condição de início da célula seja ajustada para o ponto de quadratura da curva, conforme ilustra a figura 11. Ressalta-se que o ponto de quadratura da curva de transmissão é a região que proporciona o posicionamento do ponto quiescente de operação na região mais linear da curva de resposta da célula. Utilizando-se uma lâmina de retardo de um quarto de onda (ou $\lambda / 4$, ou $\pi / 2$ ) colocada entre um dos polarizadores e o cristal, com os seus eixos (extraordinário e ordinário) alinhados com os eixos x 'e y' do cristal, obtém-se uma montagem conforme ilustra a figura 12, a seguir. 
Pode-se descrever que o atraso de fase total, $\Gamma$, agora com a inserção da lâmina de atraso, é a soma do atraso de fase eletricamente induzido com uma parte adicional, $\phi_{r}$, introduzida pela lâmina retardadora, e que pode ser escrita como:

$$
\Gamma_{t}=\phi_{r}+\pi \frac{V}{V_{\pi}}
$$

Figura12- Célula Pockels, como modulador de amplitude, com a inserção de uma Lâmina de retardo de $\lambda / 4$ onda.

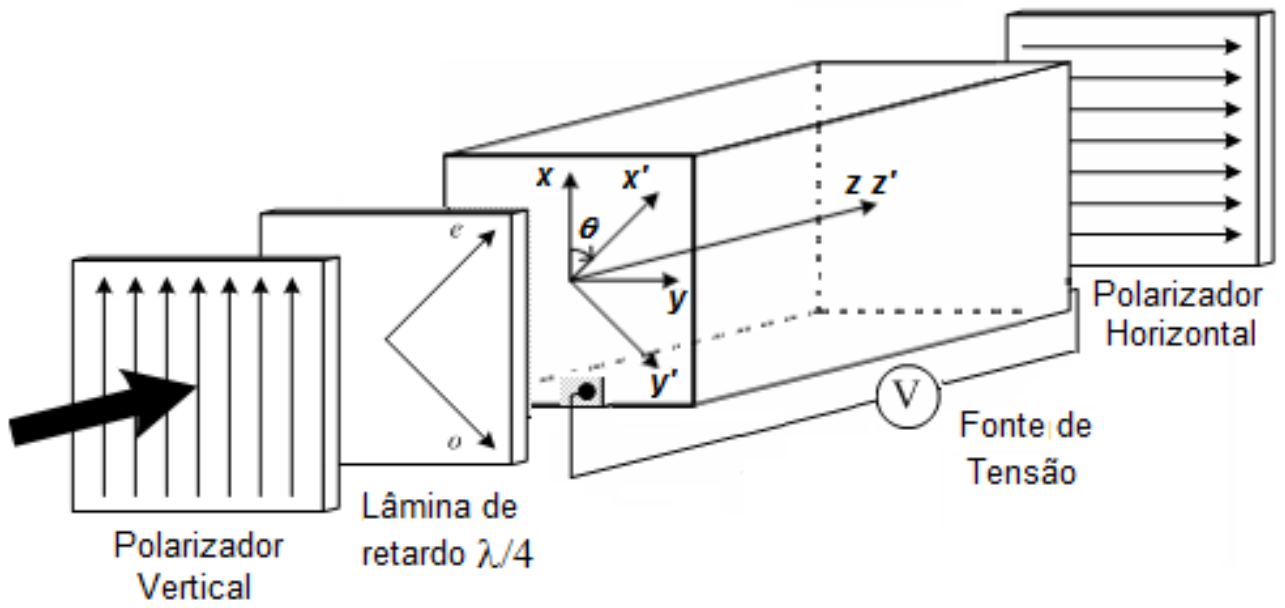

Fonte: Autor

Considerando que $\phi_{r}=\pi / 2$, a intensidade da luz transmitida, $T$, que é a relação entre a intensidade da luz de saída e a de entrada, como uma função da tensão aplicada $V(t)$ é dada pela eq.(52), abaixo:

$$
T=\frac{I_{o}}{I_{i}}=\operatorname{sen}^{2}\left(\frac{\pi}{4}+\frac{1}{2} \pi \frac{V(t)}{V_{\pi}}\right)
$$

Este componente de fase adicional, $\phi_{r}$, desloca a curva na figura 11 para a esquerda, como visto na figura 13 , a seguir.

Quando não há tensão aplicada ( $\mathrm{V}=0)$, a polarização linear vertical é convertida em polarização circular. Isto faz com que apenas a metade da luz seja transmitida, conforme ilustrado na figura 13.

Se for adotada a condição em que $V \ll V \pi$ pode-se admitir que haverá uma certa linearidade na curva de resposta do fator de transmissão da célula. 
A figura 14, a seguir, mostra, graficamente, a curva de resposta do fator de transmissão com variações na tensão aplicada $(\Delta V)$ que irão causar uma resposta aproximadamente linear de intensidade na saída da célula.

Figura 13 - Curva de transmissão da célula Pockels em função da tensão aplicada (relacionada ao valor de $V \pi$ ) e com a influência de uma lâmina de retardo de $\lambda / 4$.

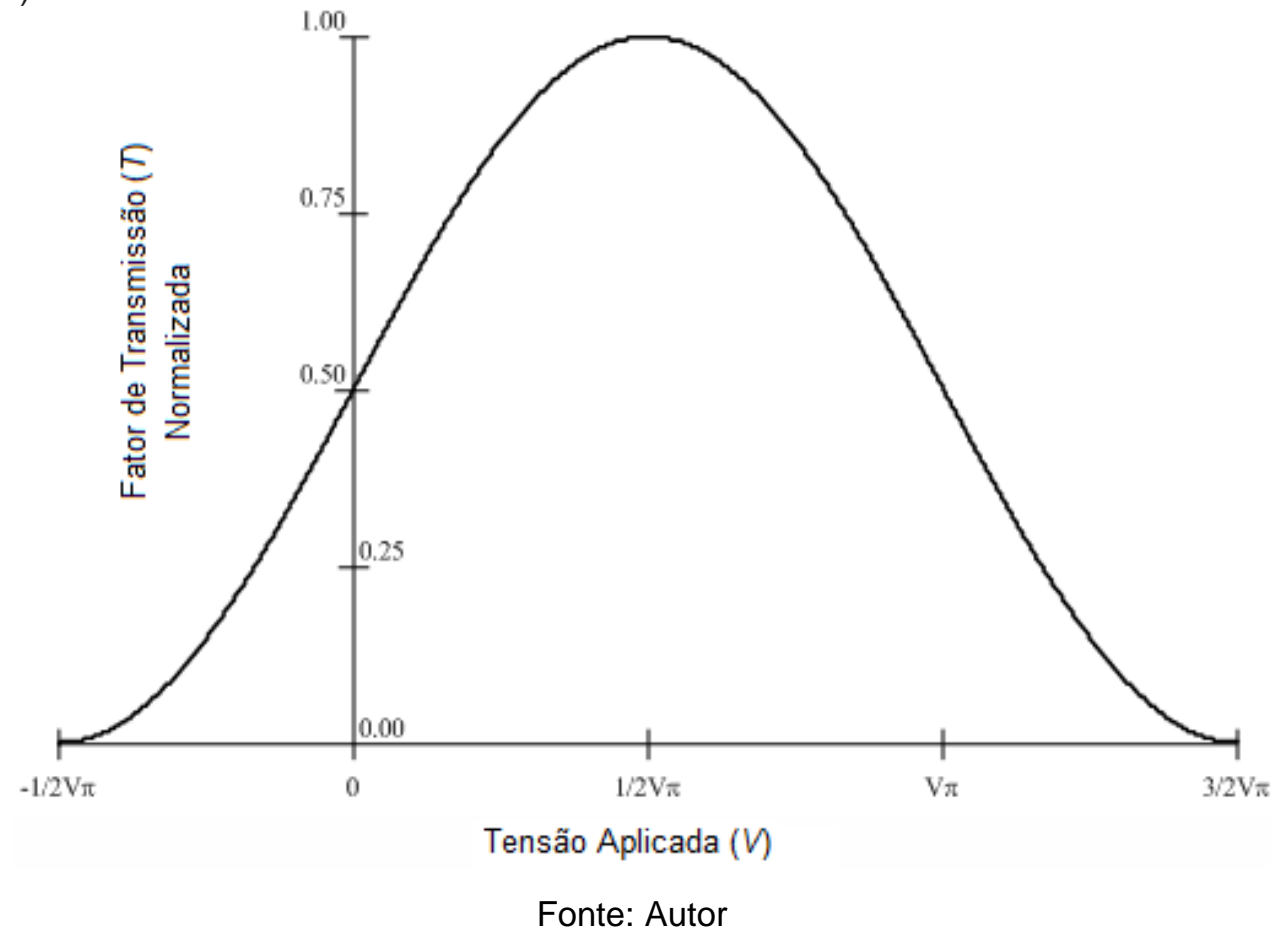

Figura 14 - Representação da modulação da intensidade de saída devida à variação da tensão aplicada à célula Pockels.

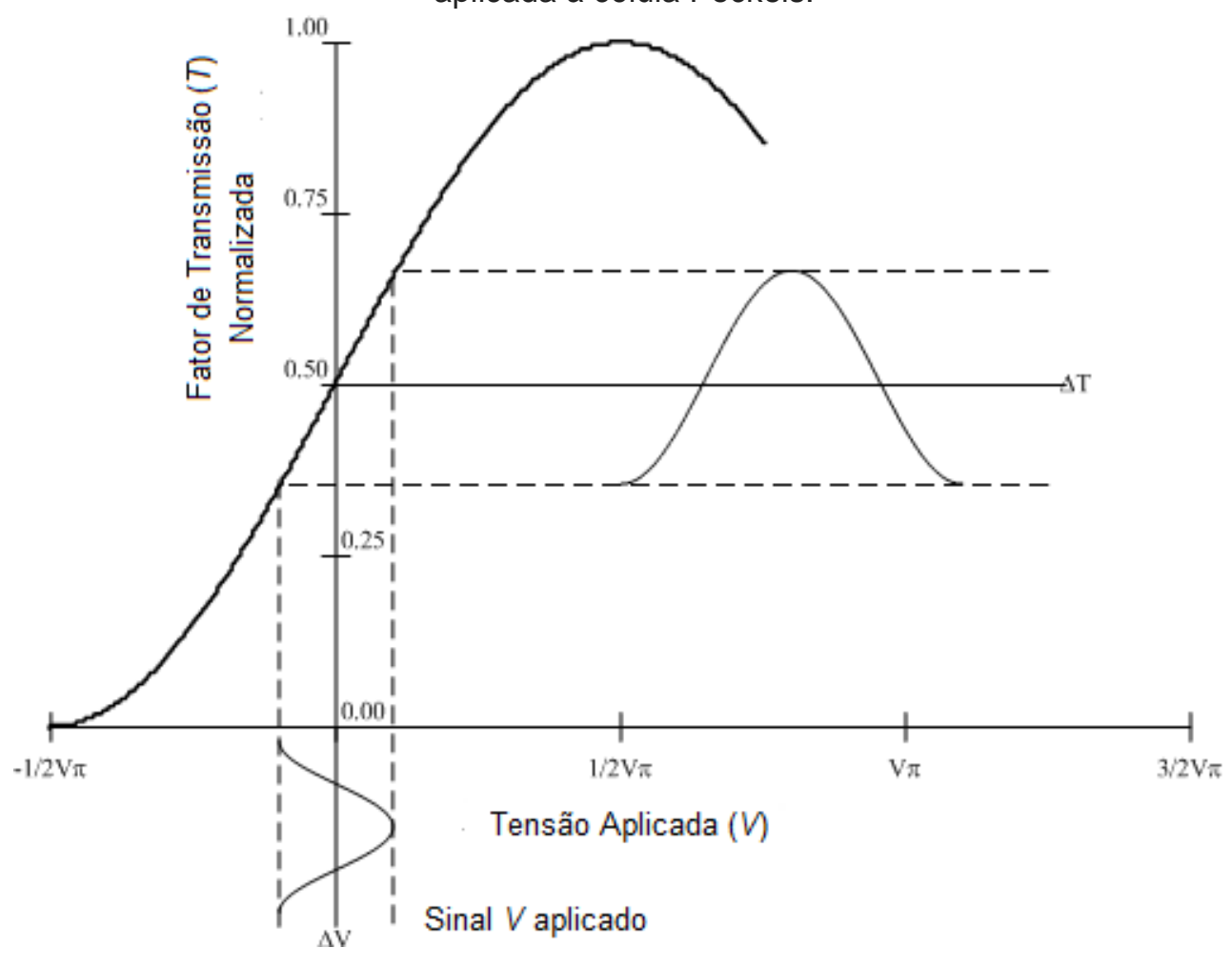

Fonte: Autor 
Como visto anteriormente o esquema do sensor óptico mostrado na figura 12 , implica na passagem de luz pela célula Pockels em uma única direção, passando apenas uma única vez pelo cristal eletro-óptico. Esta configuração é denominada passagem única (“single pass"). Contudo, outra configuração pode ser construída proporcionando a propagação da luz bidirecionalmente, ou seja, fazendo com que a luz se propague pelo cristal duas vezes. Isso é conseguido colocando-se um espelho na extremidade do cristal ou da célula Pockels, de modo que a luz seja refletida e passe de volta através da célula. Essa configuração é denominada dupla passagem ("double pass").

As evoluções dos estados de polarização da luz no interior da célula Pockels são diferentes nas configurações "single pass" e "double pass". Numa configuração de passagem única a luz é polarizada pelo primeiro polarizador linear e é convertida em polarização circular pela placa de retardo de 1/4 de onda. A célula Pockels, em seguida, altera a fase da luz polarizada circularmente de modo a se obter uma polarização elíptica. Esta polarização é observada pelo analisador (segundo polarizador) onde a informação de diferença de fases é convertida em informação de amplitude.

Na configuração "double pass", o segundo polarizador linear é substituído por um espelho e o polarizador inicial, agora também atua como o analisador do sistema. A luz passa pelo polarizador, pela lâmina de retardo e pela célula Pockels indo incidir no espelho. A reflexão da luz no espelho muda a direção de propagação de forma que a segunda passagem, através da célula de Pockels, continue afetando o estado de polarização da luz. Assim duplica-se a sensibilidade do sensor, pois quando a luz chega ao analisador de polarização têm-se duplamente o efeito eletro-óptico adquirido na célula Pockels.

Entretanto, quando a luz passa pela placa de retardo de $1 / 4$ de onda duas vezes, a condição de quadratura inicial da curva de transmissão é perdida. Para corrigir isso, é preciso substituir a placa de retardo de $1 / 4$ de onda por uma de $1 / 8$ de onda. Isso garante que se permaneça no ponto de operação de quadratura, garantindo uma birrefringência total igual à da placa de retardo de $1 / 4$ de onda. A figura 15 , a seguir, ilustra a configuração dupla passagem da célula Pockels. 
Figura 15 - Célula Pockels integrando modulador de amplitude na configuração "double pass" .

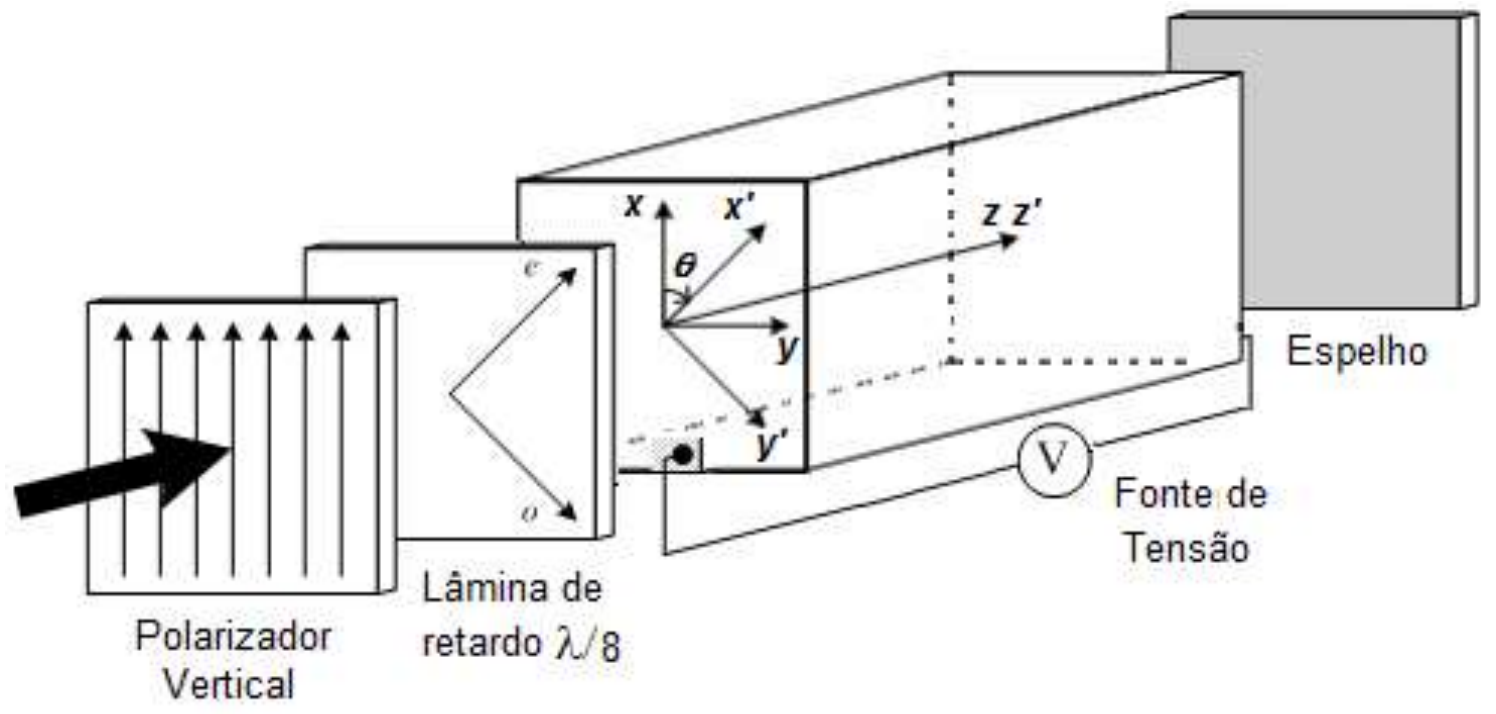

Fonte: Autor

$\mathrm{Na}$ configuração dupla passagem a eq.(52), que descreve o comportamento da célula Pockels, altera-se para:

$$
T=\frac{I_{0}}{I_{i}}=\cos ^{2}\left(\frac{\pi}{4}+\pi \frac{V(t)}{V_{\pi}}\right)
$$

A figura 16, a seguir, ilustra graficamente a curva de transmissão em função da tensão aplicada (relacionada ao valor de $\mathrm{V} \pi$ ) com a influência da lâmina de retardo de $1 / 8$ de onda e espelho da configuração "double pass".

Como pode-se ver no gráfico da figura 16, a inclinação no ponto de quadratura mudou. Além da inversão no sinal de saída, nota-se ainda a duplicação da sensibilidade do modulador de amplitude. A figura 17, a seguir, ilustra como a sensibilidade desta configuração "double pass" é maior do que a configuração "single pass" mostrada na figura 14. 
Figura 16- Curva de transmissão em função da tensão aplicada (relacionada ao valor de $\bigvee \pi$ ) da configuração "double pass".

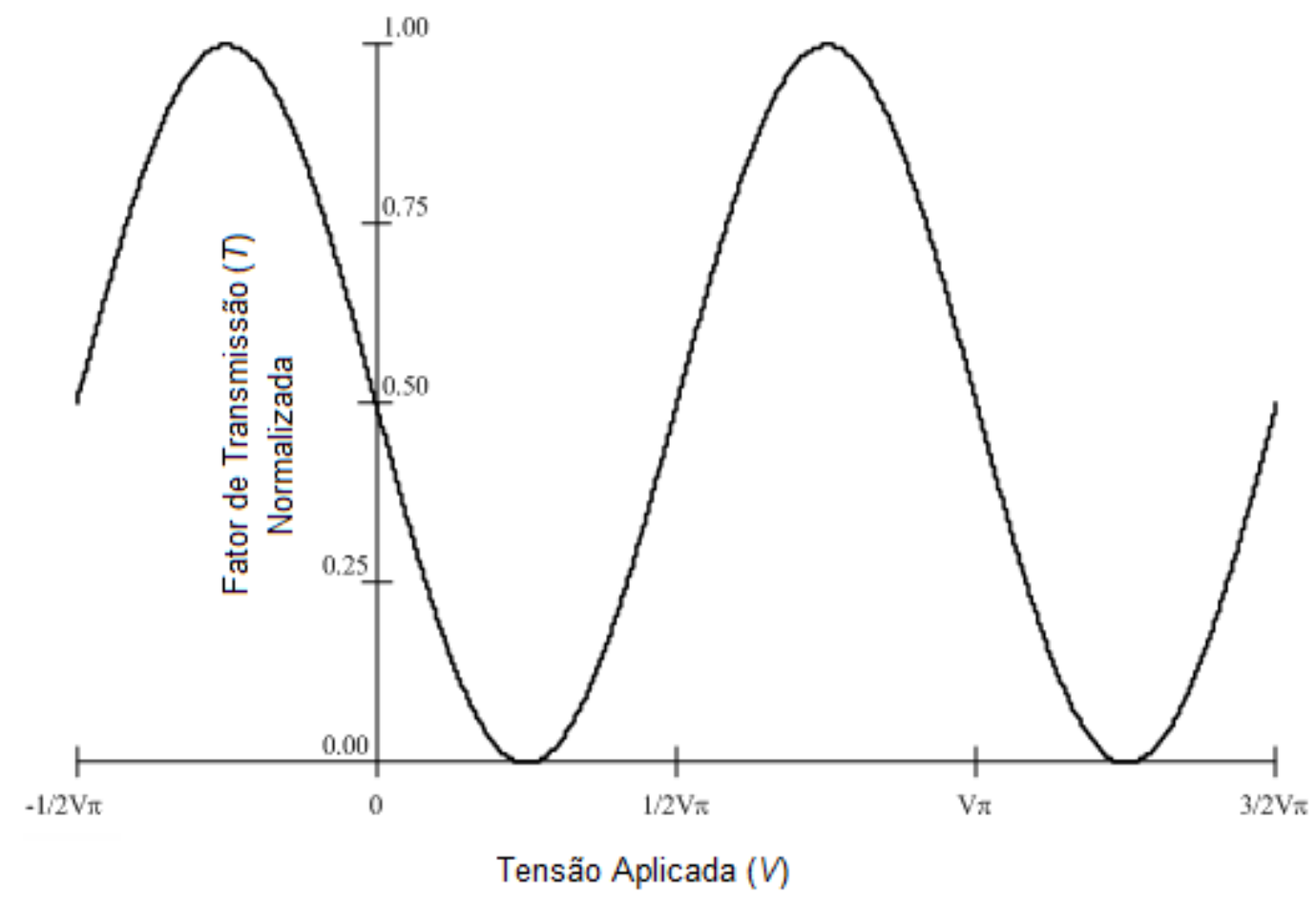

Fonte: Autor

Figura 17 - Representação da modulação da intensidade devida à variação da tensão aplicada na célula Pockels na configuração "double pass".

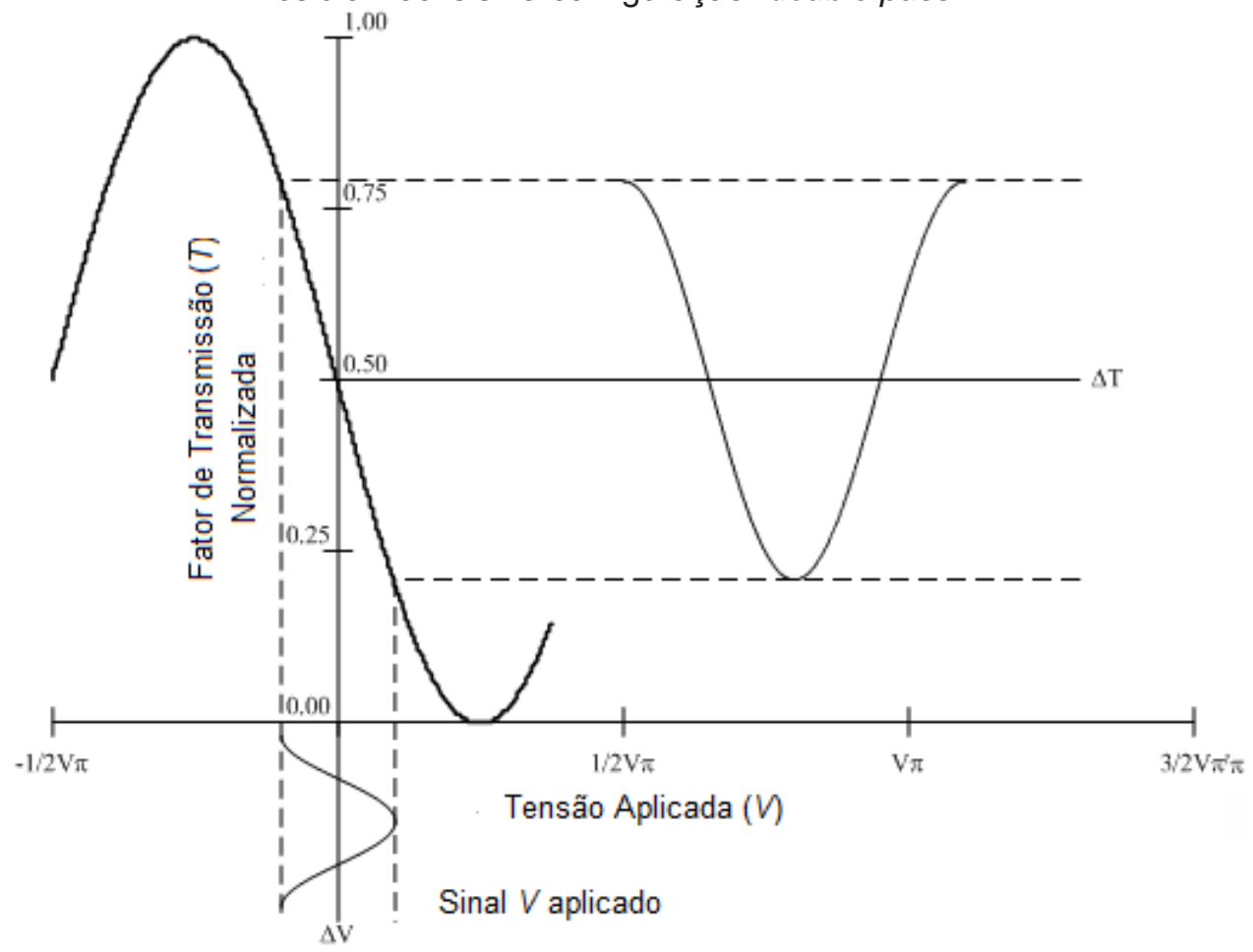

Fonte: Autor 


\subsubsection{ANÁLISE DAS CONFIGURAÇÕES DE CÉLULAS POCKELS POR MATRIZ DE JONES}

O método denominado Matriz de Jones pode ser utilizado para descrever o estado de polarização das configurações das células Pockels "single pass" ou passagem única e "double pass" ou de dupla passagem.

A figura 12 apresenta uma configuração equivalente à "single pass", onde $\theta=45^{\circ}$. A partir da mesma, será descrito, matematicamente, utilizando matrizes de Jones, o estado de polarização da luz ao passar através de cada um dos elementos ópticos presentes naquela configuração.

Inicialmente, será suposta uma luz polarizada linearmente, orientada paralelamente ao eixo $x$ da configuração, proveniente de um enlace a fibra óptica e trafegando na direção positiva de z. Isto é descrito pelo vetor normalizado de Jones dado a seguir

$$
J_{P}=\left[\begin{array}{l}
1 \\
0
\end{array}\right]
$$

Esta luz passa através de um polarizador linear orientado paralelamente ao eixo $\mathrm{x}$. Este polarizador linear é descrito pela seguinte matriz de Jones

$$
J_{\text {PLentrada }}=\left[\begin{array}{ll}
1 & 0 \\
0 & 0
\end{array}\right] .
$$

O vetor de Jones que descreve o estado de polarização da luz depois de passar pelo polarizador é dado por

$$
J_{\text {saidaPL }}=J_{P L} J_{P}
$$

e que se torna

$$
J_{\text {saídaPL }}=\left[\begin{array}{l}
1 \\
0
\end{array}\right]
$$


A luz segue polarizada linearmente ao longo da direção x e passa por uma placa de retardo de $1 / 4$ de onda, com o seu eixo extraordinário de refração alinhado com o eixo $x^{\prime}$, sendo descrito por

$$
J_{1 / 4 \text { onda }}(\theta, \phi)=\left[\begin{array}{cc}
\cos (\theta)^{2}+\sin (\theta)^{2} e^{-i \phi} & \cos (\theta) \sin (\theta)\left(1-e^{-i \phi}\right) \\
\cos (\theta) \sin (\theta)\left(1-e^{-i \phi}\right) & \sin (\theta)^{2}+\cos (\theta)^{2} e^{-i \phi}
\end{array}\right],
$$

onde $\phi$ é a quantidade de retardamento e $\theta$ é a orientação do eixo extraordinário de refração em relação ao eixo $x$. Para esta placa de retardo de $1 / 4$ de onda têm-se $\phi=\pi / 2$ e $\theta=45^{\circ}$. A transmissão através deste elemento é descrita por

$$
J_{\text {saida } 1 / 4 \text { onda }}=J_{1 / 4 \text { onda }}(\theta, \phi) J_{\text {saídaPL }}
$$

e que se torna

$$
J_{\text {saida } 1 / 4 \text { onda }}=\left[\begin{array}{l}
\frac{1}{2}-\frac{1}{2} i \\
\frac{1}{2}+\frac{1}{2} i
\end{array}\right]
$$

Depois de passar pela placa de retardo de 1/4 de onda, a luz polarizada linearmente possui agora polarização circular à direita (RHCP - Right-Hand Circular Polarization). O próximo elemento da configuração "single-pass" é a célula Pockels. A célula Pockels, age como uma placa de retardo variável com a quantidade de atraso, $\Gamma$ dada por $\Gamma=\frac{\pi V}{V_{\pi}}$, dependente da relação entre a tensão $V$ aplicada ao cristal e o valor da tensão $V_{\pi}$. Utilizando-se a orientação dos eixos cristalográficos descritos na figura 12, quando um campo elétrico é aplicado longitudinalmente no cristal ocorrerá a birrefringência induzida pelo campo, alterando-se o elipsoide de índices (relacionado aos eixos ordinário e extraordinário do cristal). Alinhando-se o eixo extraordinário com o eixo rotacionado $x$, a matriz de Jones da célula Pockels é dada por 


$$
J_{\text {Pockels }}(\theta, \Gamma)=\left(\begin{array}{cc}
\cos (\theta)^{2}+\sin (\theta)^{2} e^{-i \Gamma} & \cos (\theta) \sin (\theta)\left(1-e^{-i \Gamma}\right) \\
\cos (\theta) \sin (\theta)\left(1-e^{-i \Gamma}\right) & \sin (\theta)^{2}+\cos (\theta)^{2} e^{-i \Gamma}
\end{array}\right)
$$

Assim a onda que se propaga pelo cristal terá, agora, polarização elíptica, com sua elipsidade modificada pela tensão $V$ aplicada ao cristal. Desta forma, a matriz de Jones que descreve a onda óptica de saída da célula é dada por:

$$
J_{\text {saídaPockels }}=J_{\text {Pockels }}(\theta, \Gamma) J_{\text {saída } 1 / 4 \text { onda }}
$$

e que fica

$$
J_{\text {saídaPockels }}=\left[\begin{array}{l}
\frac{1}{2}-\frac{1}{2} i e^{\left(-i \frac{\pi V}{V_{\pi}}\right)} \\
\frac{1}{2}+\frac{1}{2} i e^{\left(-i \frac{\pi V}{V_{\pi}}\right)}
\end{array}\right]
$$

Esta luz parcialmente elíptica passa, agora, por outro polarizador denominado analisador e que está orientado a 90ํem relação ao primeiro polarizador, ou seja, paralelamente ao eixo y, sendo descrito pela matriz de Jones a seguir.

$$
J_{P L \text { saida }}=\left[\begin{array}{ll}
0 & 0 \\
0 & 1
\end{array}\right]
$$

A luz que sai deste analisador é dada por

$$
J_{\text {saídaPLsaída }}=J_{P L \text { saida }} J_{\text {saídaPockels }}
$$

tornando-se

$$
J_{\text {saídaPLsaida }}=\left[\begin{array}{c}
0 \\
\frac{1}{2}+\frac{1}{2} i e^{\left(-i \frac{\pi V}{V_{\pi}}\right)}
\end{array}\right]
$$


A matriz anterior descreve o estado da luz de saída da configuração "single pass" e mostra a dependência da intensidade da luz que sai da configuração com tensão $V$ aplicada.

A análise para a configuração "double pass" pode ser desenvolvida utilizando-se o modelamento por de Matriz de Jones similarmente à descrita para a configuração "single pass", com pequenas modificações. Umas delas é a nova matriz para a placa de retardo de $1 / 8$ de onda, agora com $\phi=\pi / 4$ e $\theta=45^{\circ}$. A transmissão através deste elemento é dada por:

$$
J_{\text {saida } 1 / 8 \text { onda }}=\left[\begin{array}{l}
\frac{1}{2}+\frac{1}{4} \sqrt{2}-\frac{1}{4} i \sqrt{2} \\
\frac{1}{2}-\frac{1}{4} \sqrt{2}+\frac{1}{4} i \sqrt{2}
\end{array}\right]
$$

Após a placa de retardo a luz (polarizada linearmente) passa pelo cristal eletroóptico, ficando a matriz de saída do cristal com:

$$
J_{\text {saidaPockelsdouble }}=\left[\begin{array}{l}
\frac{1}{2}+\frac{1}{4} \sqrt{2} e^{\left(-i \frac{\pi V}{V_{\pi}}\right)}(1-i) \\
\frac{1}{2}-\frac{1}{4} \sqrt{2} e^{\left(-i \frac{\pi V}{V_{\pi}}\right)}(1-i)
\end{array}\right]
$$

Agora, na configuração "double pass", a luz se depara, ao sair do cristal, com um espelho (reflexão total) cuja matriz de Jones representativa é:

$$
J_{\text {Espelho }}=\left[\begin{array}{cc}
1 & 0 \\
0 & -1
\end{array}\right]
$$

Essa matriz leva em consideração a reflexão normal de um espelho, em que ambos os vetores campo elétrico ortogonais da luz polarizada são chaveados. No entanto, verifica-se que a matriz de Jones no caminho de retorno através da óptica de polarização é descrita trocando-se a fase para $+90^{\circ}$, ou invertendo-se a polaridade 
(fase) de uma das ondas, obtendo-se uma polarização circular à esquerda (LHCPLeft-Hand Circular Polarization).

É importante tomar cuidado para descrever corretamente a orientação das placas retardadores de ondas, quando submetidas a uma mudança de fase do eixo $x$, de $180^{\circ}$, ao passar-se de $+x$ para $-x$. Para compensar esta mudança de fase, define-se que $\theta=-45^{\circ}$ quando se descrevem as orientações das células de Pockels e da placa de retardo de $1 / 8$ de onda em relação ao eixo $x$, agora, para a segunda passagem através de cada componente óptico.

Portanto, após o espelho a matriz fica:

$$
J_{\text {saidaespelho }}=J_{\text {Espelho }} J_{\text {saidaPockelsdouble }}
$$

tornando-se:

$$
J_{\text {saidaespelho }}=\left[\begin{array}{c}
\frac{1}{2}+\frac{1}{4} \sqrt{2} e^{\left(-i \frac{\pi V}{V_{\pi}}\right)}(1-i) \\
-\frac{1}{2}+\frac{1}{4} \sqrt{2} e^{\left(-i \frac{\pi V}{V_{\pi}}\right)}(1-i)
\end{array}\right] .
$$

Passando pelo cristal de Pockels, pela segunda vez. A matriz de Jones fica:

$$
J_{\text {saídaPockelsdouble }}=J_{\text {Pockels }}(-\theta, \Gamma) J_{\text {saidaespelho }}
$$

tornando-se

$$
J_{\text {saidaPockelsdouble }}=\left[\begin{array}{c}
\frac{1}{2}+\frac{1}{4} \sqrt{2} e^{\left(-i \frac{2 \pi V}{V_{\pi}}\right)}(1-i) \\
-\frac{1}{2}+\frac{1}{4} \sqrt{2} e^{\left(-i \frac{2 \pi V}{V_{\pi}}\right)}(1-i)
\end{array}\right]
$$

Esta luz passa, novamente, pela placa de retardo de $1 / 8$ de onda, denotado por 


$$
J_{\text {saida } 1 / 8 \text { ondavolta }}=J_{1 / 8 \text { onda }}(-\theta, \phi) J_{\text {saidaPockelsdouble }}
$$

tornando-se:

$$
J_{\text {saida } 1 / 8 \text { ondavolta }}=\left[\begin{array}{c}
\frac{1}{2}-\frac{1}{2} e^{\left(-i \frac{2 \pi V}{V_{\pi}}\right)} \\
-\frac{1}{2}-\frac{1}{2} e^{\left(-i \frac{2 \pi V}{V_{\pi}}\right)}
\end{array}\right]
$$

Essa luz é levada a passar, novamente, pelo mesmo polarizador (agora, como analisador) $\left[\begin{array}{ll}0 & 0 \\ 0 & 1\end{array}\right]$, que está, agora, orientado a $90^{\circ}$ em relação à primeira passagem, ou seja, orientado paralelamente ao eixo y, e que é descrito pela matriz de Jones apresentada na eq.(52).

A luz que sai deste analisador é dada por:

$$
J_{\text {saídaPLsaídadouble }}=J_{P L \text { saída }} J_{\text {saída } 1 / 8 \text { ondavolta }}
$$

tornando-se:

$$
J_{\text {saídaPLsaídadouble }}=\left[\begin{array}{c}
0 \\
-\frac{1}{2}-\frac{1}{2} i e^{\left(-i \frac{2 \pi V}{V_{\pi}}\right)}
\end{array}\right]
$$

Observa-se que a equação anterior é similar à eq.(66), que descreve a luz proveniente da célula Pockels na configuração "single pass", diferindo apenas pelo sinal do segundo elemento do vetor e pelo fator 2 no expoente do último termo deste elemento, o que representa a sensibilidade dobrada da célula, conforme esperado. 


\section{MATERIAIS E MÉTODOS}

\subsection{ESTUDO DOS TRANSFORMADORES ÓPTICOS PARA ALTA TENSÃO}

As motivações que deram origem aos objetivos deste trabalho foram levantadas junto a trabalhos anteriormente desenvolvidos e em desenvolvimento no LSO (SILVA, 2011; SANTOS, 1996), baseados na técnica de interferometria de luz branca (WLI - do inglês "White Light Interferometry") com recuperação eletro-óptica, culminando na identificação das alternativas viáveis para a implementação de um protótipo de um novo TPO de alta tensão baseado nessa técnica.

Na parte óptica do novo protótipo de TPO, cujo desenvolvimento é descrito neste trabalho, deve ser mantida a característica de utilização de dois interferômetros de birrefringência conectados em série. Porém, neste caso, não mais serão introduzidos atrasos de fase fixos elevados (maior que o comprimento de coerência da fonte de luz) em cada um deles. Este papel, na presente proposta deve ser desempenhado pela fibra óptica do enlace que conecta os dois interferômetros.

A figura 18, a seguir, ilustra o diagrama completo de um protótipo de TPO para medida de altas tensões, composto por quatro elementos básicos, que são:

- Interferômetro sensor (célula de alta tensão);

- Interferômetro recuperador (célula de baixa tensão);

- Enlaces ópticos;

- Unidade de Processamento de sinal.

O primeiro interferômetro é constituído, basicamente, por uma célula eletro-óptica do tipo Pockels com modulação longitudinal e chamado de sensor primário ou interferômetro sensor, sendo projetado e construído para poder ser submetido a elevadas tensões de forma adequada e segura. Na saída deste interferômetro a informação relativa à tensão a ser medida comparece codificada somente no espectro da luz e não em sua intensidade. O segundo interferômetro, denominado interferômetro recuperador, é projetado e construído de modo a proporcionar uma diferença de caminho óptico (OPD - do inglês: "Optical Path Diference") igual à do 
sensor, de modo a se conseguir a recuperação da informação inserida na luz pelo primeiro interferômetro.

O objetivo deste trabalho concentra-se no desenvolvimento do interferômetro sensor (primário) de um TPO. Contudo, considera-se fundamental, antes de abordar o tema principal, descrever o sistema completo dos TPOs baseados na técnica de interferometria de luz branca para melhor posicionar o leitor com respeito ao cenário em que se insere o trabalho e sua contribuição ao tema.

Figura 18 - Diagrama em blocos de um protótipo de TPO baseado na técnica WLI.

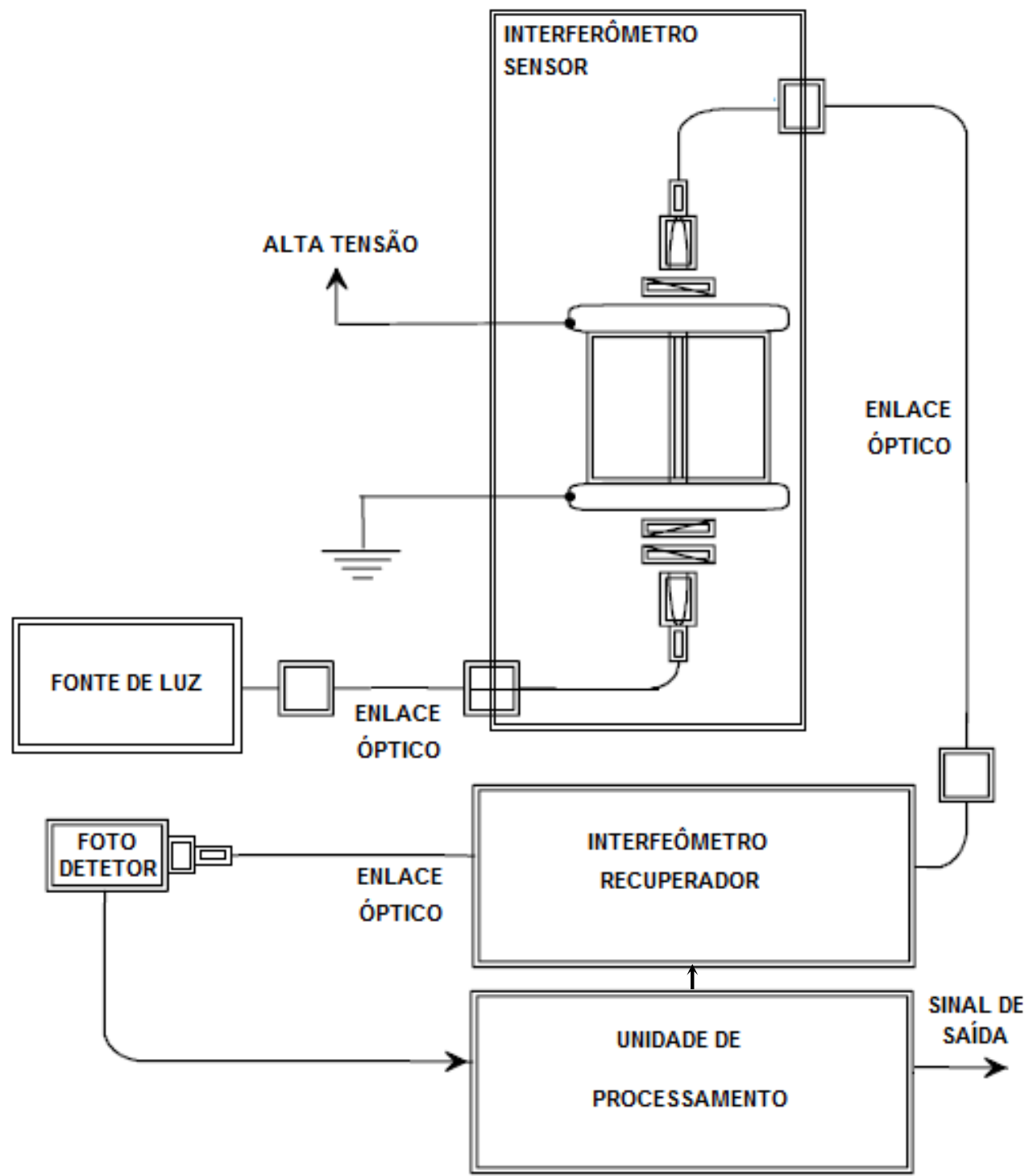

Fonte: Silva (2011)

A seguir, descreve-se cada elemento que constitui o protótipo de TPO apresentado na figura 18. 


\subsubsection{INTERFERÔMETRO SENSOR (CÉLULA DE ALTA TENSÃO)}

O interferômetro sensor, também chamado de célula Pockels de alta tensão, deve ser especialmente projetado com rigidez dielétrica capaz de suportar elevados valores de tensão elétrica aplicada e condicionado a uma sensibilidade adequada para reproduzir a tensão medida na forma de um sinal óptico com linearidade, estabilidade e precisão na faixa dinâmica pretendida.

A constituição da célula sensora é realizada a partir de um conjunto de montagens mecânicas, ópticas e elétricas que formam o dispositivo como um todo e no qual é aplicada uma alta tensão proveniente, por exemplo, de um sistema elétrico de potência, e que deverá ser sensoriada e entregue em sua saída na forma de um sinal óptico que contém alguma característica modulada de forma proporcional àquela alta tensão aplicada.

Como descrito anteriormente, a célula sensora, do protótipo é constituída por um modulador eletro-óptico, montado na configuração longitudinal, a partir de materiais geometricamente adequados, de forma a atender as exigências das especificações de projeto, ou seja, faixa de amplitude da tensão a ser medida, linearidade e precisão.

Os protótipos de células sensoras de alta tensão, anteriormente, desenvolvidos no LSO em relação aos seus dispositivos ópticos, têm sido implementados totalmente na forma volumétrica, ou seja, todos os dispositivos ópticos utilizados para a confecção das células são discretos e não integrados ou implementados a partir de componentes a fibras ópticas.

Outro aspecto importante da construção das células eletro-ópticas, a serem utilizadas como interferômetros sensores de alta tensão, é a característica de passagem do feixe de luz pelo cristal eletro-óptico, já mencionado no capítulo relacionado ao efeito eletro-óptico, e que pode se dar de duas formas: passagem única (denominada topologia "single pass") ou dupla passagem ("double pass"). 
As vantagens da topologia "double pass", em relação à "single pass", estão na maior facilidade que a mesma proporciona no processo de alinhamento óptico (que é um dos alvos deste trabalho) e na potencial diminuição do comprimento do cristal utilizado, visto que a luz passará duas vezes pelo cristal sofrendo o efeito eletroóptico duas vezes.

Além destas características descritas, há outra muito estudada e que está relacionada com o número de cristais eletro-ópticos utilizados na construção da célula e que são denominados:

- célula de cristal único ou

- $\quad$ célula com vários cristais (multi-cristais ou multi-segmentada).

A figura 19, a seguir, ilustra essas duas configurações relacionadas com o número de cristais eletro-ópticos utilizados.

Figura 19 - ilustração das topologias de células Pockels de alta tensão. (a) cristal único e (b) multissegmentada ou multicristais.

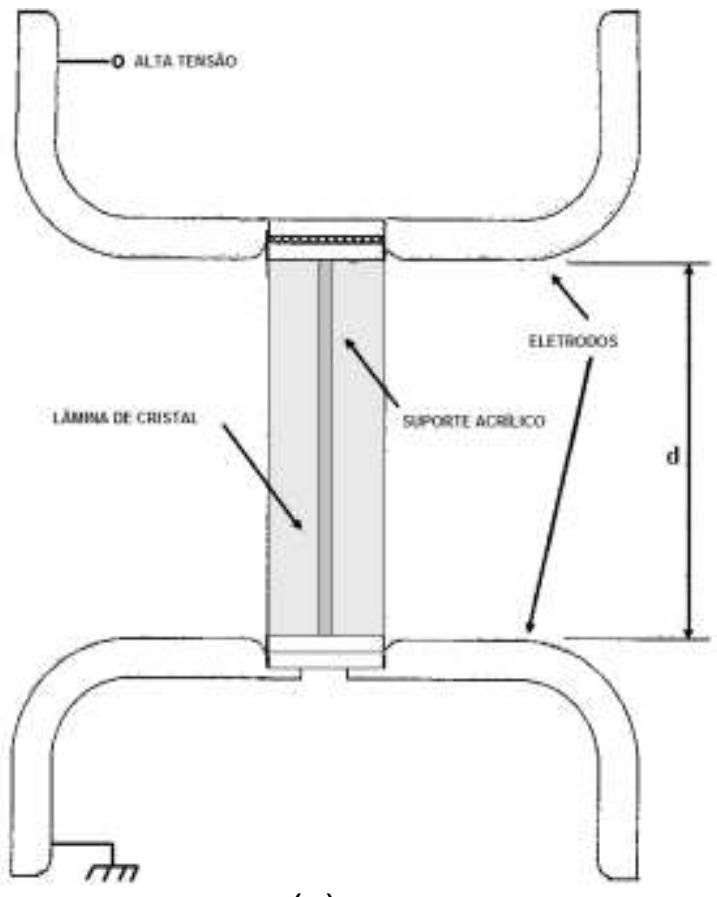

(a)

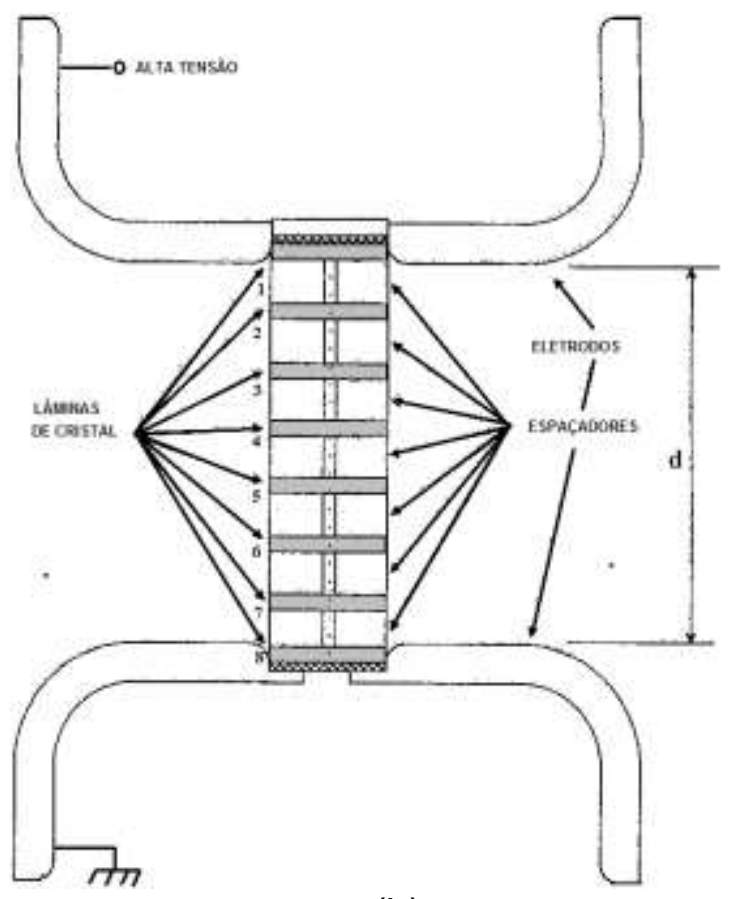

(b)

Fonte: Autor 
Ressalta-se que em ambas as configurações, por tratar-se de uma célula Pockels, os cristais ficam entre eletrodos metálicos, devidamente projetados de modo a proporcionar uma distribuição uniforme de campo sobre o único ou os vários cristais, na mesma direção de propagação do feixe de luz. O comprimento da célula sensora está relacionado diretamente com a distância entre os eletrodos. A distância será um parâmetro de projeto determinado pela classe de tensão do TPO, determinando, portanto, a rigidez dielétrica do mesmo.

O modulador eletro-óptico de um único cristal corresponde à topologia mais utilizada neste tipo de sensor. No tipo de TPO com cristal único a tensão a ser medida é aplicada totalmente ao cristal eletro-óptico, assim, a modulação da luz é proporcional à integral de linha do campo elétrico entre as extremidades do cristal, ou seja, é proporcional à própria tensão aplicada.

Um fator muito importante tanto para as topologias com o cristal único como para as multissegmentada é a influência de elementos externos e próximos ao TPO que podem alterar a distribuição do campo elétrico a que será submetido o modulador eletro-óptico.

A topologia multissegmentada (SANTOS, TAPLAMACIOGLU, HIDAKA, 1999a; SANTOS, TAPLAMACIOGLU, HIDAKA, 1999b; 2000) que utiliza vários cristais eletro-ópticos, pode ser projetada adequadamente de modo que esse efeito da influência da modificação do campo elétrico, oriundo de outros equipamentos ou elementos próximos ao TPO, seja reduzido e não afete significativamente a calibração e, consequentemente, as medições do mesmo (CHAVEZ, JAEGER, 2003).

Um elemento sensor eletro-óptico multi-segmentado pode ser constituído por um conjunto de vários cristais eletro-ópticos e apoios de material dielétrico, os quais mantêm os cristais acondicionados mecanicamente e espaçados entre si, reunidos para formar uma peça única a ser instalada entre os eletrodos. A figura 20 , a seguir, apresenta, esquematicamente, uma configuração multisegmentada, em que d1 e d2 correspondem, respectivamente, às espessuras do cristal eletro-óptico e do intervalo de ar, r é o raio do cristal, e d é a distância entre os eletrodos. 
Figura 20 - Topologia multi-segmentada de um modulador óptico eletro longitudinal: campo elétrico na direção da propagação da luz.

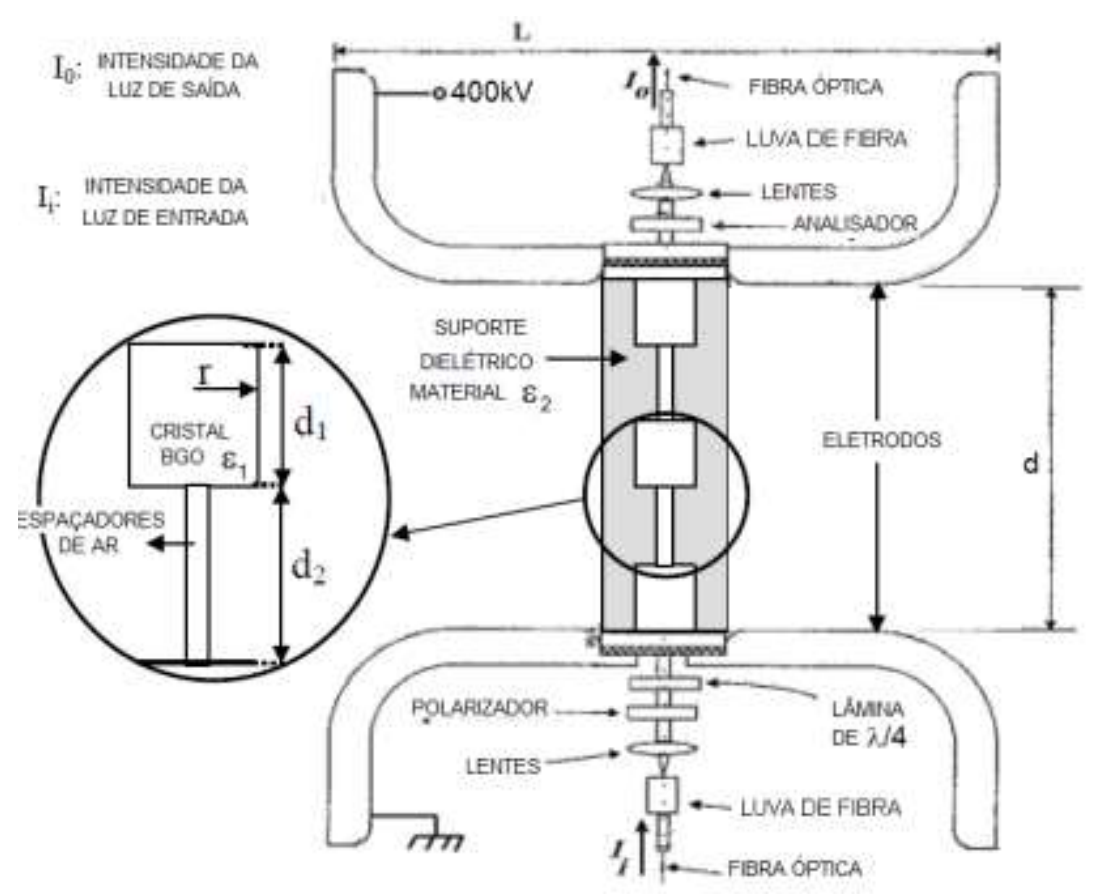

Fonte: Santos (1996) modificada

A tensão $V_{\pi}$ para sensores multisegmentados é calculada pela equação (SANTOS, 1996):

$$
V_{\pi}=\frac{\lambda_{0} K}{2 \cdot n_{0}^{3} \cdot r_{41} \cdot n \cdot d_{1}}
$$

onde $\lambda_{0}$ é o comprimento de onda da fonte de luz no vácuo, $n_{0}$ é o índice de refração ordinário, $r_{41}$ é o coeficiente de Pockels relevante do cristal, $n$ é o número de peças de cristal e Ké um fator eletrogeométrico dado por:

$$
K=\left[n \cdot d_{1}+\frac{\varepsilon_{1}}{\varepsilon_{2}}(n-1) \cdot d_{2}\right]
$$

onde $\varepsilon 1$ é a permissividade do cristal e $\varepsilon 2$ a permissividade do material dielétrico de suporte, sendo que $d 1$ e d2 estão definidas na figura 20 . A equação de $K$, no entanto, não é válida de uma forma geral, pois deve-se levar em consideração a forma e o tamanho das peças de cristal eletro-óptico. Por exemplo, caso a espessura dos cristais, d1, seja muito menor que a dos espaçadores, d2, e as 
permissividades dos dois materiais sejam muito diferentes, o valor calculado tenderá a divergir muito do experimental.

Geralmente, um valor equivalente de $K$ que permite uma melhor estimativa de $V_{\pi}$ pode ser obtido a partir da tensão aplicada aos elétrodos e do campo elétrico médio no interior dos cristais, como indica a equação a seguir:

$$
K=\frac{V}{\bar{E}_{1}}
$$

onde

$$
\bar{E}_{1}=\frac{1}{n} \sum_{i=1}^{n} E_{1(i)}
$$

e $E_{\text {1(i) }}$ ó campo elétrico médio calculado em cada cristal.

A simplificação apresentada pelas equações 80 e 81 é válida para o caso de todos os cristais apresentarem o mesmo comprimento $\mathrm{d} 1$.

Em um protótipo de célula Pockels de alta tensão a cristal único construído no LSO, o modulador eletro-óptico utilizado consistiu no conjunto formado por um cilindro de acrílico que possui tanto a função de acondicionar o cristal eletro-óptico utilizado (de acordo com a sua geometria) como a de promover a isolação e proteção mecânica do mesmo. Este cilindro foi colocado entre dois eletrodos metálicos, os quais são submetidos à alta tensão a ser medida. O cilindro, ainda, foi terminado por discos que acondicionam dispositivos ópticos, tais como o polarizador e a lâmina retardadora.

A figura 21a, a seguir, ilustra, como exemplo, a composição dos discos com o cilindro de acrílico (composto por duas metades em "meia cana"), que tem a função de acondicionar o cristal eletro-óptico. Já a figura 21b mostra a vista lateral em corte do aspecto final do elemento sensor do modulador eletro-óptico longitudinal para medição de altas tensões, obtido como descrito anteriormente. 
Figura 21 - a) Esquema representativo a composição dos discos com o cilindro de acrílico contendo o cristal eletro-óptico e b) Vista lateral em corte do aspecto final do elemento sensor do modulador eletro-óptico longitudinal para medição de altas tensões.

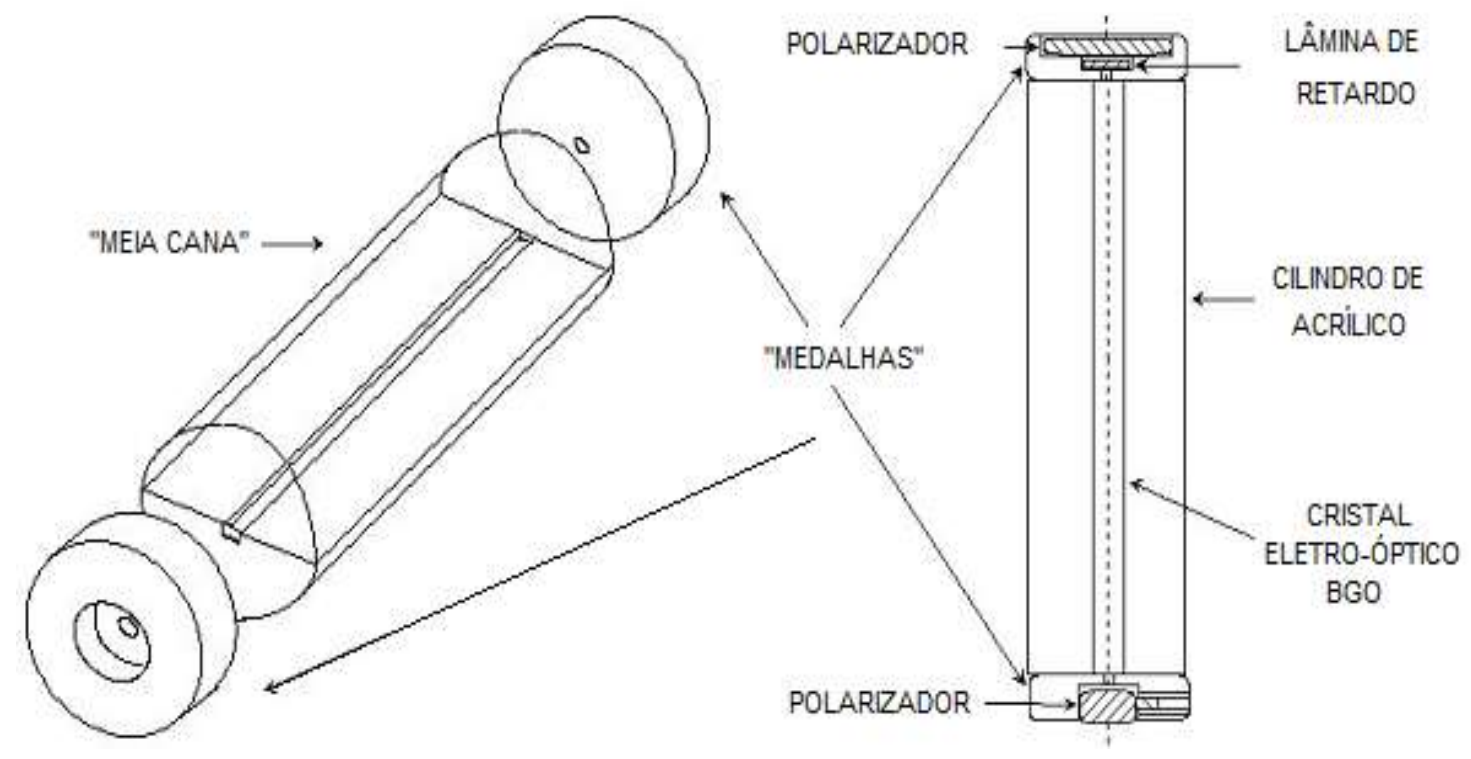

(a)

(b)

Fonte: Silva (2011)

Os outros dispositivos responsáveis pela colimação e alinhamento do feixe óptico são incorporados à célula sensora de alta tensão por meio de posicionadores fixados aos eletrodos, como indicado na figura 22.

Figura 22 - Posicionadores para colimação e alinhamento do feixe óptico incorporados à célula sensora de alta tensão.

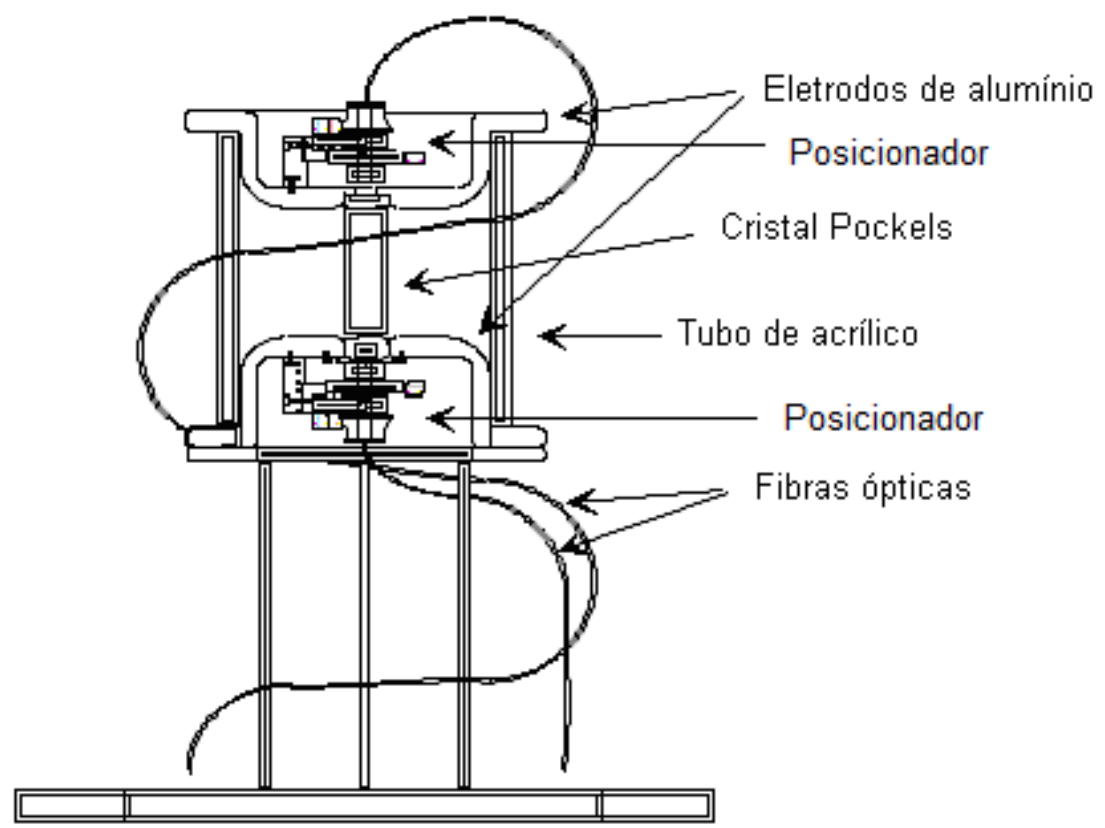

Fonte: Santos (1996) modificada. 
A configuração do protótipo de célula sensora eletro-óptica (ou célula Pockels), apresentado, que constitui o sensor de alta tensão (como é chamado o conjunto do modulador com os acopladores ópticos e elétricos necessários para a medição de altas tensões), foi definida a partir das experiências e trabalhos anteriores (de mestrado e doutorado) de integrantes do grupo do LSO, tendo sido objeto de publicações nacionais e internacionais e que estão citadas ao longo deste trabalho. A configuração também foi definida a partir de estudos de viabilidade técnica e dos materiais disponíveis. O protótipo construído, no entanto, apresentava várias limitações de performance, tal como alinhamento da óptica, e dificuldades de montagem, tal como alinhamento da óptica, que tornavam difíceis seu emprego prático e sua reprodução.

O foco principal deste trabalho de doutorado foi estudar e desenvolver novas topologias de células Pockels dedicadas à medição de altas tensões que superassem as limitações de performance e fabricação apresentadas pelo protótipo anteriormente desenvolvido. Neste processo de desenvolvimento foram utilizadas e implementadas várias configurações de células de alta tensão, ao longo do trabalho de doutorado, as quais o autor participou e que serão descritas, a seguir, de forma cronológica.

\subsubsection{EVOLUÇÃO DOS PROTÓTIPOS DE TPO DO LSO EM RELAÇÃO À CÉLULA POCKELS DE ALTA TENSÃO}

A - A primeira configuração implementada no LSO foi a projetada e desenvolvida por Santos (1996), baseada na topologia "single pass", ou transmissiva, com um único cristal, e é caracterizada por um modulador longitudinal. Nesta montagem, os eletrodos superior e inferior foram feitos de alumínio maciço usinado e foram separados por um tubo de acrílico de $200 \mathrm{~mm}$ de diâmetro interno. A figura 23a, a seguir, mostra a vista em corte da célula de alta tensão e a figura 23b mostra a célula sensora montada e sob teste, no LSO. No centro do eletrodo inferior há um furo de $32 \mathrm{~mm}$ de diâmetro que permite a passagem do elemento sensor do modulador de alta tensão e no eletrodo superior há uma reentrância para acomodar o disco superior do elemento citado. 
Figura 23-a) Vista esquemática em corte da célula eletro-óptica de alta tensão e b) Foto da célula eletro-óptica montada.

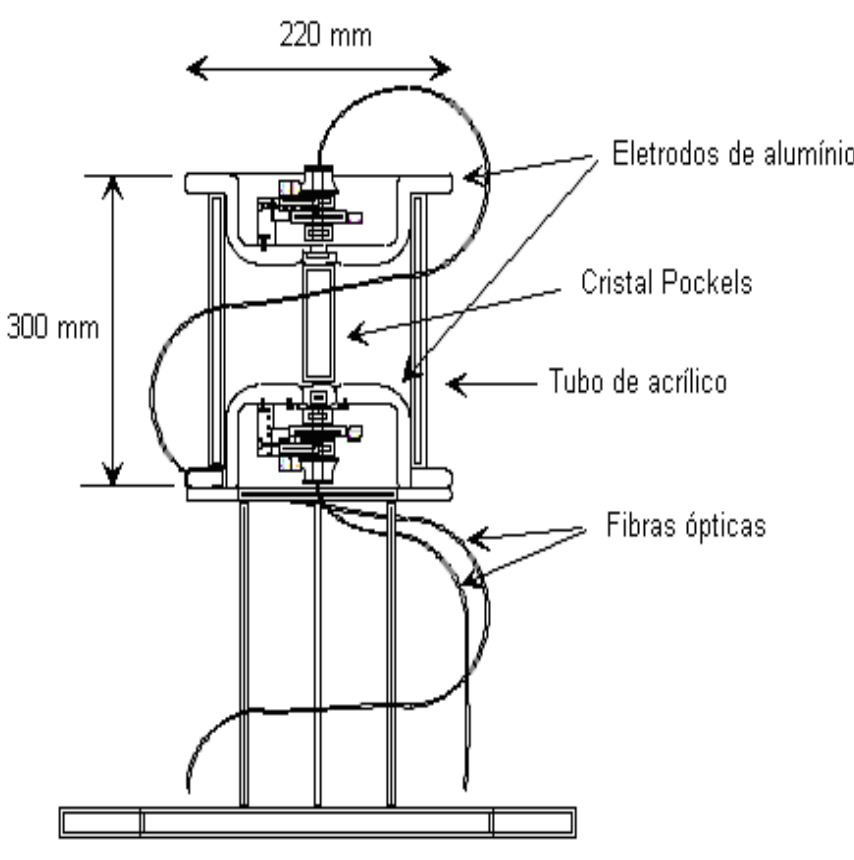

(a)

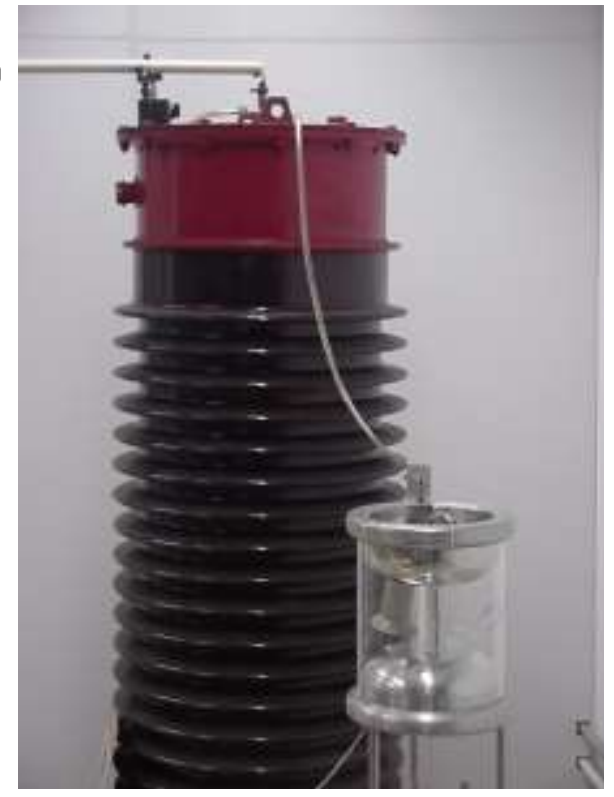

(b)

Fonte: Silva (2011) modificada

Nas cavidades internas dos eletrodos de alumínio são acomodados os componentes ópticos necessários para montagem do modulador Pockels: discos, posicionadores, pigtails colimadores e suportes de fibras ópticas.

Utilizando-se um cristal de BGO (cujo índice de refração ordinário é $\mathrm{n}_{\circ}=2,098$ e o coeficiente eletro-óptico relevante é $r_{41}=1,03 \times 10^{-12} \mathrm{~m} / \mathrm{V}$ ) com dimensões de $1 \times 5 \times 100 \mathrm{~mm}^{3}$, a tensão de meia onda da célula de alta tensão foi teoricamente calculada a partir da eq.(47), obtendo-se os valores de $69,4 \mathrm{kV}$ e $81,5 \mathrm{kV}$ para os comprimentos da luz de $1321 \mathrm{~nm}$ e $1550 \mathrm{~nm}$, respectivamente.

Como placa retardadora foi utilizada uma lâmina de $1 \mathrm{~mm}$ de espessura de niobato de lítio ( $\mathrm{LiNbO}_{3}$ ), com direção de propagação ao longo do eixo x, com o intuito de inserir no interferômetro sensor uma OPD fixa de aproximadamente 35 comprimentos de onda entre as componentes da onda óptica. Nessas condições, a informação da tensão aplicada à célula de alta tensão está contida no espectro da luz de saída e não em sua intensidade. 
A figura 24, a seguir, mostra fotos da célula sensora de alta tensão, com o modulador eletro-óptico montado em seu interior, sob aplicação de alta tensão a partir de um transformador de potencial, localizado no laboratório do LSO e com uma ponta de prova de $20 \mathrm{kV}$ comercial utilizada para o monitoramento e comparação da tensão aplicada à célula de alta tensão.

Figura 24- a) Célula eletro-óptica de alta tensão e b) Célula de alta tensão e transformador de potencial.

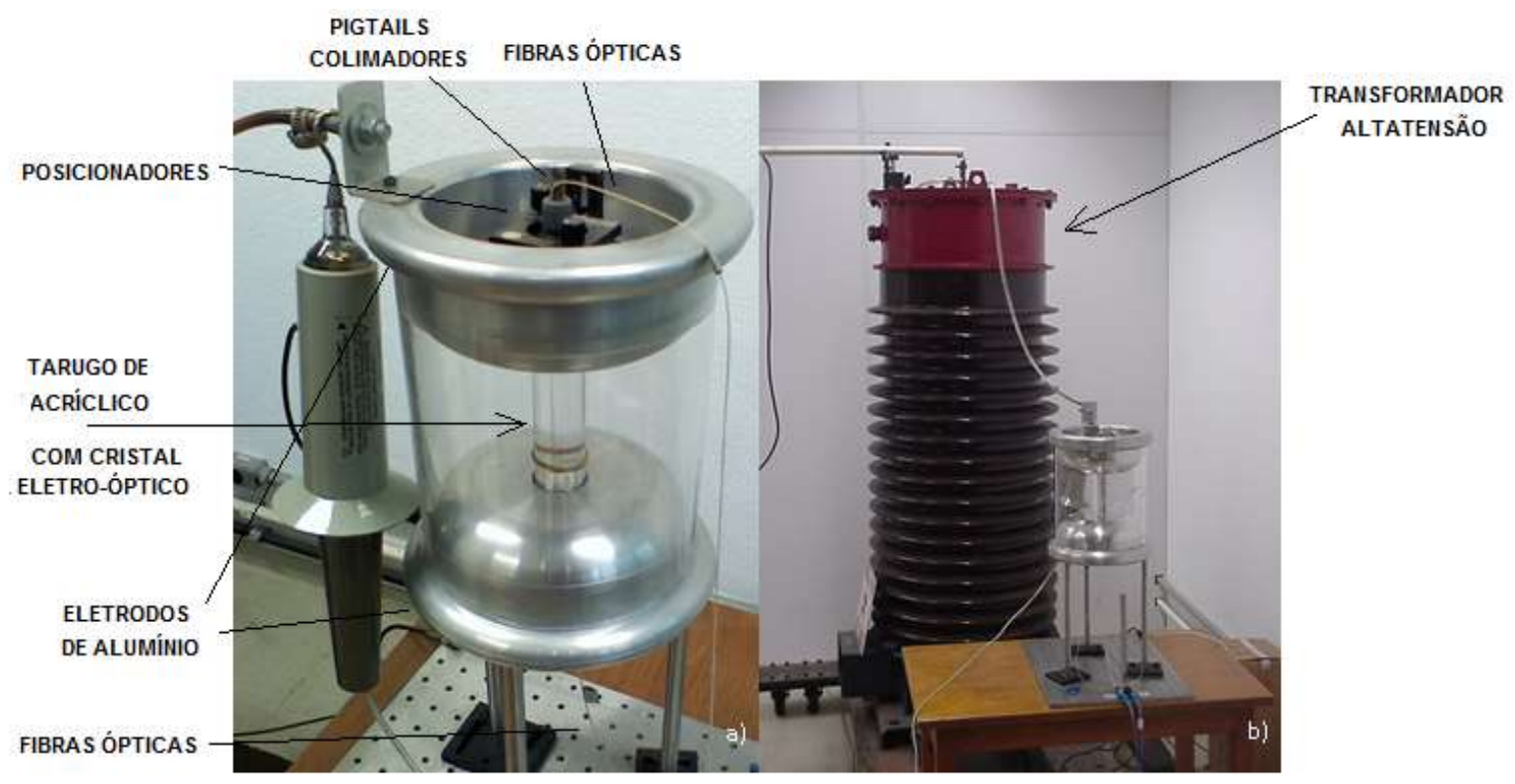

(a)

(b)

Fonte: Silva (2011) modificada

B- A segunda configuracão desenvolvida, e que deu início a este trabalho, foi a que utiliza a topologia multisegmentada com 8 cristais de BGO. A motivação do desenvolvimento da mesma foi a de reproduzir e melhorar o processo de construção daquela que Santos (1996) desenvolveu no seu trabalho de doutorado na universidade de Tokyo, Japão. As figuras 25a e 25b, a seguir, ilustram a descrição da célula de alta tensão com esta topologia desenvolvida por Santos (1996) e as figuras $26 \mathrm{a}, 26 \mathrm{~b}$ e $26 \mathrm{c}$, a seguir, ilustram a célula desenvolvida com ajuda do grupo do LSO neste trabalho. 
Figura 25 - a) Desenho da célula de alta tensão desenvolvida por Santos (1996) e b) característica da lâmina de cristal eletro-óptico utilizada na construção do sensor.

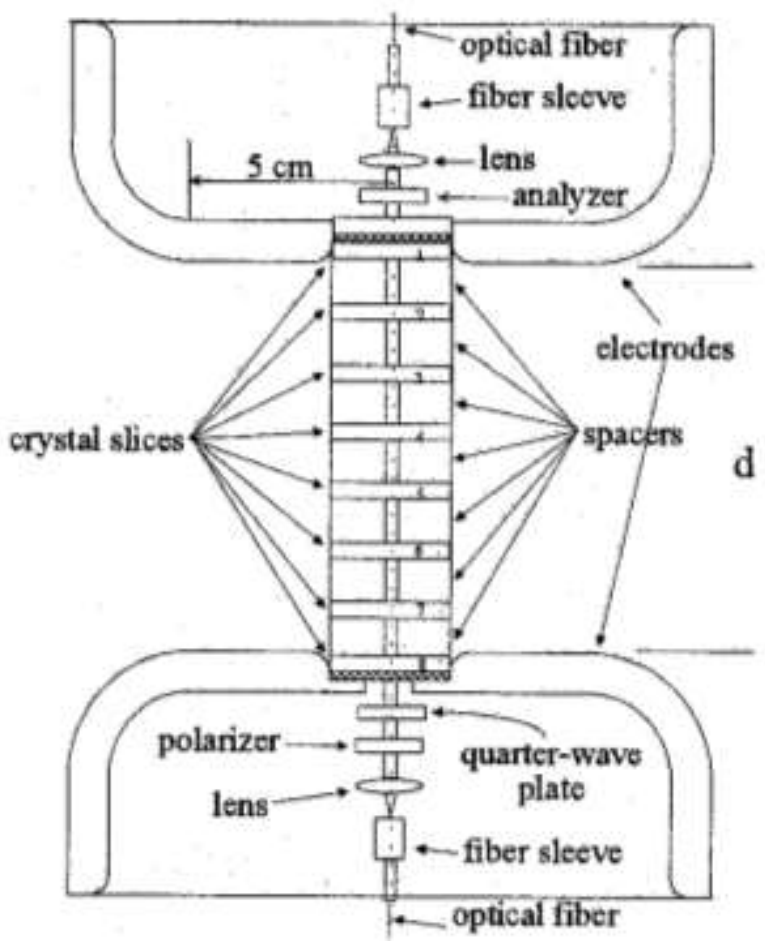

(a)

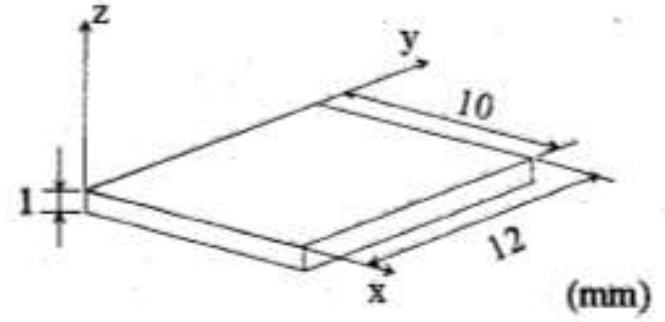

(b)

Fonte: Santos (1996)

Outro fator importante a ser relatado está ligado à disponibilidade dos cristais eletroópticos, como o BGO, que, em muitos momentos, foi o componente mais crítico no desenvolvimento da célula de alta tensão. Foram encontradas dificuldades na identificação de bons fornecedores, o que resultou em problemas com: a qualidade dos cristais obtidos (que apresentaram divergências das especificações), o prazo de entrega (por vezes muito longo) e os preços (inicialmente elevados). Os primeiros cristais adquiridos foram da empresa alemã MolTech (MOLTECH, 2012) e os últimos foram da empresa chinesa Sinoceramics,Inc. (SINOCERAMICS, 2015). 
Figura 26 - a) Primeira célula de alta tensão desenvolvida no doutorado e b) detalhe da lâminas de cristais BGO e c) foto ilustrativa dos elementos da célula desenvolvida.

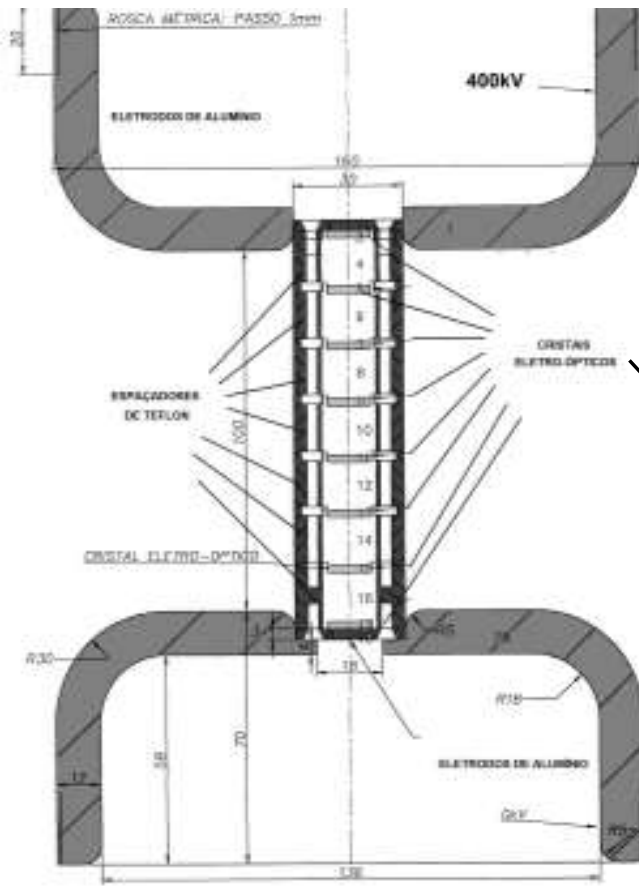

(a)

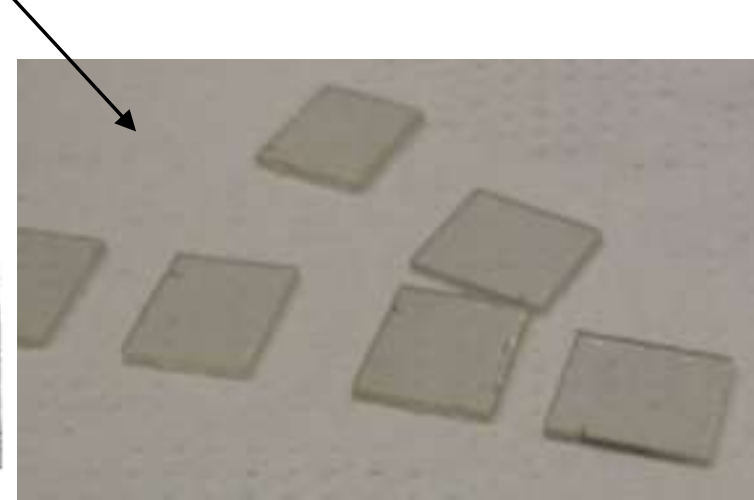

(b)

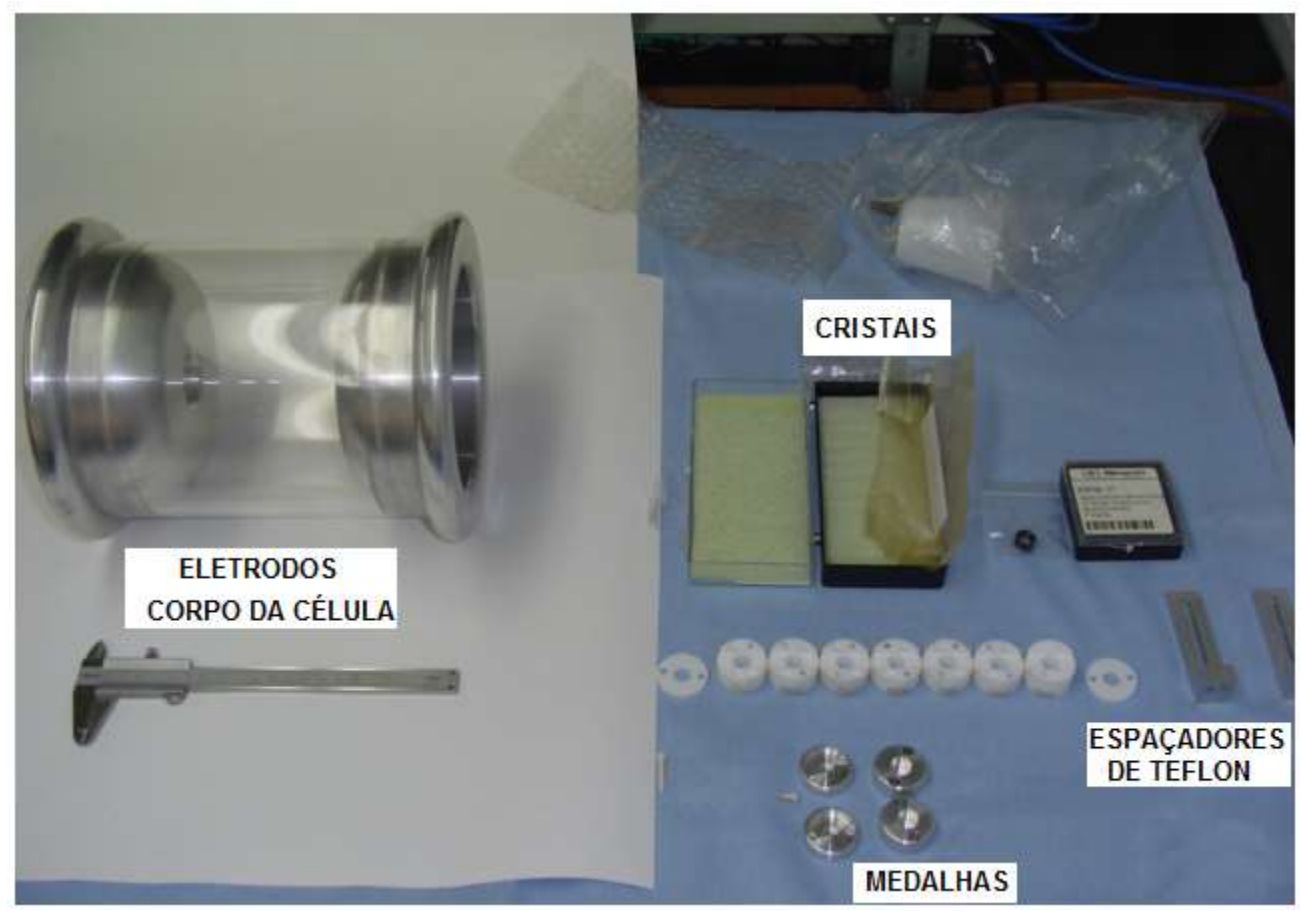

(c)

Fonte: Santos (1996) e Autor 
C- A terceira configuração desenvolvida, ainda no arranjo "single pass" ou transmissiva e multi-segmentada, com 8 cristais de BGO, foi realizada com uma modificação no cilindro que acondicionava os cristais para um conjunto de duas peças em meia cana justapostas. Uma das peças em "meia cana" continha uma canaleta de $5 \times 1 \times 20 \mathrm{~mm}^{3}$ destinada a acomodar as lâminas de cristal de BGO. As figuras $27 \mathrm{a}, 27 \mathrm{~b}$ e 27c, a seguir, mostram as fotos do novo suporte de acrílico feito para o acondicionamento dos cristais.

Figura 27 - Fotos do suporte do de acrílico de acondicionamento dos Cristais a) aberto, b) fechado e c) com os cristais posicionados.

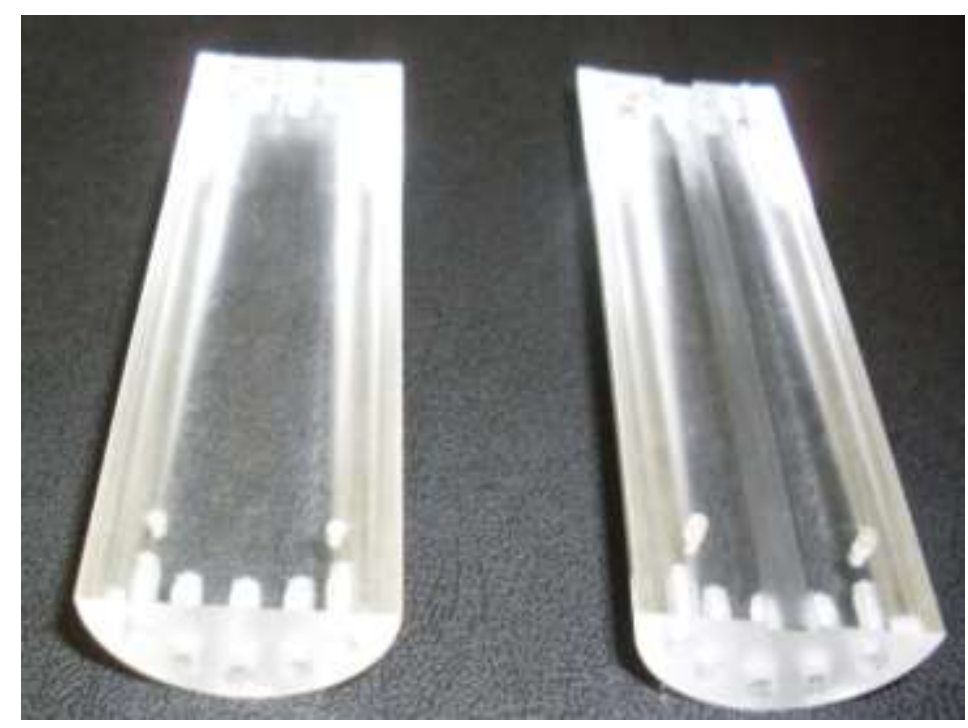

(a)

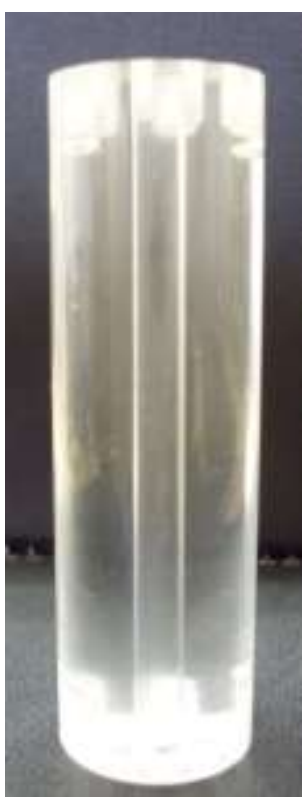

(b)

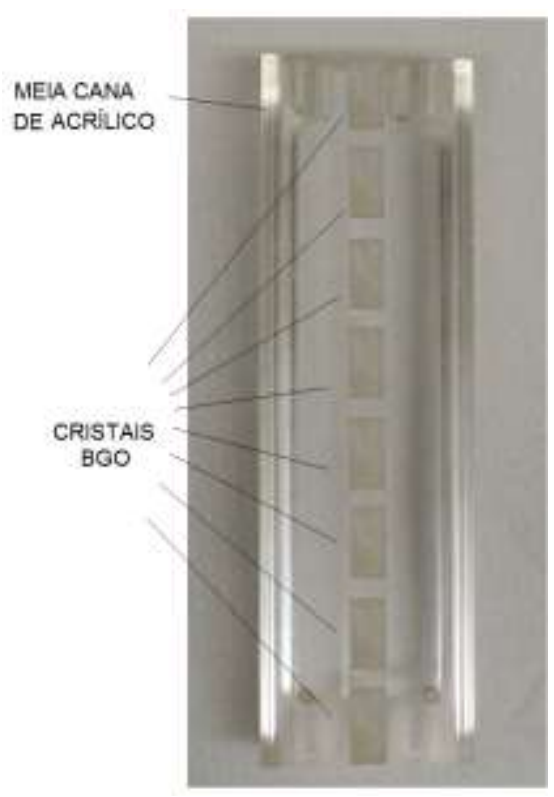

(c)

Fonte: Autor 
Mais uma vez este tipo de implementação mostrou-se, tal como a anterior, de difícil implementação, tanto em relação ao corte, polimento e posicionamento dos cristais eletro-ópticos quanto ao alinhamento dos cristais com os espaçadores. Além dos aspectos mecânicos problemáticos, essa configuração com suporte cilíndrico de acrílico composto por duas metades em "meia cana" afetou a rigidez dielétrica do conjunto, promovendo ruptura prematura do mesmo, por descargas elétricas superficiais ocorridas na interface entre as peças em "meia cana", observadas durante os testes de alta tensão aplicada. Portanto, devido às dificuldades encontradas, essa configuração foi, momentaneamente, abandonada.

D- A quarta configuracão desenvolvida deu início à abordagem da topologia "double pass", ou reflexiva, e com cristal único, sendo que, nesta etapa, buscou-se o espelhamento de uma das faces do cristal eletro-óptico utilizado.

Nesta nova versão optou-se, também, pelo projeto de um novo conjunto de eletrodos de forma a diminuir o tamanho, visando o acondicionamento, do mesmo, em um isolador de alta tensão cerâmico, para uso em campo, com classe de isolação compatível com sistemas de potência operando com tensão nominal de 69 $\mathrm{kV}$, a ser preenchido com gás $\mathrm{SF}_{6}$ a fim de propiciar uma maior rigidez dielétrica ao conjunto. A figura 28 , a seguir, mostra o desenho do referido isolador, adquirido do fabricante PPC Santana.

A definição do nível de tensão de operação deste protótipo foi realizada visando atender às necessidades de um projeto de pesquisa em curso no LSO, ao qual este trabalho está ligado. $O$ projeto em questão é patrocinado pela Companhia de Eletricidade do Estado da Bahia (COELBA) como parte de seu programa de P\&D fiscalizado pela Agencia Nacional de Energia Elétrica (ANEEL), sendo identificado pelo código PD0047-0034/2010 e denominado "SISTEMA DE AFERIÇÃO DE TRANSFORMADORES DE INSTRUMENTOS UTILIZANDO TPS E TCS ÓPTICOS SEM INTERRUPÇÃO DE FORNECIMENTO". Tal projeto visa desenvolver um sistema baseado em TPs e TCs ópticos que permita calibrar em campo Tls convencionais a serviço da medição, conectados em barramentos operando no nível de tensão de $69 \mathrm{kV}$, instalados em subestações de distribuição daquela concessionária. 
Figura 28 - Desenho do isolador cerâmico utilizado para encapsular a célula de alta tensão do protótipo de TPO desenvolvido

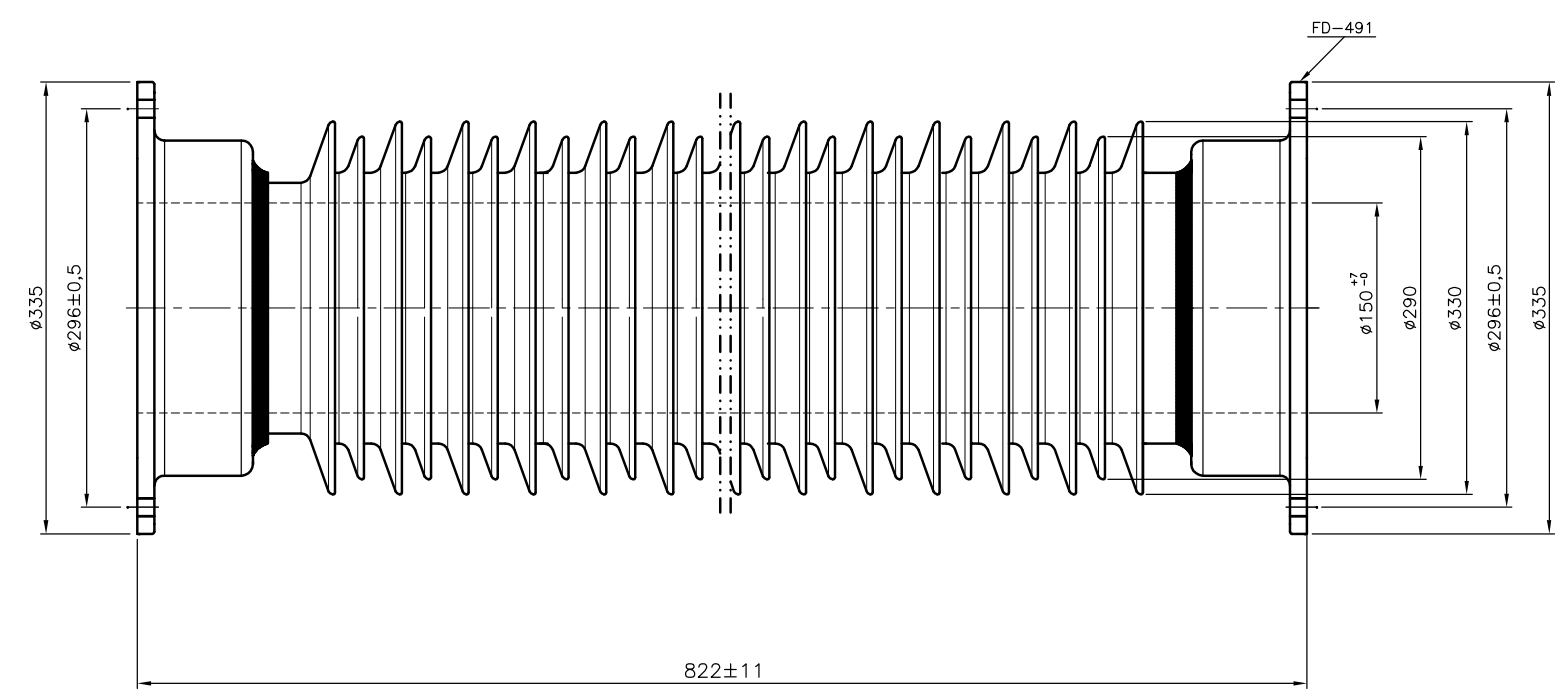

CONTEM O9 SAIAS GRANDES

CONTEM 08 SAIAS PEQUENAS

Fonte: PPC Santana

As modificações nesta versão de célula Pockels foram feitas alterando inclusive as caraterísticas do sistema de alinhamento do feixe de luz, pois além do posicionador de 5 eixos $(x, y, z$ e dois eixos de inclinação $\theta$ e $\phi)$ foi incluído um estágio de rotação de modo a permitir o alinhamento do plano de polarização do feixe óptico com os eixos do cristal.

A partir dessas mudanças foram adquiridos cristais eletro-ópticos com novas geometrias específicas para esta montagem, como, por exemplo, tamanhos maiores visando facilidade de manuseio e consequentemente uma robustez mecânica maior.

Outro fator importante a se destacar nesta versão é que os cristais foram adquiridos a partir de outro fornecedor, como descrito anteriormente, (Sinoceramics Inc.) com preços e qualidades altamente competitivos, fornecidos inclusive com polimentos e filmes finos antirreflexo para evitar perdas na entrada do feixe de luz no cristal eletroóptico.

O diagrama em blocos ilustrado na figura 29, a seguir, mostra a do sistema global, incluindo o estágio recuperador, da nova configuração de um protótipo de TPO 
baseado na técnica WLI com a célula sensora que usa a topologia reflexiva "double pass", sendo que ressalta-se a nova configuração dos eletrodos, o cristal eletroóptico (no detalhe), com a face de entrada do feixe de luz recoberta por um filme fino de caraterística antirreflexo (AR- coating) e a outra face espelhada para se obter reflexão total do feixe, culminando na passagem do mesmo, pelo cristal eletro-óptico, duas vezes ("double pass"). Tal tipo de célula sensora, proposta neste trabalho, sucedeu àquela apresentada na figura 18. Os métodos e os processos de espelhamento e deposição de filme fino antirreflexo são descritos na próxima seção deste documento.

Figura 29 - Diagrama em blocos da nova configuração de protótipo de TPO baseado na técnica WLI com célula sensora na topologia reflexiva "double pass" com detalhe da óptica utilizada e do cristal eletro-óptico com faces espelhada e antireflexiva.

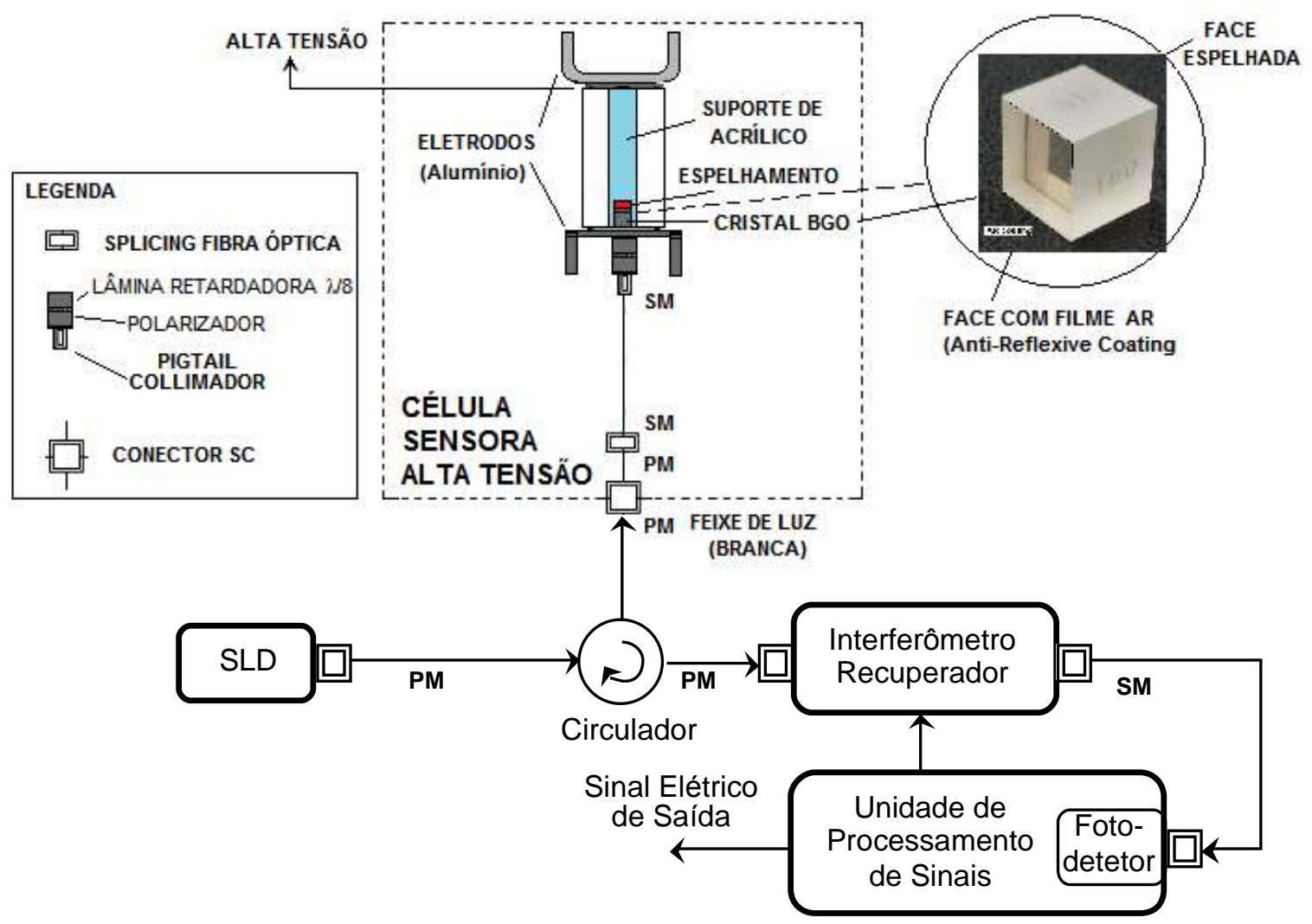

Fonte: autor

A figura 30a e a foto da figura 30b, a seguir, mostram um desenho (em vista explodida) da nova topologia e as peças da célula já confeccionada. 
Figura 30 - Vista explodida da nova topologia (a) e foto das peças da célula sensora na topologia reflexiva "double pass" (b)

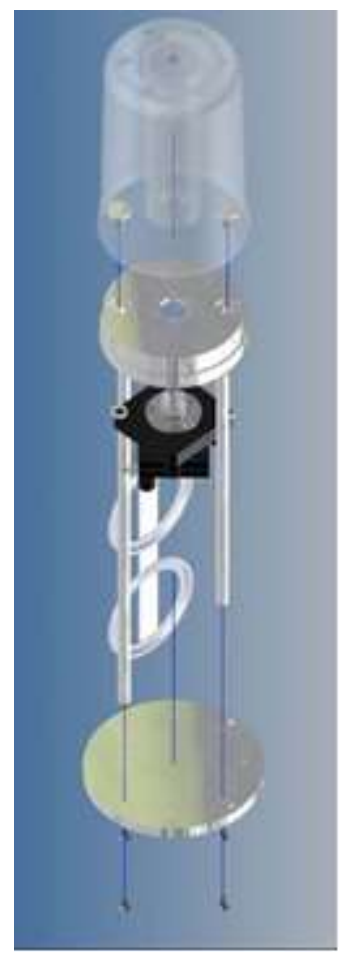

(a)

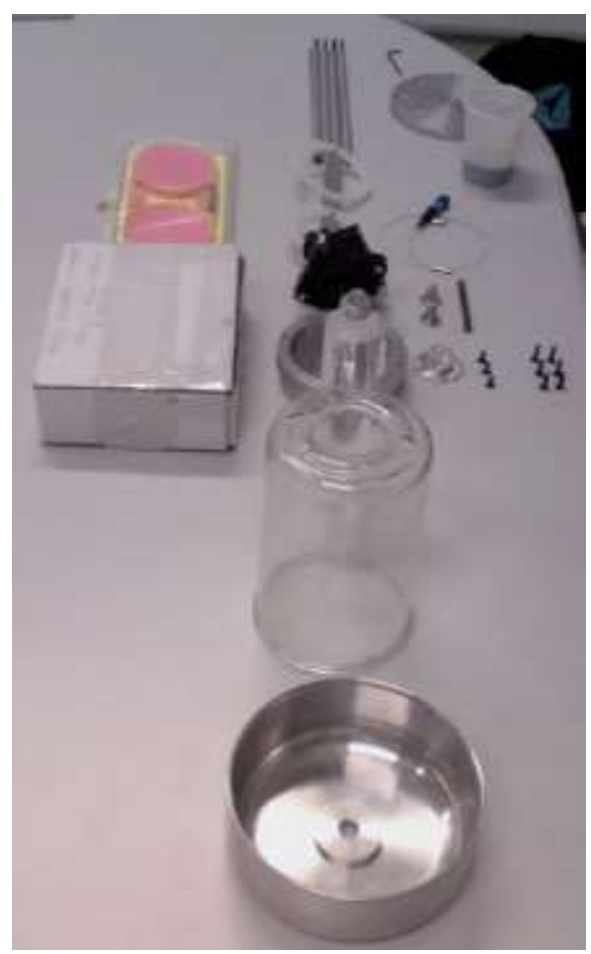

(b)

Fonte: Autor

A figura 31, a seguir, mostra o arranjo do modulador eletro-óptico na topologia reflexiva "double pass", conceituado anteriormente, contextualizado agora na nova célula de alta tensão.

Figura 31 - Arranjo representativo do modulador eletro-óptico na topologia reflexiva "double pass" da nova célula de alta tensão.

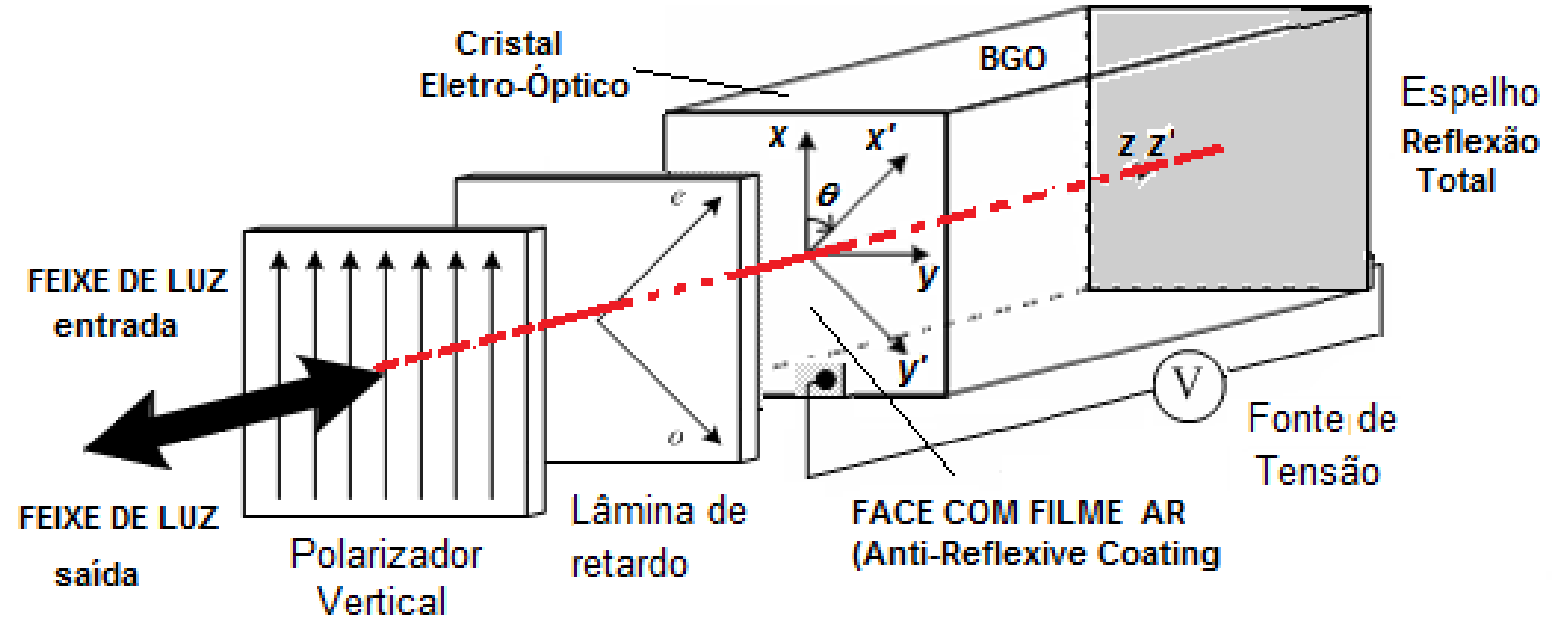

Fonte: Autor 


\subsubsection{ESPELHAMENTO E APLICAÇÃO DE FILME ANTI-REFLEXO (AR COATING) NOS CRISTAIS DE BGO PARA UTILIZAÇÃO NO MODULADOR ELETRO-ÓPTICO SENSOR}

Nesta nova topologia "double pass" foi necessário um trabalho de aplicação de filmes finos nos cristais eletro-ópticos $\mathrm{BGO}\left(\mathrm{Bi}_{4} \mathrm{Ge}_{3} \mathrm{O}_{12}\right)$ que foi orientado em duas linhas, que são:

- Aplicação de filmes Anti-reflexo: O objetivo da aplicação, na face de entrada do cristal eletro-óptico, do filme $A R$ é a de diminuir ao máximo possível a perda, por reflexão, quando se insere o feixe de luz no cristal (LY, MOEHLECKE, ZANESCO, 2007).

- Aplicação de filmes de alumínio (Al), visando reflexão total (ou espelhamento). O objetivo da aplicação de um "espelhamento" na face de posterior do cristal eletro-óptico é obter a máxima reflexão possível do feixe de luz que passa pelo cristal provocando a dupla passagem do feixe pelo mesmo.

A partir de uma amostra, do cristal $\left(5 \times 5 \times 5 \mathrm{~mm}^{3}\right)$, cedida pela empresa Sinoceramics para um outro experimento, as duas aplicações dos filmes foram realizadas levandose em consideração o comprimento de onda central de trabalho, de 1550nm devido ao SLD utilizado. É importante ressaltar que a primeira amostra foi fornecida apenas com polimento nas faces do cristal perpendiculares ao eixo óptico, sem nenhum outro beneficiamento, pois é o que havia disponível.

A técnica utilizada neste trabalho para espelhamento (LAVRAS, 2002) e deposição de filmes AR (MARDEGAN, 2004), nas faces dos cristais é conhecida como PVD (Physical Vapour Deposition) e foi realizada no Laboratório de Produção de Filmes Finos - Eletron beam (LPFF-E) do Instituto de Estudos Avançados (IEAv) - DCTA.

Para a deposição foi utilizada uma evaporadora da marca LEYBOLD L-560, cuja foto é mostrada na figura 32, equipada com uma bomba mecânica para fazer o prévácuo ( $1 \times 10^{-1}$ até $1 \times 10^{-3}$ torr) e uma bomba turbomolecular (alto-vácuo), que atinge pressões na faixa de $1 \times 10^{-2}$ a $1 \times 10^{-6}$ torr. A vantagem desta bomba é a produção de um vácuo limpo, imprescindível para o processo de evaporação por vapor físico. No início do processo a pressão na câmara a vácuo é reduzida até atingir $1.10^{-6}$ torr e, em seguida, a válvula de gás $\mathrm{O}_{2}$ de alta pureza $(99,999 \%)$ é aberta, injetando este gás na câmara de evaporação até que a pressão atinja $1 \times 10^{-4}$ torr. 
Figura 32 - Evaporadora LEYBOLD L-560 utilizada no processo (PVD).

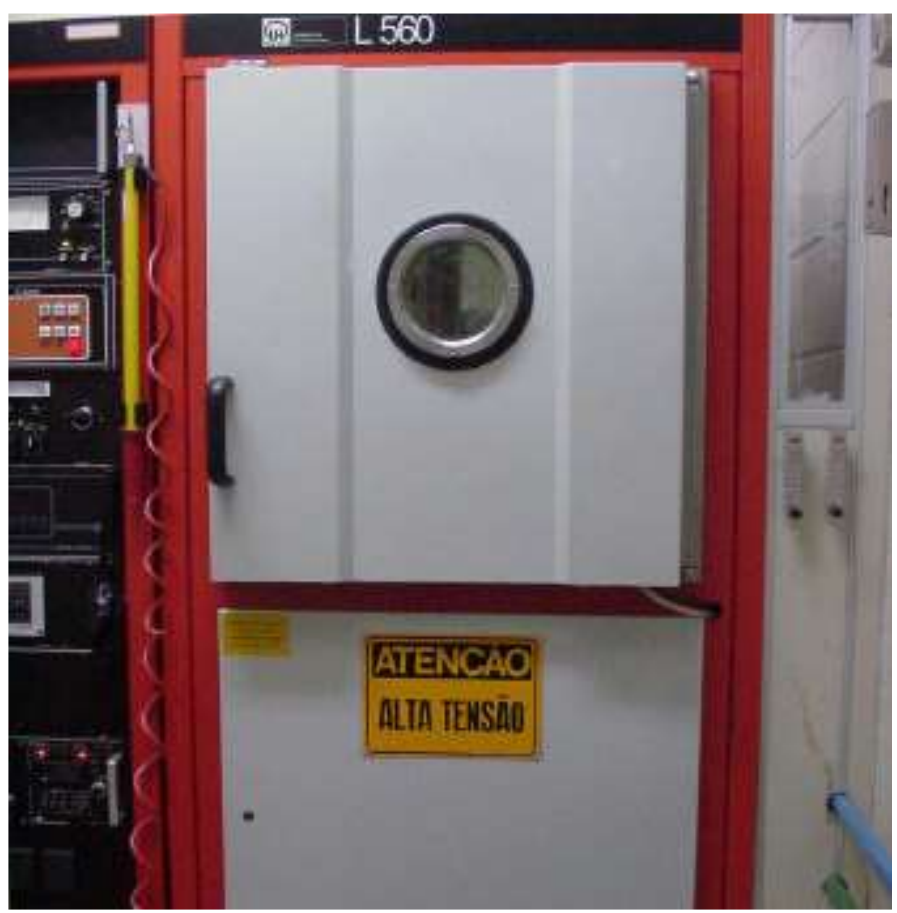

Fonte: Lavras (2002)

$\mathrm{Na}$ técnica de feixe de elétrons, o sistema produz vapor neutro de íons que migram até o substrato. É necessário um nível considerável de energia para realizar-se o processo da evaporação. Neste caso, a tensão de aceleração do canhão de elétrons é da ordem de $11 \mathrm{kV}$.

Os materiais a serem evaporados são aquecidos quando o feixe de elétrons incide sobre o material, que é colocado dentro de um cadinho no interior da câmara. Esse feixe de elétrons possui um momento que é transferido para o material a ser aquecido, sendo convertido em calor. Os materiais são fundidos a uma determinada temperatura. O ponto de fusão na superfície do material, onde houve maior aquecimento pela incidência do feixe de elétrons, é chamado de banho.

Por meio dessa técnica a deposição de filmes finos pode ser realizada pelo aquecimento do "alvo" de material do qual se deseja produzir os filmes em um ambiente de alto vácuo. O material aquecido se evapora e se deposita nos substratos e nas paredes da câmara de processo. O equipamento de evaporação permite altas taxas de deposição (como $0,5 \mu \mathrm{m} / \mathrm{min}$ para o $\mathrm{Al}$ ) sem causar danos à superfície do substrato devido à baixa energia das espécies incidentes, 
contaminação mínima do filme pelo gás residual devido ao alto vácuo e pouco aquecimento do substrato (LAVRAS, 2002).

A uniformidade da espessura do filme é obtida distribuindo-se os substratos em um suporte tipo sistema planetário que, durante a evaporação, gira em torno do eixo vertical da câmara de processo, enquanto que os vários suportes giram em torno de um eixo secundário. O valor da espessura é obtido por meio de um oscilador de quartzo, durante o processo de deposição do filme. Esses valores são comparados com os resultados obtidos, a posteriori, por elipsometria, difração de raios-x de baixo ângulo e pelo método de envelope. Filmes de multicamadas podem ser obtidos pela evaporação sequencial dos materiais que compõem o filme.

A figura 33, a seguir, mostra as fotos da amostra do cristal BGO antes e depois da aplicação dos filmes.

Figura 33 - Amostra de cristal eletro-óptico de $\mathrm{Bi}_{4} \mathrm{Ge}_{3} \mathrm{O}_{12}$ : a) antes das aplicações dos filmes, b) face de entrada do feixe de luz com filme anti-reflexão (AR coating) e c) face posterior "espelhada" com filme para reflexão total.

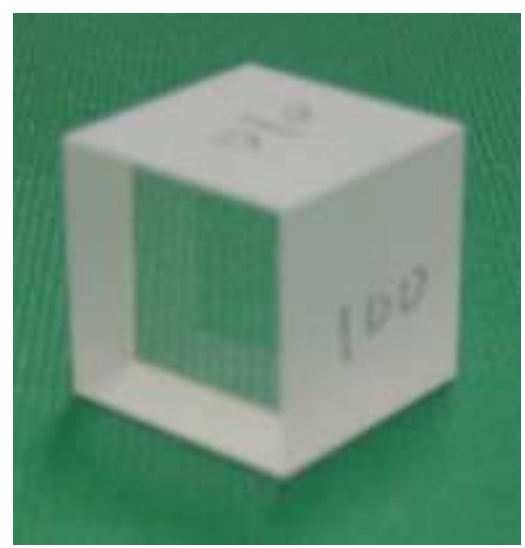

(a)

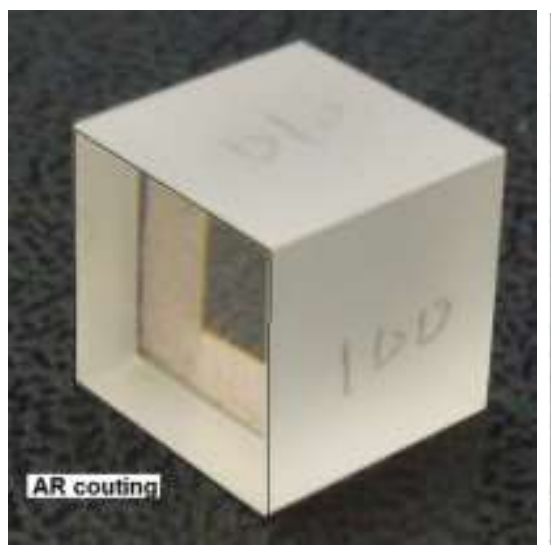

(b)

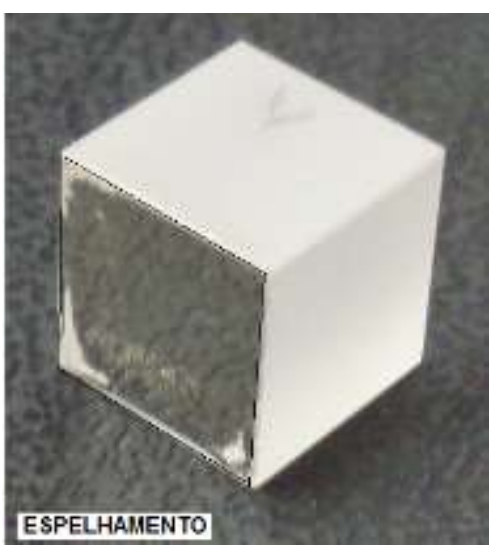

(c)

Fonte: Autor

Em consulta ao fornecedor da amostra de BGO foi averiguada a possibilidade de inserção do filme AR e de espelhamento em faces dos cristais fornecidos. O setor técnico da empresa respondeu positivamente sobre a possibilidade de fornecer os cristais com as dimensões necessárias e com filme AR em uma das faces, mas que o espelhamento ainda não era possível. Em vista disso, foi adquirido um lote com 
vários comprimentos de cristais (tais como $5 \times 5 \times 20 \mathrm{~mm}^{3}, 10 \times 10 \times 20 \mathrm{~mm}^{3}$, entre outros) com filmes AR em uma das faces e a outra apenas polida opticamente. Esses cristais foram espelhados utilizando os laboratórios, equipamentos e equipe do laboratório de óptica (EFO-O) do departamento de Fotônica do IEAv, conforme ilustram as fotos da figura 34 .

Figura 34 - Lote de BGOs adquiridos onde a) vários tamanhos, b), c) e d) detalhe da face "espelhada" realizada no IEAv.

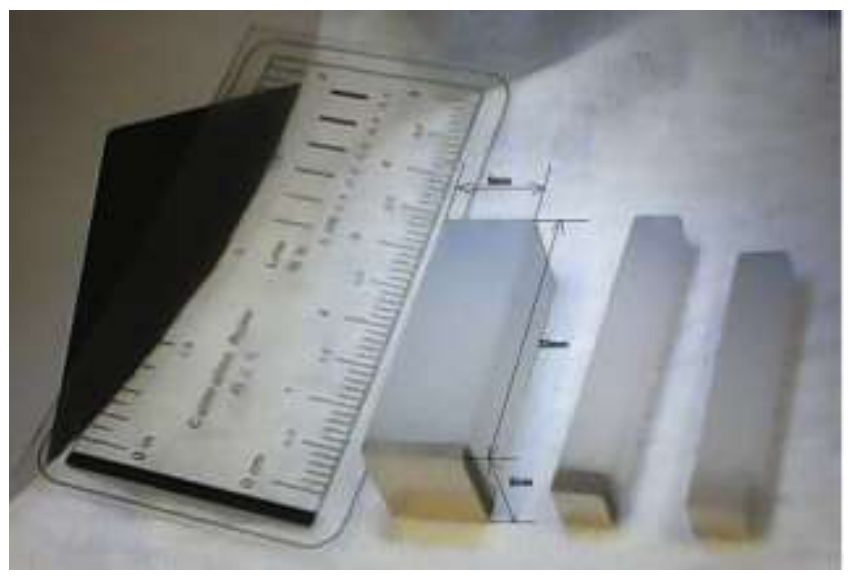

(a)

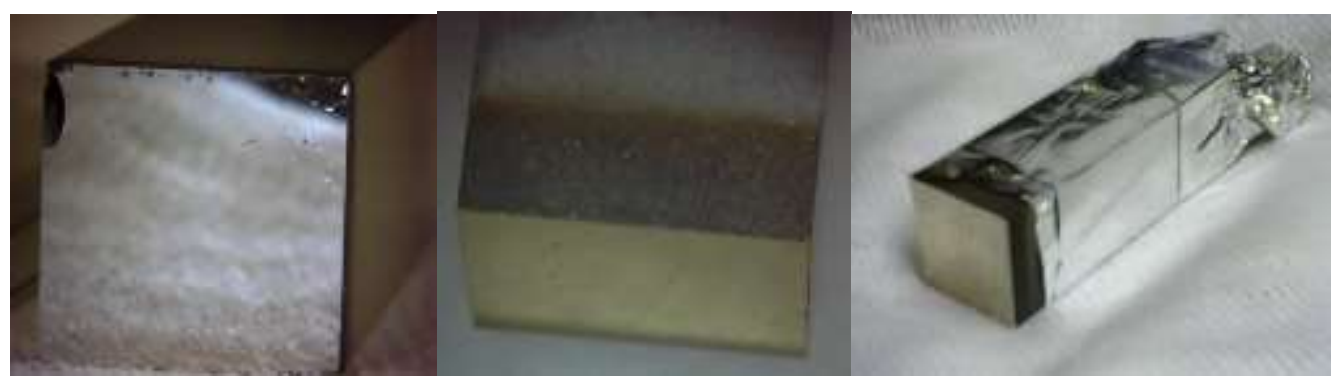

(b)

(c)

(d)

Fonte: Autor

Evidenciou-se que a metodologia no espelhamento dos cristais ainda não estava totalmente estabelecida, pois verificou-se que existiam alguns problemas de aderência dos filmes (com alumínio como material predominante) do material de espelhamento. Entretanto, o processo vem evoluindo satisfatoriamente com a inserção de outros materiais, tais como: Sulfeto de Magnésio - MgS, visando uma melhor aderência, e Prata - Ag e Ouro - Au, visando uma melhor refletância, a qual resultou em torno de $91 \%$ (para $\lambda=1550 \mathrm{~nm}$ ). 
Apesar dos problemas relatados, os filmes refletores apresentaram qualidade e durabilidade suficientes para atender às necessidades do protótipo desenvolvido neste trabalho.

Em contato realizado no início de 2015, a empresa Sinoceramics acenou com a possibilidade de também aplicar o filme de reflexão total numa das faces dos cristais, de modo que já foi solicitada uma amostra para comparação e qualificação dos filmes aplicados no IEAv.

\subsubsection{ENLACE ÓPTICO}

$\mathrm{Na}$ configuração de TPO ilustrada na figura 29, devido à necessidade de comunicação entre os elementos é necessário o uso de alguns enlaces ópticos, compostos, por fibras ópticas (monomodo e PM), Pigtails colimadores, circuladores, conectores e emendas, que são:

- Enlace entre fonte de luz (SLD) e interferômetro sensor;

- Enlace entre Interferômetro sensor e interferômetro recuperador;

- Enlace entre interferômetro recuperador e fotodetector;

$\mathrm{Na}$ configuração proposta, como a luz emitida pela fonte deve chegar ao interferômetro sensor pela mesma fibra que levará sua luz refletida ao interferômetro recuperador, é necessária a inserção de um componente que permita a separação das luzes contrapropagantes. Há pelo menos dois tipos de componentes a fibras ópticas capazes de realizar esta função: os acopladores direcionais e os circuladores. A diferença básica entre os dois é que os acopladores direcionais dividem a potência óptica inserida em um de seus acessos entre dois outros acessos. Caso esta divisão seja equitativa, o processo impõe uma diminuição de $50 \%$ (equivalente a $3 \mathrm{~dB}$ ) na potência óptica transmitida, além da perda de inserção em excesso devido a imperfeições do componente. Já o circulador encaminha praticamente toda a potência óptica inserida em um de seus acessos ao próximo, sucessivamente. Assim, a potência óptica inserida, ao ser transmitida para o próximo acesso, sofre apenas a atenuação devida à perda de inserção em excesso do componente. A principal desvantagem dos circuladores está associada ao seu 
preço, tipicamente muito superior ao acoplador direcional de mesmo número de acessos.

Uma vez que o componente em questão se inclui tanto no enlace entre a fonte óptica e o interferômetro sensor quanto no enlace entre os interferômetros sensor e recuperador, privilegiando a performance do circuito óptico, no sentido de impor a menor atenuação possível nos enlaces, optou-se por prever a utilização de um circulador de 3 acessos, ao invés de um acoplador direcional, conforme mostrado na figura 29.

Na parte do enlace que liga o interferômetro sensor ao circulador a luz precisa deixar a fibra óptica e se propagar livremente para atravessar os componentes da célula sensora (polarizador e lâmina de retardo) e ser inserida no elemento sensor (cristal eletro-óptico), sendo novamente recolhida à fibra óptica depois de ser refletida na face espelhada do cristal e ter percorrido o caminho de volta por todos os componentes. Para acoplar de forma eficiente a luz entre os modos de propagação livre e guiado na fibra utilizam-se lentes adequadamente projetadas e construídas para este fim. No caso em questão, como o trecho de propagação livre é relativamente extenso, o feixe expandido de luz deve ter a distância do centro da lente até sua cintura projetada para coincidir com a distância do centro da lente até a face espelhada do cristal. Um componente que incorpora lentes capazes de projetar a posição da cintura do feixe a grandes distâncias é denominado colimador. Um colimador que incorpore de um de seus lados, como um de seus acessos, um trecho de fibras ópticas é normalmente chamado de pigtail colimador.

De modo a melhorar o desempenho do sistema sensor, escolheu-se empregar um pigtail colimador constituído por uma lente tipo índice gradual (Gradual Index GRIN), ao invés de lentes esféricas ou asféricas, pois os mesmos oferecem vantagens, tais como: apresentam baixa perda por inserção (por possuírem camadas anti-refletoras em suas faces e por estas estarem perfeitamente acopladas às fibras), produzem feixes de diâmetro de cintura reduzido (@ 0,45 mm), apresentam baixa divergência $\left( \pm 0,15^{\circ}\right)$ e produzem montagens mecânicas mais compactas e, portanto, mais robustas e estáveis (pois são encapsuladas em invólucro de aço de dimensões reduzidas. No entanto, o emprego das lentes GRIN 
no enlace óptico apresentou a desvantagem de exigir alinhamento angular preciso, requerendo um esforço adicional e um cuidado especial no trabalho de alinhamento das lentes.

No intuito de minimizar as perdas por acoplamento e facilitar o alinhamento e manuseio dos componentes ópticos, procurou-se trabalhar com fibras ópticas (monomodo ou PM) conectorizadas nos protótipos. Por outro lado, por ser a luz emitida pelo SLD parcialmente polarizada, em uma razão de polarização de aproximadamente $5 \mathrm{~dB}$, o ideal seria empregar fibra mantenedora de polarização (Polarization-Maintaining Optical Fiber - PM) na conexão entre o SLD e o interferômetro sensor.

Adicionalmente, pelo fato da luz na saída do interferômetro sensor ser polarizada e o interferômetro recuperador também ser um polarizador é importante manter constante a orientação da direção de polarização da luz entre os dois interferômetros, caso contrário pode ocorrer um efeito chamado desvanecimento (fading) do sinal interferométrico. Como a fibra monomodo não mantém a direção de polarização o ideal seria utilizar fibras mantenedoras de polarização PM entre os interferômetros para evitar tal efeito.

A utilização de fibras ópticas do tipo monomodo não inviabilizaria a realização do trabalho uma vez que, se estas fibras não forem perturbadas termicamente ou mecanicamente, ou, se as variações introduzidas por elas forem pequenas, é possível compensar o sistema (óptico e eletrônico) de modo que o sinal de saída do TPO não se degrade significantemente ou apresente uma deriva com a qual não se possa conviver. Tais compensações são feitas nos protótipos dos TPOs anteriormente implementados.

Outros aspectos que impossibilitaram em um primeiro momento a utilização de fibras ópticas do tipo PM nos protótipos realizados durante o desenvolvimento dos trabalhos anteriores foram: seu elevado custo e a indisponibilidade de equipamentos para fazer emendas de fusão em fibras deste tipo. Entretanto, com a aquisição (pelo Projeto COELBA LSO/PEA EPUSP) de equipamento capaz de fazer emendas de 
fusão em fibras PM (Vytran GPX3400) (VYTRAN, 2014), a substituição das fibras monomodo pelas fibras PM tornou-se factível.

Utilizaram-se na montagem, inicialmente, conectores do tipo SC, os quais além da praticidade de encaixe rápido, por pressão demonstram bom desempenho nos quesitos de perda por inserção e repetitividade. Contudo, este tipo de conector não apresenta robustez adequada para uso em situações de campo, onde o manuseio pode ser feito por pessoas não habilitadas, e fatores como sujeira e umidade ambiental podem degradar rapidamente a performances dos mesmos. Em vista disso, em protótipos finais, a serem levados para uso em campo, prevê-se a utilização de conectores do tipo E2000, os quais são especialmente projetados para ser muito mais resistentes ao manuseio e pouco sujeitos a contaminação por poluentes ambientais.

Para a escolha da fonte de luz empregada no TPO, o requisito básico é que ela deve produzir luz de baixa coerência temporal, ou banda espectral larga (MARCHESE, WILDERMUTH, STEIGER, 2012; SANTOS, TAPLAMACIOGLU, HIDAKA; 1999). Escolheu-se então empregar como fonte de luz um diodo superluminescente (SLD), pois este tipo de componente produz luz de coerência espectral moderadamente baixa, e moderada coerência espacial, conseguindo assim acoplar uma quantidade significativa de luz nas fibras ópticas utilizadas.

O SLD empregado no TPO foi o modelo SLD - 76 - HP, fabricado pela empresa Superlum Diodes, LTD, que emite luz no comprimento de onda de $1560 \mathrm{~nm}$ e possui potência óptica da ordem de até $5 \mathrm{~mW}$, que apresenta as especificações técnicas contidas no Anexo 1. Na conversão dos sinais ópticos em sinais elétricos, foi utilizado um fotodetector na entrada do circuito de processamento eletrônico de sinais. Este fotodiodo é um diodo PIN de Arseneto de Índio e Gálio (InGaAs), fabricado pela Appointech, Inc., cujas informações técnicas estão detalhadas no Anexo 2. 


\subsubsection{INTERFERÔMETRO RECUPERADOR (CÉLULA DE BAIXA TENSÃO)}

As topologias de interferômetros recuperadores, cuja função já foi descrita em capítulos anteriores, foram duas, sendo que ambas, foram contempladas no trabalho de Pinheiro e que foram implementadas e qualificadas no LSO (SILVA, 2011), são:

- em óptica volumétrica e

- em óptica integrada.

\subsubsection{INTERFERÔMETRO RECUPERADOR EM ÓPTICA VOLUMÉTRICA}

A primeira topologia utilizada como interferômetro recuperador (ou célula recuperadora) foi baseada em um modulador eletro-óptico transversal volumétrico de birrefringência, em conjunto com a célula sensora de alta tensão na topologia transmissiva. A figura 35, a seguir, descreve o esquema do sistema Sensor Eletroóptico em WLI.

Figura 35 - Esquema do sistema Sensor Eletro-óptico em WLI com interferômetro recuperador volumétrico.

CÉLULA SENSORA DE ALTA TENSÃO

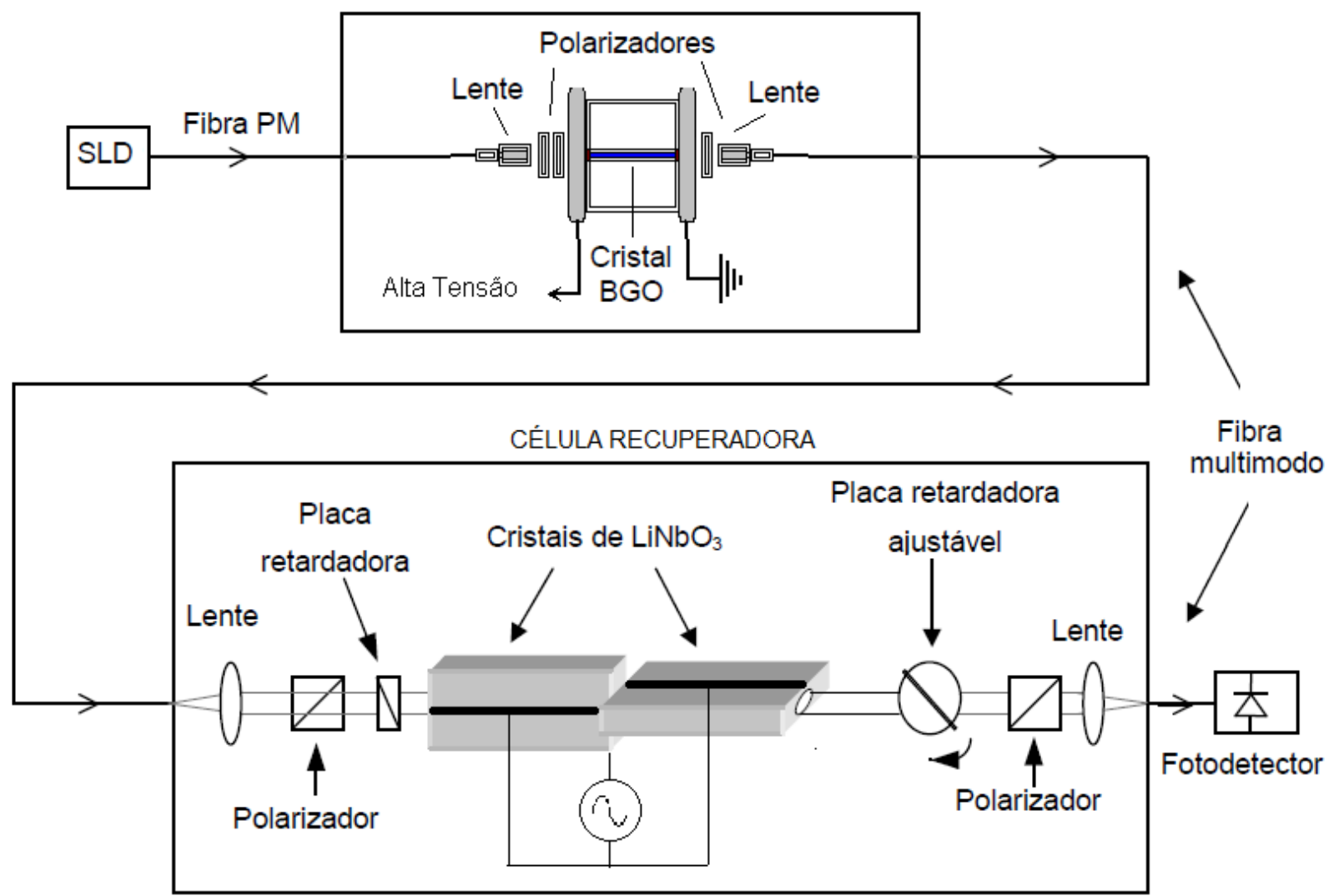

Fonte: Silva (2006) modificada 
Nessa célula recuperadora, volumétrica, utilizou-se uma topologia bi-segmentada cruzada, a partir de dois cristais de $\mathrm{LiNbO}_{3}$, iguais em comprimento, serialmente dispostos com seus eixos orientados transversalmente girados em $90^{\circ}$, visando minimizar ao máximo a birrefringência intrínseca dos mesmos. Utiliza duas placas retardadoras, também de $\mathrm{LiNbO}_{3}$, a primeira responsável pela inserção de um OPD (fixo) próxima àquela inserida pela célula sensora de alta tensão e a segunda, montada em uma base giratória, possibilitando um ajuste fino na recuperação da OPD. Assim, na saída do interferômetro recuperador, a informação da tensão aplicada à célula de alta tensão deixa de estar contida no espectro da luz para estar codificada em sua intensidade.

A figura 36 , a seguir, ilustra a célula recuperadora volumétrica montada no LSO, por Silva (2006).

Figura 36 - Interferômetro recuperador volumétrico construído

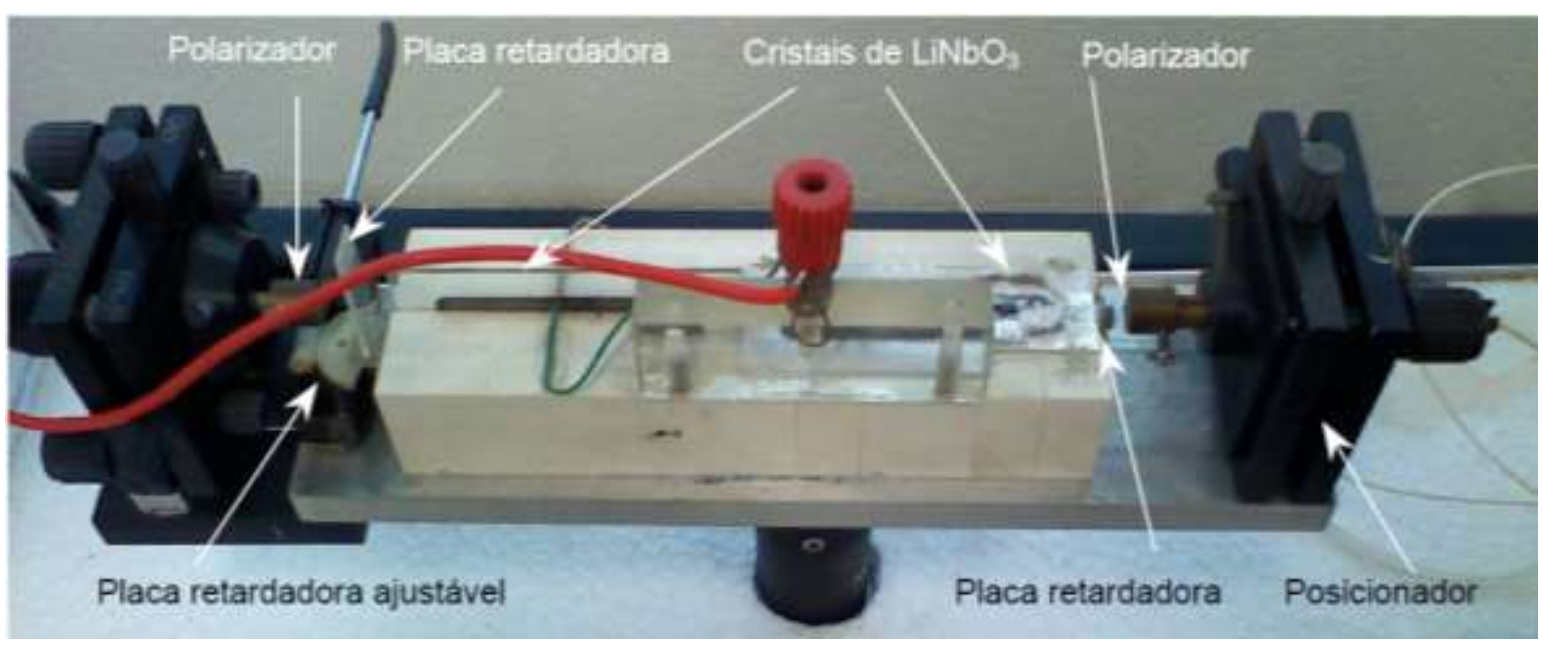

Fonte: Silva (2006)

$O V_{\pi r}$ do sistema recuperador volumétrico pode ser calculado a partir da equação de um modulador eletro-óptico transversal típico dada a seguir [YARIV, 2003]

$$
V_{\pi r}=\frac{\lambda_{0}}{n_{o}^{3} \cdot r_{33-} n_{o}^{3} r_{13}}\left(\frac{d}{L}\right)
$$


onde: $\lambda_{0}=1321 \mathrm{~nm}$ é o comprimento central da fonte de luz, $n_{0}=2,2273$ e $n_{e}=$ 2,1515 são os índices de refração ordinário e extraordinário do cristal de niobato de lítio ( $\mathrm{LiNbO}_{3}$ ), respectivamente, $r_{13}=8,6 \times 10^{-12} \mathrm{~m} / \mathrm{V}$ e $r_{33}=30,8 \times 10^{-12} \mathrm{~m} / \mathrm{V}$ são os coeficientes eletro-ópticos Pockels , $d=1 \mathrm{~mm}$ é a espessura do cristal de e $L=108$ $\mathrm{mm}$ o comprimento dos eletrodos de baixa tensão aplicados sobre os cristais de $\mathrm{LiNbO}_{3}$.

A relação entre as tensões $\bigvee_{\pi s}$ e $V_{\pi r}$ necessárias para gerar um mesmo atraso de fase nas células de alta e de baixa tensão, que pode ser interpretada como uma relação de transformação $\left(\mathrm{K}_{\mathrm{T}}\right)$ própria do TPO, é dada pela tabela 1, a seguir:

Tabela 1 - Dados da relação de transformação $\left(\mathrm{K}_{\mathrm{T}}\right)$ do TPO

\begin{tabular}{|c|c|c|c|}
\hline$\lambda_{0}(\mathrm{~nm})$ & $\mathrm{V}_{\pi \mathrm{r}}(\mathrm{V})$ & $\mathrm{V}_{\pi \mathrm{s}}(\mathrm{kV})$ & $\mathrm{K}_{\mathrm{T}}$ \\
\hline 1321 & 57,7 & 69,4 & 1202,8 \\
\hline 1550 & 67,7 & 81,5 & 1203,8 \\
\hline
\end{tabular}

Fonte: Autor

A partir dos valores apresentados na tabela 1, observa-se que o valor de $\mathrm{K}_{T}$, no caso é de aproximadamente 1200 vezes, mostrando-se praticamente independente do comprimento de onda, conforme esperado.

O interferômetro recuperador volumétrico birrefringente descrito apresentou algumas desvantagens, tais como:

- montagem volumétrica e delicada

- elevada tensão de meia onda ( $V_{\pi}$ em torno de $\left.58 \mathrm{~V}\right)$,

- sensibilidade a vibrações mecânicas,

- baixa imunidade eletromagnética,

- dificuldades de conectorização,

- sensibilidade à variação da temperatura,

- necessidade de um preciso alinhamento axial e angular entre os componentes ópticos. 
As desvantagens sugeriram a necessidade da busca de uma alternativa de implementação de um novo interferômetro recuperador visando a eliminação ou, ao menos, a minimização, das desvantagens verificadas do interferômetro recuperador volumétrico, sendo que, considerou-se que a principal desvantagem a ser reduzida é o elevado valor de $V_{\pi}$ do modulador, uma vez que este parâmetro dificulta a implementação da unidade de processamento eletrônico de sinais, responsável por fornecer a tensão de modulação ao interferômetro recuperador.

Algumas alternativas foram estudadas (SILVA, 2006, 2011) dentre elas citam-se:

- interferômetros birrefringentes utilizando cristais com coeficientes eletroópticos mais elevados;

- interferômetros construídos a partir de fibras eletro-ópticas (com técnicas de poling térmico e poling por ultravioleta) (MORAIS, R.P.S., 2003);

- interferômetros com bobina de fibra óptica enrolada sobre transdutores piezoelétricos cilíndricos [Morais, R.P.S. , 2003] e

- interferômetros baseados em óptica integrada (KITANO, 2001).

- modulador canal birrefringente,

o interferômetro de Mach-Zehnder e

o modulador eletro-óptico em Y.

\subsubsection{INTERFERÔMETRO RECUPERADOR EM ÓPTICA INTEGRADA}

Com base nas alternativas estudadas, a segunda topologia adotada como interferômetro recuperador, foi a de um interferômetro de Michelson com braços desbalanceados, constituído a partir de um modulador eletro-óptico em $\mathrm{Y}$, em óptica integrada (disponível comercialmente) com três acessos, como ilustra a figura 37.

Figura 37 - Representação esquemática do modulador eletro-óptico em Y, em óptica integrada de três acessos.

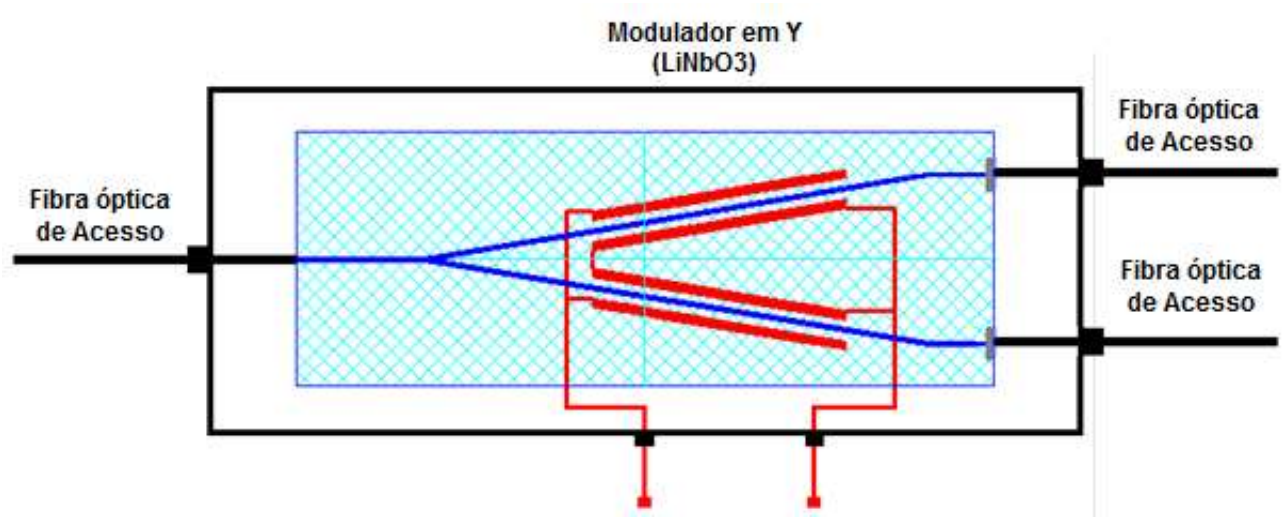

Fonte: Silva (2011) modificada 
Visando à aplicação do interferômetro de Michelson como interferômetro recuperador, aplicado ao TPO, foi necessária a modificação do componente mostrado na figura 37 para a configuração de um interferômetro com braços desbalanceados, sendo que os comprimentos dos braços do modulador (comprimento físico das fibras ópticas de saída) foram ajustados de forma que a diferença de caminho óptico introduzisse a diferença de fase $\Delta \phi$ desejada, ou seja, a mesma introduzida pelo interferômetro sensor de alta tensão.

Após acertar os comprimentos das fibras ópticas de saída do modulador eletroóptico integrado foi feita a metalização das extremidades de suas fibras de saída do Y. A figura 38, a seguir, ilustra o esquema do modulador eletro-óptico indicando uma diferença entre os comprimentos de seus braços de $\Delta L$. Em seguida, essas fibras ópticas foram metalizadas utilizando solução de prata, com o objetivo de maximizar a visibilidade do modulador eletro-óptico, em óptica integrada, como um interferômetro de Michelson desbalanceado.

Figura 38 - Representação esquemática do modulador eletro-óptico ilustrando as fibras de saída com seus comprimentos ajustados para uma diferença de caminho óptico $\Delta L$.

Modulador em $Y$ (LiNbO3)

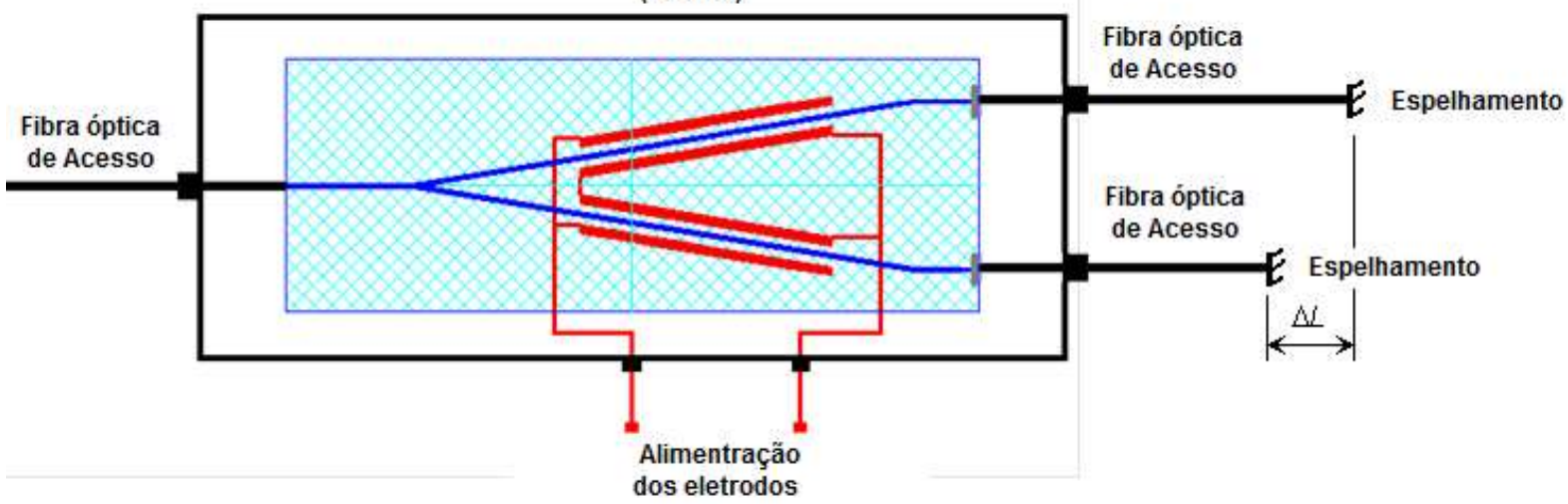

Fonte: Silva (2011) modificada

Para a implementação do interferômetro recuperador para compor o protótipo do TPO, o dispositivo modulador eletro-óptico comercial escolhido por Silva (2011) foi o chip óptico integrado multifuncional (IOC - LiNbO3 multi-function integrated optical chip), modelo PMD1333-I, fabricado pela empresa Beijing SWT Optical Communication Technology Co. Ltd., mostrado nas figuras 39a e 39b. 
Figura 39 - a) Chip óptico integrado multifuncional (IOC - LiNbO3 multi-function integrated optical chip), modelo PMD1333-I b) Aspecto final do modulador Y em óptica integrada. Em primeiro plano estão as fibras ópticas de acesso de saída do modulador após a metalização com Prata

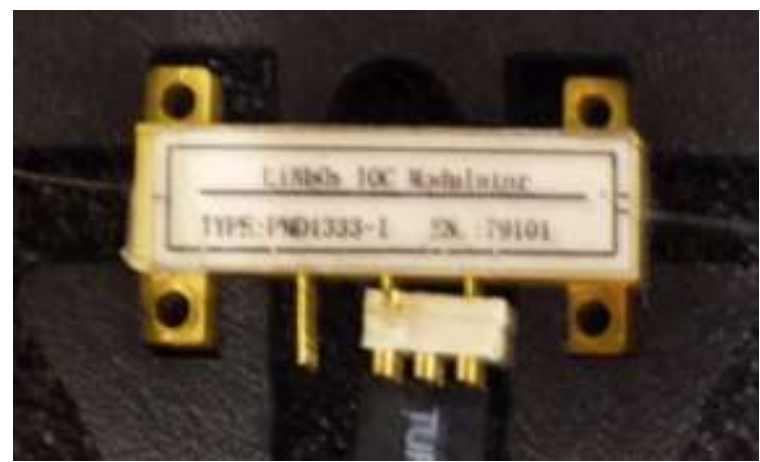

(a)

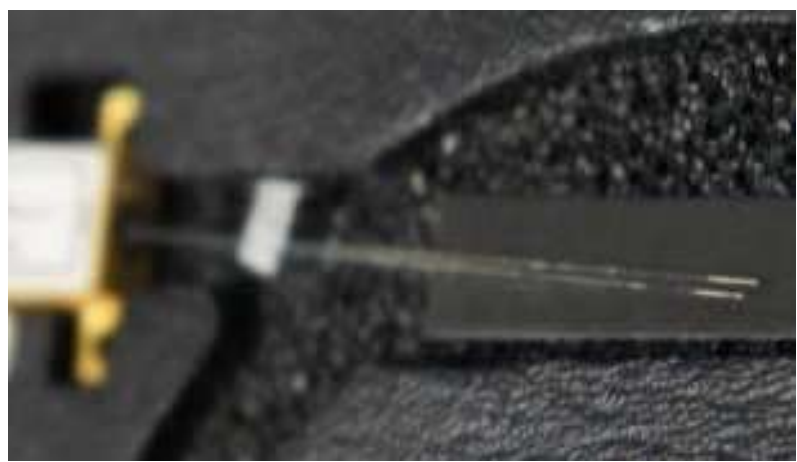

(b)

Fonte: Fonte: Silva (2011) modificada

Este dispositivo é um modulador de fase eletro-óptico construído com guias de onda em $\mathrm{LiNbO}_{3}$ e eletrodos metálicos depositados na superfície do substrato, nas laterais dos guias de onda conectados eletricamente em configuração push-pull. As fibras ópticas de acesso de saída, do modulador, polidas e espelhadas com solução de prata são mostradas na figura 39b.

Optou-se por este componente, comercialmente disponível, devido a várias características, destacando-se as pequenas dimensões, baixo valor de tensão de meia onda $(V \pi \cong 4,5 V @ 1550$ nm - cerca de quinze vezes menor que a versão anterior), facilidade de integração com o sistema óptico, facilidade de conectorização e o custo relativamente baixo.

Como citado, anteriormente, para recuperar o sinal interferométrico, pela técnica WLI, o atraso de fase fixo inserido pelo interferômetro recuperador deve ser igual ao introduzida no interferômetro sensor, $\Delta \phi$, devido à lâmina de retardo, dado por:

$$
\Delta \phi=\frac{2 \pi}{\lambda_{S L D}}\left|n_{e}-n_{o}\right| L
$$


onde: $\lambda$ SLD é o comprimento de onda central da fonte luminosa (1550nm), $n_{e}-n_{o}$ é a birrefringência do $\mathrm{LiNbO}_{3}(2,286-2,200=0,086)$ e $L$ é a espessura da lâmina de $\mathrm{LiNbO}_{3}$ (igual a $1 \mathrm{~mm}$ ).

Nessas condições, aplicando-se a eq.(85), obtém-se 0 atraso de fase do interferômetro sensor (célula de alta tensão), $\Delta \phi=110,25 \pi$ rad.

Para que o interferômetro recuperador introduza o mesmo atraso de fase verificado no interferômetro sensor, definida como $\Delta \phi$, calculado anteriormente, a diferença de caminho óptico $\Delta L^{\prime}$ introduzida é dada por (SANTOS, 1996):

$$
\Delta L^{\prime}=\frac{\lambda}{2 \pi}\left(\frac{\Delta \phi}{n_{0}}\right)
$$

sendo $n_{0}$ o índice de refração efetivo da fibra óptica do pigtail do modulador PMD1333-I (no valor de 1,4452) e $\lambda$ o comprimento de onda central da luz (1550 $n m)$. Aplicando a eq.(86) calculou-se um valor de: $\Delta L^{\prime}=59,12 \mu \mathrm{m}$.

A luz que transita pelos braços do modulador, em $Y$, desbalanceado, mostrado na figura 38, devido à reflexão nas extremidades das fibras ópticas, acumula uma diferença de caminho óptico de $2 \Delta L$. Assim, para que o valor da OPD seja o mesmo introduzido pela célula sensora de alta tensão, o valor da diferença de comprimentos dos pigtails espelhados deve ser: $\Delta L=\Delta L^{\prime} / 2=29,56 \mu \mathrm{m}$.

A figura 40 ilustra o esquema do protótipo de TPO desenvolvido no trabalho de Silva (2011) utilizando o interferômetro recuperador com modulador eletro-óptico em óptica integrada em $\mathrm{Y}$ conectado em série com um interferômetro sensor transmissivo (single pass). 
Figura 40 - Esquema do TPO proposto por Silva (2011), que utiliza interferômetro recuperador em óptica integrada reflexivo e interferômetro sensor transmissivo (single pass).

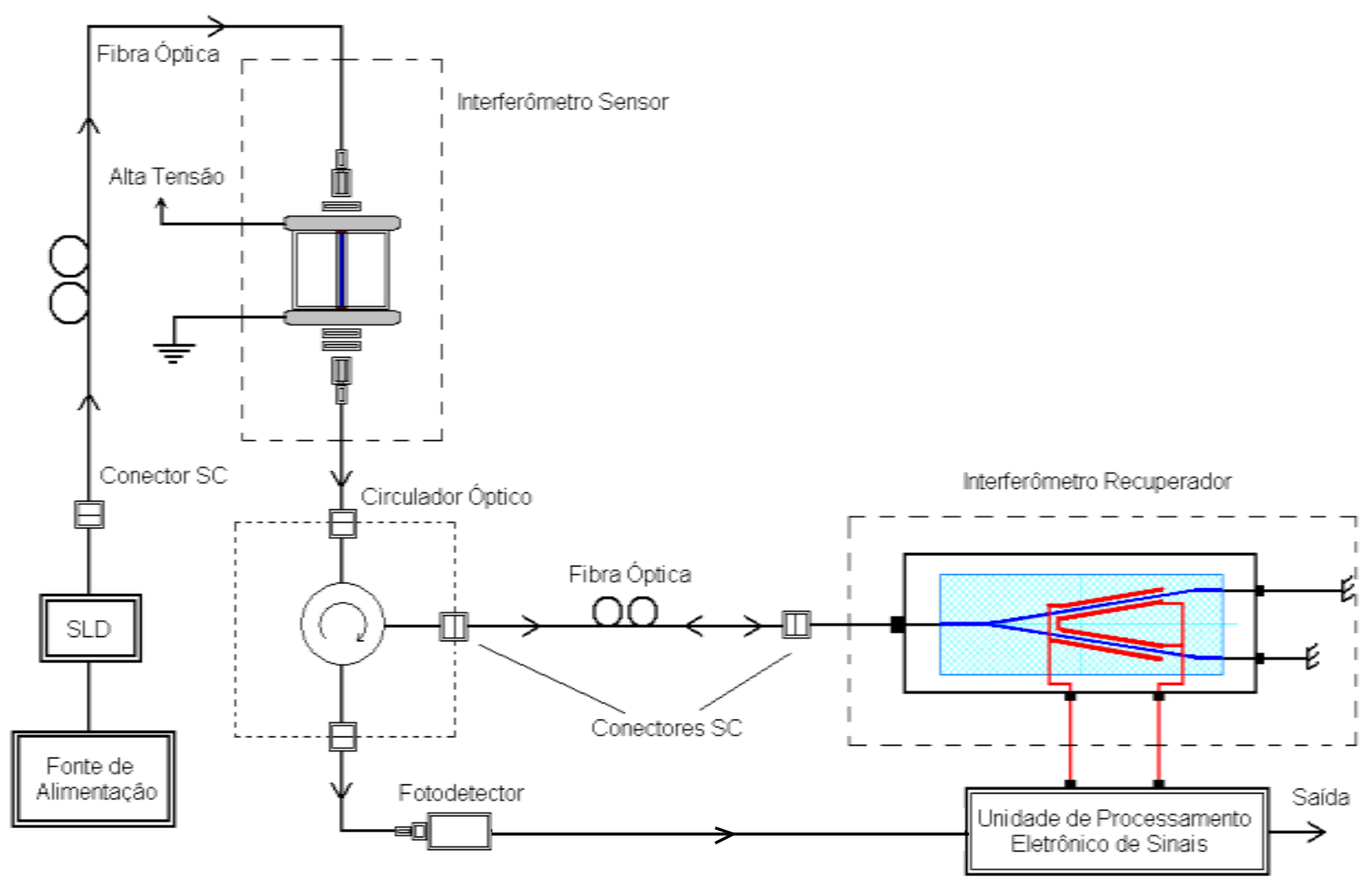

Fonte: Fonte: Silva (2011) modificada

Visando aproveitar os resultados do trabalho de Silva (2011) e avançar em direção ao objetivo deste trabalho, uma nova proposta de arranjo equivalente ao da figura 40, porém utilizando um interferômetro sensor reflexivo, pode ser vista na figura 41 , a seguir. 
Figura 41 - Esquema do TPO proposto neste trabalho, que utiliza interferômetro recuperador em óptica integrada reflexivo e interferômetro sensor reflexivo (double pass).

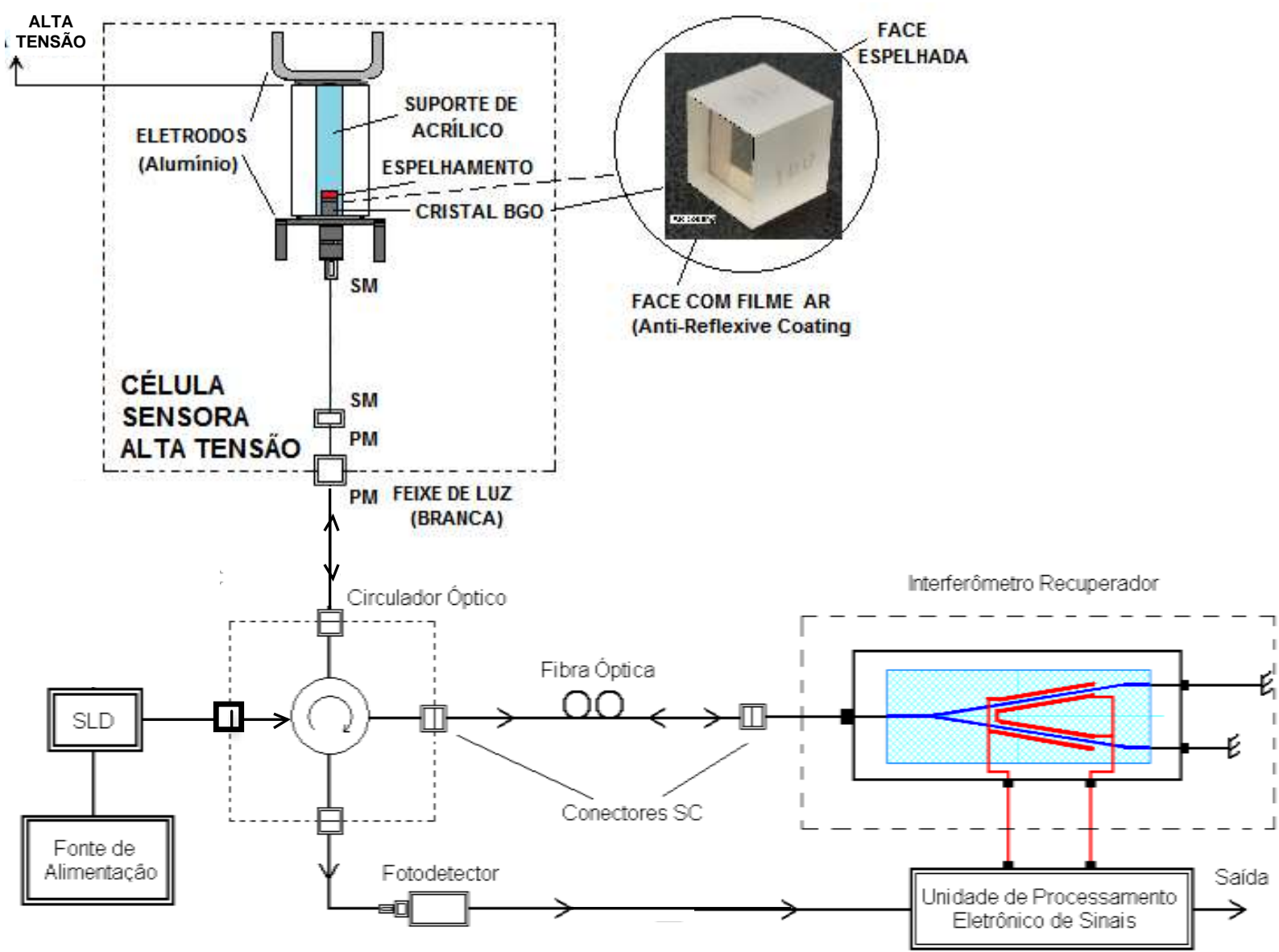

Fonte: Fonte: Silva (2011) modificada

No arranjo proposto, ilustrado na figura 41 , nota-se a necessidade do uso de um circulador de quatro acessos, uma vez que ambos os interferômetros são reflexivos.

Apesar de atraente, a proposta citada não foi implementada devido a problemas encontrados no protótipo de Silva (2011) que ainda não haviam sido superados. O mais severo deles diz respeito à deriva térmica do interferômetro recuperador, causada em grande parte pelas variações de comprimento dos pigtails espelhados devido à dilatação térmica. Tais variações são proporcionais a esses comprimentos e poderiam ser reduzidas caso fosse possível fazer os pigtails mais curtos. Como os processos mecânicos utilizados para cortar e polir os pigtails exigiam que os mesmos ficassem com comprimentos mínimos em torno de cinco centímetros a sensibilidade de $\Delta L$ à variação de temperatura ficou relativamente elevada. Outro problema importante refere-se ao fato do componente, devido à sua técnica de fabricação, comportar-se inerentemente como um polarizador e o fabricante não 
fornecê-lo com pigtails em fibras PM. Isto acabou dificultando sobremaneira a montagem do protótipo de Silva (2011) por facilitar o surgimento do fenômeno de desvanecimento por deriva de alinhamento de polarização.

Os problemas apontados desestimularam o emprego da configuração acima descrita. Entretanto, a busca de novos moduladores em óptica integrada, objetivando-se a aplicação como interferômetro recuperador em TPO, teve continuidade frente à evolução e disponibilidade de novos componentes no mercado. Além disso, buscou-se uma nova topologia que utilizasse nos enlaces fibras ópticas do tipo PM diminuindo consideravelmente a deriva de polarização. Esta busca culminou na nova proposta, apresentada a seguir.

\subsection{NOVA TOPOLOGIA DE TPO COM INTERFERÔMETRO SENSOR REFLEXIVO (DOUBLE PASS) E INTERFERÔMETRO RECUPERADOR EM ÓPTICA INTEGRADA TRANSMISSIVO (SINGLE PASS)}

O protótipo recentemente desenvolvido de TPO objetiva o uso de um novo interferômetro sensor, alvo deste trabalho, baseado na topologia reflexiva descrita no item $D$ da seção 3.1.2. Buscando melhorar a performance deste protótipo em relação a desenvolvimentos anteriores, atentou-se para a necessidade de trabalhar não só no estudo e projeto do interferômetro sensor, mas do TPO como um todo.

O TPO baseado na técnica WLI é um sistema sensor composto por vários elementos (fonte de luz, interferômetros sensor e recuperador e unidade de processamento de sinais) interligados em série por vários trechos de um enlace a fibras ópticas, o qual pode ser classificado como um sistema baseado em Interferometria de Baixa Coerência a Fibras Ópticas (FOLCl - do inglês "Fiber Optic Low Coherence Interferometry"). Neste tipo de sistema a performance global depende de todos os elementos, incluindo os componentes do enlace.

Desta forma, além do desenvolvimento do interferômetro sensor, decidiu-se realizar o desenvolvimento e a implementação de uma nova versão de interferômetro recuperador, em óptica integrada ambos aliados de forma integrada ao reprojeto do 
enlace de comunicação. Tal processo culminou com a topologia totalmente original descrita a seguir.

Os critérios adotados como prioritários para balizar as escolhas das novas soluções a serem adotadas no desenvolvimento do TPO foram:

- adoção da topologia reflexiva no interferômetro sensor;

- redução das sensibilidades mecânica e térmica dos trechos do enlace de comunicação a fibra óptica;

- simplificação das montagens;

- redução do número de componentes no interferômetro sensor;

- redução da tensão de meia onda do interferômetro recuperador $\left(\mathrm{V}_{\pi \mathrm{r}}\right)$;

Como, em decorrência do atendimento ao primeiro critério de projeto, adotou-se a topologia reflexiva para o interferômetro sensor, o trecho de enlace de comunicação a ele ligado resumiu-se a uma fibra óptica.

A próxima decisão tomada no desenvolvimento TPO, em atendimento ao segundo critério de projeto, foi a definição do uso de uma fibra óptica do tipo PM neste trecho do enlace. A escolha deveu-se ao fato de que, sendo a luz comunicada em ambos os sentidos nesse trecho ser linearmente polarizada, o uso de fibras PM evitaria o efeito de desvanecimento por deriva de orientação de polarização.

Procurando atender o terceiro critério de projeto, simplificando a montagem do interferômetro sensor, sugeriu-se aproveitar a característica da fibra PM de entregar luz linearmente polarizada com direção de plano de polarização definida e constante, para permitir a remoção do polarizador previsto na entrada no interferômetro sensor. Para isso, seria necessário colocar um polarizador na saída da fonte de luz (SLD).

Buscando evitar o acréscimo de mais um componente no TPO considerou-se a possibilidade de inverter a ordem dos interferômetros no sistema, dado que já existe a previsão de um polarizador na saída do interferômetro recuperador, sendo a luz em sua saída, portanto, linearmente polarizada. Tal inversão de ordem é possível, pois nos sistemas que empregam a técnica WLI com interferômetros constituídos por 
moduladores eletro-ópticos em série, o sinal resultante na saída do sistema independe do sentido em que o sinal óptico trafega (Santos, 2011).

Tal inversão seria facilmente obtida no arranjo mostrado na figura 41, bastando inverter entre si os acessos do circulador aos quais os interefrômetros estão ligados. O problema, neste caso, seria a necessidade de instalar um novo polarizador na entrada do fotodetetor, tornando inútil a estratégia.

Neste ponto, considerando que o interferômetro recuperador na topologia reflexiva apresentara problemas ainda não resolvidos e que o arranjo da figura 41 exigia um circulador de 4 acessos (mais caro que um de 3 acessos - Anexo 3), levantou-se a hipótese do uso de um recuperador na topologia transmissiva, semelhante ao arranjo mostrado na figura 29, porém modificado, de forma que o circulador tivesse seu primeiro acesso conectado diretamente à fonte de luz, seu segundo acesso ligado ao interferômetro recuperador e seu terceiro acesso ligado ao fotodetetor, como mostrado na figura 42 , a seguir.

Figura 42 - Esquema de arranjo de TPO com circulador ligado ao SLD.

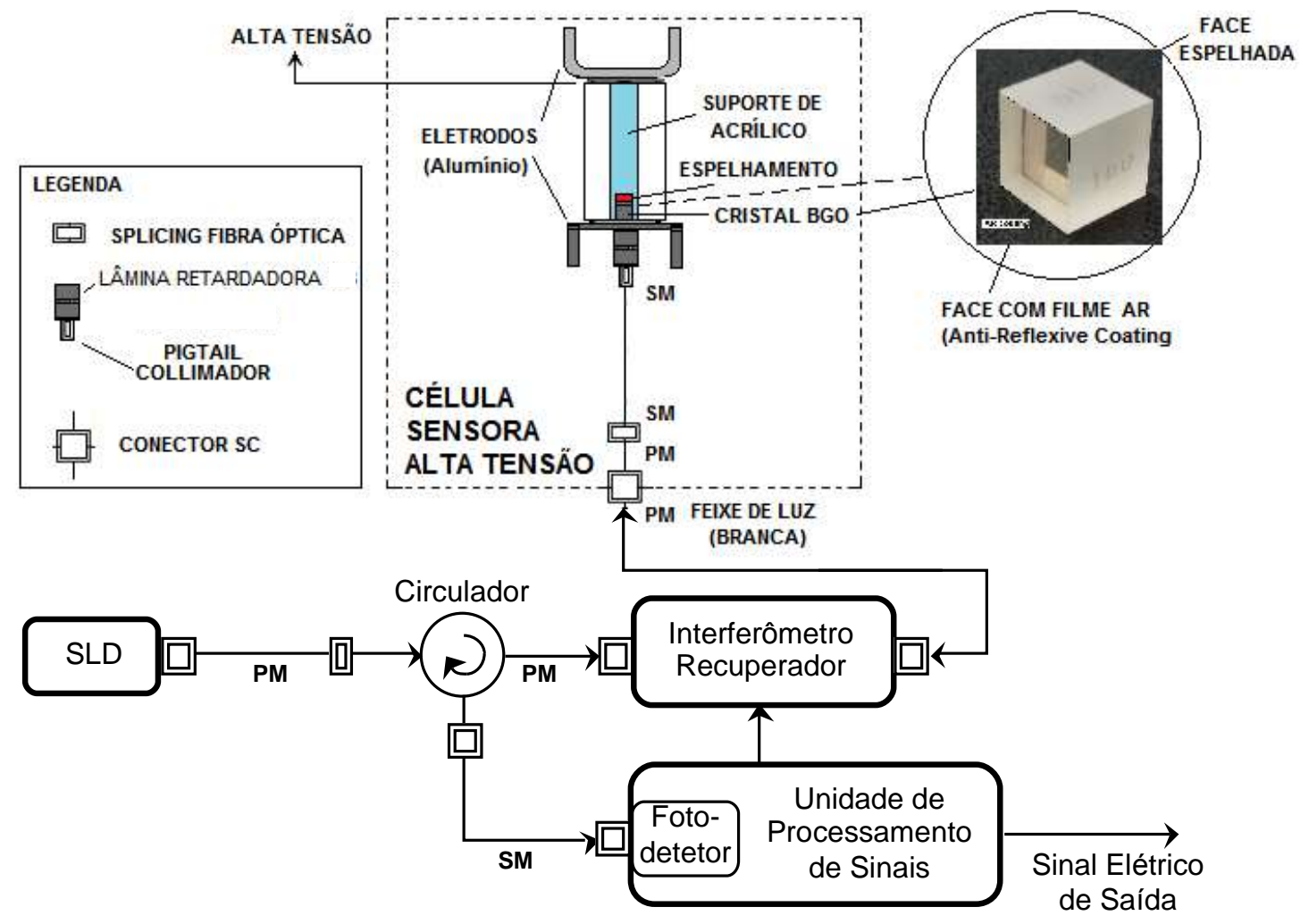

Fonte: Autor 
No arranjo da figura 42, observa-se que a remoção do polarizador no interferômetro sensor não ocasiona problemas no sinal óptico que transita em direção a ele. Porém, como a luz é inserida com sua direção de plano de polarização orientada a $45^{\circ}$ dos eixos do cristal, aparecem duas componentes de polarização ortogonais propagando-se por ele. Ao serem refletidas na face espelhada e retornarem, ambas as componentes são acopladas na fibra óptica PM do enlace. As duas componentes sofrerão atrasos de fase acumulados diferentes ao longo da fibra PM, pois a mesma é birrefringente, gerando uma OPD elevada entre elas. O efeito desta OPD é descorrelacionar as componentes, de forma semelhante à função desempenhada pelas lâminas retardadoras existentes nos interferômetros sensor e recuperador.

Considerou-se, então, a idéia de aproveitar este efeito e utilizar a própria fibra PM do trecho de enlace como lâmina de retardo, eliminando assim também a lâmina retardadora do elemento sensor. Foram imaginadas algumas estratégias para realizar este propósito, porém a que pareceu mais adequada foi a de usar a fibra óptica PM ao mesmo tempo como lâmina descorrelacionadora das componentes de polarização no sentido de propagação da luz do interferômetro recuperador para o sensor e como lâmina recorrelacionadora no sentido inverso. Para que isso ocorra é necessário que se retire o polarizador da saída do interferômetro recuperador se promova um alinhamento de orientação de planos de polarização de forma que cada uma das componentes de polarização da luz viaje paralelamente a um dos eixos (rápido ou lento) da fibra óptica PM.

Além disso, deve-se fazer com que a componente que viajou paralelamente ao eixo rápido num sentido de propagação seja levada a viajar paralelamente ao eixo lento da mesma fibra no outro sentido, e vice-versa. Para realizar esta troca de eixos de polarização a solução natural é o emprego de um rotator Faraday. Colocando um componente deste tipo com ângulo de rotação de $45^{\circ}$ em série com o trecho de enlace na entrada no interferômetro sensor as componentes de polarização são giradas, expandidas, colimadas, propagadas pelo cristal eletro-óptico, refletidas pela face espelhada, novamente propagadas pelo cristal, focalizadas e novamente giradas de $45^{\circ}$ ao passar novamente pelo rotator. Ao final deste processo, as componentes de polarização giraram seus planos de polarização de $90^{\circ}$, trocando de posição. Ao serem acopladas na fibra óptica PM do enlace e por ele se 
propagarem de volta ao interferômetro recuperador sofrerão atrasos de fase contrários aos experimentados no sentido de propagação de ida para o sensor e serão, portanto, recorrelacionadas.

Um problema que surge com esta abordagem é que as componentes de polarização com suas orientações invertidas são levadas a atravessar o modulador eletro-óptico do interferômetro sensor. Neste caso, o atraso de fase inserido pelo modulador entre as componentes num sentido propagação da luz seria retirado no outro sentido, o que impediria uso da técnica de modulaçãoo/demodulação síncrona. Para evitar este problema é necessário girar $90^{\circ}$ novamente as direções dos planos de polarização das componentes para que as mesmas ingressem na volta ao modulador do interferômetro recuperador com as mesmas orientações em que passaram por ele na ida. Isto é obtido pela inserção de um segundo rotator Faraday de $45^{\circ}$ na saída do interferômetro recuperador.

Com a inclusão de todas as modificações citadas, o esquema completo do protótipo proposto e desenvolvido neste trabalho é ilustrado na figura 43 , a seguir.

Figura 43 - Esquema do novo sistema proposto para desenvolvimento do protótipo de TPO neste trabalho.

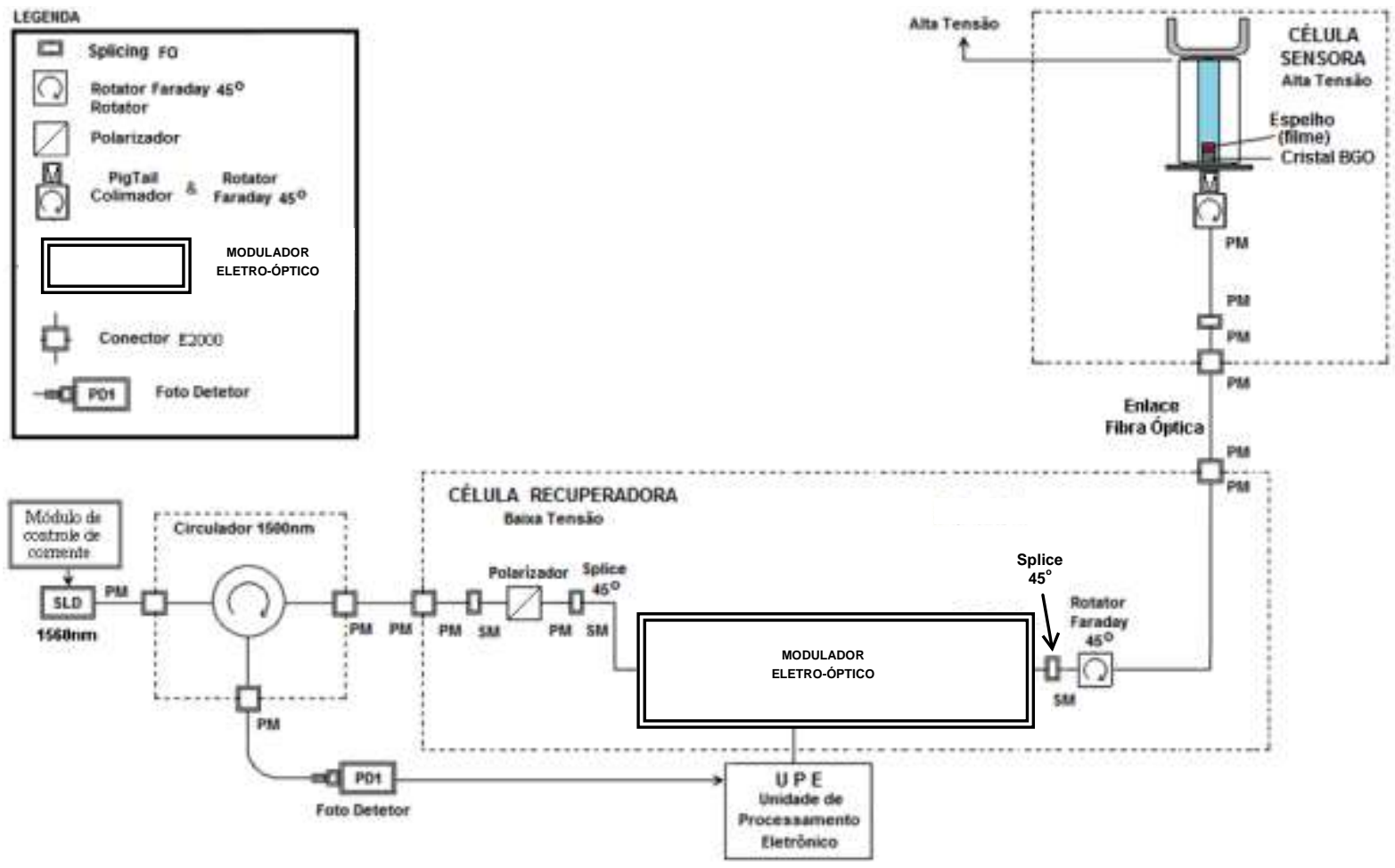

Fonte: Autor 
A estratégia descrita atende bem ao terceiro e ao quarto critérios de projeto, pois permite simplificações do sensor e do recuperador, uma vez que em ambos são removidos os polarizadores e as lâminas retardadoras, simplificando as montagens e reduzindo o número de componentes no interferômetro sensor.

Adicionalmente, atende-se também o quinto ao critério de projeto, pois ao fazer a luz atravessar duas vezes o interferômetro recuperador dobra-se o efeito de sua modulação, o que, na prática, equivale a reduzir pela metade o valor da tensão aplicada necessária para obter um atraso de fase desejado, reduzindo com isso a tensão de meia onda do interferômetro recuperador $\left(\mathrm{V}_{\pi \mathrm{r}}\right)$ à metade.

Como parte do trabalho de desenvolvimento do protótipo de TPO proposto, buscouse no mercado um componente, em óptica integrada, adequado para ser usado como modulador eletro-óptico na célula recuperadora. $\mathrm{O}$ componente mais adequado encontrado foi um Controlador de Polarização eletro-óptico, fornecido pelo fabricante EOspace [EOSPACE, 2011], cuja foto é mostrada na figura 44. Tal componente é construído em $\mathrm{LiNbO}_{3}$, (com corte segundo o eixo $\mathrm{x}$ ), com propagação da luz ao longo do eixo $z$, ele conta com um número de estágios que pode variar de 3 a 8 e é terminado com pigtails de FO monomodo. As características deste componente estão descritas no Anexo 4.

Figura 44 - Controlador de polarização multiestágio.

\section{- EOSPACE Polarization Controller}

Fonte: EOSpace (2011)

O controlador de polarização adquirido foi especificado para ter 3 estágios e operar no comprimento de onda de $1550 \mathrm{~nm}$. Através da aplicação de tensões adequadas nos terminais ( $\mathrm{Va}, \mathrm{Vb}$ e $\mathrm{Vc}$ ) de cada estágio (eq.(87, 88 e 89), o componente transforma uma polarização arbitrária da luz em sua entrada em uma determinada polarização da luz em sua saída, como ilustrado nas figuras 45a e 45b. 
Figura 45 - Controlador de polarização EOSPACE: a) configuração de guia de onda tipo canal com eletrodos, de um estágio e b) configuração da disposição dos 3 estágios internos.

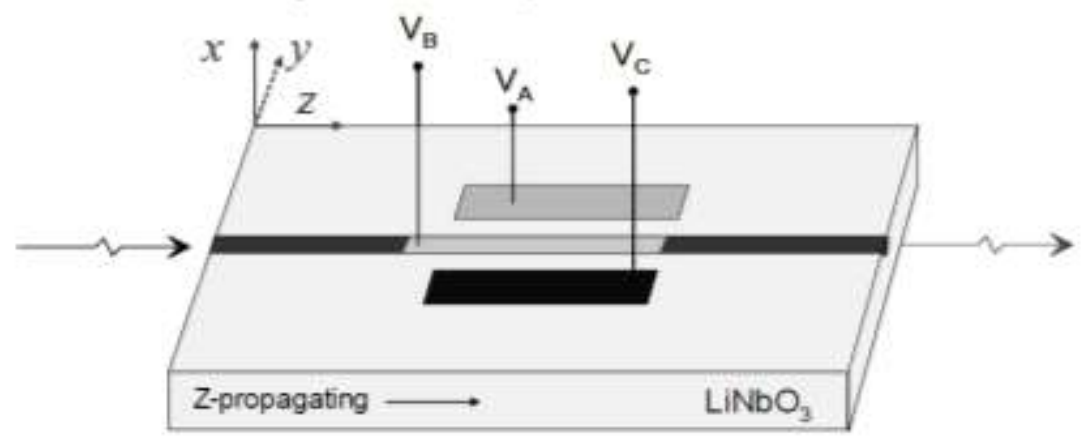

(a)

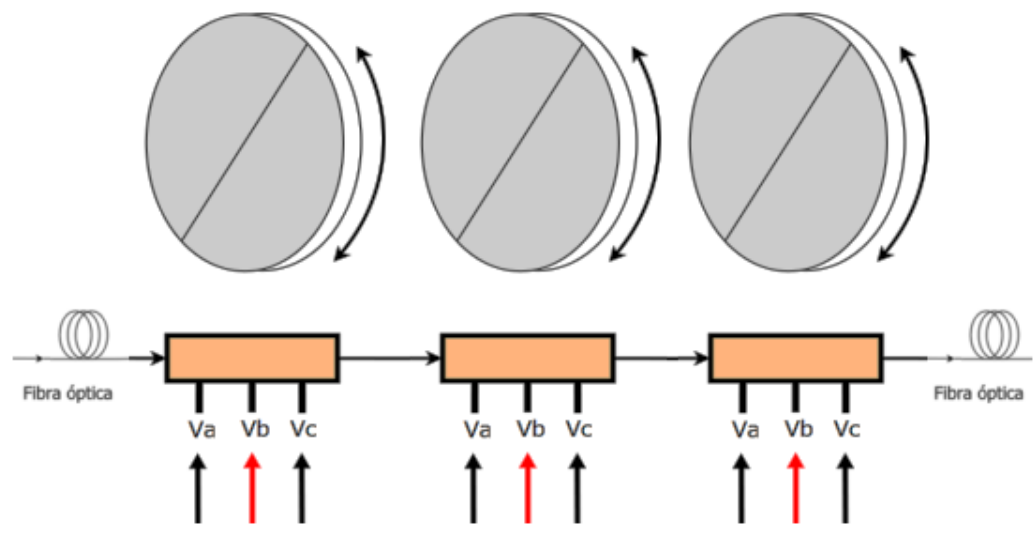

(b)

Fonte: EOSpace (2011)

Existe uma restrição para o máximo valor das tensões a que podem ser submetidos aos estágios do controlador de polarização, sendo que no caso do componente fabricado pela EOSPACE o valor máximo especificado é de $30 \mathrm{~V}$. Cada estágio pode se comportar como uma lâmina de retardo ajustável, de acordo com as tensões aplicadas em seus terminais. Entre as técnicas de controle possíveis para este dispositivo podemos, por exemplo, utilizar um único estágio do dispositivo para operar como um retardador de $\delta$ comprimentos de onda e com ângulo de orientação $\alpha / 2$, sendo que as tensões de operação necessárias são (EOSPACE, 2011):

$$
\begin{aligned}
& V_{A}=2 \cdot V_{0} \cdot \delta \cdot \sin (\alpha)-V_{\pi} \cdot \delta \cdot \cos (\alpha)+V_{A, B I A S} \\
& V_{B}=0 V \\
& V_{C}=2 \cdot V_{0} \cdot \delta \cdot \sin (\alpha)-V_{\pi} \cdot \delta \cdot \cos (\alpha)+V_{C, B I A S}
\end{aligned}
$$


onde: $V_{\pi}$ é a tensão necessária para induzir um desvio de fase de $180^{\circ} \mathrm{s}$ entre os modos TE e TM de um único estágio, $V_{0}$ é a tensão necessária para acoplar toda a energia do TE para o modo de TM, ou vice-versa, de um único estágio, $\mathrm{V}_{\mathrm{A}, \mathrm{BIAS}} \mathrm{e}$ $\mathrm{V}_{\mathrm{C}, \mathrm{BIAS}}$, são as tensões requeridas para ser aplicada aos eletrodos $\mathrm{A}$ e $\mathrm{C}$, respectivamente, a fim de levar a zero a birrefringência entre modos TE e TM. Normalmente, $V_{A, \text { Bias }} \cong-V_{C, \text { Bias, }} \delta$ é o retardo desejado (em comprimentos de onda). Por exemplo, para gerar uma lâmina de $1 / 8$ de onda, definem-se os seguintes parâmetros: $\delta=1 / 8 \mathrm{e} \alpha / 2$ é o ângulo de orientação da lâmina de onda desejado.

A figura 46, a seguir, mostra a foto do primeiro protótipo da nova célula sensora de alta tensão, construído segundo o arranjo proposto na figura 43.

Figura 46 - Foto do arranjo óptico da nova célula sensora de alta tensão com a indicação dos elementos que o compõem.

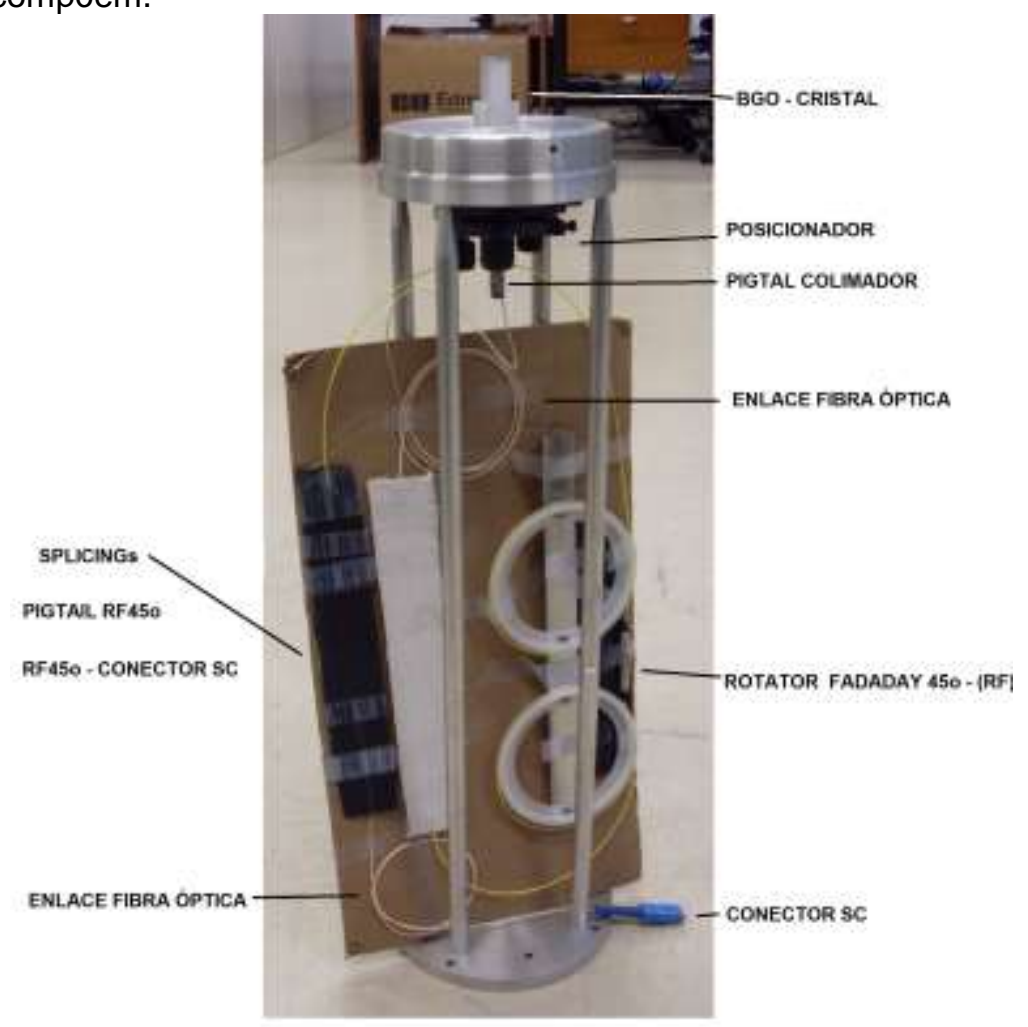

Fonte: Autor

$\mathrm{Na}$ montagem retratada na figura 46, utilizou-se como rotator Faraday um componente discreto, com dois pigtails a fibra monomodo, ao qual foram emendados um pigtail terminado em conector padrão SC e um pigtail colimador, ambos com fibras SM. 
É importante ressaltar que o fato do rotator Faraday não possuir fibras PM em seus acessos, assim como os pigtails colimador e conectorizado serem construídos com fibras SM, implicam que esse enlace irá inserir uma deriva de polarização devido ao mesmo não manter a polarização prejudicando fortemente o sinal de luz de saída da célula sensora e que é inserido posteriormente na célula recuperadora.

Note-se que o trecho de fibra que liga o conector ao rotator Faraday poderia ser PM, mas isso exigiria que o componente tivesse seu pigtail com esse tipo de fibra fornecido pelo fabricante. Já o trecho que liga o rotator ao colimador não poderia ser PM, uma vez que atraso de fase introduzido por este trecho não seria compensado na volta do feixe de luz, mas sim dobrado.

Para contornar o problema de deriva de polarização foram verificadas duas possíveis soluções, levando-se em conta as condições de disponibilidade e ou compra de novos componentes e da adaptação com a estrutura disponível para montagem.

A primeira "solução seria diminuir, ao mínimo possível, o tamanho dos braços" (trechos), de fibra SM do rotator Faraday diminuindo o efeito de deriva. Contudo, essa solução demandaria cortar os pigtails tanto do rotator Faraday como do pigtail conectorizado com SC e previu-se uma grande dificuldade do decepamento, clivagem e manuseio na execução das emendas ("splicings"), pois o equipamento de emendas GPX-3400 possui uma limitação do tamanho mínimo para que as fibras possam ser fixadas ao suporte de posicionamento ("fiber holder") de fibras da máquina. Esta solução não seria completa, apenas minimizaria o efeito indesejado.

A segunda solução seria a inversão da ordem dos componentes no interferômetro sensor, com a inserção de um colimador com pigtail PM antes do rotator Faraday. Neste caso o rotator deveria ser volumétrico e agiria sobre o feixe expandido, o que eliminaria todos os problemas de deriva de polarização.

$\mathrm{Na}$ prática, a implementação desta solução poderia ser feita acoplando-se mecanicamente dois componentes distintos: um colimador com pigtail PM e um rotator Faraday volumétrico. No entanto, durante a busca por componentes 
comerciais desses tipos surgiu a idéia de se fazer a aquisição e adaptação de um componente chamado Faraday mirror, que é composto por um expansor de feixe, um rotator Faraday de $45^{\circ}$ e um espelho, montados num único invólucro, como mostrado na figura 47a. A adaptação consistiria na retirada do espelho e na modificação da distância de trabalho (working distance) da lente focalizadora para projetar a cintura do feixe para um ponto que coincidisse com a face espelhada da cristal EO, como mostrado na figura 48a.

Tal implementação somente poderia ser feita pelo fabricante do componente. Foi então realizada uma consulta ao fabricante OZoptics, cuja foto do produto é mostrada na figura 47b, que se prontificou a fazer o desenvolvimento e fornecimento de um dispositivo modificado de acordo com a necessidade do projeto (sem espelhamento, com o invólucro aberto e com a característica de "work distance" adequada) a um custo muito atrativo, viabilizando a aquisição do mesmo.

A figura 48b mostra uma foto do novo componente desenvolvido neste trabalho, 0 qual foi chamado de colimador Faraday (Faraday collimator) fornecido pela OZoptics sob encomenda para este trabalho

Figura 47 - a) Desenho ilustrativo de um Faraday Mirror, b) Foto do componente da OZoptics.

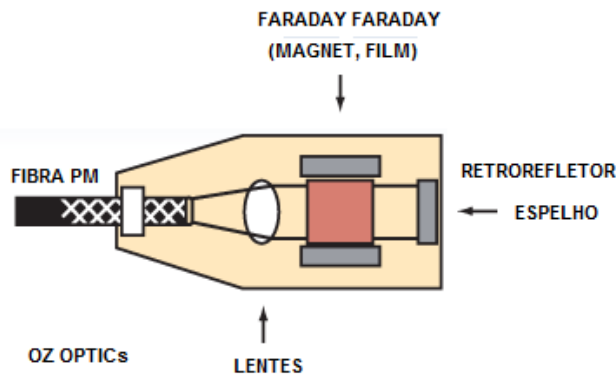

(a)

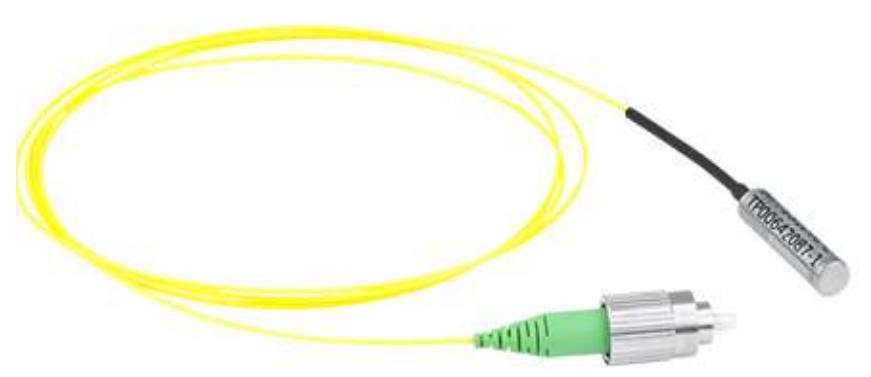

(b)

Fonte: OZoptics. 
Figura 48 - a) Desenho do rotator Faraday $45^{\circ}$ da OZoptics com o elemento refletor retirado e com distância de trabalho modificada e b) Foto do colimador Faraday adquirido da OZoptics.

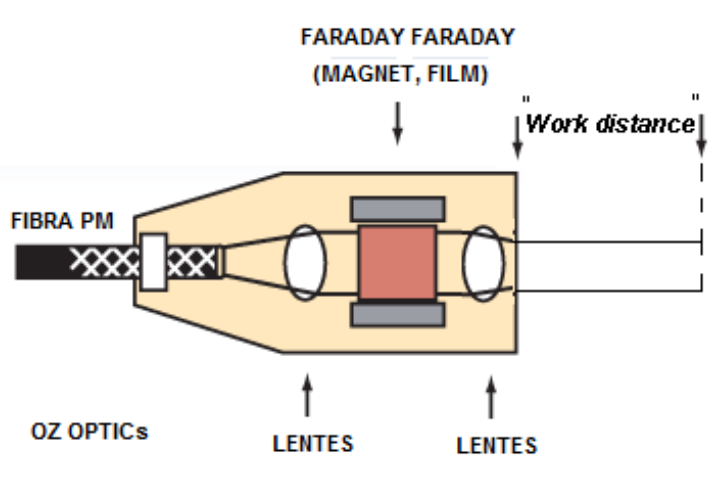

(a)

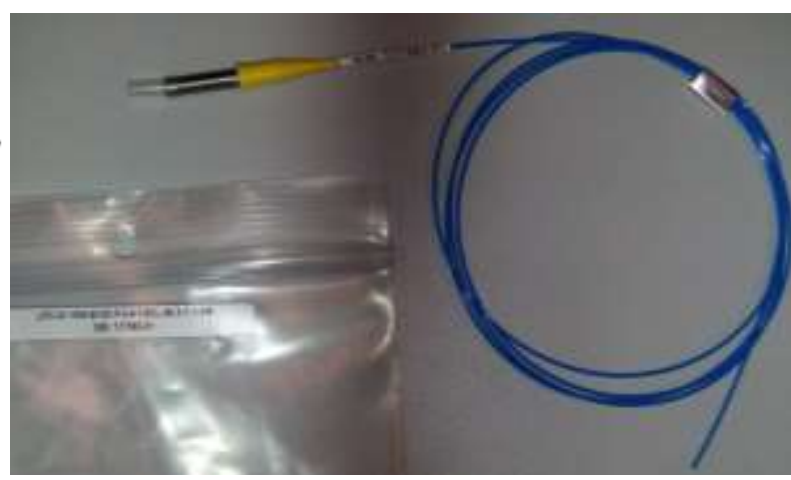

(b)

Fonte: Autor

A foto da figura 49a, a seguir, ilustra a nova célula sensora montada (ainda sem o tarugo de acrílico de acondicionamento) com Rotator Faraday e colimador separados ao lado da célula anterior (com topologia single pass). Já a figura 49b mostra a nova célula sensora completamente montada utilizando o colimador Faraday.

Figura 49 - a) Nova célula sensora de alta tensão montada com componentes ópticos discretos (rotator Faraday e pigtail colimador) e b) nova célula sensora de alta tensão montada já com o novo componente óptico desenvolvido (colimador Faraday).

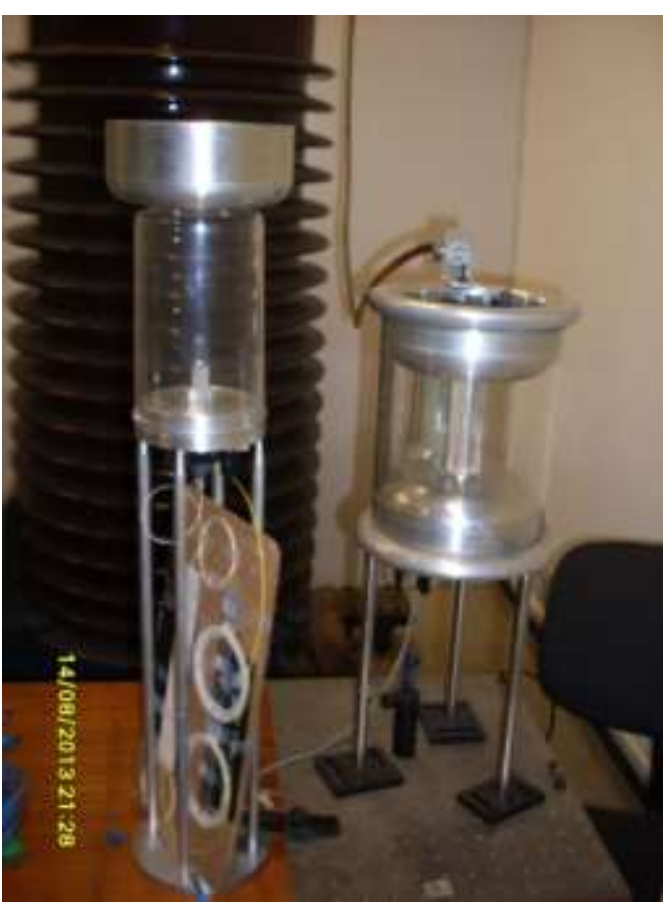

(a)

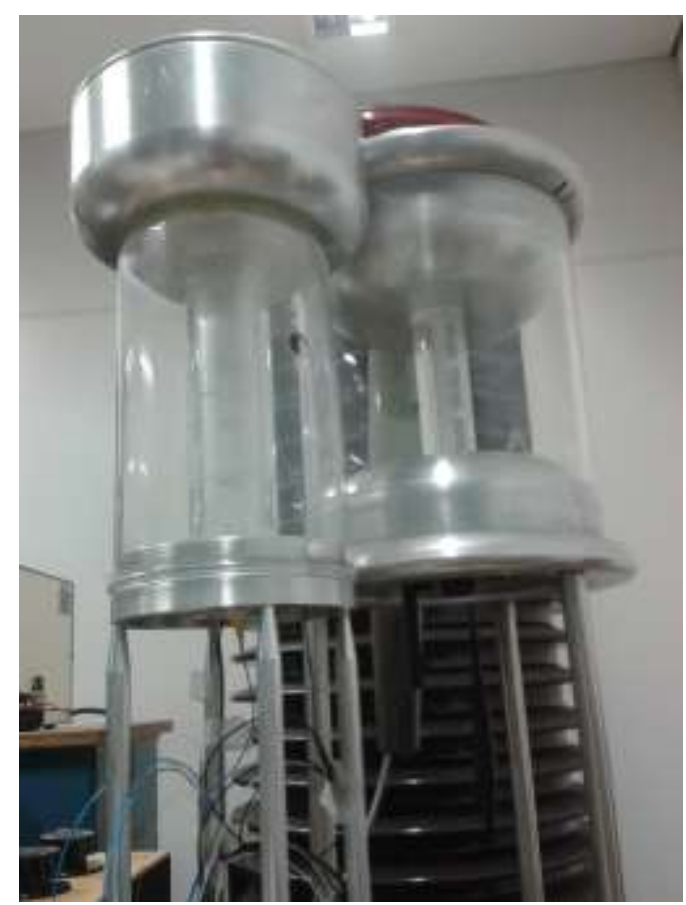

(b)

Fonte: Autor 
Em um ensaio preliminar de suportabilidade com tensão à frequência industrial, à seco, com o novo arranjo da célula de alta tensão, realizados no IEEIUSP, constatou-se que a mesma possui uma rigidez dielétrica abaixo de 60kV. Como citado anteriormente, no contexto deste trabalho objetiva-se poder operar o protótipo desenvolvido de TPO em campo realizando medições em sistemas operando com tensão nominal de $69 \mathrm{kV}$. Em vista disso, torna-se necessário que o mesmo atenda aos requisitos de isolação estabelecidos na norma pertinente. Pela norma NBR 6855 (2009), um TP para operar em sistemas de $69 \mathrm{kV}$ deve atender à classe $72 \mathrm{kV}$ e suportar tensões aplicadas de até $149 \mathrm{kV}$. Para atender este requisito torna-se necessária a inclusão da célula sensora no isolador oco preenchido com gás $\mathrm{SF}_{6}$ mostrado na figura 28 , de modo a aumentar a rigidez dielétrica do conjunto e tornalo adequado para operação ao tempo. Os resultados relativos a esta parte do desenvolvimento são relatadas no capítulo 5 , no qual são apresentados os ensaios elétricos realizados com o protótipo.

\subsection{UNIDADE DE PROCESSAMENTO DE SINAL DE SAÍdA DO TRANSFORMADOR DE POTENCIAL ÓPTICO}

Para o processamento dos sinais dos protótipos dos TPOs desenvolvidos no LSO tem sido utilizada a técnica denominada demodulação síncrona de sinais interferométricos, criada e patenteada por Almeida (ALMEIDA; AVILEZ, 2003; ALMEIDA; SANTOS, 2005, ALMEIDA et al, 2006). Esta técnica também foi utilizada na Unidade de Processamento de Sinais que compõe o protótipo de TPO desenvolvido neste trabalho e é explanada, a seguir, de forma resumida, visto que a mesma não pertence ao foco central deste trabalho e já foi divulgada previamente. (SANTOS; ALMEIDA; SILVA, 2011).

A informação de alta tensão a ser demodulada, obtida pelo interferômetro sensor, parte da análise da fotocorrente, $l d(t)$ detectada no fotodiodo conectado à fibra óptica de saída do interferômetro recuperador, proveniente da porta 3 do circulador. 
O fotodetector detecta a potência luminosa que incide sobre ele, convertendo-a em corrente elétrica, sendo que a potência óptica é proporcional à intensidade luminosa. Quando um feixe de luz de potência $P$ incide sobre o fotodiodo o valor de $I d$, produzida pelo mesmo é dada por (ALMEIDA, 2001, SILVA, 2006):

$$
I_{d}=\eta_{d}\left(\frac{q \cdot \lambda_{0}}{h \cdot c}\right) \cdot P=\eta_{f d} \cdot P
$$

onde: $q=-1,602177 \times 10^{-19} \mathrm{C}$ é a carga do elétron, $h=6,629075 \times 10^{-34} \mathrm{~J} . \mathrm{S}$ é a constante de Planck, $\lambda o$ é o comprimento da onda associada ao fóton, $c$ é a velocidade de propagação da luz no vácuo, $\eta_{d}$ é a eficiência quântica do fotodiodo, $\eta_{f d}$ é a responsividade do fotodiodo e $P$ é a potência óptica.

$\mathrm{Na}$ eq.(88) anterior verifica-se que a foto-corrente $I_{d}$ é proporcional à potência óptica, $P$, a qual é dada pela integral sobre a área do fotodiodo da intensidade do feixe de luz $\left(I_{r}\right)$ proveniente do interferômetro recuperador (trazida pela fibra óptica de saída do mesmo) e pode ser descrita por:

$$
P=A_{e} I_{r}
$$

onde $A_{e}$ é a constante de proporcionalidade que relaciona a potência óptica recebida com a intensidade óptica do feixe de luz incidente sobre um determinado fotodiodo. $A_{e}$ possui dimensão de área e pode ser chamada de área efetiva do fotodiodo.

Considerando-se que as áreas do fotodiodo e do feixe de luz, proveniente da fibra óptica, são finitas e fixas, a corrente $I_{d}$ pode ser relacionada com a intensidade $I_{r}$, da seguinte forma (SILVA, 2006, ALMEIDA et al., 2006; KEISER, 1991):

$$
I_{d}=\eta_{f d} \cdot A_{e} \cdot I_{r}
$$

Levando-se em consideração, também, que há um casamento das diferenças de caminhos ópticos dos interferômetros sensor e recuperador, a intensidade óptica na saída do interferômetro recuperador, dada pela eq. eq.(90) pode ser reescrita como (ALMEIDA, 2001): 


$$
I_{r}=I_{r 0}\left\{1+\frac{1}{2} e^{-\left[\frac{\left(\phi_{1}-\phi_{2}\right) \lambda_{0}}{2 L_{c}^{2}}\right]} \cos \left(\phi_{1}-\phi_{2}\right)\right\}
$$

onde: $\phi_{1}$ e $\phi_{2}$ são os atrasos de fase ópticos induzidos eletricamente pelos interferômetros sensor e recuperador, respectivamente e $I_{10}$ é a intensidade média do sinal de saída do interferômetro recuperador.

Os atrasos de fase $\phi_{1}$ e $\phi_{2}$, em caráter genérico, podem se vinculados em função do $V_{\pi}$ do modulador escolhido através da relação (ALMEIDA, 2001):

$$
\phi_{i}=\pi \frac{V_{i}}{V_{\pi i}}
$$

onde o índice $i=1,2$; refere-se a um dos interferômetros do sistema, sendo 1 para o interferômetro sensor e 2 para o interferômetro recuperador, respectivamente.

Aplicando-se ao modulador interferômetro recuperador uma tensão de modulação senoidal da forma: $V_{2}(t)=V_{2}$ sen $\left(\omega_{2} t\right)$, o atraso de fase resultante do sistema será [ALMEIDA; SANTOS, 2005]:

$$
\phi_{2}(t)=\phi_{2} \operatorname{sen}\left(\omega_{2} t\right)
$$

onde $\phi_{2}=\pi \frac{V_{2}}{V_{\pi 2}}$ é o valor máximo do atraso de fase introduzido pelo interferômetro recuperador, quando a tensão de modulação secundária atinge o seu valor máximo, $V_{2}$.

Simplificando a eq.(91) adotando-se que $\phi=\left(\phi_{1}-\phi_{2}\right)$, Ir pode ser dada por [ALMEIDA; SILVA, 2007]: 


$$
I_{r}=I_{r 0}\left\{1+\frac{1}{2} e^{-\left[\frac{\phi \lambda_{0}}{2 L_{c}^{2}}\right]} \cos (\phi)\right\}
$$

Assim, a corrente ld $(t)$ no fotodetector pode ser obtida, aplicando-se a eq.(93) na eq.(94) e em seguida na eq.(90) (ALMEIDA, 2001):

$$
I_{d}(t)=I_{d 0}\left\{1+\frac{1}{2} e^{-\left[\frac{\left(\phi_{1}(t)-\phi_{2}(t)\right) \lambda_{0}}{2 L_{c}^{2}}\right]} \cos \left[\phi_{1}(t)-\phi_{2} \operatorname{sen}\left(\omega_{2} t\right)\right]\right\}
$$

Onde: $I_{d o}=\eta_{f d} A_{e} I_{r 0}$ é o valor médio de $I_{d}(t)$ e $\phi_{1}(t)=\pi \frac{V_{1}(t)}{V_{\pi 1}}$, sendo $V_{1}(t)$ a tensão, variável no tempo, aplicada ao sensor primário que se deseja medir, que também pode ser puramente senoidal, como $V_{2}(t)$.

Caso ambas as modulações sejam pequenas, especialmente se não ultrapassarem os limites: $-\pi / 2<\phi_{1}$ e $\phi_{2}<\pi / 2$, pode-se considerar o termo que define a visibilidade praticamente constante e igual a 1 , ou seja, $e^{-\left[\frac{\left(\phi_{1}(t)-\phi_{2}(t)\right) \lambda_{0}}{2 L_{c}^{2}}\right]} \cong 1$, assim, a corrente $I d(t)$ no fotodetector pode ser reescrita por (ALMEIDA, 2001):

$$
I_{d}(t)=I_{d 0}\left\{1+\frac{1}{2} \cos \left[\phi_{1}(t)-\phi_{2} \operatorname{sen}\left(\omega_{2} t\right)\right]\right\}
$$

Neste contexto, a figura 50 ilustra $l_{d}(t)$, para a modulação $\phi_{2}(t)=\phi_{2} \operatorname{sen}\left(\omega_{2} t\right)$ aplicada à fase óptica do interferômetro recuperador, e sem nenhuma modulação de fase óptica aplicada ao interferômetro sensor $\left(\phi_{1}(t)=0\right)$; onde $\omega_{2}=2 \pi / T_{2}$ e $T_{2}=1 / f_{2}$ é o período da frequência $f_{2}$ da modulação aplicada ao interferômetro recuperador, sendo que, para o último protótipo foi adotado o valor de $30720 \mathrm{~Hz}$, pois este valor permitia uma taxa de amostragem de 512 amostras por ciclo de $60 \mathrm{~Hz}$. A corrente $l d(t)$ vem multiplicada por uma fator $K_{v}$ que é o fator que descreve a influência da visibilidade dos moduladores relacionados aos interferômetros sensor e recuperador. 
Figura 50 - Forma de onda simulando 32 ciclos da foto-corrente detectada no fotodiodo conectado à fibra óptica de saída do interferômetro recuperador (sem modulação de fase óptica aplicada ao interferômetro sensor).

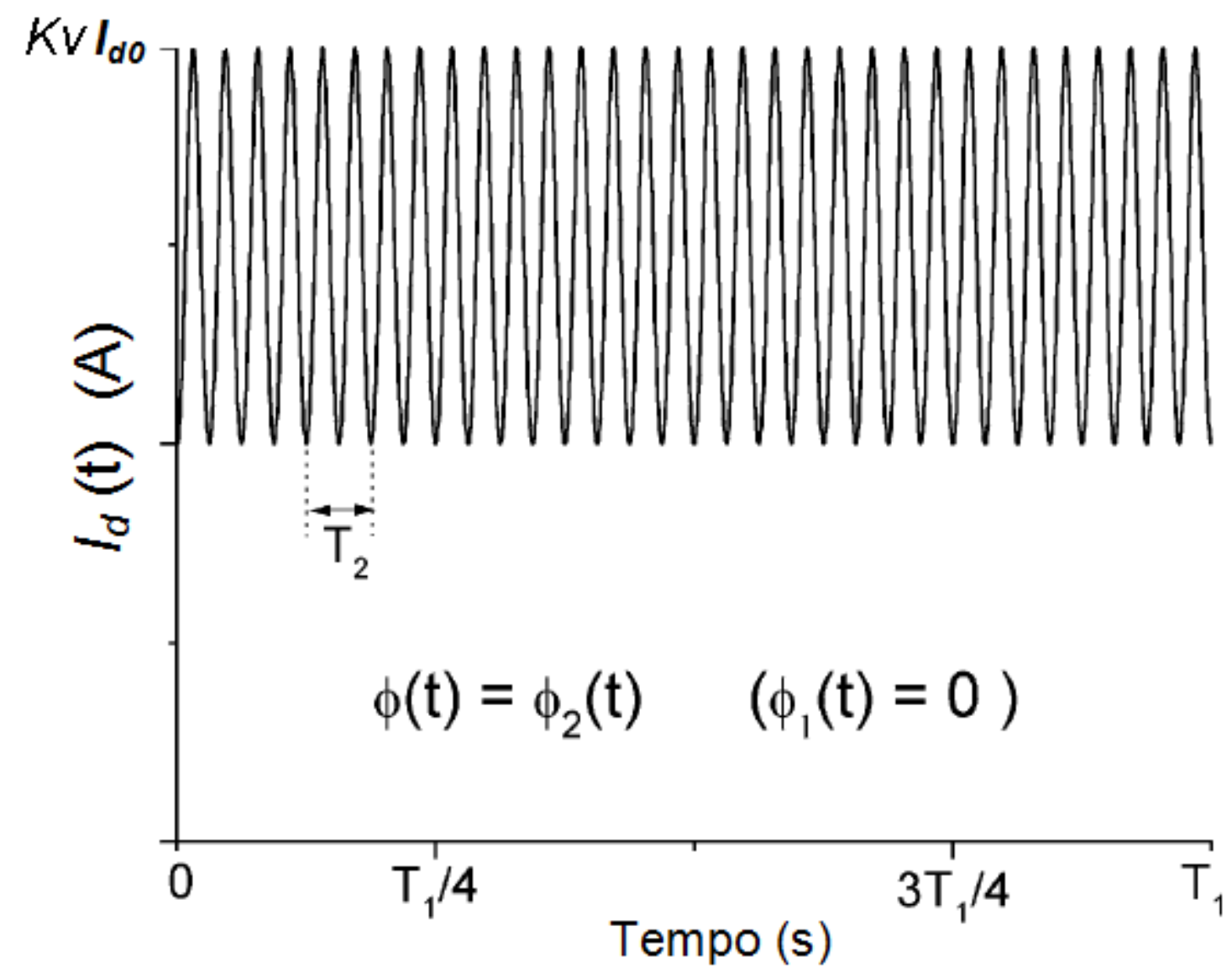

Fonte: ALMEIDA; SANTOS (2005) modificada

A figura 51, a seguir, ilustra a forma de onda de $I_{d}(t)$, para as modulações $\phi_{1}(t)=0,5$ $\operatorname{sen}\left(\omega_{1} t\right)$ e $\phi_{2}(t)=\pi / 2$ sen $\left(\omega_{2} t\right)$, aplicadas aos atrasos de fase ópticos dos interferômetros sensor e recuperador, respectivamente.

Com o intuito de melhorar a visualização, utilizou-se $\omega_{2}=16 \omega_{1}, \phi_{1}=0,5, \phi_{2}=\pi / 2$, onde $\omega_{1}=2 \pi / T_{1}, T_{1}=1 / f_{1}$ é o período da frequência fundamental $f_{1}$ da alta tensão aplicada ao sensor. Analogamente, $\omega_{2}=2 \pi / T_{2}$. 
Figura $51-I_{d}(t)$, para as modulações $\phi_{1}(t)=0,5 \operatorname{sen}\left(\omega_{1} t\right)$ e $\phi_{2}(t)=\pi / 2 \operatorname{sen}\left(\omega_{2} t\right)$, sendo $\omega_{2}=16 \omega_{1}$.

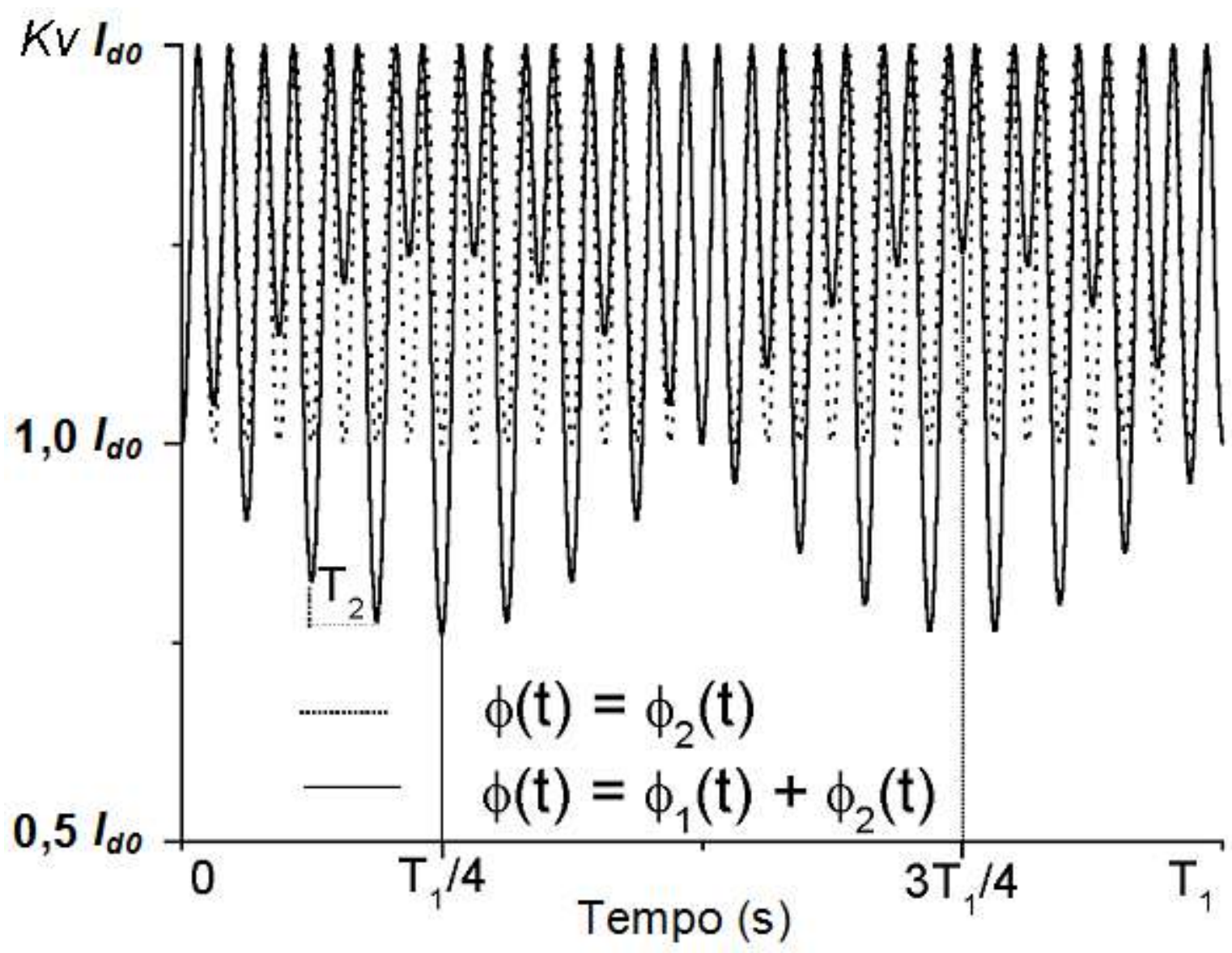

Fonte: ALMEIDA (2001) modificada

Observa-se para cada ciclo da frequência $\omega_{1}$ da alta tensão, que:

- Os valores dos vales variam com $\phi_{1}(t)$, e ocorrem próximos aos instantes $T_{2} / 4$ e $3 T_{2} / 4$ de cada ciclo da modulação de fase óptica $\phi_{2}(t)$. Os mesmos se alternam acima e abaixo do valor de referência obtido para $\phi_{1}(t)=0$;

- Os valores dos picos não variam com a modulação de fase óptica $\phi_{1}(t)$ e ocorrem em instantes simétricos à $T_{2} / 2$ em cada ciclo da modulação de fase óptica $\phi_{2}(t)$.

Para proporcionar uma melhor compreensão do que foi exposto anteriormente, a figura 52 ilustra, a ampliação no domínio do tempo de um ciclo da curva da fotocorrente $I_{d}(t)$ onde $\omega_{2}=256 \omega_{1}($ ALMEIDA, 2001). 
Figura 52 - Ampliação no domínio do tempo de um ciclo de $I_{d}(t)$, para as modulações $\phi_{1}(\mathrm{t})=0,5$ $\operatorname{sen}\left(\omega_{1} t\right)$ e $\phi_{2}(t)=2 \pi \operatorname{sen}\left(\omega_{2} t\right)$, sendo $\omega_{2}=256 \omega_{1}$.

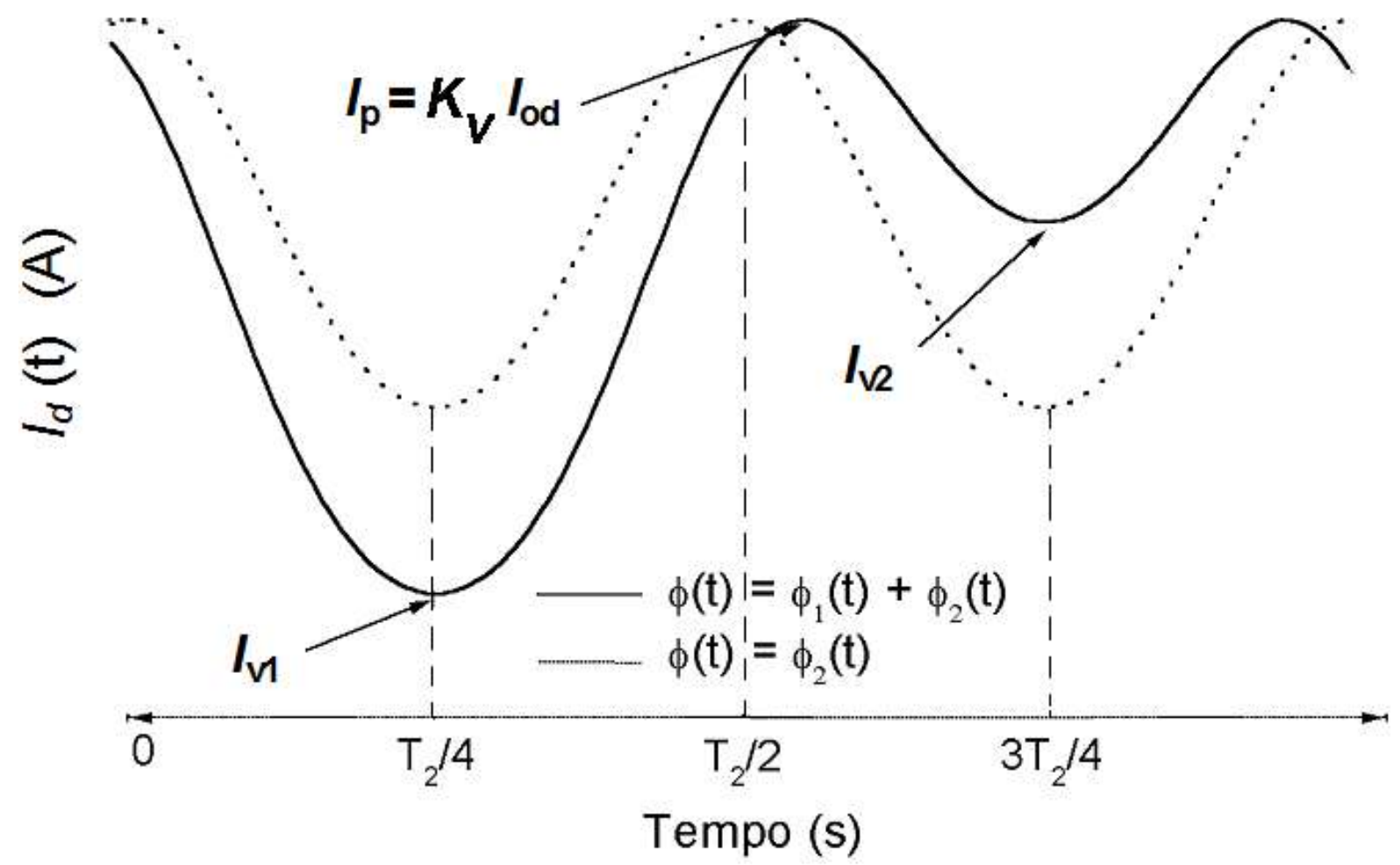

Fonte: ALMEIDA (2001) modificada

Observa-se na figura anterior, a ocorrência de:

- Valores de vales $I_{v 1}$ e $I_{v 2}$, acima e abaixo, respectivamente, do valor de referência obtido para $\phi_{1}(t)=0$;

- Um valor de pico, $I_{p}$, próximo à $T_{2} / 2$.

Expandindo $I_{d}(t)$, dada pela eq.(96), em funções de Bessel, obtém-se a expressão:

$$
\begin{aligned}
I_{d}(t)= & I_{d 0}\left\{1+\frac{1}{2}\left[J_{0}\left(\phi_{2}\right)+2 \sum_{n} J_{2 n}\left(\phi_{2}\right) \cos \left(2 n \omega_{2} t\right)\right] \cos \left[\phi_{1}(t)\right]\right\} \\
& -I_{d 0}\left\{\sum_{n} J_{2 n-1}\left(\phi_{2}\right) \operatorname{sen}\left[(2 n-1) \omega_{2} t\right] \operatorname{sen}\left[\phi_{1}(t)\right]\right\}
\end{aligned}
$$


onde: $n \in N^{*}, J_{n}$ é a função de Bessel de ordem $n$ e primeira espécie. Da eq.(98) e eq.(99) as componentes de baixa frequência, $\left(\omega \ll\left(\omega_{2}-\omega_{1}\right)\right)$, da corrente $I_{d}(t)$ podem ser expressas por, $I_{b f}(t)$, como (ALMEIDA, 2001):

$$
I_{b f}(t)=I_{d o}\left\{1+\frac{1}{2} J_{0}\left(\phi_{2}\right) \cos \left[\phi_{1}(t)\right]\right\}
$$

Em instrumentação óptica é comum o uso de amplificadores de transimpedância para converter em tensão a fotocorrente gerada por fotodiodos. Neste tipo de amplificador, cuja topologia básica é mostrada na figura 53, a seguir, a tensão de saída, $V_{d}(t)$, relaciona-se com a corrente do fotodiodo utilizado, $I_{d}(t)$ da seguinte forma (ALMEIDA, 2001):

$$
V_{d}(t)=R_{f} l_{d}(t)
$$

onde $R_{f}$ é a resistência de realimentação do amplificador de transimpedância.

Figura 53 - Configuração básica e um amplificador de transimpedância.

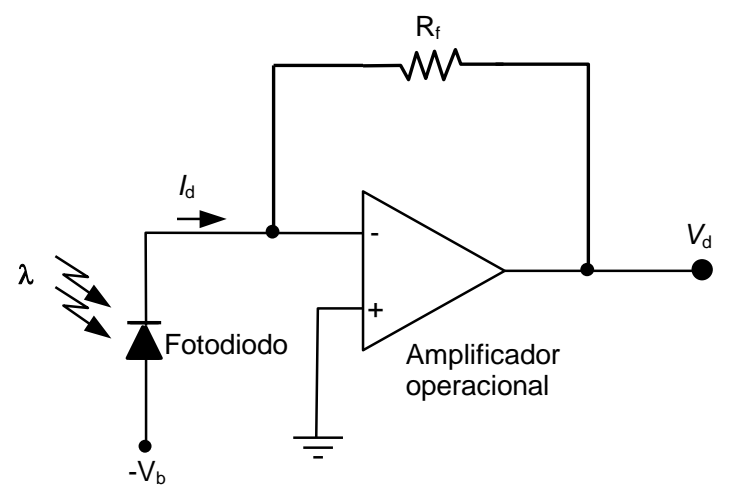

Fonte: ALMEIDA (2001) modificada

Portanto, utilizando um amplificador de transimpedância e substituindo a eq.(98) na eq.(99), as, componentes, de baixa frequência, $V_{b f}(t)$, da tensão de saída podem ser escritas como (ALMEIDA, 2001):

$$
V_{b f}(t)=V_{0 d}\left\{1+K_{V} J_{0}\left(\phi_{2}\right) \cos \left[\phi_{1}(\mathrm{t})\right]\right\}
$$


onde $V_{o d}=R_{f} l_{o d}$ e $K_{v}$ é o fator que descreve a influência da visibilidade dos moduladores relacionados aos interferômetros sensor e recuperador. Nos sistemas baseados na técnica WLI com dois interferômetros completos em série a visibilidade máxima do sistema é $K_{V}=1 / 2$, o que condiz com o fator que multiplica o termo em cosseno na eq.(98) e em todo o desenvolvimento prévio e subsequente.

Da eq.(100) deduz-se que o valor de pico da tensão de saída do sistema é:

$$
V_{p}(t)=V_{0 d}\left(1+K_{V}\right)
$$

Como foi feito anteriormente, infere-se da eq.(96) e eq.(97) que as componentes de alta frequência, $V_{a f}(t)$ da tensão de saída do amplificador de transimpedância, caracterizadas por $\omega_{1}>>\omega$, podem ser expressas como:

$$
V_{a f}(t)=V_{0 d}\left\{\frac{1}{2}\left[\cos \left(\phi_{1}(t)+\phi_{2} \operatorname{sen}\left(\omega_{2} t\right)\right)-J_{0}\left(\phi_{2}\right) \cos \left(\phi_{1}(t)\right)\right]\right\}
$$

Portanto, da eq.(102) resultam as seguintes expressões para os valores dos vales, $v_{v 1}$ e $V_{v 2}$ (ALMEIDA, 2001):

$$
\begin{aligned}
& V_{v 1}=\frac{V_{0 d}}{2}\left[\cos \left(\phi_{2}+\phi_{1}(t)\right)-J_{0}\left(\phi_{2}\right) \cos \left(\phi_{1}(t)\right)\right] \\
& V_{v 2}=\frac{V_{0 d}}{2}\left[\cos \left(\phi_{2}-\phi_{1}(t)\right)-J_{0}\left(\phi_{2}\right) \cos \left(\phi_{1}(t)\right)\right]
\end{aligned}
$$

Da eq.(103) e eq.(104), podem-se expressar os valores das tensões de vale $V_{v 1} \mathrm{e}$ $V_{v 2}$ como (ALMEIDA, 2001):

$$
V_{v 1}=\frac{V_{0 d}}{2}\left\{\cos \left(\phi_{2}\right) \cos \left[\phi_{1}(t)\right]-\operatorname{sen}\left(\phi_{2}\right) \operatorname{sen}\left[\phi_{1}(t)\right]\right\}-\frac{V_{0 d}}{2}\left\{J_{0}\left(\phi_{2}\right) \cos \left(\phi_{1}(t)\right)\right\}
$$




$$
V_{v 2}=\frac{V_{0 d}}{2}\left\{\cos \left(\phi_{2}\right) \cos \left[\phi_{1}(t)\right]+\operatorname{sen}\left(\phi_{2}\right) \operatorname{sen}\left[\phi_{1}(t)\right]\right\}-\frac{V_{0 d}}{2}\left\{J_{0}\left(\phi_{2}\right) \cos \left(\phi_{1}(t)\right)\right\}
$$

Conclui-se das equações (105) e (106) que o valor absoluto do desvio máximo entre os valores consecutivos, $\left|\Delta V_{V}\right|$, é expresso como (ALMEIDA, 2001):

$$
\left|\Delta V_{v}\right|=\left|V_{v 1}-V_{v 2}\right|=\left|-V_{0 d} \operatorname{sen}\left(\phi_{2}\right) \operatorname{sen}\left[\phi_{1}(t)\right]\right|
$$

No intervalo $0 \leq \phi_{2} \leq \pi$, o valor de $\left|\Delta V_{v}\right|$ é maximizado em relação à amplitude $\phi_{2}$ da modulação de fase óptica $\phi_{2}(t)$, quando $\phi_{2}(t)=\pi / 2$, e pode ser escrito por:

$$
\left|\Delta V_{V}\right|_{\phi_{2}=\pi / 2}=V_{0 d} \mid \operatorname{sen}\left[\phi_{1}(t)\right]
$$

Isolando $\phi_{1}(t)$ na eq.(108), anterior, obtém-se:

$$
\phi_{1}(t)_{\phi_{2}=\pi / 2}=\operatorname{arcsen}\left(\frac{V_{v 2}-V_{v 1}}{V_{0 d}}\right)
$$

Infere-se da eq.(109) que, por se estar operando num ponto de máximo da função $\operatorname{sen}\left(\phi_{2}\right), \partial \Delta V_{v} / \partial \phi_{2}=0 \mathrm{e}$, portanto, uma variação de $500 \mathrm{ppm}$ no parâmetro $\phi_{2}$ implicará numa variação inferior a $1 \mathrm{ppm}$ em $\Delta V_{v}$. Portanto, no intervalo $\left|\phi_{2}\right| \leq \pi$, $\phi_{2}=\pi / 2$ é o valor da amplitude de modulação de fase óptica que:

- Maximiza a sensibilidade diferencial dos valores dos vales em relação a $\phi_{1}(t)$;

- Minimiza a deriva do fator de escala eletrônico em relação à variação de $\phi_{2}$;

- Maximiza a faixa dinâmica de medida de $\phi_{1}(t)$, isto é, $\left|\phi_{1}(t)\right|_{\max }=\pi / 2$

$\mathrm{Na}$ eq.(109) utiliza-se o valor de $V_{O d}$ para calcular a tensão aplicada ao sensor, $V_{S}$ proporcional $\phi_{1}(t)$. Porém este valor não é lido pelo sistema de processamento de sinais. O único valor disponível é a tensão de pico, $V_{P}$, que se relaciona com $V_{o d}$ 
pela eq.(101). Desta forma, pode-se expressar a tensão aplicada em função de $V_{P}$ substituindo a eq.(101) na eq.(109), obtendo-se:

$$
V_{s}=\frac{V_{\pi s}}{\pi} \operatorname{arcsen}\left(\frac{V_{v 2}-V_{v 1}}{V_{p} /\left(1+K_{V}\right)}\right)
$$

onde $V_{s}$ é a tensão aplicada ao interferômetro sensor e $V_{\pi s}$ é a tensão de meia onda do mesmo interferômetro

O desenvolvimento apresentado pressupõe que a visibilidade dos dois interferômetros é máxima. Nessa circunstância, $K_{V}=1 / 2$. Na prática, a visibilidade dos interferômetros é usualmente menor que 1. Em vista disso deve-se medir experimentalmente (que está relacionada ao valor de $V_{\pi}$ da célula sensora) a visibilidade total do sistema e determinar empiricamente o valor de $K_{V}$ a ser substituído na eq.(110). Esta medição é feita impondo-se uma tensão contínua na célula recuperadora de modo que os vales fiquem equilibrados, como pode ser visto na curva pontilhada da figura 52, e nessa condição medindo-se os valores de $V_{p} \mathrm{e}$ $V_{v 1}$ ou $V_{v 2}$ (que nessa condição são iguais). Calculando-se a diferença entre $V_{p}$ e $V_{v 1}$ ou $V_{v 2}$ e dividindo-se esta diferença por $V_{p}$ obtém-se a visibilidade $K_{v}$.

Uma vez apresentado e discutido o tratamento matemático do processamento de sinais empregado, ilustra-se na figura 54, a seguir, o diagrama de blocos do processador do sinal implementado para a demodulação do sinal de alta tensão em CA, aplicado ao interferômetro sensor do protótipo de TPO. 
Figura 54 - Diagrama de blocos do processador do sinal de saída do interferômetro recuperador do protótipo de TPO

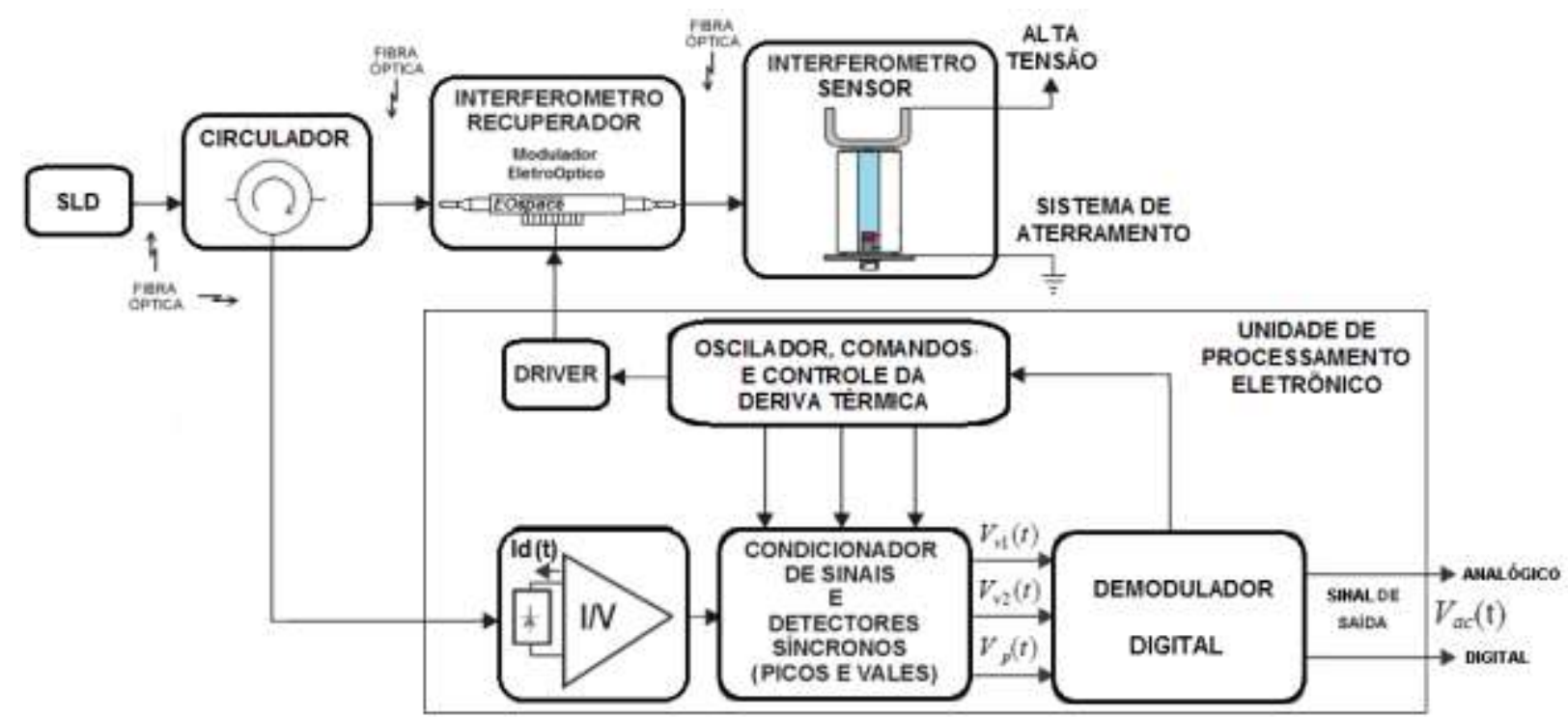

Fonte: ALMEIDA; SANTO (2005) modificada.

No diagrama de blocos da figura 54 evidenciam-se as etapas de:

- conversão da foto-corrente detectada em tensão por meio de um amplificador de transimpedância $(I / V)$,

- detecção síncrona dos valores das tensões dos vales e dos picos do sinal de saída do amplificador de transimpedância,

- filtragem e diferença dos valores das tensões dos vales consecutivos e subsequente divisão deste resultado pelo valor da tensão de pico. A saída consiste na demodulação do sinal de alta tensão aplicado ao interferômetro sensor,

- filtragem e realimentação para controle da deriva térmica do interferômetro recuperador; e

- demodulador digital desenvolvido a partir de conversores Analógico-Digital na medida das tensões de pico e de vale obtidos pela unidade de processamento com 80 amostragens por ciclo de $60 \mathrm{~Hz}$. 


\section{MÉTOdOS COMPUTACIONAIS PARA O AUXíLIO AO PROJETO DE CÉLULAS POCKELS DE ALTA TENSÃO}

O último quesito a determinar para completar o desenvolvimento do protótipo de TPO é a definição do valor da tensão de meia onda do modulador eletro-óptico do interferômetro sensor, $V_{\pi s}$. Como mencionado anteriormente, este valor está intimamente relacionado com os valores de campo elétrico gerados no interior do sensor pela tensão aplicadas entre os eletrodos da célula sensora.

No intuito de auxiliar o projeto de sensores eletro-ópticos para medidas de altas tensões, foram utilizados dois métodos computacionais que calculam a distribuição do campo elétrico no interior do sensor, de acordo com a sua geometria e materiais. Esses métodos são:

- Método de simulação de Carga - CSM (Charge Simulation Method) (HIDAKA, 1996)

- Método dos Elementos Finitos (MEF) (RUBINI et al., 2004, 2005; PASSARO et al., 2005; SANTOS et al., 2006a; 2006b).

Utilizando-se as simulações computacionais pode-se ter uma melhor estimativa da distribuição do campo elétrico e, consequentemente, uma verificação dos pontos de máximo estresse elétrico do sensor. Essa estimativa também visa obter o valor da tensão de meia onda $(\bigvee \pi)$ do sensor eletro-óptico. Este valor, cujo significado foi descrito na sessão 2.6, se afigura como um índice de mérito desse tipo de sensor.

\section{1 - MÉTODO DE SIMULAÇÃO DE CARGAS - CSM}

O método CSM foi desenvolvido por Hidaka (1996) e é um programa computacional de simulação de campos elétricos utilizado por Santos (1996) no projeto de um sensor eletro-óptico destinado a medir altas tensões. A versão do programa utilizado, denominada EFCAX94, é capaz de simular geometrias descritas em duas dimensões (2D) com simetria axial. Utilizando este programa foram realizadas simulações do sensor eletro-óptico desenvolvido na configuração multi-segmentada, 
utilizando-se 8 lâminas de cristais com a espessura de $1 \mathrm{~mm}$ cada, em duas situações: com e sem a influência de um elemento metálico perturbador da distribuição do campo elétrico na vizinhança do sensor.

A forma de utilização do CSM é bastante simples, bastando inserir os dados da geometria do sensor e definirem-se as condições de contorno, tais como potencial aplicado entre os eletrodos e as características da permissividade de cada material relacionado com o elemento eletro-óptico do sensor.

Os elétrodos propostos naquela configuração têm uma forma arredondada de modo a evitar as bordas que podem produzir regiões de gradientes de campos elétricos elevados, o que pode provocar 0 aparecimento do efeito corona e, consequentemente, reduzir a rigidez dielétrica do conjunto favorecendo a ocorrência de descargas elétricas entre os eletrodos. Essa geometria foi obtida a partir de várias iterações no processo de simulação e pode ser vista na figura 55 , a seguir.

Figura 55 - Geometria final obtida para o sensor eletro-óptico usando o método CSM (SANTOS, 1996)

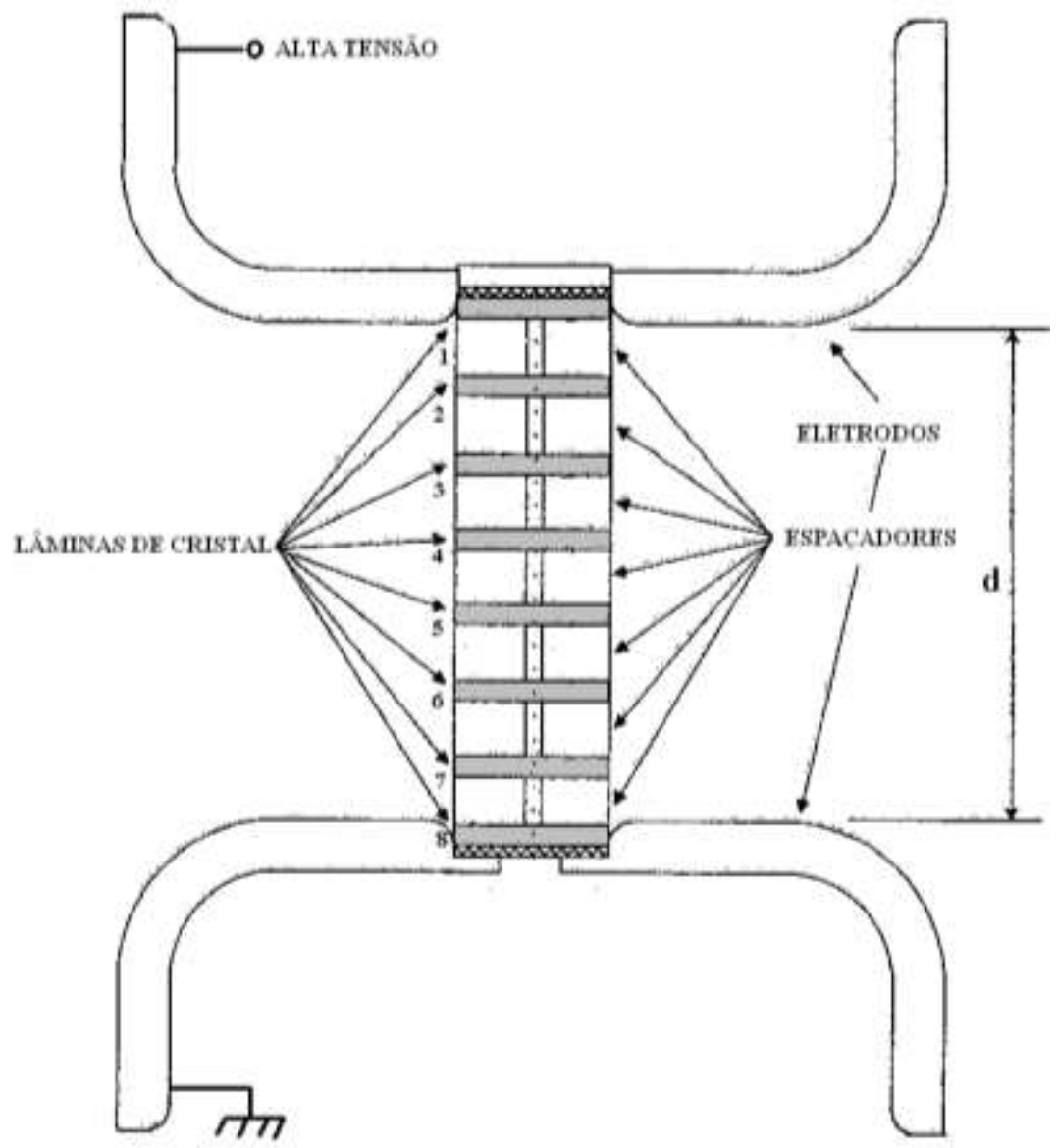

Fonte: Santos (1996) 
Os valores médios do campo elétrico obtidos pelo método CSM, em cada lâmina de cristal, estão indicados na tabela 2, a seguir. Tais valores foram obtidos calculando a média do campo elétrico, em 40 pontos ao longo do trajeto de um feixe luminoso em cada uma das lâminas de cristal eletro-óptico. Na simulação foi utilizada a aplicação de uma tensão de $400 \mathrm{kV}$, entre os eletrodos, o que resultou um campo elétrico máximo em torno de $68 \mathrm{kV} / \mathrm{cm}$.

Tabela 2 - Média do Campo elétrico em cada lâmina

\begin{tabular}{|c|c|c|c|c|c|c|c|c|}
\hline $\begin{array}{c}\text { Número } \\
\text { (Lâminas) }\end{array}$ & 1 & 2 & 3 & 4 & 5 & 6 & 7 & 8 \\
\hline $\mathrm{EI}(\mathrm{kV} / \mathrm{cm})$ & 2,36 & 2,72 & 2,84 & 2,69 & 2,52 & 2,38 & 2,13 & 1,79 \\
\hline
\end{tabular}

Utilizando esses valores, o atraso de fase total $\left(\Gamma_{T}\right)$, resultante do atraso acumulado nas $n$ lâminas, é dado por:

$$
\Gamma_{T}=\frac{2 \pi}{\lambda} n_{o}^{3} \cdot r_{41} \sum_{i=1}^{n}\left(\bar{E}_{l(i)} \cdot d_{1}\right)=\frac{2 \pi}{\lambda} n_{o}^{3} \cdot r_{41} \cdot d_{1} \sum_{i=1}^{n} \bar{E}_{l(i)}
$$

Um valor equivalente $\bar{E}_{1}$ através de todas as oito lâminas dos cristais é dado por:

$$
\bar{E}_{1}=\frac{1}{8} \sum_{i=1}^{8} \bar{E}_{l(i)}=2,43 \quad(\mathrm{kV} / \mathrm{cm})
$$

A tensão aplicada $\vee$ pode ser calculada utilizando a equação simplificada por:

$$
V=K \bar{E}_{1}
$$

onde $K$ é o comprimento equivalente. Neste caso $V=400 \mathrm{kV}$ e $\bar{E}_{1}=0.243 \mathrm{kV} / \mathrm{mm}$, resultando em $K \approx 1646 \mathrm{~mm}$.

Santos demonstra em seu trabalho (SANTOS, 1996) que $V_{\pi_{T}}$ neste caso é dado por:

$$
V_{\pi_{T}}=\frac{\lambda_{0} \cdot K}{2 n_{o}^{3} r_{41} n d_{1}}
$$


O valor de $V_{\pi_{T}}$ obtido pela equação anterior foi de 6,84 MV, onde os parâmetros utilizados são: $n_{0}=2.098, r_{41}=1.0310^{-12}[\mathrm{~m} / \mathrm{V}]$ (para BGO), $d_{1}=1 \mathrm{~mm}$ e $d=110 \mathrm{~mm}$, $\mathrm{n}=8$ e $\lambda_{0}=632.8 \mathrm{~nm}$. Esse valor é menor do que $0.3 \%$ de diferença que o calculado por Santos (1996), para o caso de campo elétrico perfeitamente uniforme, pela equação que utiliza $K=n d_{1}+\frac{\varepsilon_{1}}{\varepsilon_{2}}(n-1) d_{2}$. Levantou-se a questão de quanto a medida da tensão aplicada seria afetada no caso de uma distribuição não uniforme do campo elétrico ao longo do caminho óptico.

Para examinar esta questão decidiu-se estudar casos de campos não uniformes e, para tanto, foram feitas simulações levando-se em consideração objetos aterrados (anéis) colocados próximos do sensor eletro-óptico, como indicado na figura 56.

Figura 56 - Geometria utilizada para verificação da influência de objeto aterrado nas proximidades do sensor eletro-óptico usando o método CSM.

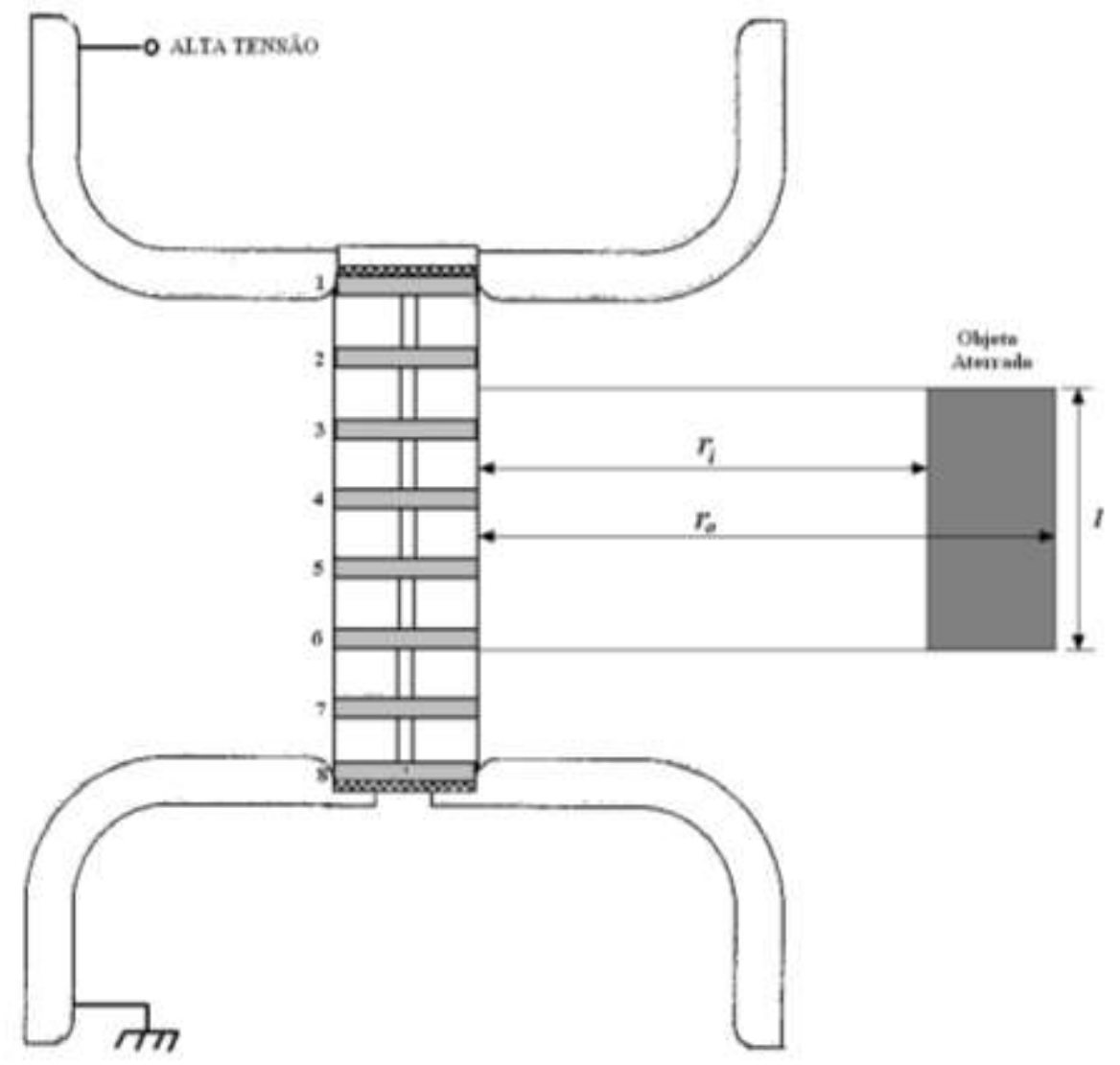

Fonte: Santos (1996) modificada 
A versão utilizada do CSM é apropriada somente para a simetria axial. Assim, o objeto aterrado, mostrado por uma forma retangular na figura 56, representa uma seção transversal de um anel metálico que cerca o sensor eletro-óptico. Foram utilizadas, para a simulação, duas diferentes configurações, onde se variou o tamanho e a posição do anel metálico de modo a se estudar não só o efeito desses objetos aterrados na distribuição do campo elétrico, mas também o valor médio do campo elétrico nesse sensor eletro-óptico, que por sua vez determina o valor de $V_{\pi T}$.

As configurações utilizadas em dois casos estão indicadas na tabela 3 , a seguir:

Tabela 3 - Descrição das medidas utilizadas para os casos 1 e 2

\begin{tabular}{|c|c|c|}
\hline CASOS & \multicolumn{2}{|c|}{ MEDIDAS } \\
\hline \multirow{2}{*}{1} & diâmetro interno & $r_{\mathrm{i}}=100 \mathrm{~mm}$ \\
& diâmetro externo & $r_{0}=120 \mathrm{~mm}$ \\
& Largura do anel & $I=40 \mathrm{~mm}$ \\
\hline \multirow{2}{*}{2} & diâmetro interno & $r_{\mathrm{i}}=50 \mathrm{~mm}$ \\
& diâmetro externo & $r_{0}=70 \mathrm{~mm}$ \\
& Largura do anel & $I=40 \mathrm{~mm}$ \\
\hline
\end{tabular}

Fonte: Autor (2006)

Os resultados obtidos para essas configurações foram comparados com os da configuração sem a presença de nenhum anel (Caso 0) e são mostrados na tabela 4.

Tabela 4 - Dados da Simulação pelo método CSM para os casos 0, 1 e 2 relativos a objetos aterrados próximos ao sensor eletro-óptico.

\begin{tabular}{|c|c|c|c|c|c|c|c|c|c|c|}
\hline Casos & $\bar{E}_{1}(1)$ & $\bar{E}_{1(2)}$ & $\bar{E}_{1(3)}$ & $\bar{E}_{1(4)}$ & $\bar{E}_{1(5)}$ & $\bar{E}_{1}(6)$ & $\bar{E}_{1}(7)$ & $\bar{E}_{1(8)}$ & $\bar{E}_{1}=\frac{1}{8} \sum_{i=1}^{8} \bar{E}_{l(i)}$ & $V_{\pi T}$ \\
$(\mathrm{MV})$
\end{tabular}


Dos resultados obtidos pelas simulações, contidos na tabela 4, verificou-se que, mesmo para o pior caso de não uniformidade do campo elétrico (caso 2) a mudança do valor médio do campo elétrico, no sensor eletro-óptico, é menor do que $2 \%$, influenciando pouco na performance do sensor. Considera-se que o principal fator que influencia essa performance é a uma quantidade de lâminas (8). Assim, a performance pode ser melhorada pelo aumento desse número que faria com que houvesse uma melhor amostragem do campo elétrico ao longo do caminho entre os eletrodos.

\subsection{MÉTODO DOS ELEMENTOS FINITOS - MEF}

A distribuição do campo elétrico também foi simulada aplicando um segundo código 2D que usa o Método dos Elementos Finitos, o qual explora, também, a simetria axial apresentada pelo sensor eletro-óptico. As simulações foram realizadas basicamente em duas configurações, que são: multi-segmentada (vários cristais), tal como foi estudada na subseção anterior, e com um único cristal, as quais são descritas nas subseções a seguir.

O código baseado no MEF utilizado é denominado LevSoft, e foi desenvolvido pelo grupo do Laboratório de Engenharia Virtual (LEV) do Instituto de Estudos Avançados (IEAv) do Departamento de Ciência e Tecnologia Aeroespacial (DCTA).

O método dos elementos finitos é usado largamente em diversas áreas da engenharia, sendo que a exatidão das soluções para os problemas elípticos obtidos aplicando o MEF já é bem estabelecida. Este código foi usado, também, para a análise via elementos finitos (FEA) em diversos componentes integrados ópticos baseados nos efeitos eletro-óptico (ABE; FRANCO, PASSARO, 1999; FRANCO et al., 1999)

\subsubsection{CASOS ESTUDADOS}

As simulações computacionais que serão apresentadas foram obtidas considerando cristais de $\mathrm{BGO}\left(\mathrm{Bi}_{4} \mathrm{Ge}_{3} \mathrm{O}_{12}\right.$ - Germanato de Bismuto) como o material eletro-óptico. As propriedades físicas relevantes deste material são $n_{0}=2,098$ ( 0 índice refração 
ordinário) e $r_{41}=1,03 \times 10^{-12} \mathrm{~m} / \mathrm{V}$ (o coeficiente de Pockels), e $\varepsilon_{1}=16 \varepsilon_{0}$, onde $\varepsilon_{0}$ é o permissividade do vácuo. A tensão entre os elétrodos do sensor foi suposta igual a $400 \mathrm{kV}$ (caso eletrostático) e o sensor é instalado no interior de um tanque cilíndrico metálico com potencial zero, ou seja, aterrado.

Dois tipos de sensores eletro-ópticos são estudados: um tipo de sensor com um único cristal e um tipo de sensor multi-segmentado, ou seja, com várias lâminas de cristal e que serão apresentados nas subseções seguintes.

\subsubsection{TIPO MULTI-SEGMENTADO (VÁRIAS LÂMINAS DE CRISTAL)}

Os resultados obtidos para duas configurações diferentes do sensor multisegmentado são apresentados nessa subseção. A figura 57 mostra a seção transversal do dispositivo com 2 eletrodos de alumínio com $160 \mathrm{~mm}$ de diâmetro (L) e 8 cristais de BGO são posicionados entre os elétrodos, numerados de 1 a 8 . As posições 1 e 8 são as mais próximas ao eletrodo energizado e ao eletrodo aterrado, respectivamente. As lâminas são espaçadas por ar e um material dielétrico (Teflon e/ou PVC - sendo que as permissividades elétricas das mesmas são $\varepsilon 2$ Tefflon $=3,6 \varepsilon_{0}$ e $\varepsilon_{2 P V C}=2,7 \varepsilon 0$, respectivamente). A fim de estimar a sensibilidade do sensor, o campo elétrico na área da seção transversal do feixe de luz, que atravessa o modulador, é considerado uniforme. 
Figure 57 - A geometria do sensor eletro-óptico multisegmentado

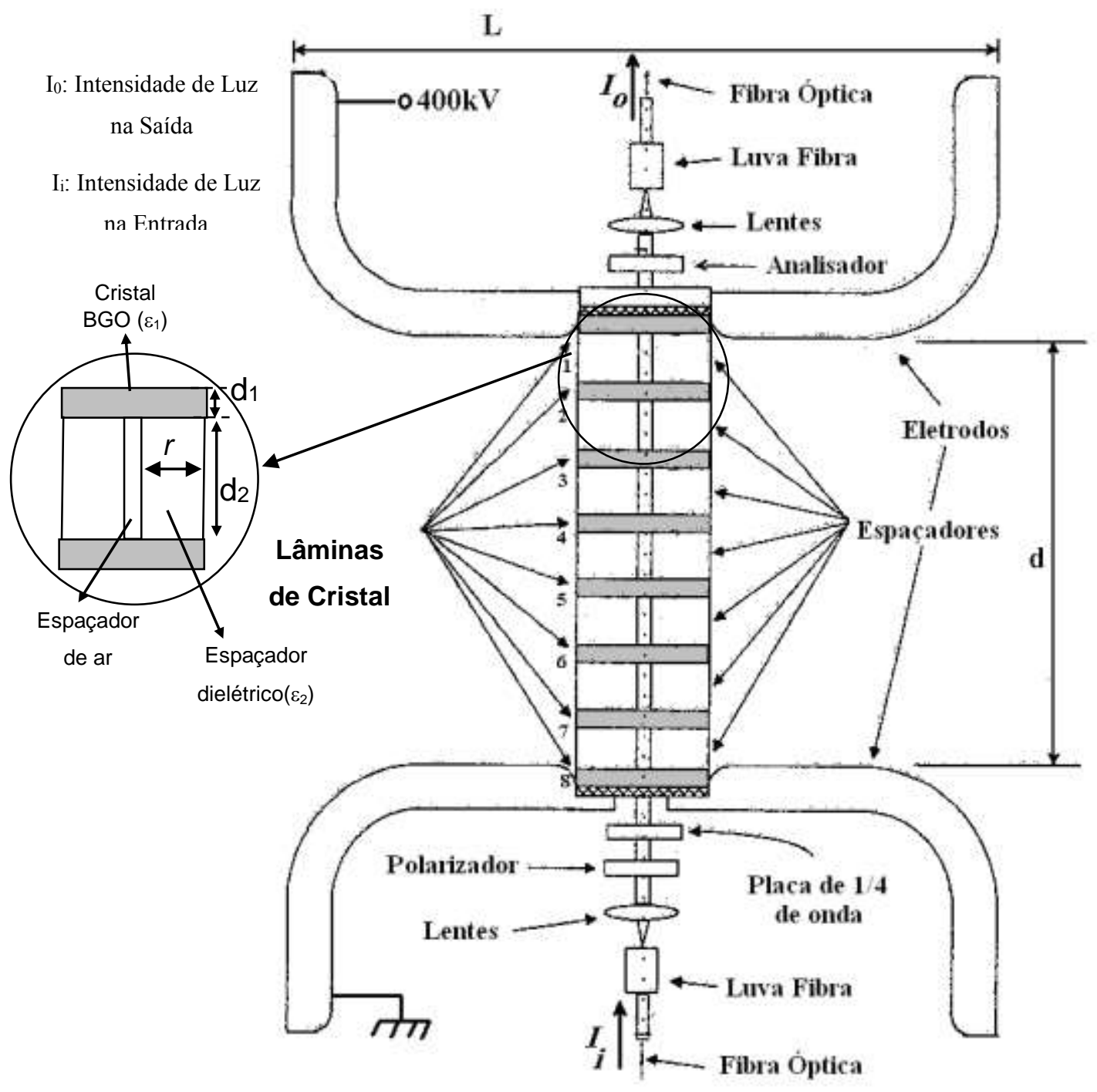

Fonte:

A tabela 5 mostra as características da célula sensora para duas configurações. 0 significado dos parâmetros $d_{1}, d_{2}$, e $r$, estão indicados na figura 56 .

Tabela 5 - Características da célula Sensora

\begin{tabular}{|c|c|c|}
\hline PARÂMETRO & CONFIGURAÇÃO 1 & CONFIGURAÇÃO 2 \\
\hline$d_{1}$ & $1.0 \mathrm{~mm}$ & $7.5 \mathrm{~mm}$ \\
\hline$d_{2}$ & 14.5 to $16.0 \mathrm{~mm}$ & $\sim 5.72 \mathrm{~mm}$ \\
\hline$\varepsilon_{2}$ & $2.7 \varepsilon 0$ & $3.6 \varepsilon 0$ \\
\hline$r$ & $5 \mathrm{~mm}$ & $0.5 \mathrm{~mm}$ \\
\hline
\end{tabular}


A configuração 1 corresponde ao sensor multi-segmentado com lâminas de cristal eletro-óptico de espessura de $1 \mathrm{~mm}\left(d_{1}\right)$. A espessura dos espaçadores dielétricos varia de aproximadamente 14,5 até $16 \mathrm{~mm}\left(\mathrm{~d}_{2}\right)$ - dependendo da posição, totalizando o comprimento de $110 \mathrm{~mm}\left(d=n d_{1}+(n-1) d_{2}\right)$.

Três simulações relativas à configuração 1 e análogas àquelas feitas no CSM e denominadas: Caso-0, Caso-1 e Caso-2, foram realizadas.

- $\underline{\text { Caso-0 }}$ corresponde à simulação computacional da distribuição do campo elétrico de um sensor eletro-óptico instalado dentro de um tanque metálico cilíndrico aterrado.

- Caso-1 e Caso-2 apresentam a mesma geometria, mas levando-se em consideração a presença de um objeto (anel metálico) aterrado na vizinhança do sensor, de modo a se verificar a influência desse objeto na distribuição do campo elétrico ao longo do caminho óptico (simetria em linha). $O$ anel, tal como nos casos simulados no CSM, apresenta diâmetros interno de $100 \mathrm{~mm}$ e externo de $120 \mathrm{~mm}$ para o caso1 e para o caso-2 os diâmetros interno e externo são $50 \mathrm{~mm}$ e $70 \mathrm{~mm}$, respectivamente, e a largura do anel é de $40 \mathrm{~mm}$; de forma idêntica ao realizados no CSM. A tensão V aplicada entre os eletrodos é de $400 \mathrm{kV}$.

A tensão $\mathrm{V}_{\pi}$ desse sensor é da ordem de 6,8 MV, obtida utilizando-se a mesma equação teórica, descrita anteriormente (eq.(112)) proposta por Santos (1999), onde os parâmetros utilizados são: $\mathrm{n}_{0}=2.098, \mathrm{r}_{41}=1.0310^{-12}[\mathrm{~m} / \mathrm{V}](\mathrm{BGO})$, $d_{1}=1 \mathrm{~mm}$ e $d=110 \mathrm{~mm}, \mathrm{n}=8$ e $\lambda=632.8 \mathrm{~nm}$.

As figuras 58a, 58b e 58c ilustram as linhas dos campos elétricos obtidos na simulação usando-se o LevSoft para os três Casos citados. 
Figure 58 - Geometria do Sensor eletro-óptico para os Casos 0, 1 e 2 - a) Caso 0 - Sem a interferência de um objeto aterrado, b) e c) Casos 1 e 2 com a interferência de um objeto (anel) aterrado.

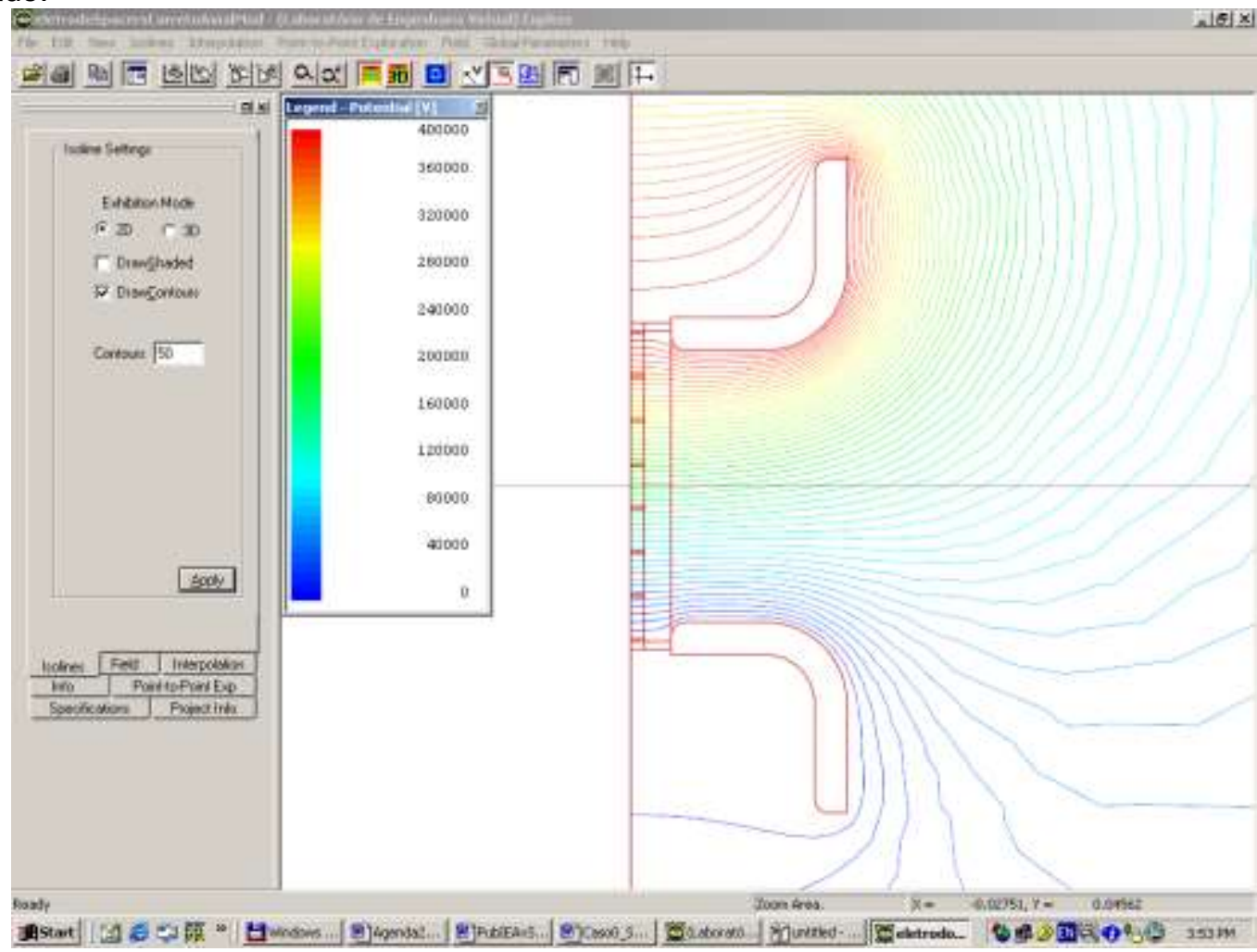

(a)

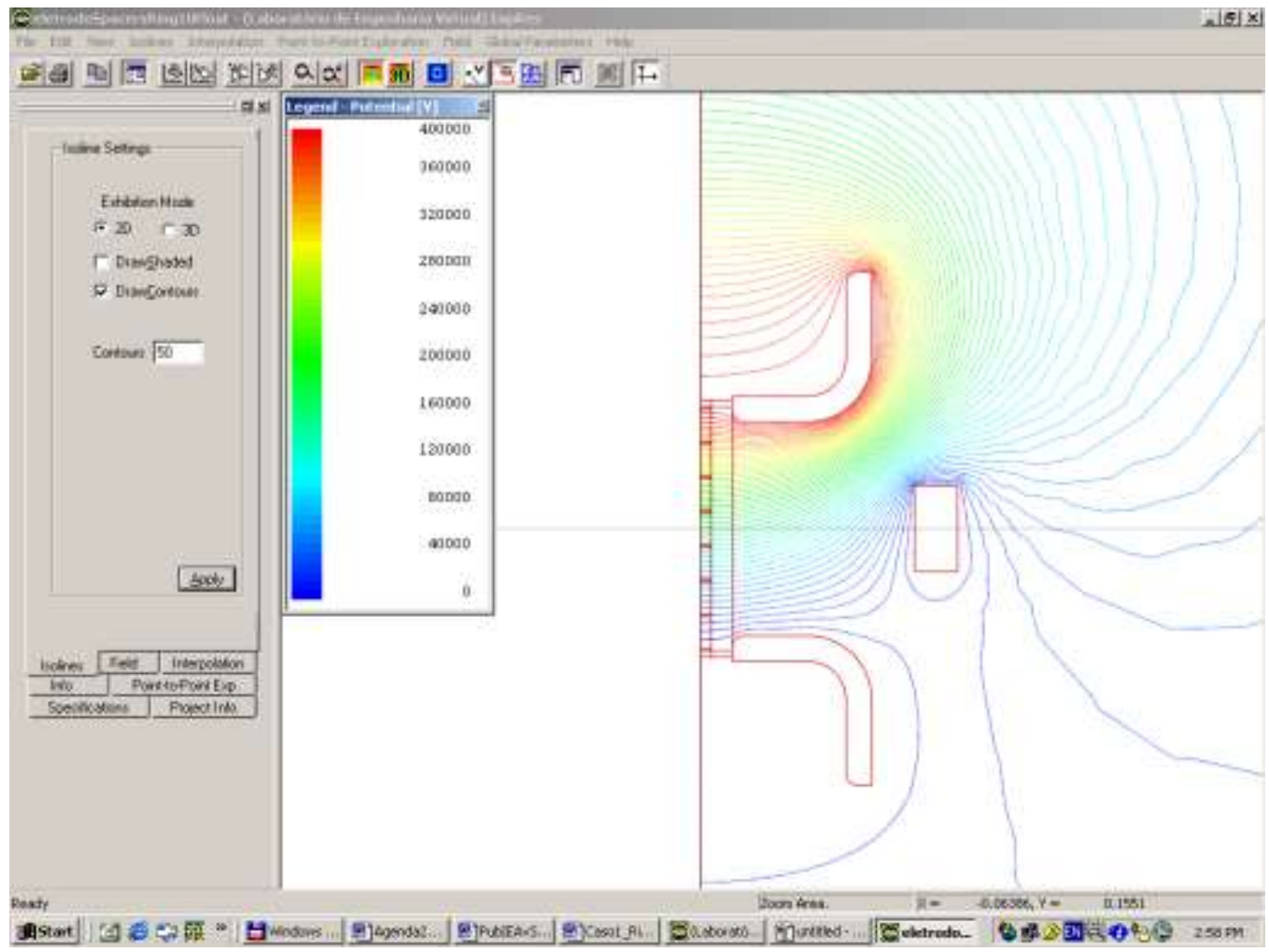

(b) 


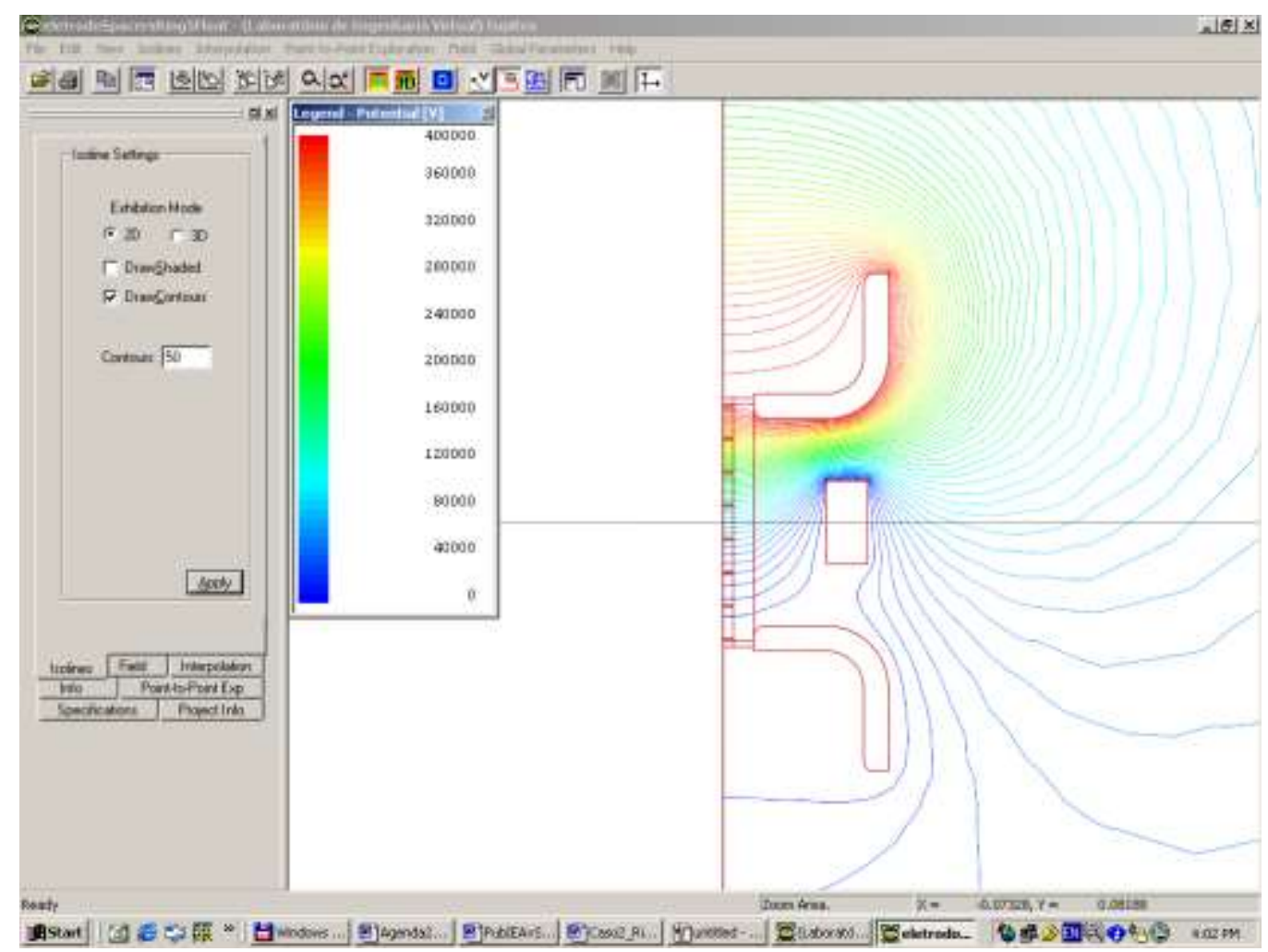

(c)

Fonte: Autor

A figura 59 ilustra a variação do campo elétrico em cada uma das 8 lâminas de cristal, para os Casos 0, 1 e 2.

Figura 59:Gráfico do campo elétrico nas lâminas de cristal (número) para os Casos 0, 1 e 2 .

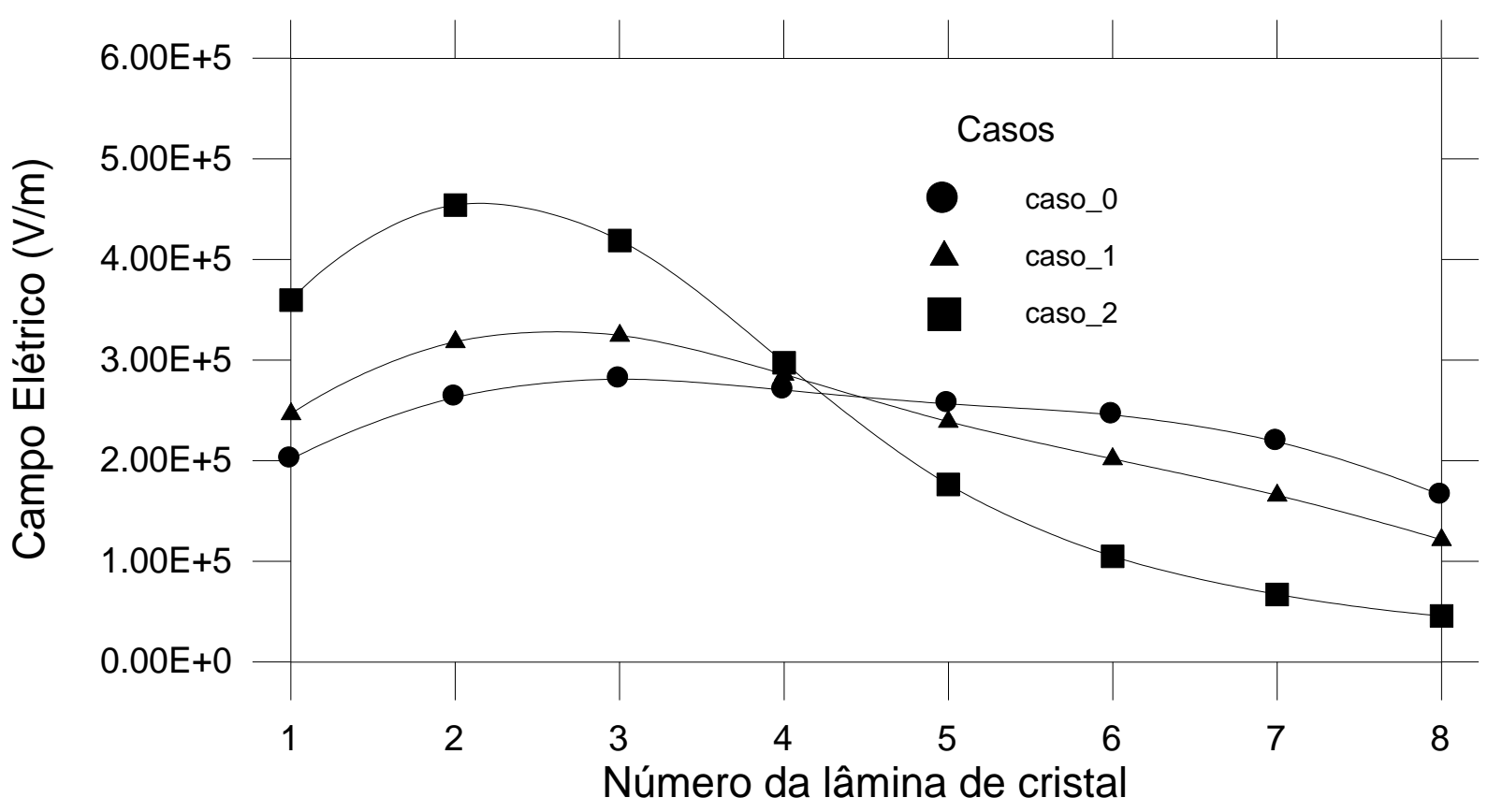

Fonte: Autor (2006) 
A figura 60 ilustra a variação do campo elétrico nas lâminas de cristal para o Caso-0 para 2 tipos de espaçadores (ar e dielétrico), que possuem permissividades diferentes, e para vários diâmetros diferentes do eletrodo, de modo a se verificar a influência destas na distribuição do campo elétrico, bem como, no campo elétrico médio total.

Figura 60- Gráfico do campo elétrico em relação às lâminas de cristal (número) (com espaçadores de ar e dielétrico).

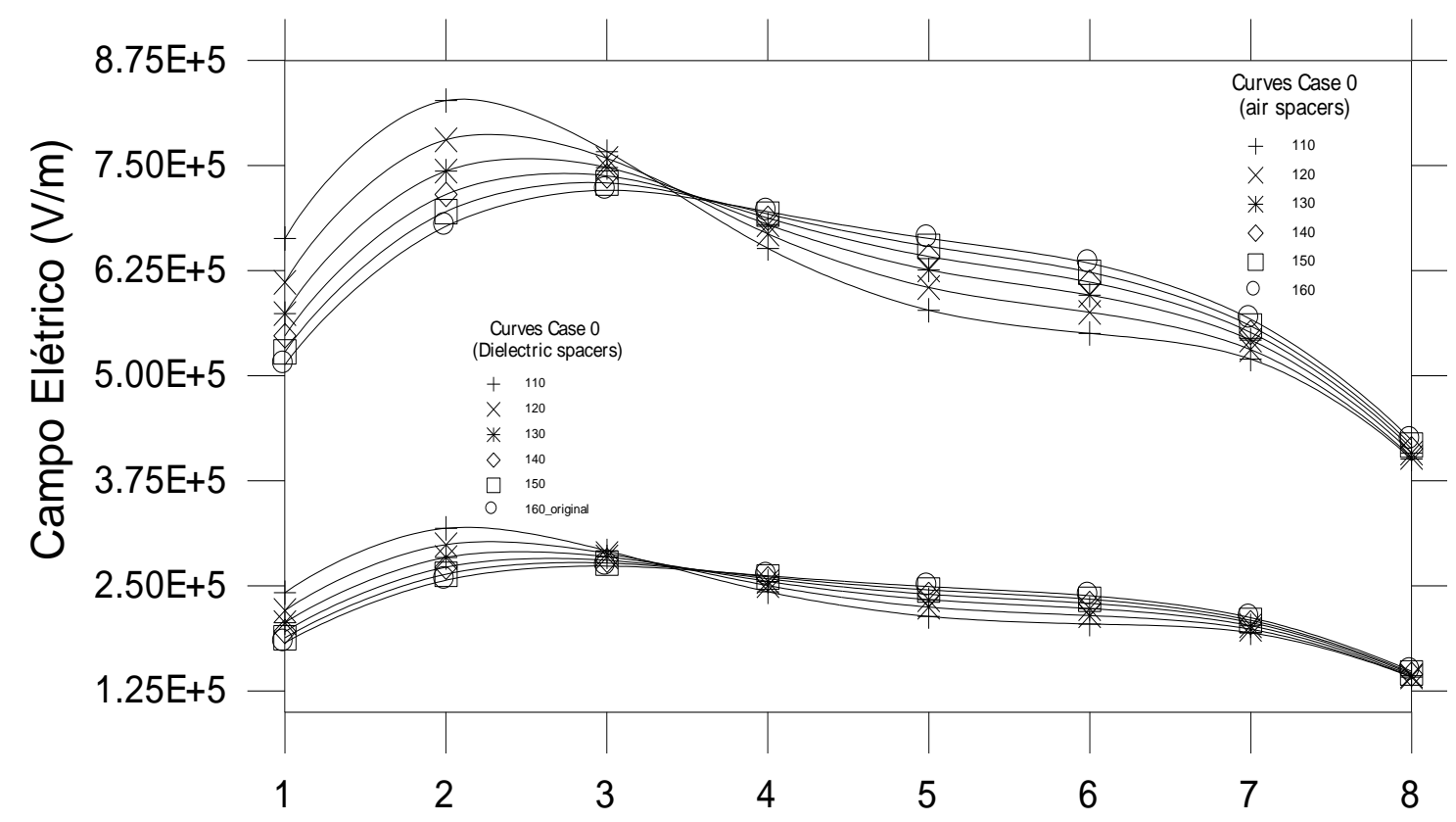

Número da lâmina de cristal

Fonte: Autor (2006)

A tabela 6 ilustra a variação da tensão $V_{\pi}$ para os Casos 0,1 e 2 (espaçamento ar) e que foram calculados utilizando-se a equação de $\mathrm{V}_{\pi} \operatorname{com} K$ proveniente do campo elétrico médio no sensor.

Tabela 6 - Variação da tensão $V_{\pi}$ para os Casos 0,1 e 2 (espaçamento ar).

\begin{tabular}{|c|c|}
\hline CASOS & $\mathrm{V}_{\pi}[\mathrm{MV}]$ \\
\hline 0 & 7,001332 \\
\hline 1 & 6,996579 \\
\hline 2 & 6,917347 \\
\hline
\end{tabular}

Fonte: Autor (2006) 
Foram realizadas simulações que verificam a influência da variação do diâmetro do eletrodo na distribuição do campo elétrico e consequentemente 0 valor de $\mathrm{V} \pi$ do sensor eletro-óptico (para o Caso-0), e que está ilustrada na figura 61.

Figure 61 - Gráfico da tensão $V_{\pi}$ em função da variação do diâmetro dos eletrodos do sensor eletroóptico para o Caso 0.

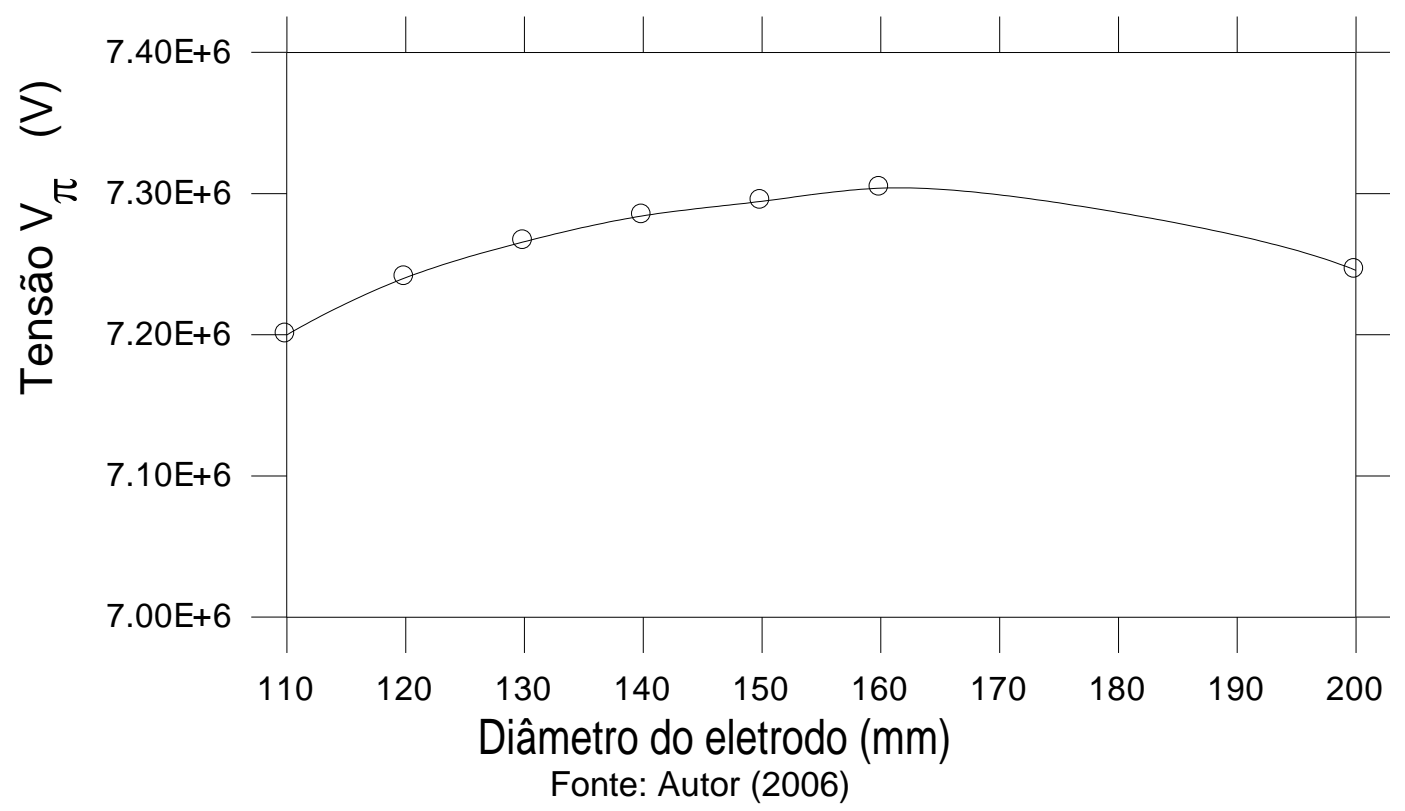

Foi realizada, também, uma simulação que verifica a influência do tipo de espaçadores dielétricos na distribuição do campo elétrico e ainda a variação do diâmetro do eletrodo do sensor eletro-óptico, e que está ilustrada na figura 62.

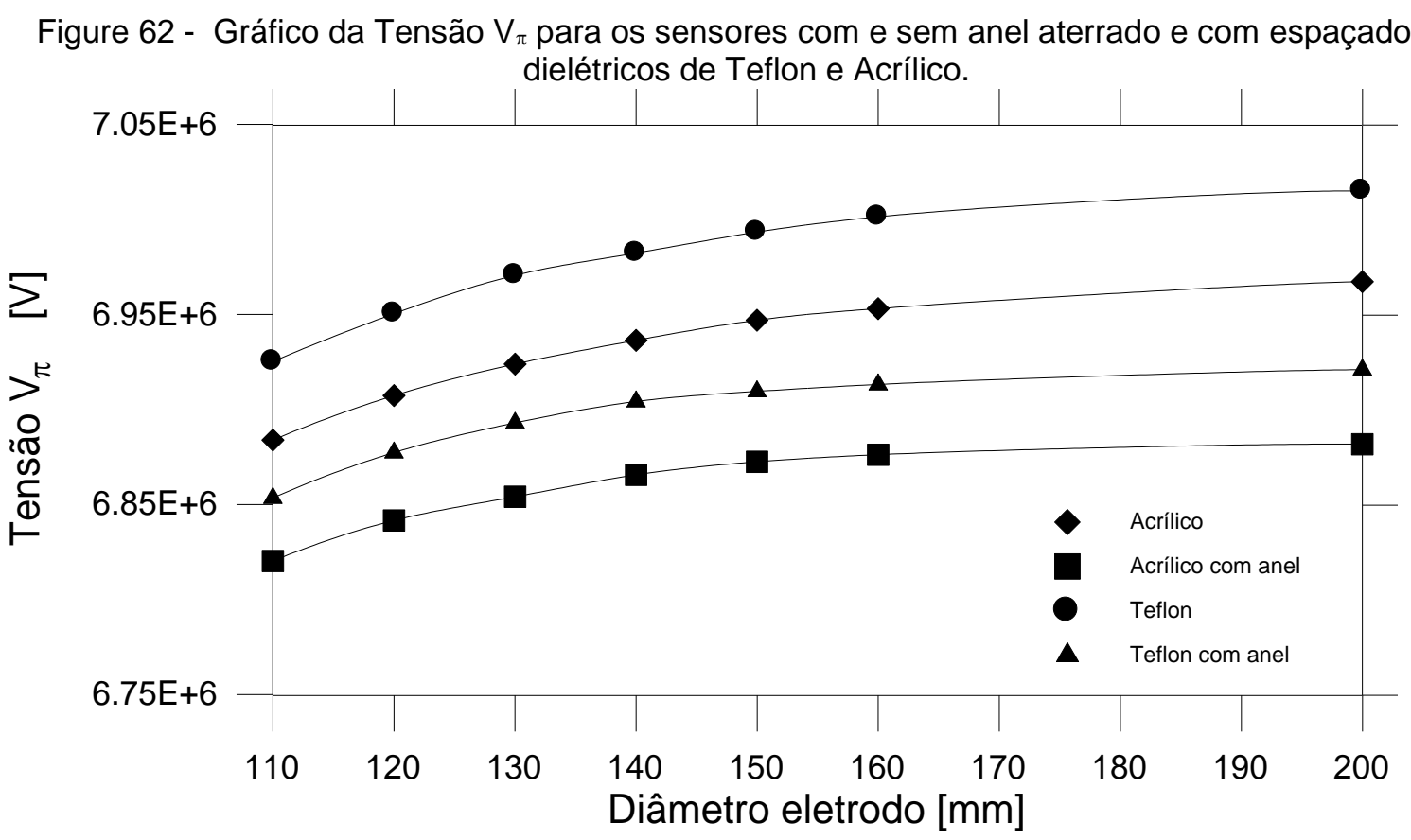

Fonte: Autor (2006) 
Um estudo do efeito do raio das lâminas de cristal eletro-óptico também foi realizado, baseado na configuração 1. A Figura 63 ilustra o campo elétrico médio em cada lâmina de cristal do elemento sensor para vários raios diferentes. Verificou-se que o raio dos cristais tem uma forte influência na tensão $V_{\pi}$, figura 64 , e pode ser utilizado de modo a se ajustar o projeto deste tipo de sensores.

Figure 63 - Média do campo elétrico dentro de cada lâmina (configuração 1) para vários raios do cristal eletro-óptico.

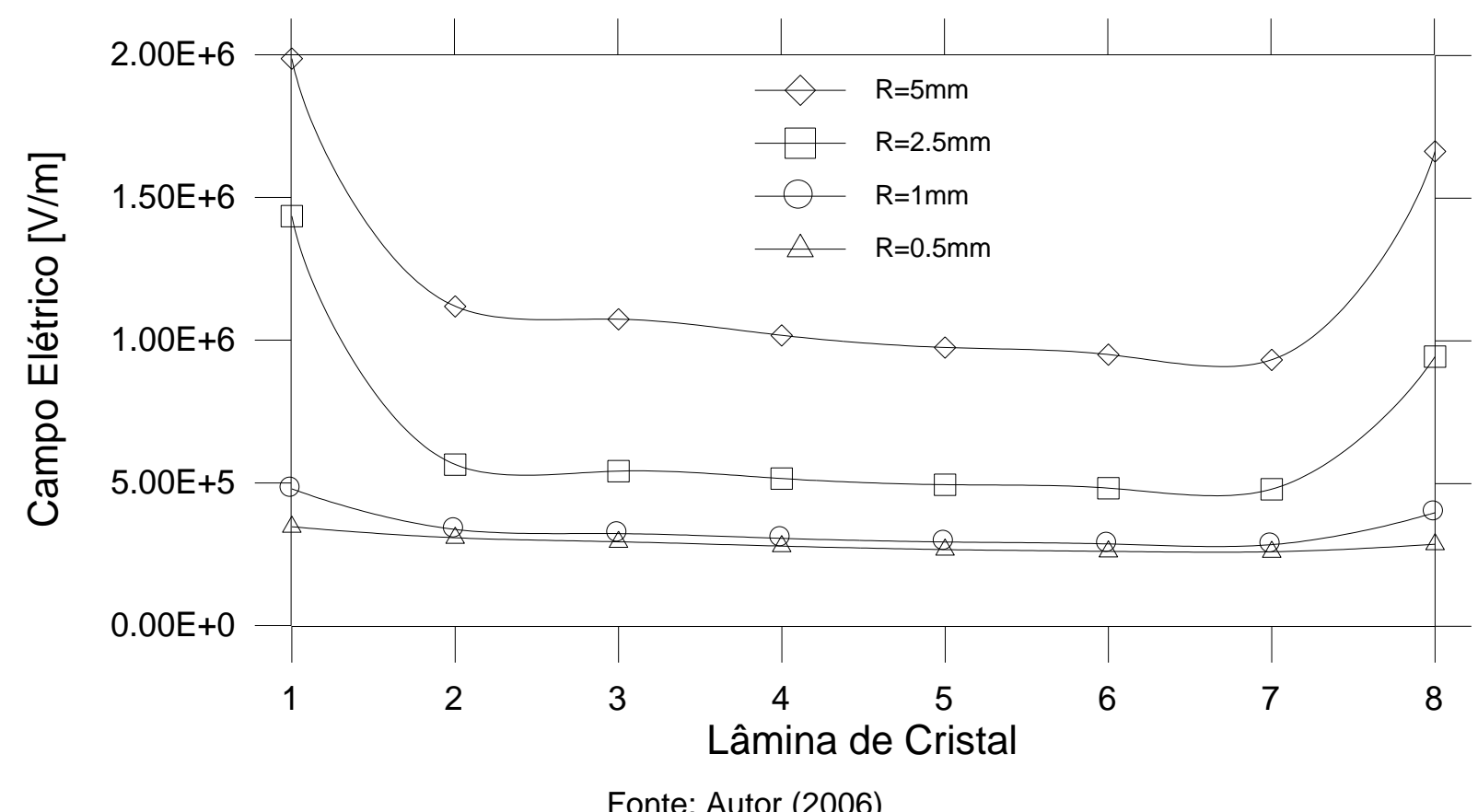

Figure 64 - Tensão $V_{\pi}$ em função do raio do cristal eletro-óptico para a configuração 1.

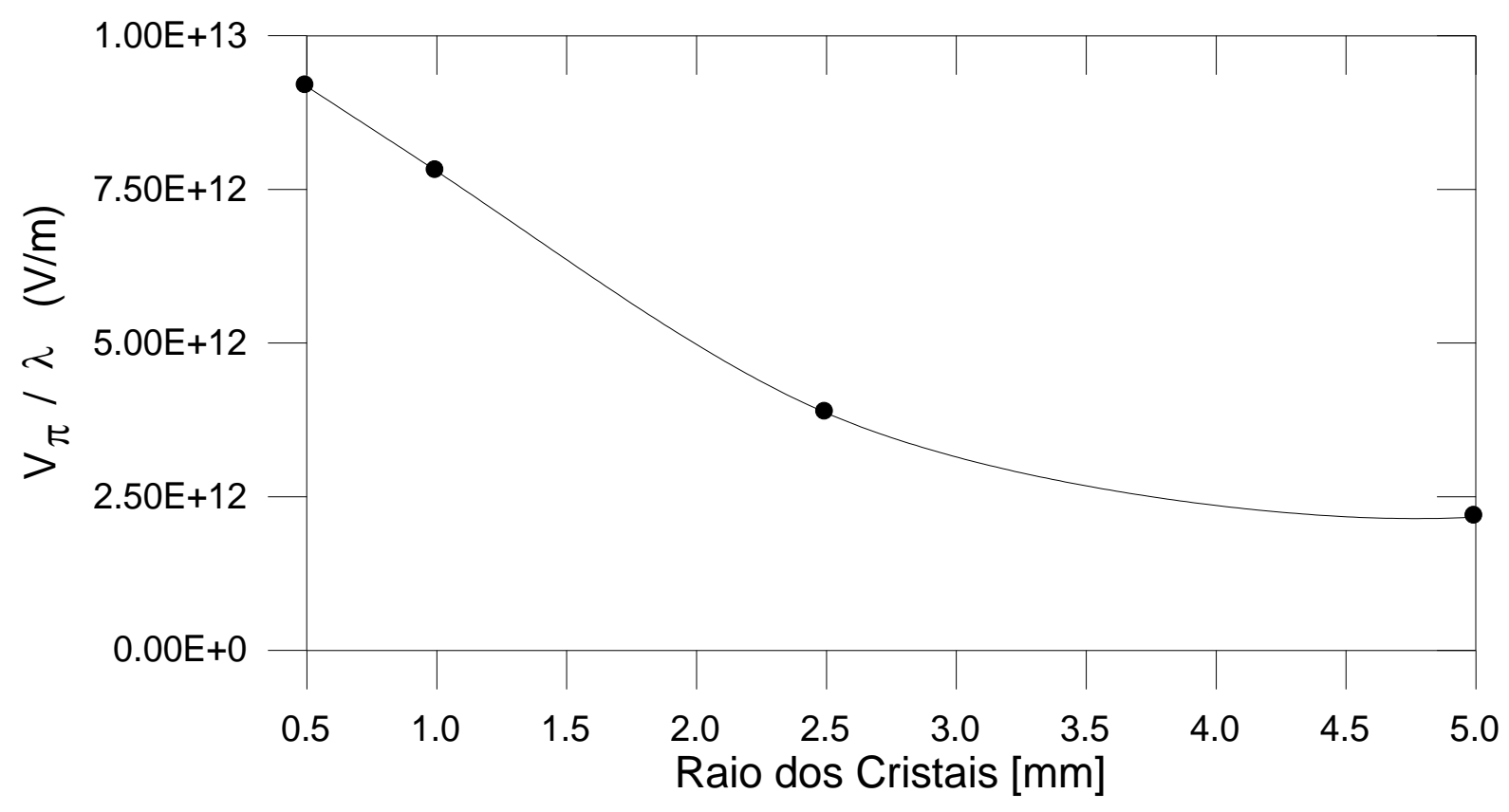

Fonte: Autor (2006) 
$\mathrm{Na}$ configuração 2 o campo elétrico varia consideravelmente dentro de cada um dos cristais e verificou-se que a equação de $K$ não é válida para cristais longos e finos. Portanto, o valor de $K$ apresenta uma discrepância de $80 \%$ se comparado à conseguida analiticamente (eq.(79)) e a simulada pelo MEF.

A figura 65 mostra o campo elétrico obtido para raios diferentes do elétrodo em função da posição de cristal de BGO para a configuração 2 . A tensão $\bigvee_{\pi}$ em função do diâmetro do elétrodo é apresentada na figura 66 e observe-se que os valores diferem $V_{\pi} / \lambda$ somente menos por de $1 \%$. O valor de $V_{\pi} / \lambda$ com a influência do anel metálico realiza-se de $9.7110^{11}$, e difere-se também menos por de $1 \%$ do valor obtido sem o anel.

Figura 65 - Campo elétrico médio nas laminas de cristal BGO para a configuração 2.

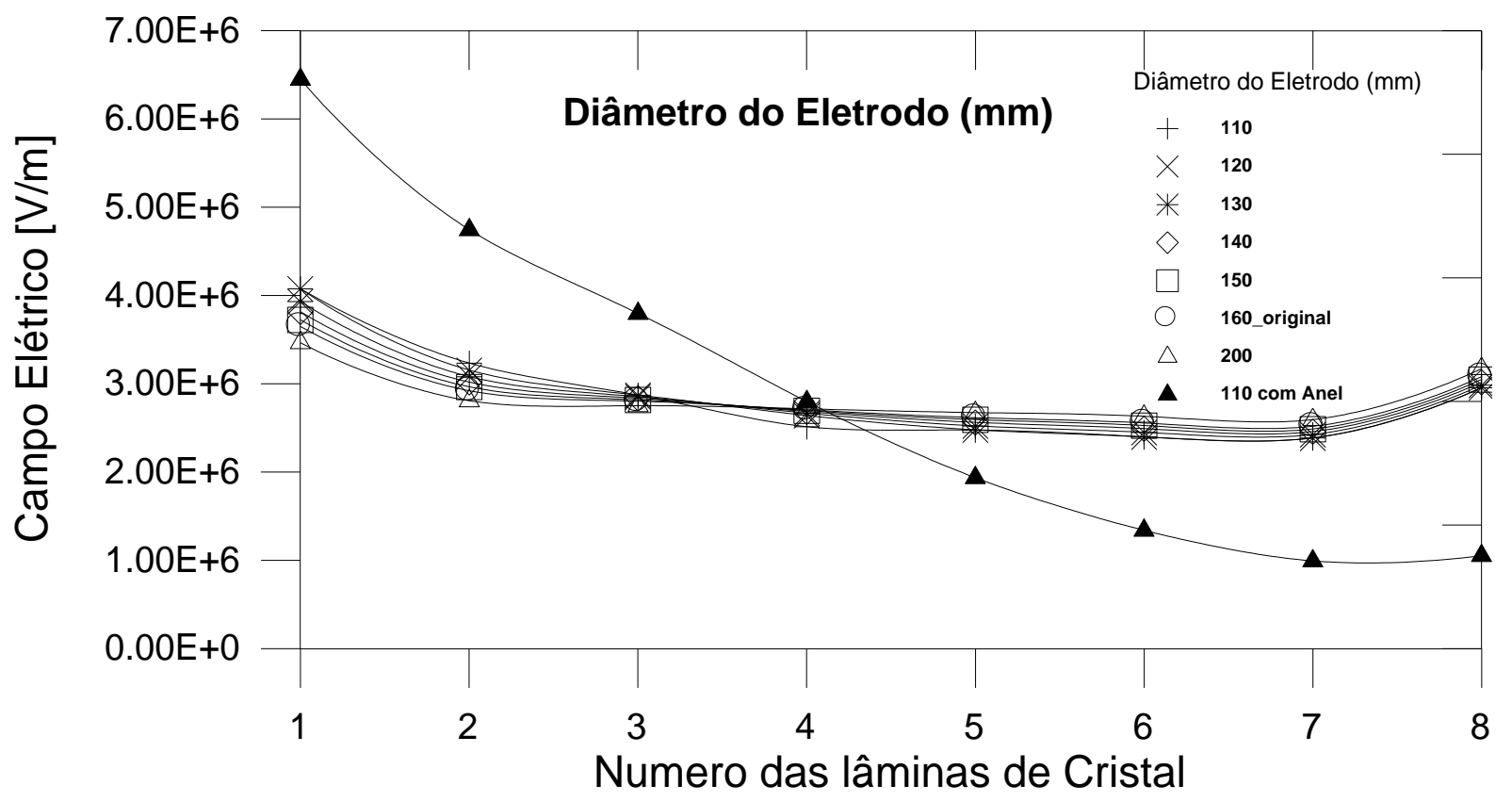

Fonte: Autor (2006) 
Figura 66 - Configuração $2-V_{\pi} / \lambda$ em função do diâmetro do eletrodo.

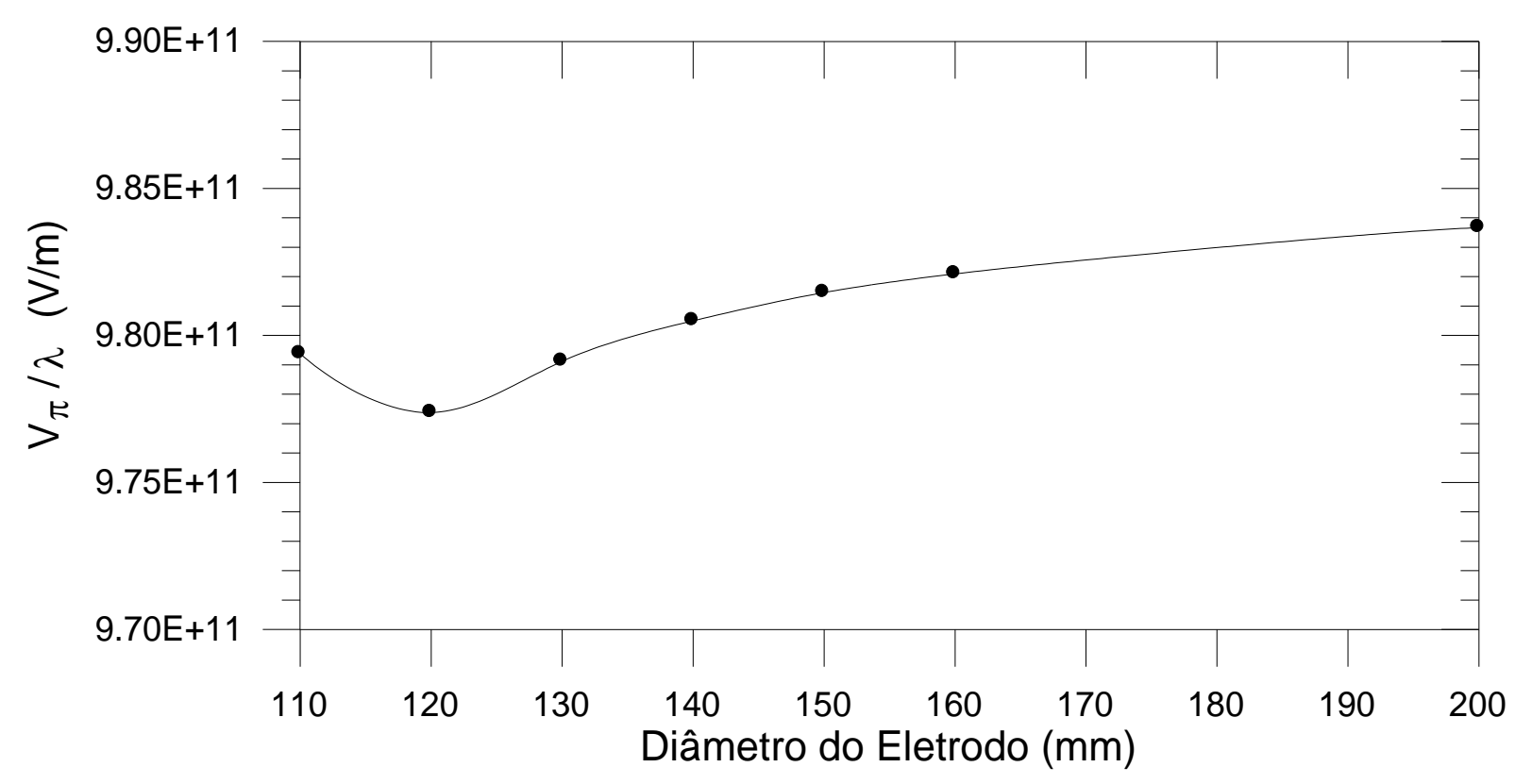

Fonte: Autor (2006)

\subsubsection{SENSOR DE CRISTAL ÚNICO}

Na figura 67 , a seguir, o campo elétrico médio e o parâmetro $\bigvee_{\pi}$ são mostrados em função da espessura de $B G O\left(d_{1}\right)$, para cristais de raio $(r)$ igual a $0.5 \mathrm{~mm}$. O campo elétrico e $V_{\pi}$ variam consideravelmente para cristais eletro-ópticos com espessuras de 1 a 12 milímetros e, particularmente, na faixa de 1 a 3 milímetros. Assim, sabendo-se que $\mathrm{V}_{\pi}$, como descrito anteriormente, se configura como um índice de mérito desse tipo de sensor, a escolha adequada da espessura do cristal afetará a resposta do sensor tanto na sensibilidade como na linearidade.

A figura 67 mostra, também, os valores de $V_{\pi} / \lambda$ experimentalmente obtidos (mostrados na tabela 7), utilizando a configuração "single pass" montada no laboratório do LSO TPO, conforme descrito na seção 3.1.1. E como pode ser visto os valores, experimentais e calculados $V_{\pi} / \lambda$ são muito próximos, diferindo apenas em menos de $3 \%$. 
Tabela 7 - Valores de $\bigvee_{\pi} / \lambda$ obtidos experimentalmente.

\begin{tabular}{|c|c|}
\hline ESPESSURA DO CRISTAL BGO & VALORES DE $V_{\pi} / \lambda$ \\
\hline $100 \mathrm{~mm}$ & $6.15 \mathrm{E}+10[\mathrm{~V} / \mathrm{m}]$ \\
\hline $70.6 \mathrm{~mm}$ & $7.54 \mathrm{E}+10[\mathrm{~V} / \mathrm{m}]$ \\
\hline $30.4 \mathrm{~mm}$ & $2.1 \mathrm{E}+11[\mathrm{~V} / \mathrm{m}]$ \\
\hline $18.8 \mathrm{~mm}$ & $3.38 \mathrm{E}+11[\mathrm{~V} / \mathrm{m}]$ \\
\hline $13.3 \mathrm{~mm}$ & $4.73 \mathrm{E}+11[\mathrm{~V} / \mathrm{m}]$ \\
\hline $10.2 \mathrm{~mm}$ & $7.97 \mathrm{E}+11[\mathrm{~V} / \mathrm{m}]$ \\
\hline
\end{tabular}

Fonte: Autor (2006)

Figura 67 - Campo Elétrico Médio e $V \pi / \lambda$ em função da espessura do cristal para o sensor de Cristal Único.

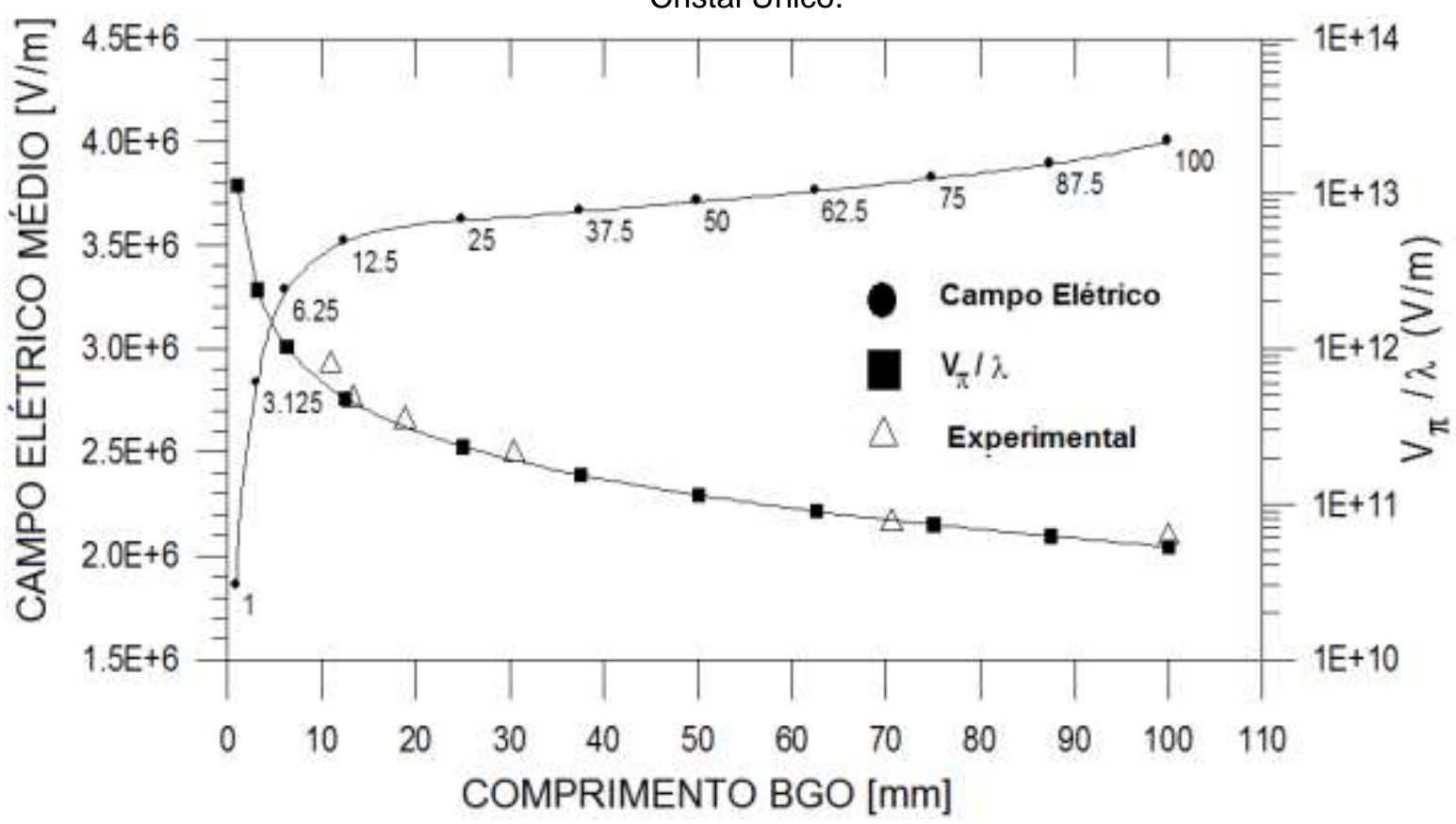

Fonte: Autor (2006)

Como exemplo, ressalta-se o uso de uma lâmina de BGO tendo como dimensões $5 \times 20 \times 18,77 \mathrm{~mm}^{3}$, o $\mathrm{V} \pi$ calculado pela eq.(114) foi igual a $\mathrm{V} \pi=421,9 \mathrm{kV}$, sendo que experimentalmente obteve-se um valor medido de $\mathrm{V} \pi=439,6 \mathrm{kV}$, o qual está em aceitável conformidade com o valor calculado. A discrepância observada, pode ser atribuída a erros no corte dos cristais de BGO que faz com que a direção de propagação da luz não seja perfeitamente paralela ao eixo óptico, z, dos cristais. Os resultados das medidas experimentais com o sensor primário estão apresentados 
em ALMEIDA et al. (2006), e demonstram claramente que o método de projeto do sensor primário desenvolvido permite prever com grande precisão o comportamento do sensor antes de sua fabricação, facilitando enormemente o desenvolvimento de novos sensores. Em vista do exposto, demonstra-se que o método desenvolvido é capaz de atender o objetivo principal deste subtema de pesquisa.

A figura 68, a seguir, apresenta uma comparação da variação do campo elétrico ao longo de uma linha axial paralela à central dentro de dois cristais, uma com o raio $r$ igual a $2.5 \mathrm{~mm}$ e a outra com r igual $0.5 \mathrm{~mm}$. Em ambos os casos, a espessura de cristal é de 7.5 milímetros e é posicionada perto do eletrodo de $400 \mathrm{kVs}$. O valor de $\mathrm{V}_{\pi}$ computado é, aproximadamente, $1.010^{12} \mathrm{~V} / \mathrm{m}$ para $\mathrm{r}=2.5 \mathrm{~mm}$ e $7.110^{11} \mathrm{~V} / \mathrm{m}$ para $r=0.5 \mathrm{~mm}$ correspondendo uma variação maior que $40 \%$. Portanto, verifica-se que para raios maiores o campo se mostra mais comportado mantendo-se uma distribuição mais uniforme e por sua vez afetando menos o valor de e $\vee_{\pi}$.

Figura 68 - Comparação da variação do campo elétrico dentro dos cristais de mesma espessura e raio diferente. As curvas mostram o campo elétrico em 10 pontos dentro do cristal e ao longo da linha central axial.

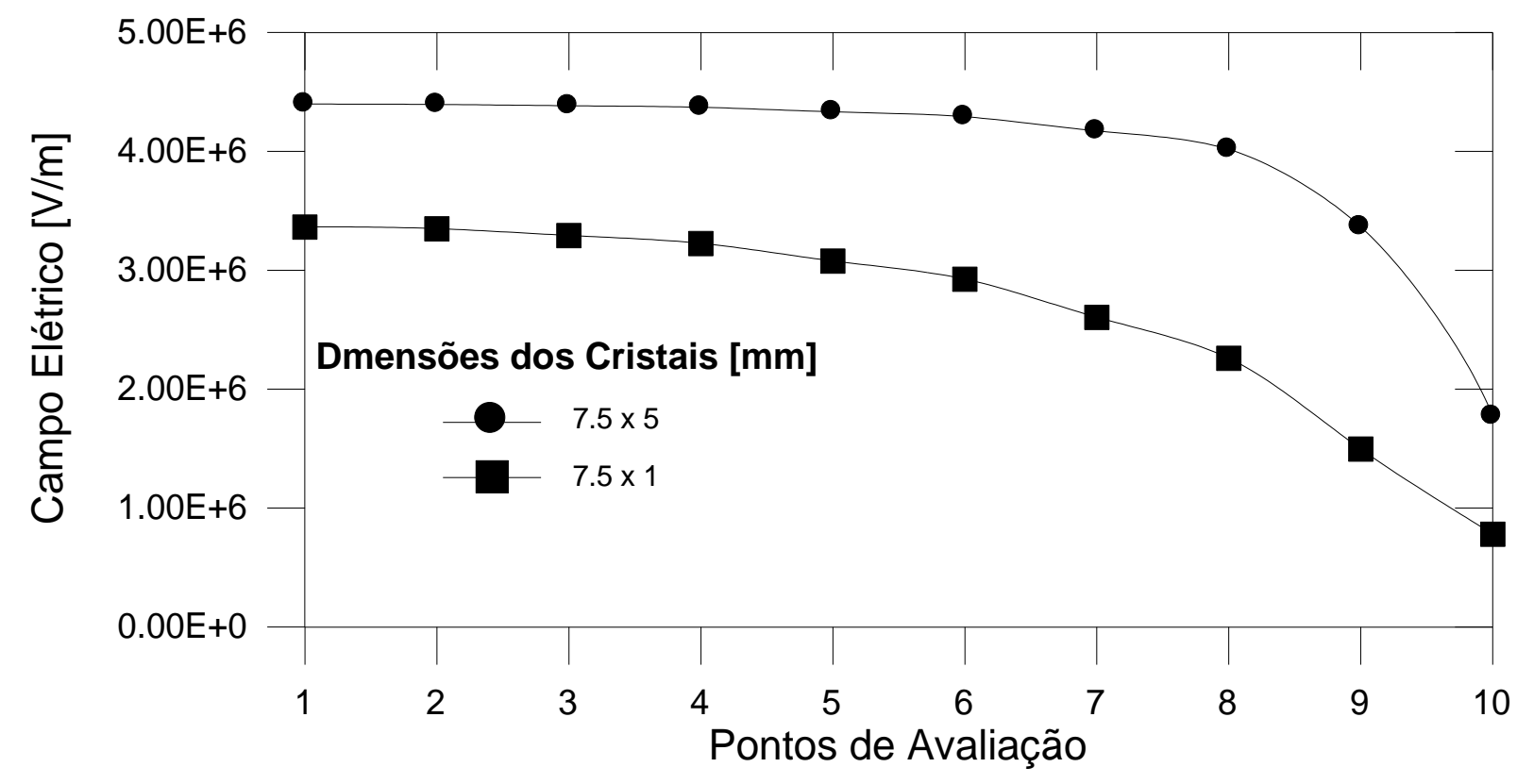

Fonte: Autor (2006) 


\subsection{COMPARAÇÃO ENTRE OS MÉTODOS CSM E MEF (LEVSOFT)}

Os campos elétricos obtidos, na linha de simetria do sensor eletro-óptico, aplicando o MEF e o CSM para as três simulações, nomeadas: caso0, caso1 e caso2, foram comparados. As figuras 69 e 70 mostram os resultados da distribuição do campo elétrico nas 8 lâminas de cristal para os dois métodos e a discrepância nas medidas obtidas, respectivamente. Os resultados obtidos foram muito próximos, entretanto, nas bordas ocorreram as maiores discrepâncias. As discrepâncias de até $17 \%$ foram obtidas perto dos eletrodos. Observe-se que as curvas obtidas aplicando os métodos MEF e CSM são muito próximas para o caso1 (RUBINI et al., 2004).

Figura 69 - Comparação do campo elétrico obtido para os casos 0, 1 e 2 aplicando os métodos CSM e FEM.

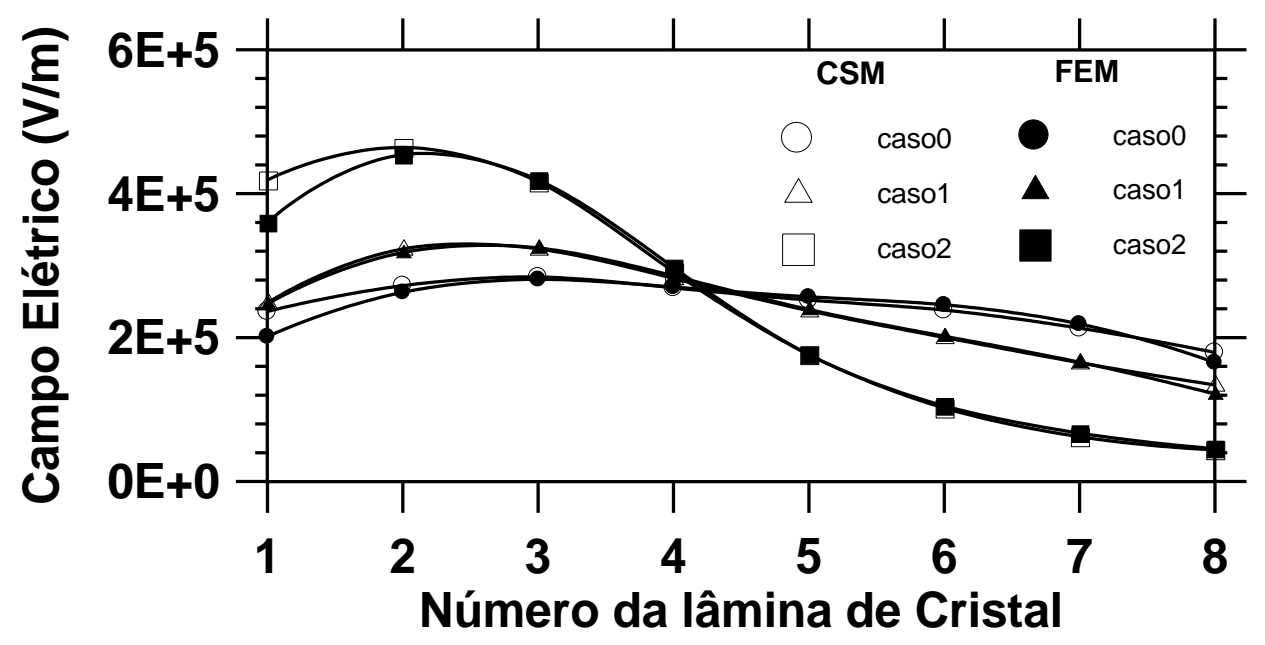

Fonte: Autor (2006)

Figura 70 - Discrepância entre os métodos de simulação para os casos 0,1 e 2 .

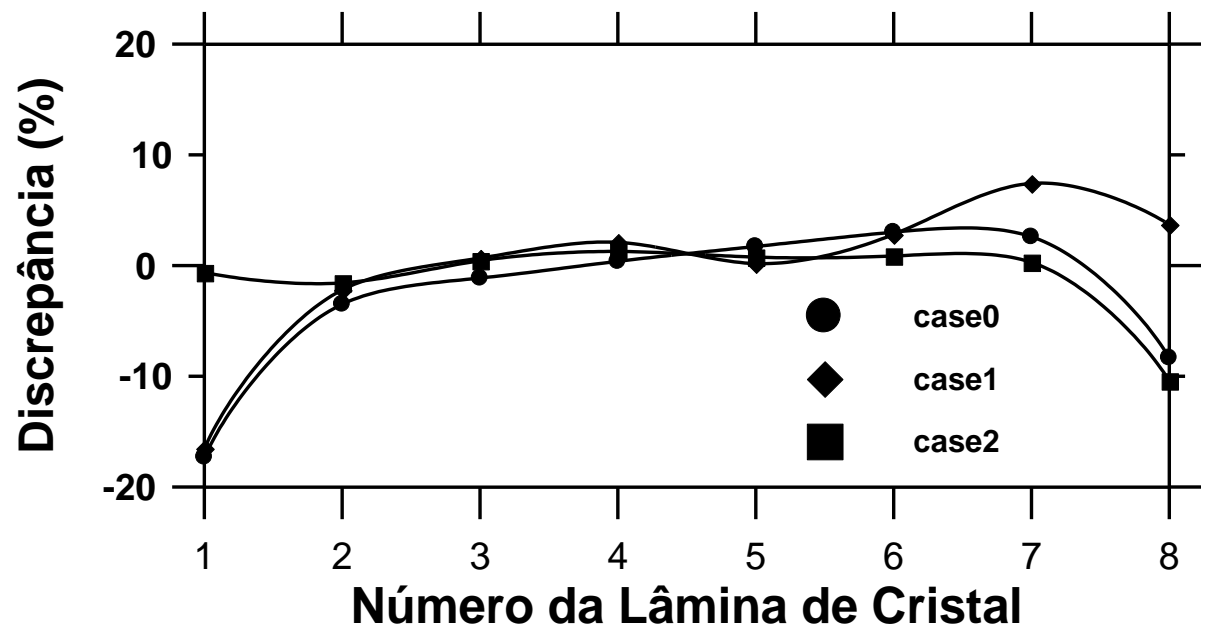

Fonte: Autor (2006) 


\subsection{ESPECIFICAÇÃO DA DIMENSÃO DO CRISTAL DE BGO PARA A CÉLULA SENSORA DE ALTA TENSÃO NA CONFIGURAÇÃO DOUBLE PASS.}

O parâmetro $V_{\pi}$, como verificado anteriormente, é um fator determinante no desenvolvimento da célula sensora aplicada ao TPOs. Portanto a especificação do mesmo é de vital importância e que impactará não só na linearidade de resposta bem como na sensibilidade.

Neste trabalho, a dimensão do cristal BGO utilizado na célula sensora de alta tensão, com a topologia "double pass", teve a sua especificação baseada, inicialmente com a classe de operação da célula sensor que é de $69 \mathrm{kV}$ e que definirá, por sua vez, o valor da tensão $\mathrm{V}_{\pi}$ que implicará diretamente na sensibilidade (visibilidade) e linearidade da célula.

Para a operação na classe $69 \mathrm{kV}$ especificou-se um $V_{\pi \mathrm{s}}$, em torno de $140 \mathrm{kV}$, ou seja, aproximadamente o dobro do valor de operação e utilizando-se a curva da figura 66, que descreve $V \pi / \lambda$ em função do tamanho do cristal para a configuração de sensor de cristal único, verificou-se que para um cristal com uma dimensão de $30 \mathrm{~mm}$, obtém-se um valor de $V \pi / \lambda$ aproximadamente igual a 1,95E+11 [V/m] (figura 66 modificada), e que operando com um $\lambda=1500 \mathrm{~nm}$ promove um valor de $V_{\pi}$ torno de $285 \mathrm{kV}$, conforme ilustra a figura 71.

Contudo, como a topologia utiliza é reflexiva (double pass), caracterizada pela passagem do sinal de luz duas vezes pelo cristal, esse valor de $V_{\pi}$ cai pela metade, ou seja, 142,5kV, valor adequado para a implementação da célula sensora de alta tensão. 
Figura 71 - Obtenção do valor de $V \pi$ (@1550nm) para um cristal de 30mm de espessura

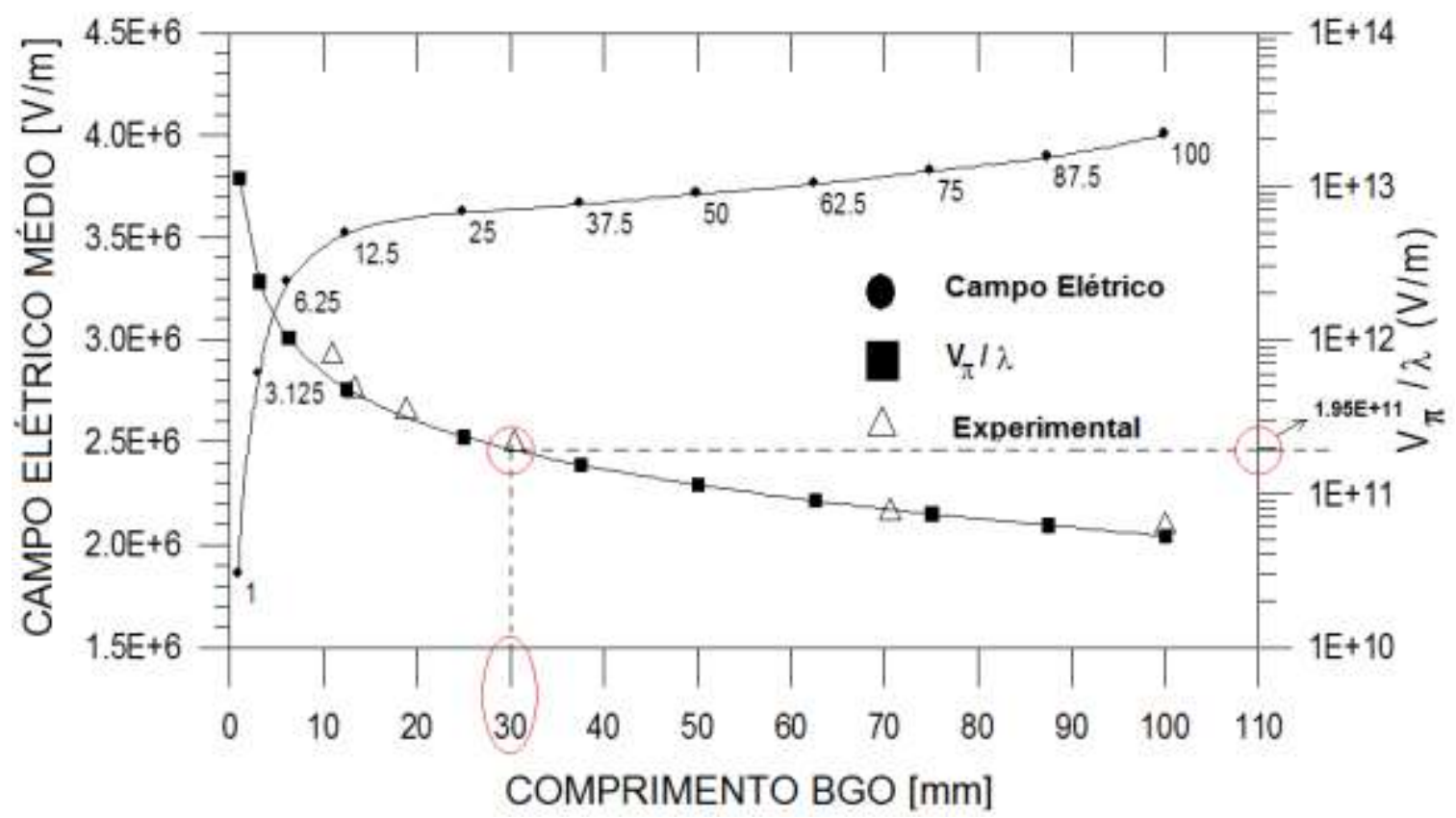

Fonte: Autor 


\section{RESULTADOS EXPERIMENTAIS}

O protótipo de TPO, com a célula de alta tensão na topologia reflexiva, foi submetido a ensaios funcionais para verificar o seu desempenho quando submetido a tensões $\mathrm{CA}$ na faixa de $25 \mathrm{kV} r m s$ a $69 \mathrm{kV}$ rms e tensão de aproximadamente $140 \mathrm{kV} r \mathrm{~s}$ visando teste de suportabilidade.

Nestes ensaios foram realizados os primeiros testes de integração de todos os sistemas do TPO, além das análises da tensão elétrica em C.A. aplicada ao interferômetro sensor e da tensão demodulada na saída, digital, do processador de sinais.

Os ensaios foram realizados nos laboratórios de metrologia do IEE-USP e de altas tensões da CTEEP (Companhia de Transmissão de Energia Elétrica Paulista) em Bauru -SP, onde o protótipo do TPO, em fase final de desenvolvimento, pode ser confrontado com os Tl's de referência da CTEEP, bem como o do Laboratório de Metrologia da USP (IEE-USP). O laboratório da CEETP realiza ensaios de alta tensão em equipamentos elétricos de $15 \mathrm{kV}$ a $550 \mathrm{kV}$ de sistemas de potência, tais como: transformadores de corrente, transformadores de potencial capacitivos e indutivos, buchas de transformadores e de cubículos, para-raios de carboneto de silício e de óxido de zinco, cadeias de isoladores, capacitores, entre outros.

O protótipo foi, inicialmente, submetido a teste de suportabilidade no qual foi aprovado para operação em $69 \mathrm{kV}$, sendo que os dados dos testes de encontram-se no adendo $B$.

Os circuitos ópticos (contidos nas células sensora e recuperadora), utilizados neste trabalho, foram integrados à eletrônica de processamento de sinal e o conjunto submetido a ensaios de caracterização do protótipo de TPO. Na implementação do processador destaca-se que: 
O modulador contido no interferômetro recuperador foi alimentado com sinal senoidal proveniente da Unidade de Processamento Eletrônico de Sinais (cuja frequência é de $30720 \mathrm{~Hz}$ e tensão $V_{\pi r}$ em torno $2,5 \mathrm{~V}$ ).

Para atender ao requisito de se utilizar uma fonte de espectro largo (e baixa coerência temporal) devido à técnica utilizada, a fonte de luz empregada foi um diodo superluminescente (SLD), cujo comprimento de onda central típico é $1560 \mathrm{~nm}$ e potência de saída típica de $5 \mathrm{~mW}$.

A detecção óptica foi feita através de um fotodiodo PIN (InGaAs), com faixa espectral de 1250-1600 $\mathrm{nm}$ e responsividade 0,9 (A/W).

A fotocorrente detectada foi convertida em tensão por meio de um amplificador de transimpedância com ganho em torno de 3 milhões $(V / A)$.

No que se refere ao percentual medido de luz refletida na extremidade espelhada do cristal, na célula sensora de alta tensão, o valor apresentado, foi acima de $90 \%$, valor típico para o espelhamento utilizando-se alumínio (LAVRAS, 2002).

\subsection{ENSAIOS FUNCIONAIS DO CONJUNTO TPO E UNIDADE DE PROCESSAMENTO ELETRÔNICO}

$\mathrm{Na}$ Figura 72, a seguir, ilustra-se o arranjo utilizado para o ensaio do TPO onde notase a fonte de alimentação, capaz de aplicar tensões de até aproximadamente 550 kVrms $(60 \mathrm{~Hz})$, ligada não só à célula de alta tensão do protótipo de TPO bem como aos TPs de referência da CTEEP e do IEE-USP.

Tanto a célula sensora como a recuperadora estão ligados por um enlace à fibras ópticas PM que por sua vez está ligada ao circulador óptico e também à fonte de luz e pôr fim ao fotodetector ligado à Unidade de Processamento de Sinais do TPO que está conectado à célula recuperadora (via modulador eletro-óptico) através de cabo multifilar. 
O enlace com fibras PM mostrou-se muito eficiente e insensível a manipulações e vibrações.

Os sinais das referências e do TPO são digitalizados pela Unidade de Processamento de Sinais à uma taxa de 80 amostras por ciclo.

O protótipo de TPO, conforme dito anteriormente, foi submetido a ensaios funcionais para verificar o seu desempenho quando submetido à tensões C.A., em $60 \mathrm{~Hz}$, na faixa de $25 \mathrm{kVrms}$ a $69 \mathrm{kVrms}$ em passos de $5 \mathrm{kVrms}$.

Figura 72 - Foto do arranjo utilizado para os ensaios do protótipo de TPO nas instalações do laboratório de alta tensão da CTEEP.

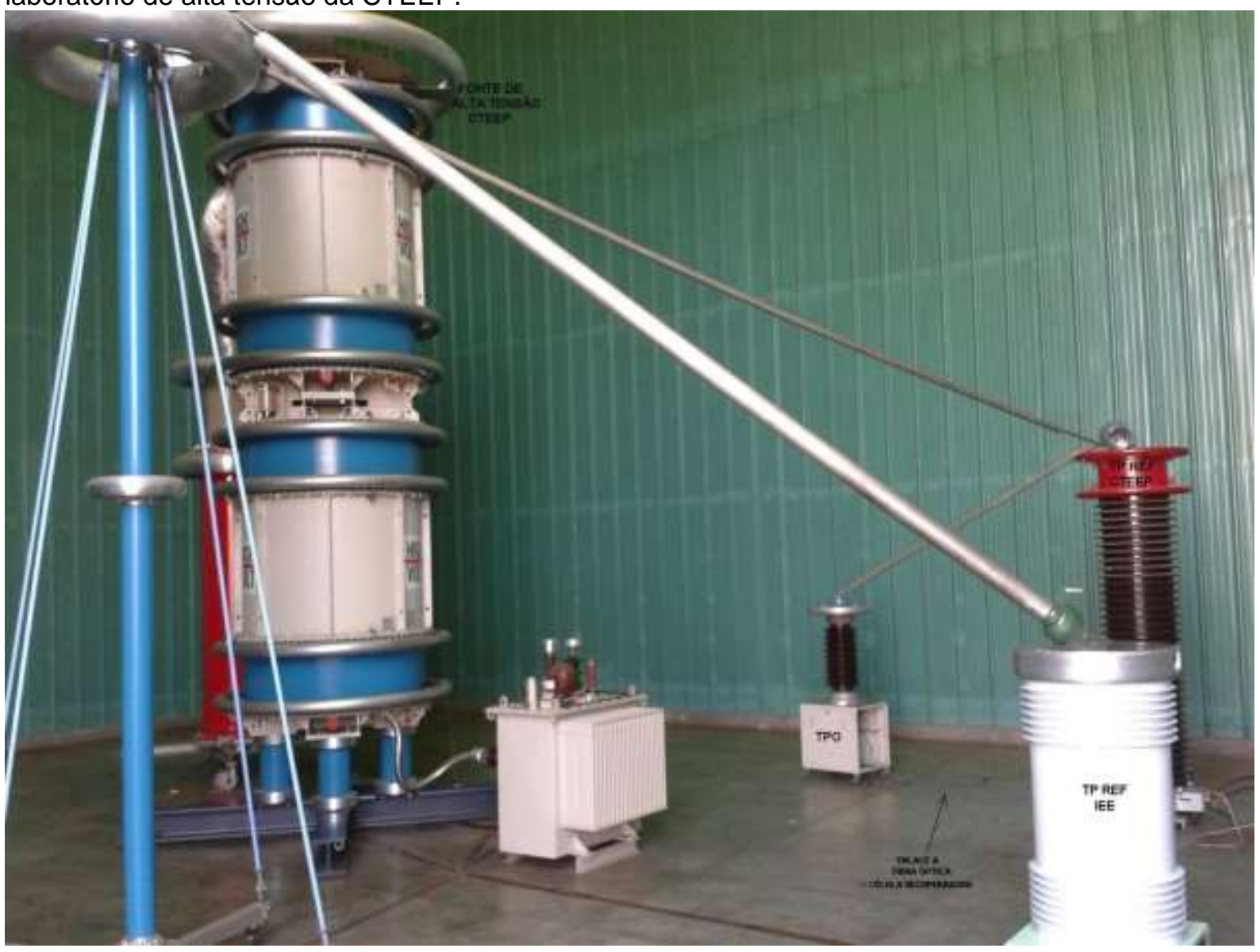

Fonte: Autor

A foto contida na Figura 73, a seguir, mostra bancada montada, que contém a célula recuperadora interligada à fonte óptica e em conjunto com a unidade de processamento eletrônico, visando os ensaios do TPO a partir da aquisição das formas de onda. 
Figura 73 - Foto da bancada com o sistema da célula recuperador em conjunto sistema de aquisição de dados visando o ensaio do TPO, sendo: a) Fonte óptica (alimentação+SLD+circulador óptico), b) Célula Recuperadora (transmissiva-"single pass"-modulador EOSPACE), c) Unidade de Processamento Eletrônico de sinais, d) Osciloscópio e e) Computador (para leitura dos dados provenientes da unidade de processamento eletrônico).

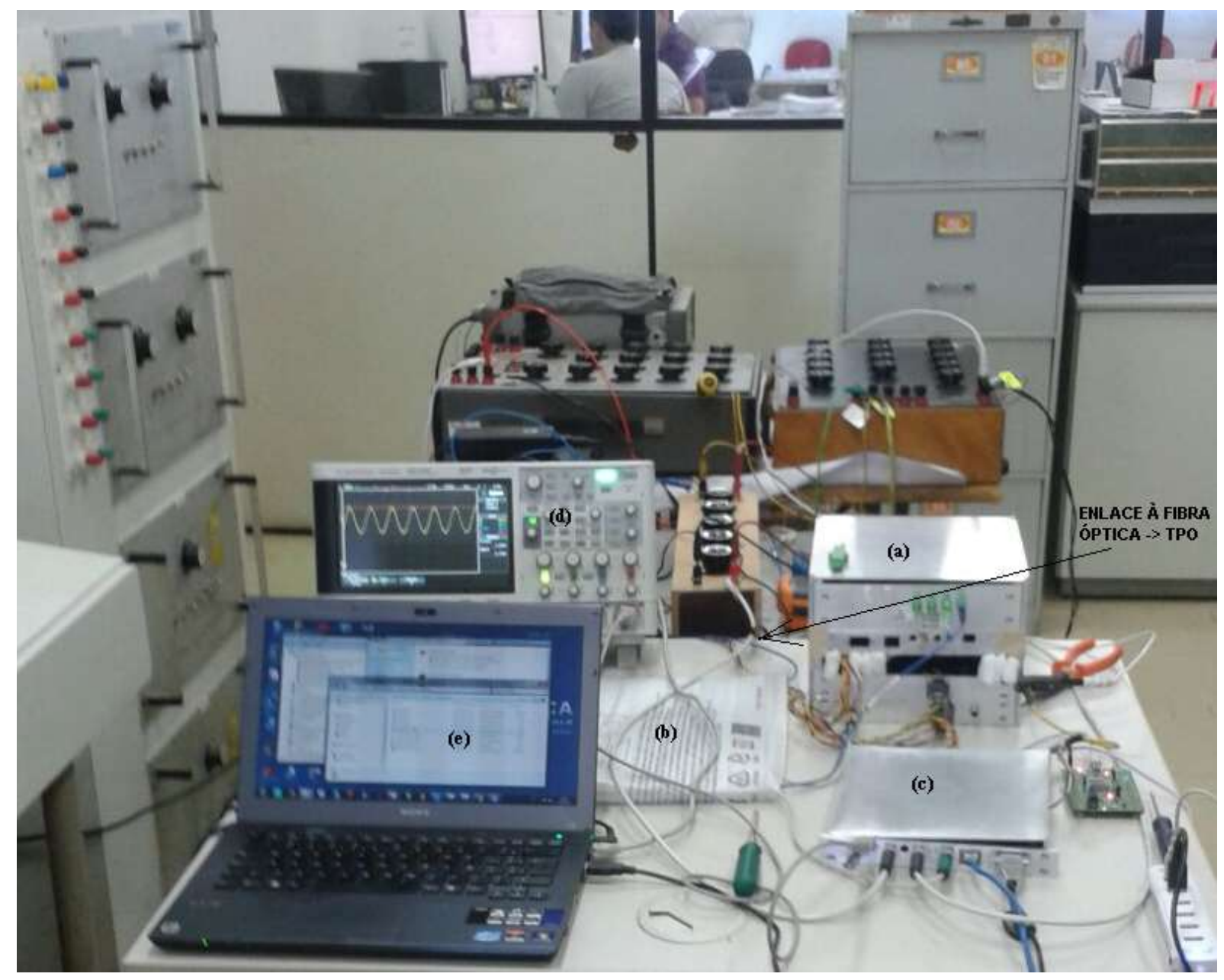

Fonte: Autor

Inicialmente foram realizados alguns ajustes relacionados ao método, já descrito, de demodulação síncrona de sinais interferométricos a partir da verificação dos picos e vales e que culmina na obtenção da informação de tensão, proveniente da célula sensora de alta tensão do TPO. Assim, as formas de onda ilustradas nas figuras 74 e 75, a seguir, descrevem a informação proveniente do interferômetro recuperador simulando uma situação de ausência e presença, respectivamente de sinal externo (alta tensão aplicada à célula sensora). 
Figura 74 - Forma de onda proveniente da célula recuperadora (cor verde) e o sinal eletro-óptico na malha interna do detector de vale (cor magenta) sem sinal de alta tensão aplicada (vales em equilíbrio). (O sinal, de cor azul, mostra os pulsos de sincronismo interno da Unidade de Processamento Eletrônico de sinais e o sinal em amarelo, representa o valor armazenado do vale).

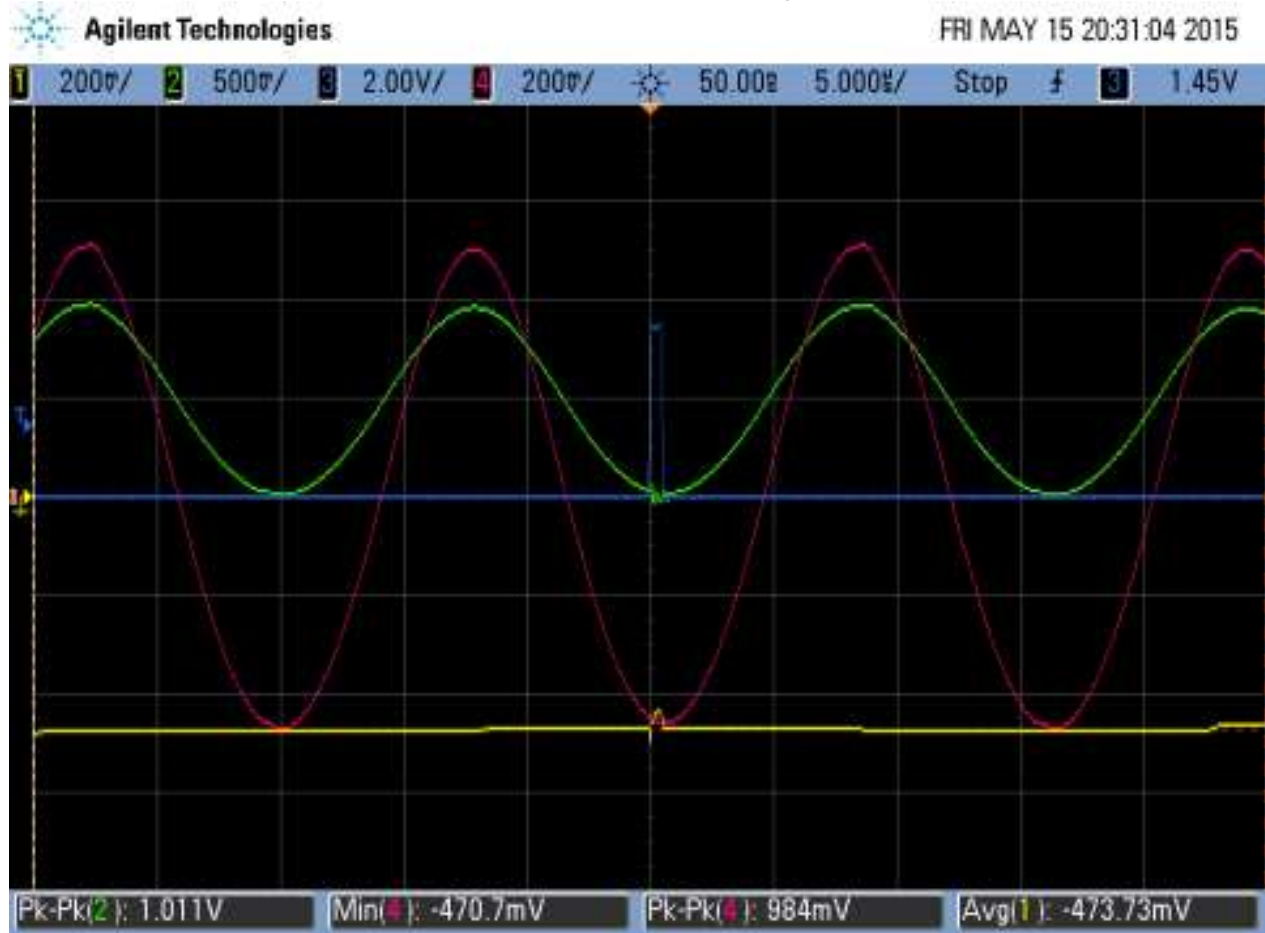

Fonte: SHIGUERU (2015).

Figura 75 - Forma de onda proveniente da célula recuperadora (cor verde) e o sinal eletro-óptico na malha interna do detector de vale (cor roxa) sem sinal de alta tensão de aplicada (vales em desequilíbrio). (O sinal, de cor azul, mostra os pulsos de sincronismo interno da Unidade de Processamento Eletrônico de sinais e o sinal, em amarelo, representa o valor armazenado do vale).

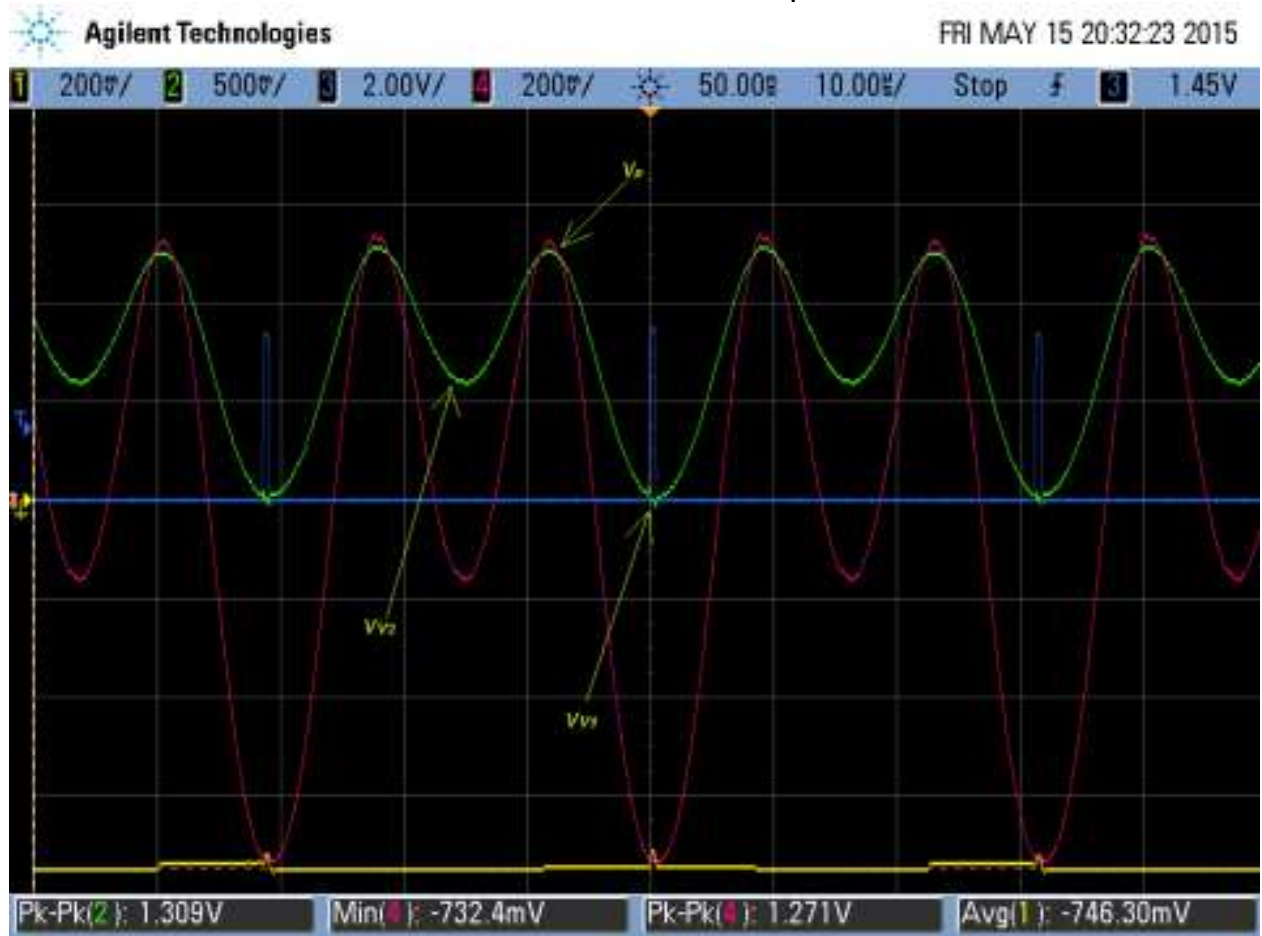

Fonte: SHIGUERU (2015) modificada. 
Ressalta-se na figura 75 os valores de tensão de pico $\left(V_{p}\right)$ e tensões dos vales $\left(V_{v t}\right.$ e $V_{v_{2}}$ ) para a situação de desiquilíbrio, ou seja, na presença de uma tensão aplicada na célula de alta tensão.

A partir do arranjo experimental ilustrado na figura 72 (no laboratório da CTEEP), o TPO foi submetido a ensaios de alta tensão na faixa de $25 \mathrm{kV} r m s$ à $69 \mathrm{kV} r m s$ (em intervalos de $5 \mathrm{kV}$ rms) e foram obtidas as formas de ondas (digitalizadas) do TPO, bem como, das referências da CTEEP e do IEE-USP. As figuras 76 e 77 ilustram as formas de onda para $25 \mathrm{kV}$ rms e $69 \mathrm{kV} \mathrm{rms}$, respectivamente, sendo que, as formas de ondas na coloração amarela são os sinais obtidos do TPO, as formas de ondas na coloração roxa do TP de referência do IEE e a coloração verde do TP de referência da CTEEP.

Figura 76 - Formas de onda da tensão da ordem de $25 \mathrm{kV}$ rms, aplicada à célula sensora de alta tensão do TPO (cor amarela) e aos TPs de referência do IEE (cor roxa) e do CTEEP (cor verde).

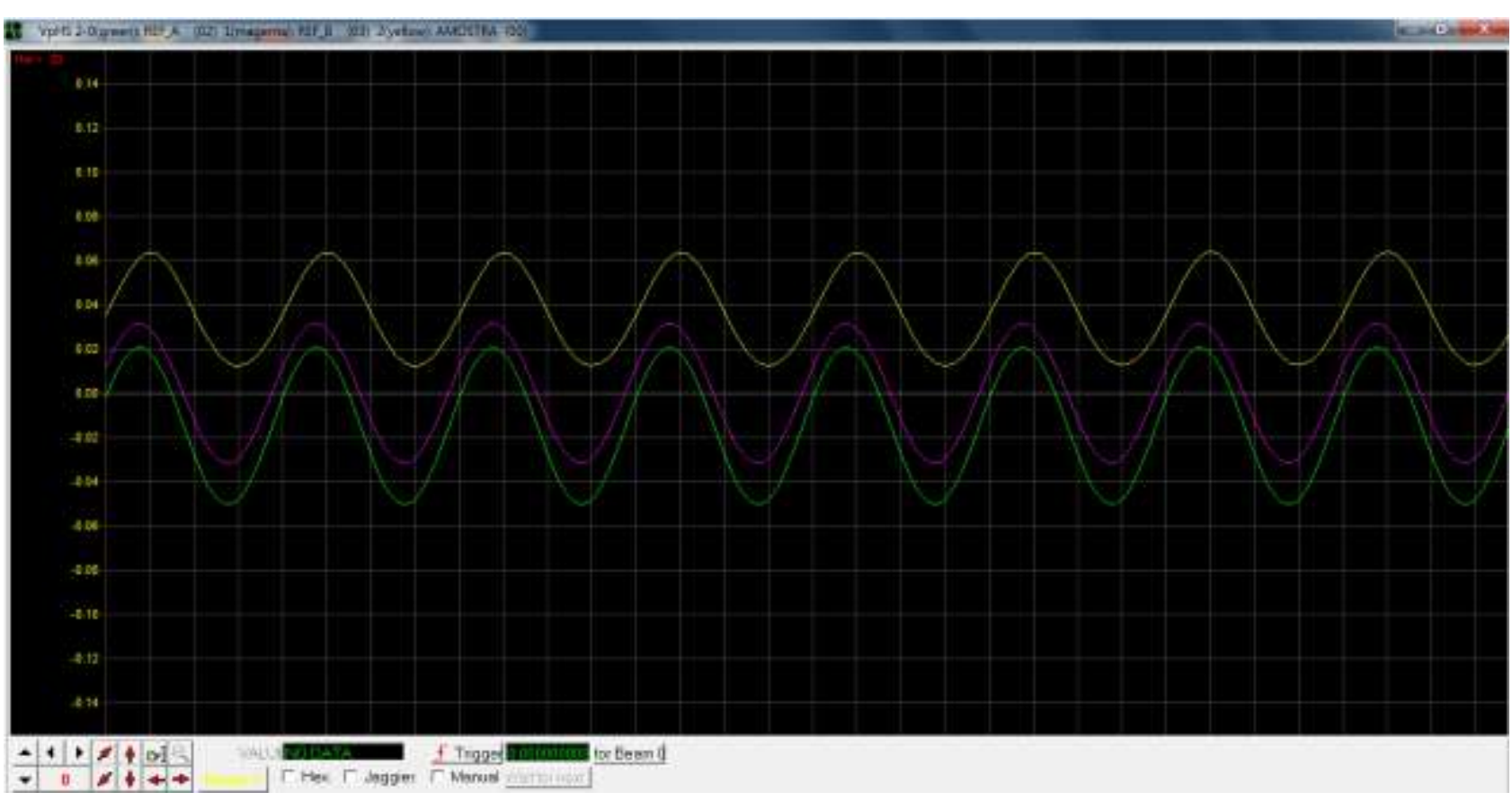

Fonte: SHIGUERU (2015). 
Figura 77 - Formas de onda da tensão da ordem de $69 \mathrm{kV}$ rms, aplicada à célula sensora de alta tensão do TPO (cor amarela) e aos TPs de referência do IEE (cor roxa) e do CTEEP (cor verde).

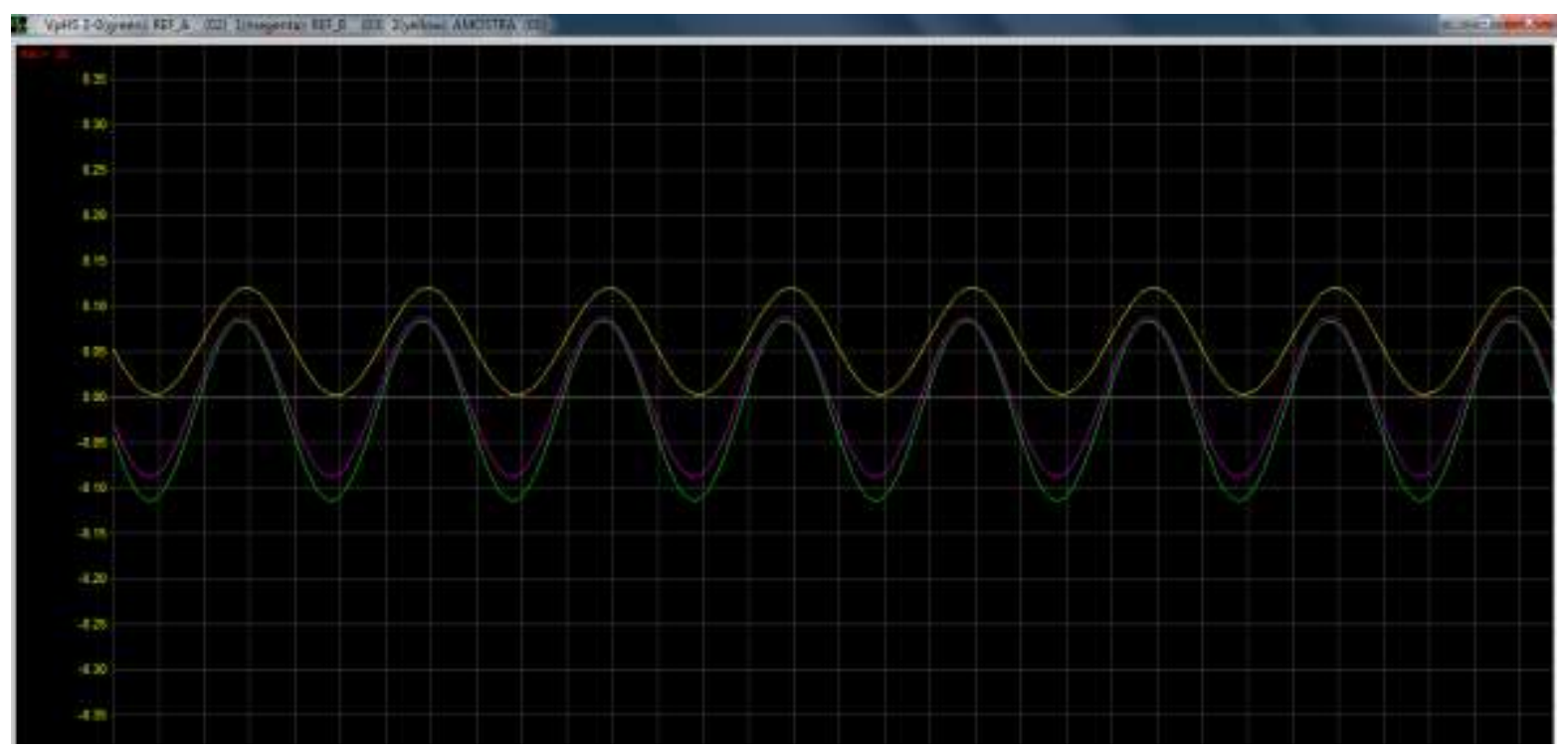

Fonte: SHIGUERU (2015).

Apesar dos ensaios visarem operação da célula na região de $69 \mathrm{kVrms}$ (classe de tensão) a nova célula de alta tensão do TPO (com isolador preenchido por SF6) foi submetida a tensões de $52 \mathrm{kV}$ rms, $88 \mathrm{kV}$ rms e $149 \mathrm{kV}$ rms visando avaliar, também, o limite da suportabilidade da mesma. Além disso foram feitos testes com diferentes cargas padronizadas acopladas ao TP padrão da CTEEP, conforme mostra a tabela 8.

Tabela 8 - Cargas Nominais do TP

\begin{tabular}{|c|c|c|c|c|}
\hline \multirow{2}{*}{ Simbolo da Carga } & \multicolumn{2}{|c|}{ Caracteristica da Carga } & \multicolumn{2}{c|}{ EQUIVALENCIA } \\
\cline { 2 - 5 } & Potência (VA) & Fator de Potência & ABNT & ANSI \\
\hline W & 12,5 & 0,1 & P12,5 & W \\
\hline X & 25 & 0,7 & P25 & X \\
\hline Y & 75 & 0,85 & P75 & Y \\
\hline Z & 200 & 0,85 & P200 & Z \\
\hline ZZ & 400 & 0,85 & P400 & ZZ \\
\hline
\end{tabular}

Fonte: SHIGUERU (2015)

As divergências apresentadas nas formas de onda se referem em boa parte às diferentes relações dos TP's convencionais do IEE e CTEEP, ou seja, 1000:1 e 1200:1, respectivamente. 


\section{DISCUSSÃO DOS RESULTADOS}

Os ensaios realizados tiveram o objetivo de se avaliar primeiramente a integração das células (sensora e recuperadora) do TPO com a unidade de processamento eletrônico conjuntamente com os TPs de referência (do IEE e CTEEP) e os resultados foram bastante promissores no que tange os aspectos tecnológicos relacionados à integração dos sistemas opto-eletrônicos bem como na resposta do TPO (com grandes semelhanças em forma de onda e amplitudes praticamente coincidentes).

O protótipo do TPO também contava com sensor óptico de temperatura, implementado com grade de Bragg, para coleta de dados para os ensaios térmicos da célula sensora do TPO, visando verificação da estabilidade térmica do conjunto. Contudo, durante os testes, em Bauru, a fibra relacionada ao sensor de temperatura foi rompida, o que impediu a coleta dos dados de temperatura da célula sensora.

Por ser considerado padrão metrológico de referência, o TP do IEE (denominado REF A) foi adotado como referência perante o TP Convencional da CTEEP (denominado REF B) e o TPO sob ensaio.

A figura 78 ilustra a resposta do TPO às tensões aplicadas (na faixa de $25 \mathrm{kV}$ a $69 \mathrm{kV}$ ) referenciada ao TP padrão pertencente ao IEE, visando não só uma comparação qualitativa mas, também permitir a calibração (preliminar) do TPO na faixa descrita. 
Figura 78 - Resposta do TPO às tensões aplicadas (na faixa de $25 \mathrm{kV}$ a $69 \mathrm{kV}$ ) referenciada ao TP padrão pertencente ao IEE.

CURVA (TPO X REF A (IEE))

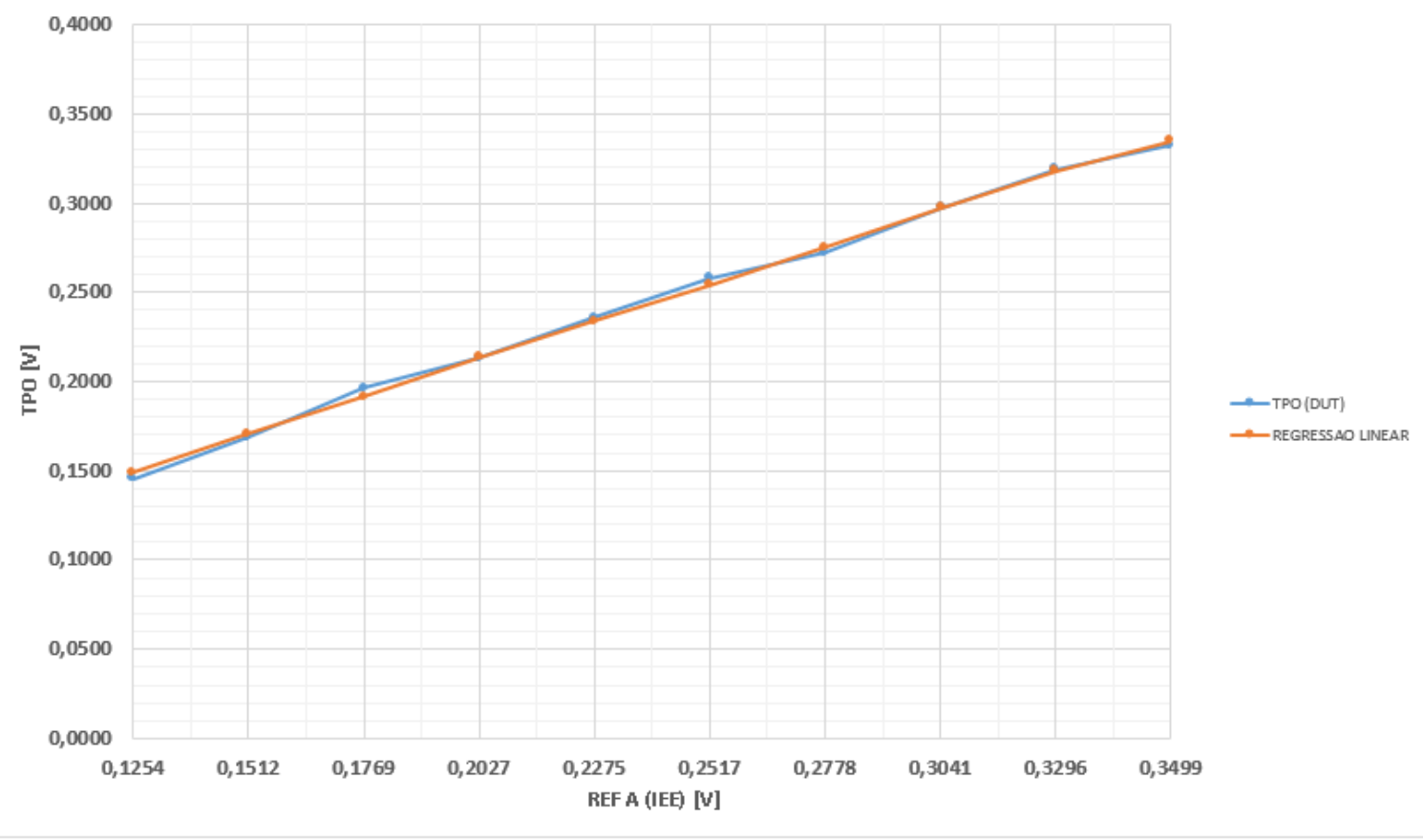

Fonte: SHIGUERU (2015)

Apesar dos ensaios ainda serem preliminares é possível estabelecer um comparativo com os sinais dos TPs pelo método clássico de análise de Fourier. A tabela 9, a seguir, ilustra os dados provenientes das fundamentais dos sinais registrados obtidas por meio da análise de Fourier dos dispositivos ensaiados.

Tabela 9 - Componentes fundamentais dos sinais dos dispositivos ensaiados obtidos por transformada de Fourier.

\begin{tabular}{|c|c|c|c|c|c|c|c|}
\hline \multirow{2}{*}{ TENSÃO [kV] } & \multirow{2}{*}{\begin{tabular}{|c|} 
IEE (REF A) \\
MAGNITUDE [V]
\end{tabular}} & \multirow{2}{*}{\begin{tabular}{|c|} 
CTEEP (REF B) \\
MAGNITUDE [V]
\end{tabular}} & \multirow{2}{*}{$\begin{array}{c}\text { TPO (DUT) } \\
\text { MAGNITUDE [V] } \\
\end{array}$} & \multicolumn{2}{|c|}{ ERRO DE MAGNITUDE (\%) } & \multicolumn{2}{|c|}{ REGRESSAO LINEAR } \\
\hline & & & & ]ERRO (TPO - REF A) & ERRO (TPO - CTEEP) & REF A & REF B \\
\hline 25 & 0,1254 & 0,1334 & 0,1455 & 13,8144 & 9,0705 & 0,1493 & 0,1494 \\
\hline 30 & 0,1512 & 0,1614 & 0,1686 & 10,3203 & 4,4610 & 0,1706 & 0,1710 \\
\hline 35 & 0,1769 & 0,1888 & 0,1968 & 10,1118 & 4,2373 & 0,1919 & 0,1922 \\
\hline 40 & 0,2027 & 0,2162 & 0,2130 & 4,8357 & 1,4801 & 0,2132 & 0,2134 \\
\hline 45 & 0,2275 & 0,2427 & 0,2360 & 3,6017 & 2,7606 & 0,2337 & 0,2339 \\
\hline 50 & 0,2517 & 0,2655 & 0,2575 & 2,2524 & 3,0132 & 0,2537 & 0,2516 \\
\hline 55 & 0,2778 & 0,2964 & 0,2720 & 2,1324 & 8,2321 & 0,2753 & 0,2755 \\
\hline 60 & 0,3041 & 0,3244 & 0,2972 & 2,3217 & 8,3847 & 0,2970 & 0,2972 \\
\hline 65 & 0,3296 & 0,3516 & 0,3190 & 3,3229 & 9,2719 & 0,3181 & 0,3182 \\
\hline 69 & 0,3499 & 0,3738 & 0,3322 & 5,3281 & 11,1289 & 0,3349 & 0,3354 \\
\hline
\end{tabular}

\begin{tabular}{|r|c|c|}
\hline \multicolumn{2}{|c|}{ REGRESSAO LINEAR PELO LMS (LEAST SQUARE MINIMUM) } \\
\hline PARAMETROS DA RETA & TPO-REF A & TPO-REF B \\
\hline INCLINAÇĀO (GRAUS) & 39,579 & 37,736 \\
\hline COEFCIENTE LINEAR & 0,046 & 0,046 \\
\hline
\end{tabular}


As figuras 79,80 e 81 , a seguir, mostram os comportamentos, em termos de magnitude, das medições dos TIs ensaiados em função da tensão aplicada.

Figura 79 - Magnitude do TI IEE (REF A)

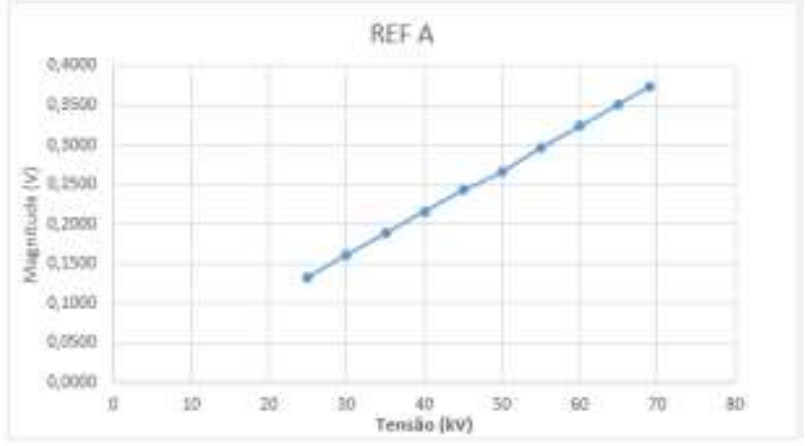

Fonte: SHIGUERU (2015)

Figura 80 - Magnitude do TI CTEEP (REF B).

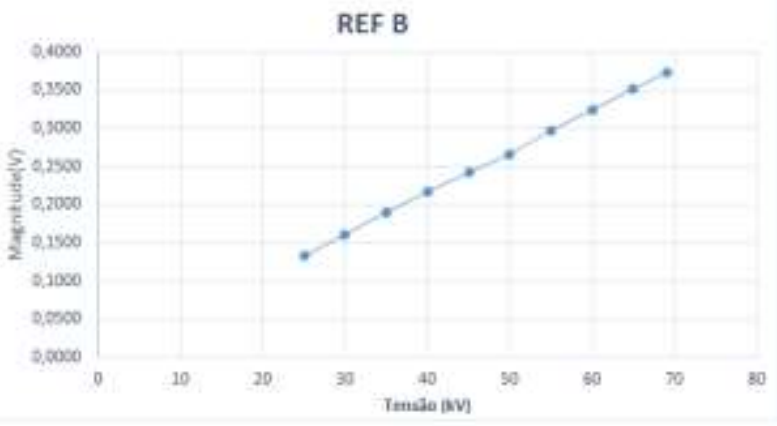

Fonte: SHIGUERU (2015)

Figura 81 - Magnitude do TPO.

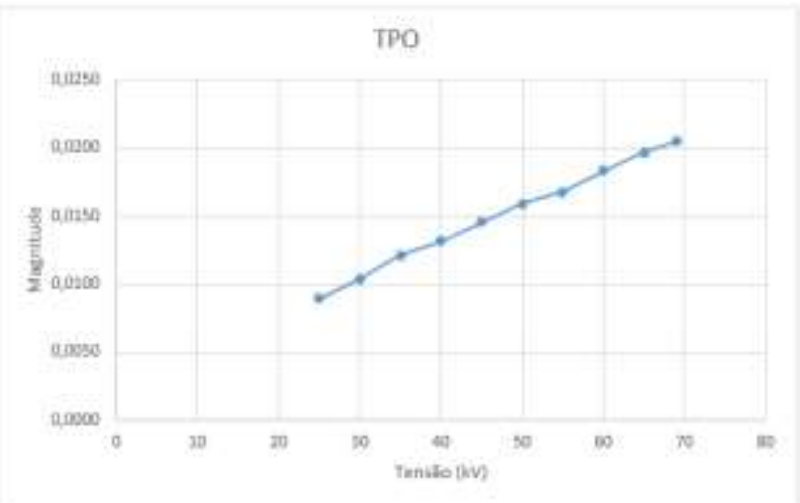

Fonte: SHIGUERU (2015)

Os resultados foram bastante promissores, pois apesar de ainda não estar calibrado, o protótipo demonstrou plenamente sua funcionalidade, uma vez que as formas de onda analógica e optoeletrônica apresentaram grandes semelhanças em termos de formas de onda e amplitudes praticamente coincidentes, características estas necessárias num sistema metrológico. As analises relativas a desvios de fase nas 
medições do TPO estão sendo desenvolvidas no de trabalho de mestrado de Shigueru futuramente apresentadas.

\section{COMENTÁRIOS E CONCLUSÕES}

Com os estudos e implementações obtidas, verificou-se o enorme potencial no desenvolvimento e aplicação da topologia "double pass" aplicada no interferômetro sensor da célula de alta tensão da proposta de projeto do TPO.

A busca por componentes e materiais, disponíveis no mercado, que pudessem ser empregados na montagem do protótipo mostrou-se bem sucedida.

A pesquisa convergiu para a escolha de um interferômetro sensor construído a partir de cristal único de BGO beneficiado com filmes finos, antirreflexo em uma face e totalmente refletor total em outra, caracterizando a topologia reflexiva, visando a sua aplicação no sistema sensor WLI de um protótipo de TPO.

O protótipo apresentou vantagens importantes em relação aos protótipos anteriormente desenvolvidos, no que tange a características como: facilidade de construção e reprodução, facilidade de alinhamento do feixe de luz em relação ao cristal eletro-óptico e aumento da rigidez dielétrica da célula sensora.

As simulações computacionais realizadas contribuíram para o auxílio ao projeto da célula sensora, principalmente na estimativa do valor da tensão de meia onda, $V_{\pi}$, da mesma, valor este que afeta não só a sensibilidade, mas também a linearidade do TPO, e das intensidades dos campos elétricos no interior da célula, o que influencia na rigidez dielétrica do conjunto.

Por fim, apesar de existirem várias etapas a serem ainda cumpridas, relacionadas a resultados experimentais a serem obtidos, os resultados alcançados permitem afirmar que os objetivos propostos para este trabalho de doutorado foram atingidos. 


\section{TRABALHOS FUTUROS}

Não foi possível, até o momento da defesa deste trabalho de doutorado, completar os ensaios destinados à calibração para determinar a classe de exatidão do TPO construído. Contudo estes ensaios deverão ser realizados em breve, pois conhecer esta característica é necessário a um sistema de medição com fins metrológicos.

Assim, também de forma inicial, foi possível analisar somente de forma qualitativa o comportamento do TPO com relação aos TPs convencionais, mesmo porque não houve tempo hábil para tratar de maneira adequada os dados obtidos, o que acabou inviabilizando a calibração completa do TPO.

Com o intuito de dar continuidade às atividades da pesquisa realizada neste trabalho e objetivando aperfeiçoar os resultados alcançados até o momento, descrevem-se a seguir as etapas e a metodologia a ser utilizada:

- Montagem de outras células "double pass" reflexivas: Os componentes e dipositivos já se encontram disponíveis para a montagem de novas versões da célula "double pass" (reflexiva). Diferentes montagens podem ser realizadas trocando o cristal por outros com tamanhos diferentes, visando a alteração e caracterização das tensões de meia onda $\left(V_{\pi}\right)$ das células;

- Simulação da célula sensora na topologia multisegmentada por método de quadratura, utilizando o programa comercial COMSOL: Esta atividade tem como objetivo da análise e verificação da quantidade e posicionamento dos cristais eletro-ópticos com o intuito de tornar a célula de alta tensão menos sensível a influências de elementos externos ao TPO, alterando a calibração pré estabelecida do mesmo. Os estudos ligados a esse subtema devem prosseguir, principalmente no que tange ao algoritmo de otimização, a fim de tornar a ferramenta mais amigável ao projetista. 
- Continuar os estudos para desenvolver protótipos de TPO capazes de operar em níveis de tensão mais elevados, a fim de atender aplicações como medição e proteção em sistemas transmissão de energia elétrica que operam, no Brasil, em classes que vão de 138 kV até 800 kV.

- Continuar os ensaios térmicos do TPO, não finalizados devido ao rompimento da fibra do sensor óptico de temperatura, visando a verificação da estabilidade térmica do conjunto célula sensora e célula recuperadora. 


\section{REFERÊCIAS}

ABE, N.M.; FRANCO, M.A.R., PASSARO. A., 1999. Analysis of a x-cut Ti:LiNbO3 eletrooptic modulator with a ridge structure. In 1999 SBMO/IEEE MTT-S, AP-S and LEOS International Microwave and Optoeletronics Conference (IMOC'99), pp.126-130.

AL-CHALABI, S.A. et al. Partially Coherent Sources in Interferometric Sensors. In: 1st International Conference on Optical Fibre Sensors. London, p. 132-135. 1983

ALLIL, R. C. S. B. "Sensores a fibra óptica com tecnologia FBG para medida de temperatura e alta tensão". Tese (doutorado) - UFRJ/COPPE/Programa de Engenharia Elétrica, 2010.

ALMEIDA C. J., AVILEZ O. V. F "Demodulador de desvio de fase óptico não recíproco num sensor óptico interferométrico, via detecção dos valores dos picos da corrente detectada no fotodetector acoplado à saída do interferômetro óptico", patent required to the Instituto Nacional da Propriedade Industrial, according to the register number PI0303.688-0, Aug. 2003.

ALMEIDA, V. R., Aplicação de Dispositivo Multifuncional a Óptica Integrada em Interferômetro de Sagnac a Fibra Óptica Birrefringente, Tese de mestrado, Divisão de Engenharia Eletrônica, Instituto Tecnológico de Aeronáutica, 1998.

ALMEIDA, J.C.J., SANTOS, J.C. Demodulação Coerente do Sinal de Saída de Transformador de Potencial Óptico. IEEE LATIN AMERICA TRANSACTIONS, VOL. 3, NO. 5, Dec 2005, p.423-428.

ALMEIDA, J.C.J., Nova Técnica de Processamento de Sinais no domínio do tempo em Giroscópios Interferométricos de Sagnac a Fibras Óptica, Tese Doutorado, Faculdade de Engenharia Elétrica e Computação,UNICAMP,2001. p.93.

ALMEIDA J.C.J., SANTOS J. C., RUBINI J. Jr., AVILEZ O. V. F.; A New Conception Of Signal Processor For A Pockels Ac High Voltage Sensor. Proceedings on 6th WSEAS INTERNATIONAL CONFERENCE ON SIGNAL PROCESSING, COMPUTATIONAL GEOMETRY \& ARTIFICIAL VISION; Atenas, WSEAS, 2006. v. 1. p. 1-7;

BOSSELMANN, T. and ULRICH, R. High-Accuracy Position-Sensing with FibreCoupled White-Light Interferometers. In: 2nd International Conference on Optical Fibre Sensors. Berlin, p. 361-364. 1984

BURAS, M. Aplicação de sensores distribuídos de fibra óptica em um modelo experimental para monitoramento de movimentos de massa, Curitiba, 2013. $160 f$.

CHAVEZ P. P., JAEGER N. A.F., Member, IEEE, Farnoosh Rahmatian, Member, IEEE; Accure Voltage Measurement by the Quadrature Method; IEEE Transactions on Power Delivery, Vol. 18. No. 1, January 2003. 
$\mathrm{CHOI}, \mathrm{H} . \mathrm{S}$. et al. High-Performance Fiber-Optic Temperature Sensor Using LowCoherence Interferometry. Optics Letters, v. 22, n. 23, Dec.1997.

EOSPACE. Polarization Controllers. EOSPACE - Polarization Controllers, 2011. Disponivel em: <http://www.eospace.com/polarization controller.htm>. Acesso em: 27 fev. 2015.

FENG Pan, Xia Xiao, Yan Xu and Shiyan Ren; An Optical AC Voltage Sensor Based on the Transverse Pockels Effect; Sensors 2011, 11, 6593-6602; doi: 10.3390/s110706593.

FENG Pan, Xia Xiao, Yan Xu, Shiyan Ren; Optical AC Voltage Sensor based on Two $\mathrm{Bi}_{4} \mathrm{Ge}_{3} \mathrm{O}_{12}$ Crystals; IEEE Transactions on Instrumentation and Measurement. Vol.61, NO. 4. April 2012.

FRANCO, M.A.R.; PASSARO, A.; SIRCILLI, F., CARDOSO, J.R., Finite element analysis of anisotropic optical waveguide with arbitrary index profile. IEEE Transactions on Magnetics,1999, vol.35, No. 3, pp. 1546-1549.

GHATAK, A. K. and THYAGARAJAN K. Optical Eletronics. Cambridge University Press, Cambridge. 1989.

HECHT, E. and ZAJAC, A. Optics. Addison Wesley, London, 2nd ed., (1987).

HICKMAN, D. An Optical Sensor Based on Temporal Coherence Properties. J. Phys. E. Sci. Instrum., n. 21, p. 187-192. 1988

HIDAKA K.; Progress In Japan Of Space Charge Field Measurement In Gaseous Dielectrics Using a Pockels Sensor; January/February 1996-Vol. 12, No. 1.

IEEE Standard, Trial (draft )-Use Standard for Optical AC Current and Voltage Sensing, 1601-2010, 2010.

IGARASHI, G.. Estudo da IEC 61850 e o seu impacto no sistema de automação de subestações. 2007. Dissertação (Mestrado em Engenharia Elétrica) Universidade de São Paulo, 67 p.

IGARASHI, G.; SANTOS, J. C. . Transformer Differential Protection Using Process Bus According to IEC 61850-9-2 and Non-Conventional Instrument Transformers. In: The 4th International Conference on Power and Energy Systems (ICPES 2014), 2014, Cingapura. The 4th International Conference on Power and Energy Systems (ICPES 2014), 2014

IGARASHI, G.;. Contribuições para a implementação de um barramento de processo segundo a norma IEC 61850-9, Tese (Doutorado) - Escola Politécnica da Universidade de São Paulo. Departamento de Engenharia de Energia e Automa-ção Elétricas, São Paulo,, 2015. 
JACKSON, D.A. and JONES J.D.C. Fibre Optic Sensors. Optica Acta 33, 1469, 1986.

KITANO, C. Aplicação da Abordagem de Domínio Espectral para Análise de Moduladores Eletroópticos Integrados. Tese doutorado, Instituto Tecnológico de Aeronáutica ITA, 2001, 397 p..

KITANO, C. Análise do Interferômetro Mach-Zehnder com Controle acústico eletroóptico.Tese de Mestrado. ITA, São José dos Campos, SP. 1993, 199 p.

KEISER, G. Optical Fiber Communications. McGraw-Hill, inc., New York, 2nd ed., 1991.

LAVRAS, L. C. M., Estudos de Espelhos Dielétricos Multicamadas para Laser de Nd-YAG, Tese de mestrado ITA, 2002, 109 p..

LY, M.; MOEHLECKE, A.; ZANESCO, I.. Implementação e Otimização de Filmes Anti-Reflexo para Células Bifaciais. Anais do I CONGRESSO BRASILEIRO DE ENERGIA SOLAR, 2007, Fortaleza.

LEFÉVRE, H., C., The Fiber-Optic Gyroscope, Artech House, 1993.

LIMA, D. K.; Transformadores para instrumentos ópticos: aspectos da viabilidade do seu uso pelas empresas do setor elétrico brasileiro, 2009. Dissertação (Mestrado em Engenharia Elétrica) - Universidade de São Paulo, 123 p.

LIMA, R. A. Sensor Eletro-óptico de Tensões Elevadas e sua Viabilidade para Implementação de TP Óptico. 2013. 111 f. Dissertação (Mestrado em Engenharia Elétrica) - Faculdade de Engenharia de Ilha Solteira, Universidade Estadual Paulista, Ilha Solteira, 2013.

LIMA, D. K.; SANTOS, J. C. . Transformadores para Instrumentos Ópticos: Sua Viabilidade no Setor Elétrico Brasileiro. In: XXSNPTEE - Seminário Nacional de Produção e Transmissão de Energia Elétrica, 2009, Recife. XXSNPTEE - Seminário Nacional de Produção e Transmissão de Energia Elétrica, 2009.

MARDEGAN, D. A., Desenvolvimento de um filtro dielétrico para fibra óptica aplicada em técnicas espectroscópicas. Dissertação (Mestrado em Engenharia Biomédica) - Universidade do Vale do Paraíba (UNIVAP), 68 p.. 2004.

MARCHESE S.V., WILDERMUTH S., STEIGER O., J. Pascal, BOHNERT K., ERIKSSON G., CZYZEWSKI J.; Optical High Voltage Sensor With Oil-and Gasfree Insulation; Imaging ans Applied Optics Technical Digest (C) 2012 OSA.

MARS-ENERGO, Optical instrument voltage transducers KRISMARS-VT, catálogo. Disponível em: http://www.mars-energo.com/home-en/referenceinstruments-for-digital-substations/opticheskie-izmeritelnye-preobrazovatelinapryazheniya.html. Acesso em 16 set. 2015. 
MOLTECH, Photorefractive Crystals SBN, BSO, BGO, Fe:LNB, catálogo. Disponível em: http://www.mt-berlin.com/frames_cryst/crystals_frameset1.htm. Acesso em 10 março. 2012.

MORAIS, R.P.S. Polling em Fibra Ópticas. Dissertação de mestrado, Universidade do Porto. Departamento de Física. 2003.

MRA.PT, SENSORES de redes de Bragg (FBG):, catálogo. Disponível em: http://www.mra.pt/industria/produtos/sensores-aquisicao-de-dados-e-

calibracao/medicao-com-fibra-optica/fibra-otica--redes-de-bragg/. Acesso em 20 nov. 2015.

EOSPACE, Products catálogo. Disponível em: http:/www.eospace.com/ product_index.htm. Acesso em 15 set. 2015.

OZOPTICS, Fiber Optic Distributed Strain and Temperature Sensors. catálogo. Disponível em: http://www.ozoptics.com/products/fiber optic distributed.html. Acesso em 20 nov. 2015.

PENÃ-LEGONA, Francisco G., MUÑOZ-MACIEL J, GÓMEZ-ROSAS G. CASILLASRODRÍGUEZ Francisco J., MORA-GONZÁLEZ M., DURÁN-RAMÍREZ V.M. C.; CASTILLO-QUEVEDO, Ultra High Voltage Surge Waveforms Measurement Using na Optical Transducer; Sensor \& Transducers journal, Vol. 116 Issue 5, May 2010, pp. 104-111.

PEREIRA, F. C., "Demodulação de sinais interferométricos de saída de sensor eletro-óptico de tensões elevadas utilizando processador digital de sinais", Dissertação (mestrado) - Universidade Estadual Paulista. Faculdade de Engenharia de Ilha Solteira. Área de conhecimento: Automação, 2013

PASSARO, Angelo ; RUBINI J. J., ; ABE, Nancy Mieko ; SASAKI, M. ; SANTOS, J.C., Finite-Element and Genetic Algorithm Design of Multi-segmented Eletrooptic Sensor for Pulsed High-Voltage Measurement. In: WCSMO6 -6TH WORLD CONGRESSES OF STRUCTURAL AND MULTIDISCIPLINARY OPTIMIZATION, 2005, Rio de Janeiro. Proceedings of WCSMO6 - 6th World Congresses of Structural and Multidisciplinary Optimization, 2005.

PEREIRA, A. C., Sistemas de Proteção e Automação de Subestações de Distribui-ção e industriais usando a norma IEC61850, In: XIII Encuentro Regional Iberoa-mericano de Cigré, 2009, Puerto Iguazú - Argentina.

R-AINGROUP, Optical Voltage Transformer, catálogo. Disponível em: http://www.raingroup.com/files/\%D0\%B1\%D1\%80\%D0\%BE\%D1\%88\%D1\%8E\%D1\%80\%D0\%B 0\%20DPSS.pdf. Acesso em 10 março de 2015.

RAHMATIAN, F., Member, IEEE, CHAVEZ, P. P., JAEGER, N. A. F., Member, IEEE, "138 kV and 345 kV Wide-Band SF6-Free Optical Voltage Transducer". IEEE Power Engineering Society Winter Meeting, PP. 1472-1477, Vancouver, CANADA, AUG. 2002. 
RAHMATIAN, F., Member IEEE, CHAVEZ, P. P., "SF6-free 550 kV combined optical voltage and current transducer system". IEEE Transmission and Distribution Conference and Exposition, v. 1, pp. 379-382, Sept. 2003.

RAO, Y.J. and JACKSON, D.A. Recent Progress in Fibre Optic Low-Coherence Interferometry, Meas. Sci. Technology, v. 7, p. 981-999. 1996.

RIBEIRO, B A., "Transformador de Potencial Óptico Baseado em FBGPZT com Demodulação por Redes Gêmeas e Filtro de Fabry-Perot", Rio de Janeiro: UFRJ/COPPE, 2011.

RIBEIRO, B. A, "Compensação de temperatura em um sensor óptico-elétrico para medidas de tensão em linhas de transmissão". Tese (doutorado) - UFRJ/ COPPE/ Programa de Engenharia Elétrica, 2015.

ROGERS, A.J. Optical Methods for Measurement of Voltage and Current at High Voltage. Optics \& Laser Technology, Volume 9, Issue 6, 1977, Pages 273-283, ISSN 0030-3992.

RUBINI J J ; ABE, N. M. ; PASSARO, A. ; SANTOS, J.C. . Analysis of the electric field distribution in a eletrooptic sensor for pulsed high voltage measurements. In: FIFTH INTERNATIONAL CONFERENCE ON COMPUTATION IN ELETROMAGNETICS - CEM2004, Stratford-upon-Avon. Earls Barton, Northats : WRIGHTSONS, 2004. p. 71-72.

RUBINI J. J. ; ABE, N. M.; PASSARO, A. ; SANTOS, J. C. Design study of an eletrooptic sensor for pulsed high-voltage measurements.. In: XXVI lberian Latin-American Congress on Computational Methods in Engineering CILAMCE 2005, Guarapari. Proceedings of the XXVI Iberian Latin-American Congress on Computational Methods in Engineering CILAMCE 2005.

SANTOS, J.C. New Optical Pockels Techniques for Direct Measurement of High Voltage. Tese de Doutorado - Universidade de Tóquio, Japão. 1996.

SANTOS J.C, M.C TAPLAMACIOGLU, K. HIDAKA; Pockels High-Voltage Measurement system; High Voltage Engineering Symposium, 22-27 August 1999 Conference Publication No. 467, () IEE, 1999a.

SANTOS J.C, M.C TAPLAMACIOGLU, K. HIDAKA; Optical high voltage measurement using Pockels microsingle crystal; Review of Scientific Instruments Vol. 70, No. 8, August 1999b.

SANTOS J.C, M.C TAPLAMACIOGLU, K. HIDAKA; Pockels High-Voltage measurement System; IEEE Transactions on Power Delivery, Vol. 15, No.1, January 2000. 
SANTOS, J.C. ; SILVA, L. P. C.;. ALMEIDA, J.C.J; RUBINI J, J.; ABE, N. M. ; PASSARO, A. . FEM Simulation Method as a Designing Tool for Eletrooptical Sensors Development. WSEAS Transactions on Power Systems, v. 1, p. 1754$1761,2006 a$

SANTOS, J.C.; SILVA, L. P. C.;. ALMEIDA, J.C.J; RUBINI J, J.; ABE, N. M. ; PASSARO, A., Study Of An Eletrooptic Sensor For High-Voltage Measurements, In: 6th WSEAS/IASME Int. Conf. on Electric Power Systems, High Voltages, Electric Machines, 2006, Tenerife. Proceedings of the 6th WSEAS/IASME Int. Conf. on Electric Power Systems, High Voltages, Electric Machines, 2006b. p. 64-69.

SANTOS, J. C.; ALMEIDA, J. C. J.; SILVA, L. P. C. . WLI High Voltage Optical Systems with Compensation for Optical Power Fluctuations. In: Third European Workshop on Optical Fibre Sensors, 2007, Napoles. International Society of PhotoOptical Instrumentation Engineers, 2007. v. 6619. p. 6619.

SANTOS, J. C. ; ALMEIDA, J. C. J ; SILVA, L P C da. White Light Interferometry High Voltage Optical Fiber Sensor Systems with Compensation for Optical Power Fluctuations. In: Yasin Moh. (Org.). Optical Fibers / Book 1. 1ed.Rijeka/Croatia: Intech Open Access publisher, 2011, v. 1, p. 1-28

SATO, S. S.; CAETANO, R. E.; FRANCO, M. A. ; SANTOS, J. C. . Simulation of Eletro-Optic Modulator based on optical waveguide formed by Residual Thermal Stress-Induced on Bi4Ge3012 substrate by Si3N4 thin Film.. Journal of Microwaves, Optoeletronics and Eletromagnetic Applications, v. 12, p. 18-28, 2012.

SATO, S. S., Simulação multifísica utilizando método dos elementos finitos auxiliando interativamente a fabricação de moduladores eletro-ópticos em substratos de $\mathrm{Bi}_{4} \mathrm{Ge}_{3} \mathrm{O}_{12}$ /. Tese (Doutorado) - Escola Politécnica da Universidade de São Paulo. Departamento de Engenharia de Energia e Automa-ção Elétricas, São Paulo, 2014. 204 p.

SILVA, L. P. C., Transformador Óptico por Interferometria de Luz Branca para Medição de Altas Tensões. 2006. 80 f. Dissertação (Mestrado em Engenharia Elétrica) - Universidade de São Paulo -USP, 63 p.

SILVA, L. P. C., Interferômetros recuperadores de baixa tensão de meia onda para sistemas interferométricos de luz branca utilizando moduladores eletroópticos, 2011. Tese (Doutorado em Engenharia Elétrica) - Universidade de São Paulo-USP, 200 p. .

SINOCERAMICS,INC., Scintillators BGO, LYSO and GSO, Disponível em: http://sinocera.en.china.cn/selling-leads/detail,1079425280,Scintillators-BGO-LYSOand-GSO.html. Acesso em 10 março de 2015.

SHIGUERU N. JR, Eletrônica de processamento para transformadores de instrumentação ópticos de sistemas de potência com foco em aplicações metrológicas in situ.Texto apresentado para o exame de qualificação da Escola Politécnica da Universidade de São Paulo, 2015.

para obtenção do título de Mestre em Ciências 
TIEME, P. M.. Implementação de Sensor de Deformação a Fibra Óptica Baseado no Interferômetro de Michelson com Luz Branca, 2000, Dissertação (Mestrado em Ciência na Área de Mecatrônica e Dinâmica de Sistemas Aeroespaciais do Curso de Engenharia Aeronáutica e Mecânica) Instituto Tecnológico de AeronáuticaITA, $136 \mathrm{p}$.

TOLANSKY, S. XXXI New contributions to interferometry. Part V.-New multiple beam white light interference fringes and their applications. The London, Edinburgh, and Dublin Philosophical Magazine and Journal of Science: Series 7, Volume 36, Issue 255, 1945.

TOLANSKY, S. An Introduction to Interferometry. Longman, London. 1973.

UDD, E. Fiber Optic Sensors: An Introduction for Engineers and Scientists, John Wiley \& Sons, New York, 1st ed., (1991).

UDD, E. An Review of Fiber-Optic Sensors. Rev. Sci. Instrum. 66, 4015, 1995.

VYTRAN, http://www.vytran.com/product/gpx-3000 series, catálogo "Vytran, a division of Thorlabs". Disponível em: Acesso em 12 dezembro de 2014.

YARIV, A., Quantum Eletronics, Third Edition, John Wiley and Sons, Inc., New York, NY, 1989.

YARIV, A. and Yeh, P. Optical Waves in Crystals - Propagation and Control of Laser Radiation. Wiley Interscience. USA. 2003.

YUAN, L.B. et al. Fiber Optic Temperature Sensor with Duplex Michelson Interferometric Technique. Sensors and Actuators, n. 86, p. 2-7. 2000. 


\section{ADENDO A - GRAU DE COERÊNCIA (FATOR DE AUTOCORRELAÇÃO)}

Descrito por Santos (1996) em um interferômetro, a interferência ocorre quando a radiação segue por caminhos diferentes da fonte de luz até o ponto de detecção. Faixas luminosas e escuras são observadas e chamadas de de interferência e podem ser descritas como a intensidade resultante da adição vetorial das amplitudes da radiação que podem atingir um certo ponto após percorrerem caminhos diferentes. Considerando esta radiação como sendo duas ondas luminosas monocromáticas linearmente polarizadas, quando elas estão sobrepostas na mesma direção de propagação a intensidade resultante $I$ em um determinado ponto é dado pela eq.(A.1), abaixo:

$$
I=U_{1}^{2}+U_{2}^{2}+2 U_{1} U_{2} \cos \Delta \phi
$$

onde $\Delta \phi=\varphi_{1}-\varphi_{2}$ é a diferença de fase entre as duas ondas luminosas e $U_{1}$ e $U_{2}$ são as suas respectivas amplitudes.

Embora este resultado tenha sido deduzido para a luz linearmente polarizada e perfeitamente monocromática, ele também pode ser aplicado a qualquer par de ondas em que todo o espectro individual e as componentes de polarização tenham a mesma relação de fase e amplitude. Tais tipos de ondas são chamadas totalmente coerentes.

Interferometria é a técnica derivada da interferência, que é a observação experimental do fenômeno de coerência. A teoria de coerência é uma descrição estatística da radiação expressa em termos de funções de correlação. Já que a fonte de luz não é completamente coerente, a coerência temporal de uma fonte de luz real pode ser representada pela função de auto-correlação $\gamma_{12}(\tau)$, que é uma quantidade complexa definida por:

$$
\gamma_{12}(\tau)=\left|\gamma_{12}(\tau)\right| e^{i \phi_{12}(\tau)}
$$


A quantidade $\phi_{12}(\tau)$ é o ângulo de fase entre os campos luminosos e $\left|\gamma_{12}(\tau)\right|$ representa o grau de coerência e pode estar situado entre $0 \leq\left|\gamma_{12}(\tau)\right| \leq 1$ de forma tal que:

$$
\begin{aligned}
& \left|\gamma_{12}(\tau)\right|=1 \rightarrow \text { limite de coerência total, } \\
& \left|\gamma_{12}(\tau)\right|=0 \rightarrow \text { limite de incoerência total e } \\
& \left|\gamma_{12}(\tau)\right|<1 \rightarrow \text { coerência parcial }
\end{aligned}
$$

Os instrumentos ou sistemas utilizados para fazer interferometria, chamados interferômetros, são tradicionalmente classificados pelo número de feixes que interferem e pelo método usado para separar estes feixes. Um interferômetro pode ser classificado como sendo de dois feixes ou de múltiplos feixes de acordo com o número de feixes que interferem. Quanto à separação dos feixes elas podem ser por divisão da frente de onda ou por divisão de amplitude. 


\section{ADENDO B - ENSAIOS DE SUPORTABILIDADE ELÉTRICA - ISA CTEEP}

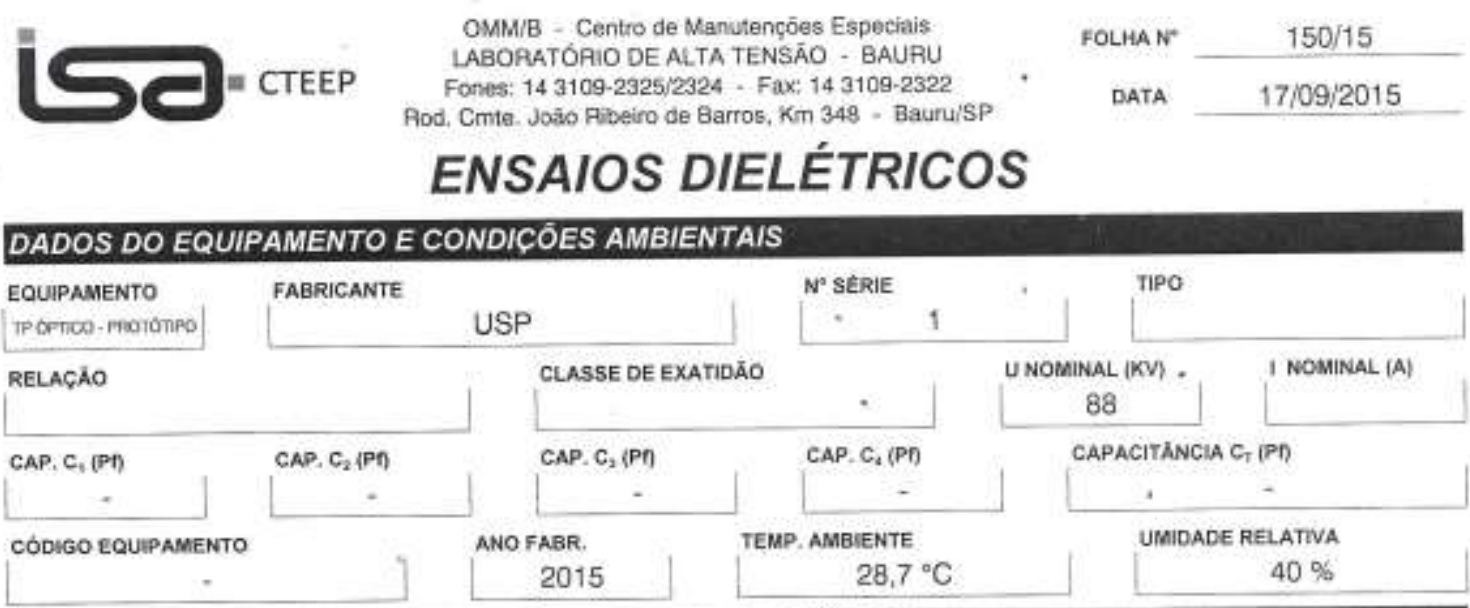

\section{ENSAIO 1- FATOR DE PERDAS DIELEETRICAS E CAPACITANCIA}

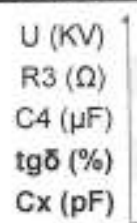

ENSAIO 2-DESCARGAS PARCIAIS

$$
U(\mathrm{KV})
$$

$\mathrm{q}(\mathrm{pC})$
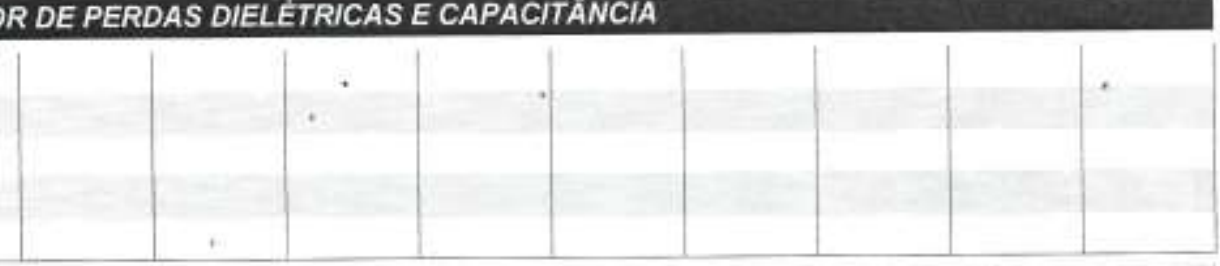

ENSAIO 3 - TENSAOO SUPORTAVEL A A FREQUENCIA INDUSTRIAL

\begin{tabular}{|c|c|c|c|c|}
\hline & 140 & KV & 60 & TEMPO (s \\
\hline ENSAIO & $R D E P$ & ITRIC & & \\
\hline $\mathrm{U}(\mathrm{KV})$ & & & & \\
\hline R3 $(\Omega)$ & & & & \\
\hline $\mathrm{C} 4(\mu \mathrm{F})$ & & & & \\
\hline $\operatorname{tg} \delta(\%)$ & & & & \\
\hline$C_{x}(p F)$ & & & & \\
\hline
\end{tabular}

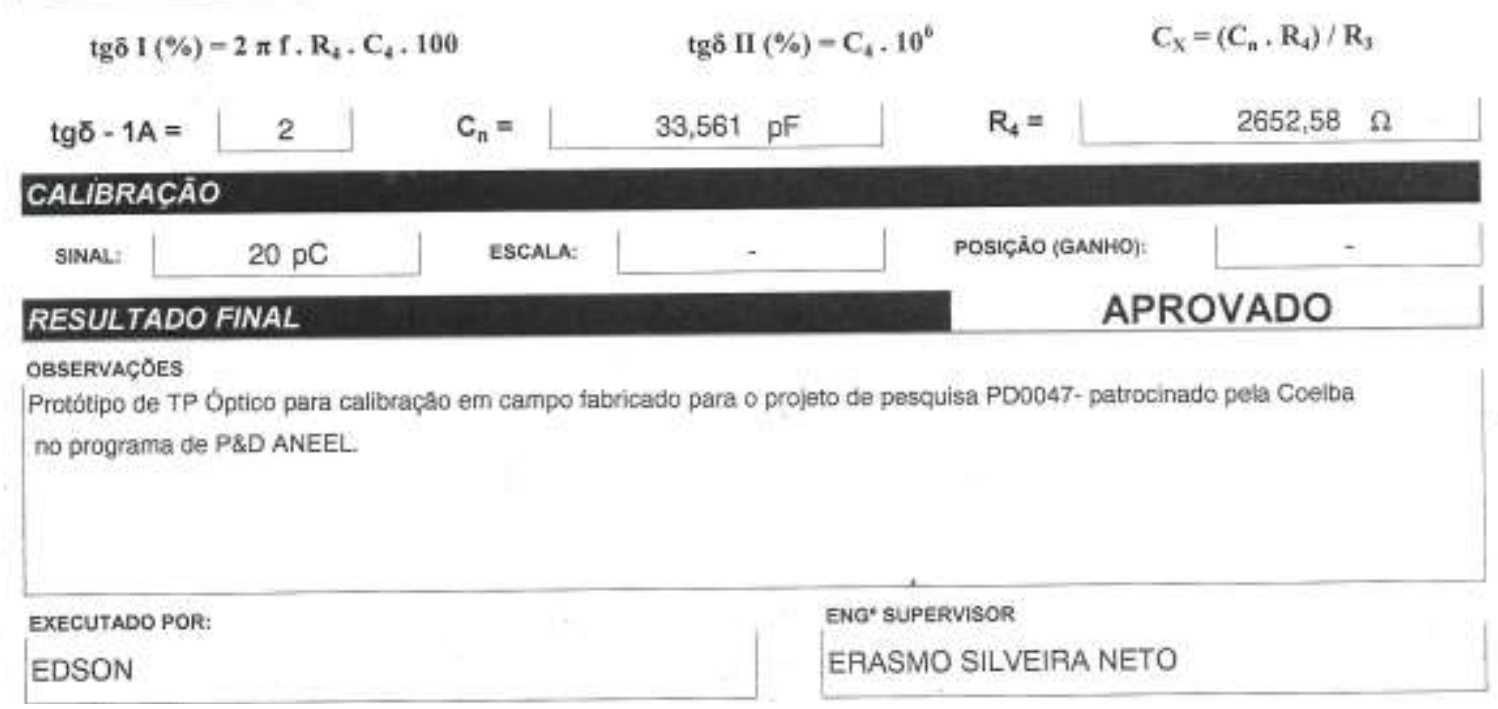




\section{ANEXO 1 - Datasheet do Diodo Superluminescente (SLD) utilizado no trabalho.}

\section{Superlum Diodes, Ltd. $\quad$ SLD-76-HP: High-Power SLDs at 1440; 1480; $1560 \mathrm{~nm}$}

Features:

High Output power, $10 \mathrm{~mW}$ ex SM fiber

flat spectrum with small Fabry-Perot modulation depth

Packages: DBUT; others on request

Additional \& customized:

PM fiber pigtails, polarized / depolarized output FC/APC terminated pigtails

Specifications

(Nominal Emitter Stabilization Temperature $+20^{\circ} \mathrm{C}$ )

\begin{tabular}{|c|c|c|c|c|}
\hline Parameter & Category & Min & Typ & Max \\
\hline $\begin{array}{l}\text { Output power ex SM fiber, emitter @ } \\
+20^{\circ} \mathrm{C} \text { SLD-76-HP fiber pigtailed }\end{array}$ & $\begin{array}{l}\mathrm{HP} 1 \\
\mathrm{HP} 2\end{array}$ & $\begin{array}{l}4.0 \\
7.5\end{array}$ & $\begin{array}{c}5.0 \\
10.0\end{array}$ & - \\
\hline SLD direct current, $\mathrm{mA}$ & $\begin{array}{l}\mathrm{HP} 1 \\
\mathrm{HP} 2\end{array}$ & 10 & 10.0 & $\begin{array}{l}400 \\
600 \\
\end{array}$ \\
\hline Forward voltage, $\mathrm{V}$ & All & - & 1.9 & 2.5 \\
\hline Peak wavelength ${ }^{*}, \mathrm{~nm}$ & All & 1440 , & 480,1 & $5 \pm 10$ \\
\hline Spectrum width, $\mathrm{nm}^{\mathrm{xx}}$ & All & $30-35$ & 45 & - \\
\hline $\begin{array}{l}\text { Residual spectral modulation } \\
\text { depth, } d B\end{array}$ & All & - & 0.25 & 0.5 \\
\hline $\begin{array}{l}\text { Secondary coherence subpeaks } \\
(10 \log ), \mathrm{dB}\end{array}$ & All & - & - & -20 \\
\hline $\begin{array}{l}\text { Slow / fast polarization ratio } \\
\text { (PM "polarized" modules), dB }{ }^{x \times x}\end{array}$ & All & 5 & 10 & - \\
\hline $\begin{array}{l}\text { Operation temperature range } \\
\text { (case) at full power, }{ }^{\circ} \mathrm{C}\end{array}$ & $\begin{array}{l}\mathrm{HP} 1 \\
\mathrm{HP} 2\end{array}$ & -55 & - & $\begin{array}{l}+70 \\
+60\end{array}$ \\
\hline Cooler current, $A^{\mathrm{xxx}}$ & All & - & - & 1.2 \\
\hline Cooler voltage, $V^{x \times x}$ & All & - & - & 3.5 \\
\hline
\end{tabular}

" each specific wavelength is subject for availability

" depending on center wavelength, please ask for details

w. Lyot-depolarized version available upon request

$\cdots \cdots 2.5 \mathrm{~A} / 4 \mathrm{~V}$ TE cooler mav be used to extend operation temperature rance

Following marking should be used for ORDERING:

SLD-761-HP(N)-(c)-(d)-wavelength

Where:

$N=1$ or 2 (for HP1 or HP2 respectively)

c=package type

$d=S M$ (isotropic) or PM (polarization maintain)

wavelength: required wavelength

Example: SLD-761-HP2-DBUT-SM-1560

$10^{-2}$ maximum feedback is allowed to run HP series SLDs safely at full power.

All specifications are subject to change without notice.
Applications:

optical sensing

optical coherence tomography

optical measurements

testing WDM/DWDM components

PERFORMANCE EXAMPLES

SLD-761-HP2-SM. Light-current curve

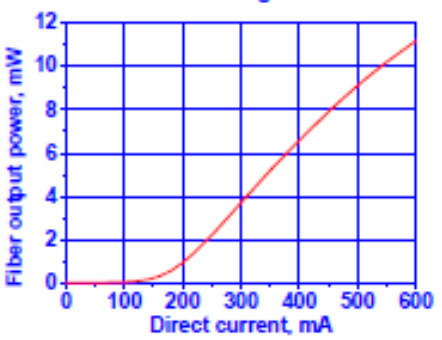

Spectrum, log plot. 761-HP2 @ 1560 nm

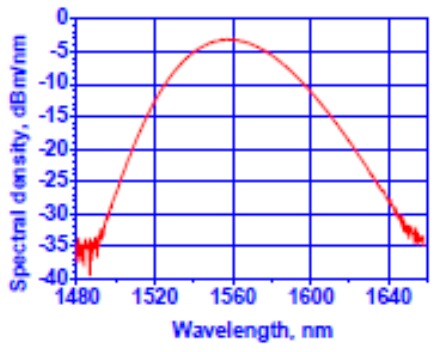

Detailed spectrum trace

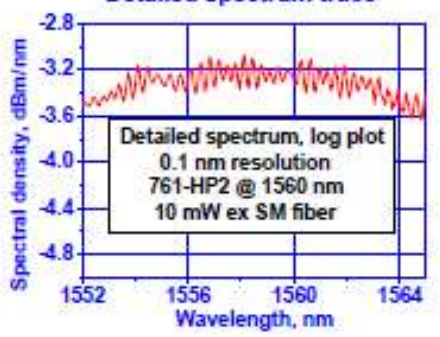

Extended displacement

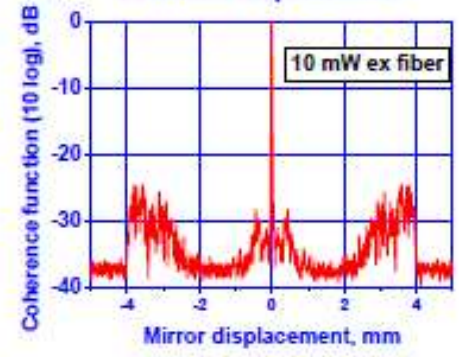

Mirror displacement $=$ Optical path difference $/ 2$ 
ANEXO 2 - Datasheet do Fotodiodo utilizado no trabalho.

\section{$1.5 \mathrm{GHz}$ InGaAs PIN Photodiode Module}

Features

- High Responshiviy

- High speed, typical $1.5 \mathrm{GHz}$

- Low dark ciarern, < ina

- Low capacitarce, typicar 0.7pF

- Operstrig bemperature range $-40^{\circ} \mathrm{C}$ to $85^{\circ} \mathrm{C}$

- Hermetically sesied TO-13 package in pioteled or receptacle housing wit) FC, ST, SC, LC, IAU or SMA cornoctar

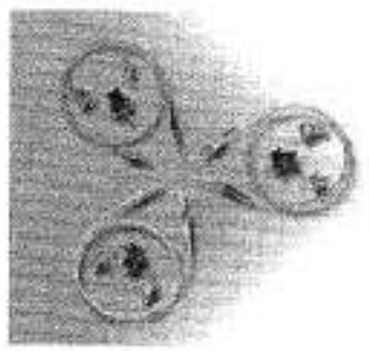

Specifications $\left(\mathrm{T}=25^{\circ} \mathrm{C},-5 \mathrm{~V}\right)$

\begin{tabular}{|c|c|c|c|c|c|c|c|}
\hline \multicolumn{2}{|l|}{$\begin{array}{r}\text { Parameier } \\
\end{array}$} & Symbol & Test Concifition & Mn. & Typ. & Max. & Unit \\
\hline \multicolumn{2}{|l|}{ Resporsinily } & $\bar{R}$ & & & & & \\
\hline 9125 um fiber & $\begin{array}{l}-1 \\
-2\end{array}$ & & $\begin{array}{l}\text { Leser source of } \\
10 \text { und } 2=1310 \mathrm{~nm})\end{array}$ & $\begin{array}{l}0.7 \\
0.8\end{array}$ & $\begin{array}{l}0.8 \\
0.8\end{array}$ & $=$ & AW \\
\hline 50 125 um fiber & $\begin{array}{r}-1 \\
-2 \\
\end{array}$ & & $\begin{array}{l}\text { LED socree of } \\
10 \text { uar } 2=1310 \mathrm{~nm} \text { ? }\end{array}$ & $\begin{array}{l}0.65 \\
0.75\end{array}$ & $\begin{array}{l}0.75 \\
0.35 \\
\end{array}$ & $\overline{-}$ & AWN \\
\hline $62.5 / 125$ um fiber & $\begin{array}{r}-1 \\
2 \\
\end{array}$ & & $\begin{array}{l}\text { LED source of } \\
10 \mathrm{um}(2=1310 \mathrm{~nm})\end{array}$ & $\begin{array}{l}0.8 \\
0.7 \\
\end{array}$ & $\begin{array}{l}0.7 \\
0.8\end{array}$ & $\therefore$ & AWW \\
\hline \multicolumn{2}{|l|}{ Spectra Rangn } & & 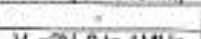 & 1250 & 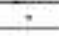 & 1600 & $\mathrm{~nm}$ \\
\hline \multicolumn{2}{|l|}{ Dark Cursent } & Id & $V_{2}=2 V, 0$ to $1 \mathrm{MHz}$ & $=$ & - & 1 & $\mathrm{nA}$ \\
\hline \multicolumn{2}{|l|}{ Capscilance } & Ct & $\mathrm{V}_{5}-2 \mathrm{~V}, 1 \mathrm{MHZ}$ & $=$ & 0.7 & 0.8 & pF \\
\hline \multirow{2}{*}{\multicolumn{2}{|c|}{$\frac{\text { Riselfal Trme }}{\text { Bendaidth }}$}} & ENr & $V_{n}=2 V, 20 \%$ to 1005 & $=$ & $<1$ & 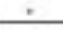 & nt \\
\hline & & B & & - & 1.5 & $=$ & $\mathrm{GHz}$ \\
\hline \multicolumn{8}{|l|}{ Relum Loss } \\
\hline \multicolumn{2}{|l|}{-1(Recoplarde) } & & & 14 & - & + & $d B$ \\
\hline \multirow{2}{*}{\multicolumn{2}{|c|}{$\frac{-4(\text { Pigtai) }}{-5 \text { (Potai) }}$}} & & & 40 & - & + & $d B$ \\
\hline & & & & 50 & - & 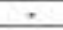 & $d B$ \\
\hline
\end{tabular}

Absolute Maximum Rating

\begin{tabular}{|c|c|c|c|c|}
\hline & Symbol & Min. & Max. & Lwit \\
\hline Oporating Tempereture & To & -40 & +85 & $c$ \\
\hline Storage Temperature & $T_{m}$ & -40 & +125 & ${ }^{\circ} \mathrm{C}$ \\
\hline Forward Curcent & I. & $\cdot$ & 5 & $m A$ \\
\hline Reverge Woltage & $V_{s}$ & $=$ & 30 & $\mathrm{v}$ \\
\hline Fenerse Current & $\ln$ & + & 500 & UA \\
\hline Lesd Soldering Temperalure (10 soc) & $T_{1}$ & - & 260 & $\mathrm{c}$ \\
\hline
\end{tabular}

Ordering Information

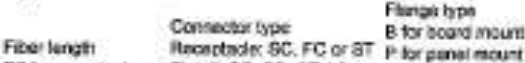

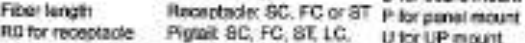

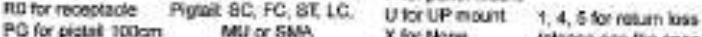

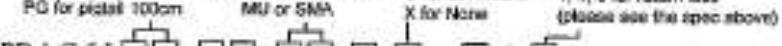

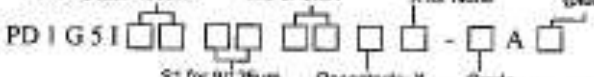

$$
\begin{aligned}
& \text { St for witsus Rsceptase } x \text { Gind }
\end{aligned}
$$

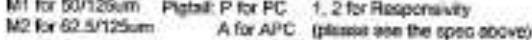




\section{ANEXO 3 - Datasheet do Circulador Óptico utilizado no trabalho.}

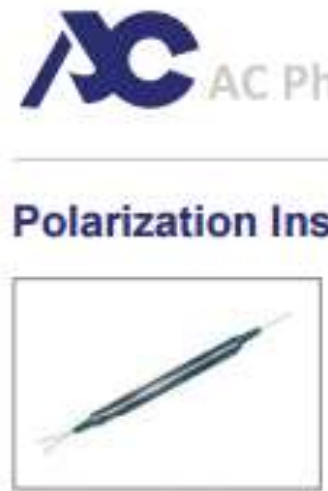

phone: $\quad 408.986 .9838$

ernail: sales@acphotonics.com

website: www.acphotonics.com

\section{Key Features}

- Low Insertion Loss

- Wide Band, High Isolation

- Low PDL

- Compact in-Ine Package

- High Stability and Rellability

- Epoxy Free Optical Path

ACP's Polarization insensitive optical circulator utlizes proprietary designs and metal bonding micro optics packaging. It provides low insertion loss, broad band high isolation, Iow PDL, excellent temperature stablity and optical path epoxy free. It can be used for wavelength add/drop, dispersion compensation, and EDFA applications. All AC Photonics' products are Telcordia qualification tested.

Performance Specifications

\begin{tabular}{|c|c|c|c|}
\hline \multirow{2}{*}{\multicolumn{2}{|c|}{ Parameter }} & \multicolumn{2}{|c|}{ Specifications } \\
\hline & & Grade P & Grade A \\
\hline \multicolumn{2}{|l|}{ Corfiguration } & \multicolumn{2}{|c|}{ Part 1 to 2 , Port 2 to 3} \\
\hline \multicolumn{2}{|c|}{ Operafing Wovelength } & \multicolumn{2}{|c|}{$1310 \pm 30 \mathrm{rm}, 1560 \pm 30 \mathrm{~nm}, 1585 \pm 30 \mathrm{rm}$} \\
\hline \multirow{2}{*}{ Insertion Lass } & Typical & $\leq 0.6 \mathrm{~dB}$ & $\leq 0.8 \mathrm{~dB}$ \\
\hline & Maximum & $\leq 0.8 d B$ & $\leq 1.00 t$ B \\
\hline \multicolumn{2}{|c|}{ Charnel Peak isclation } & \multicolumn{2}{|c|}{$\geq 50 \mathrm{~dB}$} \\
\hline \multicolumn{2}{|c|}{ Chamel Mininum Isolation } & \multicolumn{2}{|c|}{$\geq 40 d B$} \\
\hline \multicolumn{2}{|c|}{ Channel Cross Talk } & \multicolumn{2}{|c|}{$\geq 50 \mathrm{~dB}$} \\
\hline \multicolumn{2}{|c|}{ Polarization Dependent Loss } & \multicolumn{2}{|c|}{$\leq 0.15 \mathrm{~d} \theta$} \\
\hline \multicolumn{2}{|c|}{ Padarization Mode Dispersion } & \multicolumn{2}{|c|}{$\leq 0.10 \mathrm{ps}$} \\
\hline \multicolumn{2}{|l|}{ Retum Loss } & \multicolumn{2}{|c|}{$\geq 50 \mathrm{~dB}$} \\
\hline \multicolumn{2}{|l|}{ Optical Power } & \multicolumn{2}{|c|}{$\leq 300 \mathrm{~mm}$} \\
\hline \multicolumn{2}{|c|}{ Operaing Temperature } & \multicolumn{2}{|c|}{0 to $+70^{\circ} \mathrm{C}$} \\
\hline \multicolumn{2}{|c|}{ Storage Temperature } & \multicolumn{2}{|c|}{-40 to $+85^{\circ} \mathrm{C}$} \\
\hline \multicolumn{2}{|c|}{ Package Dimensions } & \multicolumn{2}{|c|}{ Q6.5 $\times$ L50mm ar $05.5 \times\llcorner 67 \mathrm{~mm}$} \\
\hline
\end{tabular}

- Optical Amplifier

- Metro Area Network

- Wavelength Add/Drop

- Dispersion Compensation

- Bi-directional Communication 
2.

Mechanical Dimensions
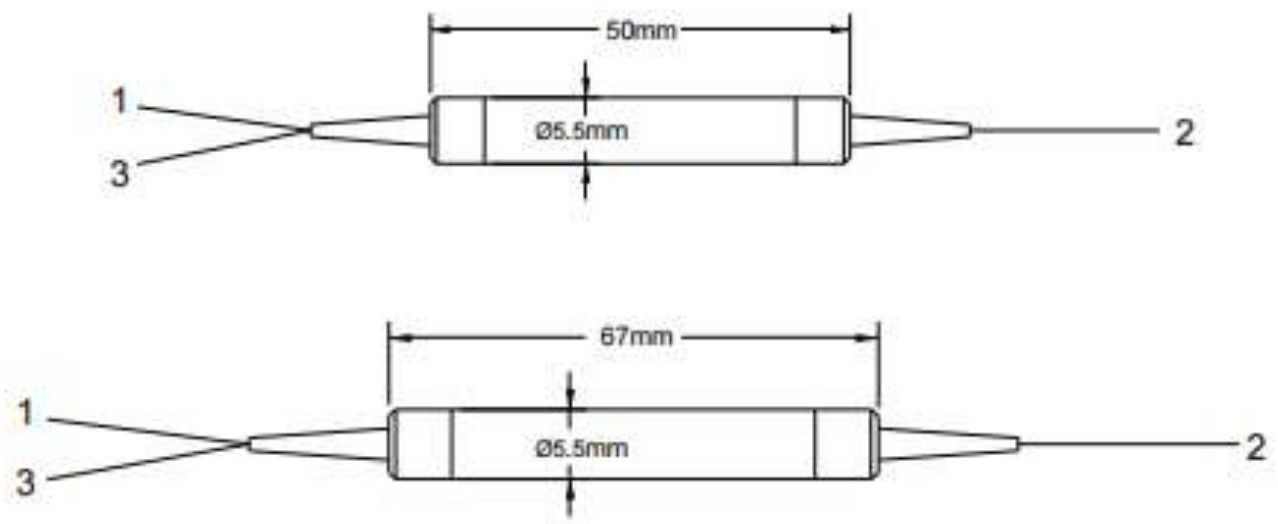

\section{Ordering Information}

\begin{tabular}{|c|c|c|c|c|c|c|c|}
\hline PIOC & & & & & & & \\
\hline & Port & Wavelength & Grade & Pigtail Style & Fiber Length & $\begin{array}{l}\text { In/Out } \\
\text { Connector }\end{array}$ & Dimensions Option \\
\hline & $3=3$ Part & $\begin{array}{l}13=1310 \mathrm{~mm} \\
15=1550 \mathrm{~mm} \\
16=1585 \mathrm{~mm}\end{array}$ & $\begin{array}{l}P=\text { Grade } P \\
A=\text { Grade } A\end{array}$ & $\begin{array}{l}1=\text { Bare Fiber } \\
2=900 u m \text { Jacket } \\
3=3 \mathrm{~mm} \text { Carte }\end{array}$ & $\begin{array}{l}1=1.0 \mathrm{~m} \\
2=2.0 \mathrm{~m}\end{array}$ & $\begin{array}{l}0=\text { None } \\
1=\text { FCIAPC } \\
2=\text { FCIPC } \\
3=\text { SCIAPC } \\
4=\text { SCIPC } \\
5=S T \\
5=1 C \text { UPC } \\
7=1 C I A P C\end{array}$ & 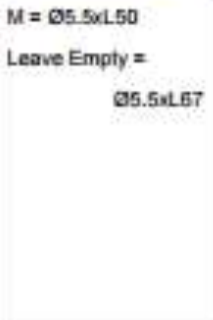 \\
\hline
\end{tabular}




\section{ANEXO 4 - Datasheet do Modulador eletro-óptico utilizado no trabalho.}

\section{Lithium Niobate Polarization Controller}

The lithium niobate polarization controller is a device that can transform any arbitrary input polarization state to any arbitrary output polarization state when suitable control voltages are applied. The device consists of a cascade of integrated polarization transformer stages - each of which can be electro-optically adjusted at high speed to act as a variable thickness waveplate with adjustable orientation. Proper control of the cascade of stages allows for endless reset-free polarization control.

The device is based on Z-propagating lithium niobate ${ }^{1}$ which has exceptionally high stability with variations in temperature.

\begin{abstract}
A high-speed, low-loss polarization controller is the key component in a polarization mode dispersion (PMD) compensator. PMD causes pulse distortion that can severely limit transmission at data rates of $10 \mathrm{~Gb} / \mathrm{s}$ and higher over long distances.
\end{abstract}

EOSPACE's polarization controller is based on our proprietary exceptionally high performance lithium niobate technology developed over the last 20 years for demanding aerospace applications.

\footnotetext{
US Patent 4691884 by Suwat Thaniyavarn, President of EOSPACE
}

\section{Key Features}

- Low insertion loss (<3 dB max)

- Low polarization dependent loss (PDL)

- Low bias and control voltages

- Available with $3,4,6$, or 8 integrated stages

- Response time $<100 \mathrm{~ns}$

- Slim Package

- Designed for Telcordia GR-468

- $\mathrm{C}$ - and L-band operation $(1.55 \mu \mathrm{m})$

\section{Applications}

- PMD compensation for 10 and 40 Gbis systems

- High-speed endless reset-free polarization control

- Polarization scrambling

- High-speed polarization multiplexing

\section{Options}

- Ultra-low insertion loss

- Custom number of stages

- Custom stage lengths

- 1.06 or 1.3 micron operation 